University of Nebraska - Lincoln

DigitalCommons@University of Nebraska - Lincoln

$1-2009$

\title{
IN SITU CHEMICAL OXIDATION OF RDX-CONTAMINATED GROUNDWATER WITH PERMANGANATE AT THE NEBRASKA ORDNANCE PLANT
}

Jeffrey. A. Albano

University of Nebraska-Lincoln, albanoj@gmail.com

Follow this and additional works at: https://digitalcommons.unl.edu/natresdiss

Part of the Natural Resources and Conservation Commons

Albano, Jeffrey. A., "IN SITU CHEMICAL OXIDATION OF RDX-CONTAMINATED GROUNDWATER WITH PERMANGANATE AT THE NEBRASKA ORDNANCE PLANT" (2009). Dissertations \& Theses in Natural Resources. 30.

https://digitalcommons.unl.edu/natresdiss/30

This Article is brought to you for free and open access by the Natural Resources, School of at DigitalCommons@University of Nebraska - Lincoln. It has been accepted for inclusion in Dissertations \& Theses in Natural Resources by an authorized administrator of DigitalCommons@University of Nebraska - Lincoln. 


\title{
IN SITU CHEMICAL OXIDATION OF RDX-CONTAMINATED GROUNDWATER WITH PERMANGANATE AT THE NEBRASKA ORDNANCE PLANT
}

by

\author{
Jeffrey A. Albano
}

\author{
A THESIS \\ Presented to the Faculty of \\ The Graduate College at University of Nebraska \\ In Partial Fulfillment of Requirements \\ For the Degree of Master of Science \\ Major: Natural Resource Sciences \\ Under the Supervision of \\ Professors Steve D. Comfort and Vitaly A. Zlotnik \\ Lincoln, Nebraska \\ January, 2009
}




\title{
IN SITU CHEMICAL OXIDATION OF RDX-CONTAMINATED GROUNDWATER WITH PERMANGANATE AT THE NEBRASKA ORDNANCE PLANT
}

\author{
Jeffrey A. Albano, M.S. \\ University of Nebraska, 2009
}

Advisors: Steve D. Comfort and Vitaly A. Zlotnik

Groundwater beneath the former Nebraska Ordnance Plant (NOP) is contaminated with the explosive hexahydro-1,3,5-trinitro-1,3,5-triazine (RDX). Laboratory and pilot-scale experiments were performed to quantify the efficacy of permanganate to remediate RDX-contaminated groundwater. Laboratory investigations were conducted to determine the effects of permanganate concentrations and temperature on RDX destruction kinetics as well as to determine the Permanganate Soil Oxidant Demand (PSOD) and permanganate $\left(\mathrm{MnO}_{4}{ }^{-}\right)$ transport properties.

Batch and column experiments showed that the Todd Valley aquifer sands contained a low PSOD indicating that permanganate mass consumption by the aquifer would be minimal. PSOD experiments also showed that the PSOD of the aquifer increased as the permanganate concentration increased. Batch experiments showed that the presence of Todd Valley aquifer media had little effect on RDX destruction kinetics and that RDX destruction kinetics and RDX mineralization increased with increasing permanganate concentrations. Batch experiments were 
conducted using RDX contaminated groundwater from the permanganate injection site $\left(C_{0}=210 \mu \mathrm{g} / \mathrm{L}\right)$ where there where no appreciable changes in RDX degradation kinetics. Additional batch studies were conducted to observe temperature effects on RDX degradation kinetics where it was shown that lower temperatures slow down RDX degradation.

To evaluate the efficacy of permanganate to remove RDX under field conditions, a pilot-scale demonstration was performed in a $9 \mathrm{~m}$ by $15 \mathrm{~m}$ well field. Groundwater was extracted from a center extraction well, spiked with permanganate and bromide, and fed into two injection wells. Groundwater was then sampled biweekly for 8 weeks in monitoring wells down gradient of the injection zone. Results showed that RDX concentrations decreased 73 to $80 \%$ following injection. Despite problems encountered in getting the permanganate uniformly distributed across the injection zone, pilot-scale results provide proof-of-concept that permanganate can be used for in-situ chemical oxidation of RDX-contaminated groundwater. 


\section{TABLE OF CONTENTS}

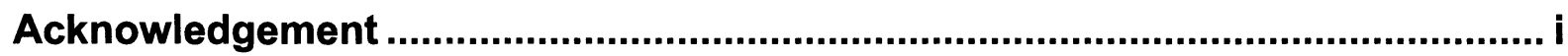

List of Tables

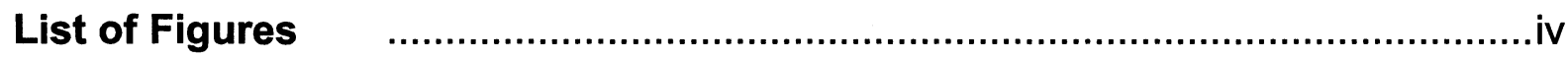

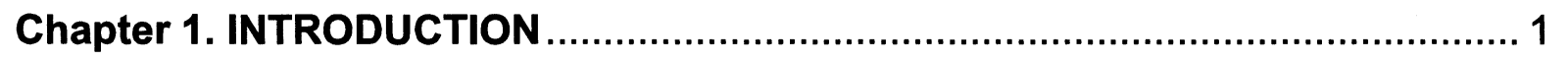

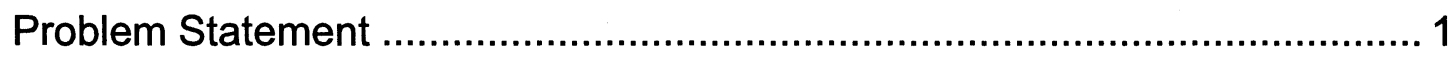

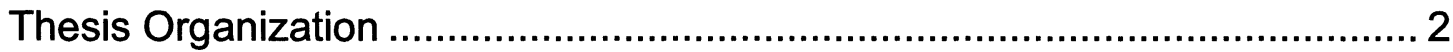

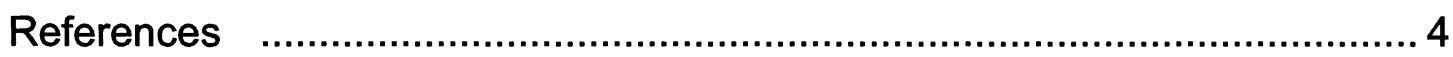

Chapter 2. LITERATURE REVIEW..................................................................... 5

Introduction to the Former Nebraska Ordnance Plant ................................ 5

Introduction to the Regional and Local Geology of the Research Study Area ..... 6

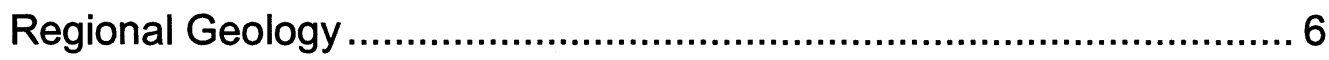

Geology of the Permanganate Injection Study Site .......................... 9

Introduction to the Hydrogeology of the Nebraska Ordnance Plant .............. 12

Regional Hydrology of the Nebraska Ordnance Plant ...................... 12

Hydrogeology of the Permanganate Injection Site .......................... 16

Contaminants of Concern at the Former NOP ……................................. 18

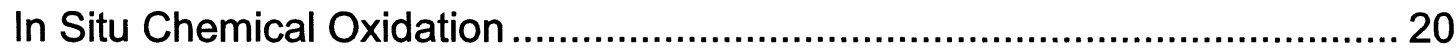

ISCO Using Permanganate ...................................................................... 23 
Aquifer Permeability Impacts During Permanganate ISCO .......................... 26

Permanganate Transport Processes....................................................... 26

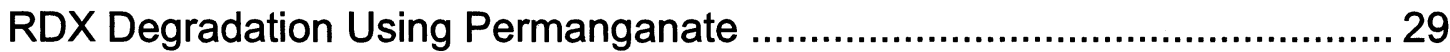

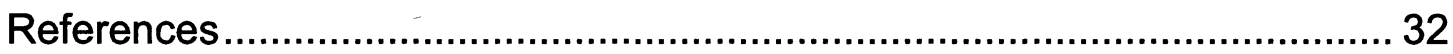

\section{CHAPTER 3. IN SITU CHEMICAL OXIDATION OF RDX-CONTAMINATED GROUNDWATER WITH PERMANGANATE AT THE NEBRASKA

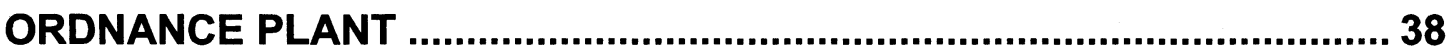

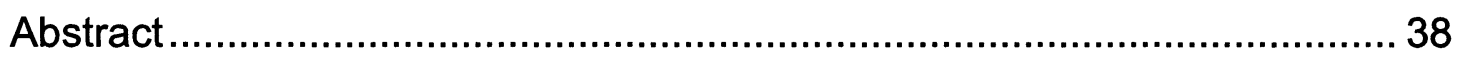

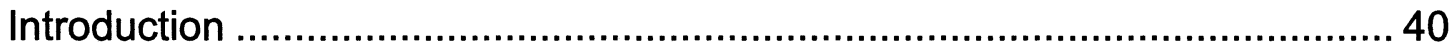

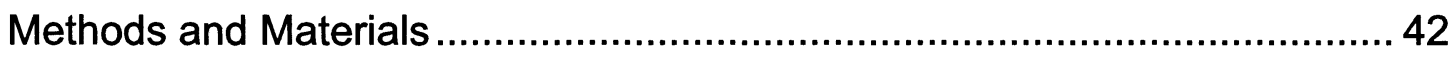

Treatability Experiments .............................................................. 42

Soil Oxidant Demand .......................................................... 42

Aquifer Slurry Experiments ................................................. 45

Treatment of NOP Groundwater with Permanganate ............. 46

In-Situ Temperature Effect on RDX Degradation by

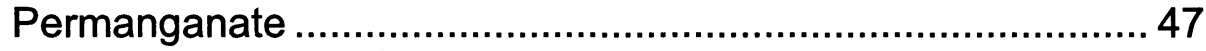

Field-Scale ISCO Demonstration with Sodium Permanganate........... 48

Aquifer Characterization .................................................... 48

Permanganate Extraction-Injection Procedure ....................... 49

Electrical Resistivity Imaging of Permanganate Injection ...................5 52

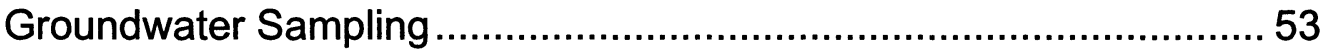

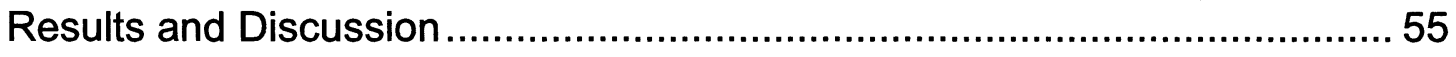




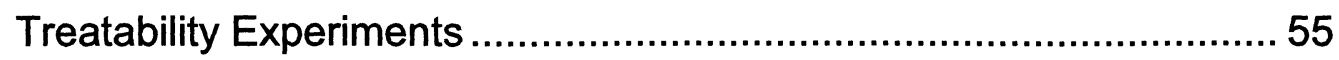

Soil Oxidant Demand ............................................................... 55

Aquifer Slurry Experiments ...............................................56

Permanganate Treatment of NOP Groundwater.................... 57

In-Situ Temperature Effect on RDX Degradation by

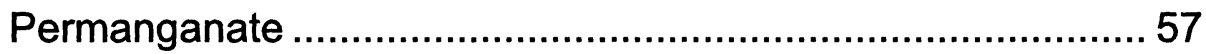

Field-Scale ISCO Demonstration with Sodium Permanganate........... 58

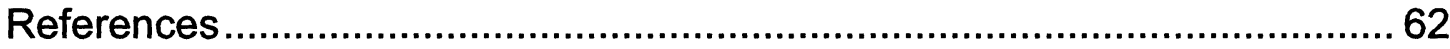

\section{APPENDIX}

A. Three-Dimensional Permanganate Transport Modeling ..................... 79

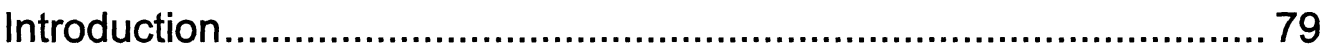

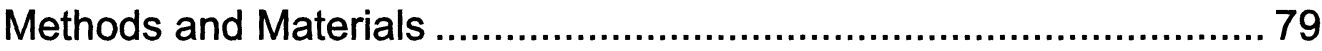

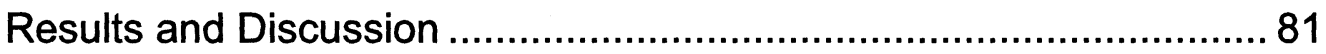

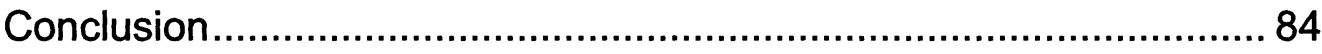

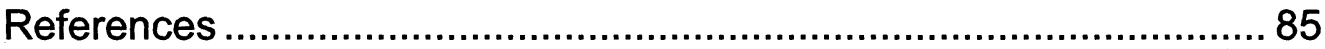

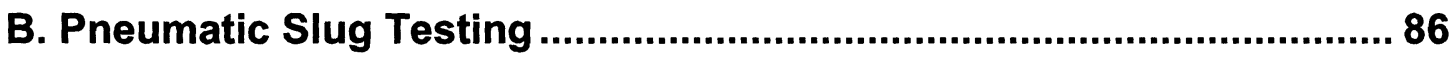

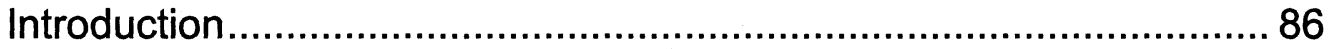

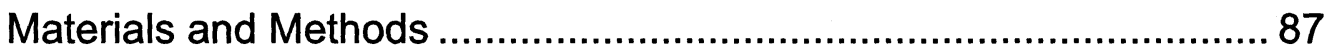

Fully Screened Pneumatic Slug Testing .............................. 87

Multi-Level Slug Tests ........................................................ 91

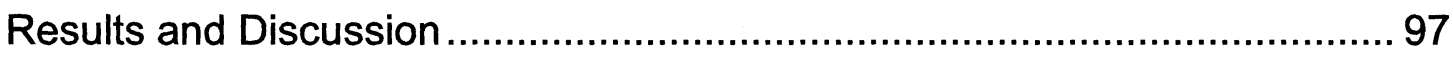

Fully Screened Slug Tests......................................................... 97 
Multi-Level Slug Tests .......................................................... 98

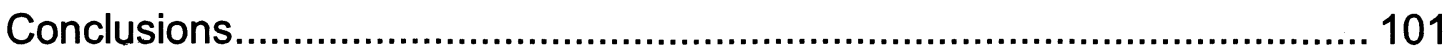

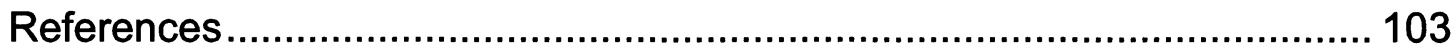

C. Full Screen Pneumatic Slug Test Results Pre Sodium Permanganate

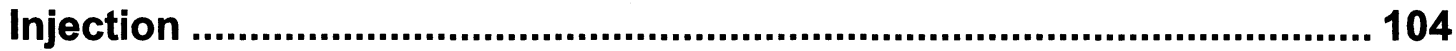

D. Full Screen Pneumatic Slug Test Results Post Sodium Permanganate

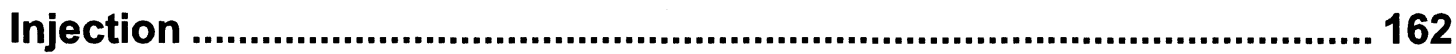

E. Miscellaneous Graphs Showing Data Collected During the Injection/Extraction of Sodium Permanganate injection ....................... 198 


\section{ACKNOWLEDGEMENTS}

The successful completion of this research would never be possible without the support of my wife, Sarah, and my two children, Joshua and Carly. I would like to thank Dr. Steve Comfort for giving me the opportunity to work with him and his outstanding research group. l'd also like to thank Dr. Vitaly Zlotnik for his mentoring throughout my graduate career. Both of these gentlemen provided guidance, constructive suggestions, and insightful criticism throughout my

graduate career. I would like to Dr. Mark E. Burbach for his field skill set coaching as part of my supervisory committee. l'd like to thank Dr. Ed Harvey for his valuable guidance throughout my graduate program. l'd like to thank Dr. Wilson Clayton with Aquifer Solutions for his help associated with the permanganate injection. l'd like to thank Dr. Todd Halihan with Oklahoma State University for sharing electrical resistivity imaging data obtained at the NOP.

I would also like to thank the research team that I was fortunate enough to work with. I'd like to thank Dr.Tunlawit Satapanajaru, Dr.Hardlijeet Boparai, and Dr. Sathaporn Onanong for their mentoring. They helped a geologist trade in his rock hammer and hand lens for a working knowledge of analytical laboratory equipment. I would like to acknowledge my labmates, Nat and Manmeet. I couldn't ask for a better group of people to work along side. Thanks are due to Environmental Protection Agency for their financial support throughout my graduate career. 
Lastly, l'd like thank the University of Nebraska for an unbelievable experience throughout my undergraduate and graduate career. GO HUSKERS! 


\section{LIST OF TABLES}

\section{CHAPTER 2}

Table 1. Property owners of Former NOP land. (modified from Woodward-Clyde, 1995)

Table 2. Grain size analysis from soil cores taken at the permanganate injection site.

Table 3. Well construction parameters of wells located in the area of focus at the permanganate injection site

Table 4. First and second order degradation rates of RDX by varying concentration of permanganate (Clayton et al. 2001) .30

\section{CHAPTER 3.}

Table 1. Soil oxidant demand (SOD) of Todd Valley aquifer determined by batch experiments

\section{Appendix B}

Table 1. Pre and post permanganate injection hydraulic conductivities ( $\mathrm{m} /$ day) calculated in wells within the pilot study site 


\section{LIST OF FIGURES}

\section{CHAPTER 2}

Fig. 1. Cross-sectional view of the Todd Valley aquifer (modified from Condra et al. (1950) and Pisken (1971))

Fig. 2. Soil electrical conductivity (SEC) measurements with depth at the permanganate injection site

Fig. 3. Regional water table elevations of the Todd Valley aquifer (modified from US Corps of Engineers, 1989, modified from Souders, 1967) 15

Fig. 4. Water table elevations within the permanganate injection site .............. 16

Fig. 5. Hydraulic conductivities within the permanganate injection site ........... 16

Fig. 6. Hydraulic conductivity variations within MW-15 screened interval ........ 18

Fig. 7. Aerial photograph of the former NOP and approximated RDX and TCE plume delineation

Fig. 8. Schematic of the injection/extraction system configuration used by Lowe et al (2002)

Fig. 9. Changes in permanganate distribution with time (modified from Bourne et al. 2004) 


\section{CHAPTER 3}

Fig. 1. Soil oxidant demand determined from column studies conducted with Todd Valley aquifer solids 66

Fig. 2. Temporal changes in RDX and ${ }^{14} \mathrm{C}$ concentrations following treatment with three initial permanganate concentrations 67

Fig. 3. Treatment of NOP groundwater with $15000 \mathrm{mg} / \mathrm{L} \mathrm{KMnO}{ }_{4}\left(\mathrm{C}_{0}=210 \mu \mathrm{g} / \mathrm{L}\right) \ldots . .68$

Fig. 4. Temporal changes in RDX concentration $\left(C_{0}=3.5 \mathrm{mg} R D X / L\right)$ in an aqueous solution treated with $15000 \mathrm{mg} / \mathrm{L} \mathrm{KMnO}_{4}$ at $11.5^{\circ} \mathrm{C}$ and room temperature $\left(23^{\circ} \mathrm{C}\right)$

Fig. 5. Schematic of injection curtain with variables used in volume calculations (Eqns. 1-6) 70

Fig. 6. A) Resistivity of ERI line parallel to injection plane showing location of extraction and injection wells used to develop permanganate curtain and monitoring wells. B) Resistivity difference after injection 71

Fig. 7. A) Resistivity of ERI line along down gradient centerline of the injection plane showing location of extraction well and down gradient monitoring wells. B) Resistivity difference after injection.

Fig. 8. ERI composite of resistivity differences after injection with locations of wells used to develop permanganate curtain (black) and monitoring wells (green) 73

Fig. 9. RDX and permanganate breakthrough curves observed in field monitoring wells 
Fig. 10. Sodium permanganate and $\mathrm{Br}^{-}$breakthrough curves obtained from $\mathrm{MW}-12, \mathrm{MW}-14$, and MW-15.

Fig. 11. A comparison of permanganate profile concentrations determined by spatial conductivity measurements

Fig. 12. (A) Hydraulic conductivities throughout the screened interval of MW-15 obtained by mulit-level slug testing indicating depths of preferential flow. (B) Hydraulic conductivities taken before and after permanganate injection 77

\section{APPENDIX A}

Fig. 1. Location of wells (G-036214 at $x=3168 \mathrm{ft}(0.6$ miles) and $\mathrm{G}-136422$ at $\mathrm{x}$ $=7022 \mathrm{ft}(1,33$ miles $))$ and their proximity to the pilot study site (Study site)

Fig. 2. Sodium permanganate breakthrough curves modeled at $x=3178 \mathrm{ft}$ and $x=7022 \mathrm{ft}$ using the Baetslé 1969 Point Source Model 83

\section{APPENDIX B}

Fig. 1. Overview of pneumatic slug test equipment without packer along full screen

Fig. 2. Overview of pneumatic water level depressor components 90 
Fig. 3. Schematic of the double packer configuration with dimensions (modified from Zlotnik et al. (2003) 92

Fig. 4. Representation of single-packer configuration and origin of associated $\mathrm{K}$ parameters used in equation 1 94

Fig. 5. Photograph of single-packer configuration ...................................... 95

Fig. 6. Photograph of MLST equipment and setup....................................... 96

Fig. 7. Hydraulic conductivities observed in MW-15 using single and double packer multi-level slug test configurations.

99

Fig. 8. Hydraulic conductivities calculated from pre and post-permanganate double packer multi-level slug tests

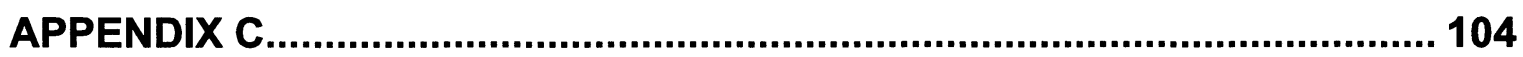

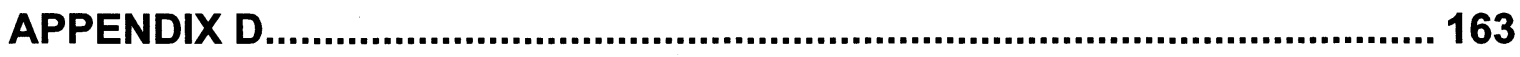

\section{APPENDIX E}

Fig. 1. Water level measurements in injections wells IW-1 and IW-2 during sodium permanganate injection 199

Fig. 2. Extraction well EW-1 sodium permanganate breakthrough curve observed during injection/extraction process 200

Fig. 3. Sodium permanganate vs electrical conductivity curve used to calculate well sodium permanganate concentration profiles 201 


\section{CHAPTER 1}

\section{INTRODUCTION}

\section{PROBLEM STATEMENT}

The former Nebraska Ordnance Plant (NOP, Mead, NE) was a military loading and packing facility that produced bombs, boosters, and shells during World War II and the Korean War. When at full capacity, the NOP occupied approximately 17,250 acres and consisted of four load lines, a bomb booster assembly plant, an ammonium nitrate plant, two explosive burning areas, a proving range, a landfill, and a wastewater treatment plant (USACE, 2007). Ordnances were routinely loaded with the high explosives RDX and TNT. To limit chemical exposure to NOP employees during manufacturing, buildings were routinely rinsed with water that was eventually discharged into drainage ditches and sumps. These ditches became grossly contaminated with TNT and RDX with soil concentrations exceeding $5000 \mathrm{mg} \mathrm{kg}^{-1}$ near the soil surface (Hundal et al., 1997). When rainfall exceeded infiltration rates, ponded water that formed in the drainage ditches literally became saturated with munitions residues (i.e., reached High Explosive (HE) solubility limits) before percolating through the profile. As a result, groundwater beneath the NOP is contaminated with several compounds used during ordnance production such as: 2,4,6-trinitrotoluene (TNT), 2,4- and 2,6dinitrotoluene (DNT), hexahydro-1,3,5-trinitro-1,3,5-triazine (RDX), octahydro1,3,5,7-tetranitro-1,3,5,7-tetrazocine $(\mathrm{HMX}), \quad$ trichloroethylene $\quad(\mathrm{TCE}), \quad$ 1,2dichloropropane, 1,3,5-trinitrobenzene (TNB), and methylene chloride. 
Although several contaminants have been detected in the NOP groundwater, RDX and TCE comprise the majority of the plume (Woodward-Clyde, 1995). RDX was used in a variety of ordnances while TCE was used as a degreaser to clean pipelines carrying liquid oxygen fuel for missiles production. The size of the contaminant plume beneath the NOP is estimated at approximately 23 billion gallons (Woodward-Clyde, 1995).

To prevent the contaminated plume from migrating offsite and in the direction of municipal well fields, an elaborate series of eleven extraction wells and piping networks were constructed to hydraulically contain the leading edge of the RDX/TCE plume. Currently this $\$ 33$ million dollar facility treats approximately 4 million gallons of groundwater per day via filtration through granular activated carbon (GAC). Annual operating costs are approximately $\$ 800,000 /$ year. Current estimates indicate that relying solely on pump and treat will take in excess of 125 years to remove the RDX/TCE plume.

This study evaluated an alternative or supplement to the current pump and treat system by performing a laboratory and pilot-scale investigations of RDX treatment by permanganate.

\section{THESIS ORGANIZATION}

This thesis consists of three chapters. Chapter One provides the general introduction of this thesis. Chapter Two provides a literature review that contains background information on the Former Nebraska Ordnance Plant (NOP), the geology and hydrogeology within the NOP, introduction to In-Situ Chemical 
Oxidation (ISCO), and RDX treatment case studies. Chapter Three provides laboratory investigation on RDX degradation by permanganate (i.e., the effects of permanganate concentrations and temperature on RDX destruction kinetics), Permanganate Soil Oxidant Demand (PSOD) studies, as well as results of a fieldscale ISCO demonstration with sodium permanganate. Appendices at the end of the thesis provide method description and results of experiments not included in Chapter Three. 


\section{REFERENCES}

Hundal, L.S., J. Singh, E.L. Bier, P.J. Shea, S.D. Comfort, and W.L. Powers. 1997. Removal of TNT and RDX from water and soil using iron metal. Environ. Pollut. 97(1-2):55-64.

USACE. 2007. The former Nebraska ordnance plant, Mead, NE: Site background and information. Available at http://www.nwk.usace.army.mil/projects /mead/Site_Information_and_Background/NOP_Fact_Sheet.pdf U.S. Army Corps of Engineers, Kansas City, MO.

Woodward-Clyde. 1995. Engineering evaluation/cost analysis for operable unit No. 2 groundwater former Nebraska ordnance plant, Mead, Nebraska Prepared for the Department of the Army, U.S. Army Engineers District, Kansas City District,. Corps of Engineers, Kansas City, MO. 


\section{CHAPTER 2}

\section{LITERATURE REVIEW}

\section{Introduction to the Former Nebraska Ordnance Plant}

The former Nebraska Ordnance Plant (NOP) was a loading and packing facility that produced bombs, boosters and shells during World War II and the Korean War. Located approximately 1 mile south of Mead, Nebraska in east central Saunders County, this facility originally spanned 17,250 acres and consisted of an ammonium nitrate plant, bomb booster assembly plant, four load lines (enumerated 1-4), demolition grounds, a sewage treatment plant, a landfill, burning grounds, proving range, and several square miles of storage igloos (Woodward-Clyde, 1995). The NOP was operated by the Nebraska Defense Corporation for the U.S. Army from 1942 through 1945. From 1945 to 1950, the NOP was on inactive status, decontaminated, and served as a storage and disposal facility for explosives and munitions. Decontaminating the site included cleaning floors, rafters, and ventilation systems. Approximately 340,000 ordnances were destroyed in unknown locations in the Burning/Proving Grounds (WoodwardClyde, 1995).

The NOP was reactivated in 1950 to produce and assemble bombs, shells, rockets, Nike warheads, block cast of 2,4,6-trinitrotoluene (TNT), supplementary charges, and boosters for the Korean Conflict. In 1956, the NOP was placed on standby status and in 1959 determined to be surplus and transferred to the General Services Administration for disposition. In 1959, the U.S. Air Force 
acquired 1,185 acres north of Load Line 4 and 34 acres of the northern portion of Load Line 1 and constructed the Offutt Air Force Base Missile Fire S-1 launch area (Atlas Missile Area). At the Atlas Missile Area, trichloroethylene (TCE) was used to clean and degrease pipelines that carried liquid oxygen fuel for missiles. The 34 acres of the northern portion of Load Line 1 was used by the Air Force as a "Tech Area" (ESE, 1983). Presently the NOP site is owned by the University of Nebraska, Army National Guard and Reserves, U.S. Department of Commerce and private interests (Table 1).

Table 1

Property Owners of Former NOP Land. (modified from Woodward-Clyde, 1995)

\begin{tabular}{|c|c|}
\hline Property Owner & Acreage \\
\hline University of Nebraska & 9,518 acres \\
Private or Corporate & 5,543 acres \\
Department of Commerce & 40 acres \\
U.S. Military Weekend Training Facility & 960 acres \\
Nebraska Air National Guard & 1,197 acres \\
\hline
\end{tabular}

Introduction to the Regional and Local Geology of the Research Study Area Regional Geology

The regional geology of the former Nebraska Ordnance Plant, as shown in cross-section below (Fig. 1), consists of Pennsylvanian shale and limestone overlain unconformable by continental shales and sandstones that are Cretaceous in age. Unconformably overlying the Cretaceous shales and sandstone are sands 
and sandy gravels from the Pleistocene epoch, which is mantled by eolian loess (medial Wisconsinan).

The Cretaceous shales and sandstones are differentiated into three groups. These groups are, in ascending order, the Dakota Group, the Colorado Group, and the Montana Group. The Montana and Colorado Groups are not present at the NOP but are present in the subsurface of northeastern Nebraska. At NOP, the Dakota Group ranges from 12.5 to $33.8 \mathrm{~m}(41-111 \mathrm{ft})$ thick. Thickness varies due to post-Cretaceous erosion that formed a southeasterly sloping paleotopographic surface (Piskin, 1971). In Nebraska, the Dakota Group is subdivided into three formations, Dakota Sandstone, Fuson Shale, and Lakota Sandstone. For simplicity, the term Omadi was assigned to the Dakota Formation by Condra and Reed (1943) to define the strata between the basal formation of the Colorado Group, the Granero Shale, and the underlying Fuson Shale of the Dakota Group.

The Pleistocene deposits near Mead, NE consist of sands and gravels of the Todd Valley Formation that range in thickness from 20.1 to $45.1 \mathrm{~m}$ (66 to 148 ft) (Piskin, 1971). The unconsolidated sands and gravels are Platte River sediments (Condra, 1903) that were deposited in multiple stages during the Pleistocene epoch. The sands and gravels consist of 95 percent quartz and feldspars and the remaining 5 percent consists of heavy mineral including zircon, magnetite, illmenite, hornblende, tourmaline, and hematite (Schuett, 1964). Possible sources for the Pleistocene sands and gravels include Cretaceous sediments within the area, local Pleistocene tills and associated outwash materials, and alluvial sediments of western origin (Stanley, 1971). 
The Pleistocene sands and gravels are divided into two units, from bottom to top these include: the sand and gravel unit and the fine sand unit. The sand and gravel unit consists of poorly to moderately sorted, subrounded to rounded clasts (Piskin, 1971). Clasts are composed of mostly fine and medium to coarse gravel with fine to very coarse sand (Piskin, 1971). The sand and gravel unit ranges in thickness from 0 to $16.8 \mathrm{~m}$ ( 0 to $55 \mathrm{ft}$ ) with maximum thicknesses located within the Cretaceous bedrock channels. The paleotopography of the sand and gravel unit indicates post-depositional erosion. The fine sand unit ranges in thickness from 10.7 to $27.4 \mathrm{~m}$ ( 35 to $90 \mathrm{ft}$ ) with thicknesses determined by the underlying sand and gravel unit's paleotopography and post-depositional erosion. Clasts in the fine sand unit coarsen downward and range from very fine to coarse sand but predominantly consist of fine to medium sand.

Overlying the fine sand unit and present at the surface at the NOP is an eolian deposit termed the Peoria Loess. The Peoria Loess consists of brownishyellow clayey silt to silty clay deposits that range from 6.1 to $12.2 \mathrm{~m} \mathrm{(20} \mathrm{to} 40 \mathrm{ft}$ ) in thickness at the northwest end of Todd Valley, which become thinner to the southeast and ranges from 3.1 to $6.1 \mathrm{~m}$ (10 to $20 \mathrm{ft}$ ) in thickness (Piskin, 1971). The Peoria Loess is medial Wisconsinan in age and is characterized by vertical fractures and root holes (Piskin, 1971). 


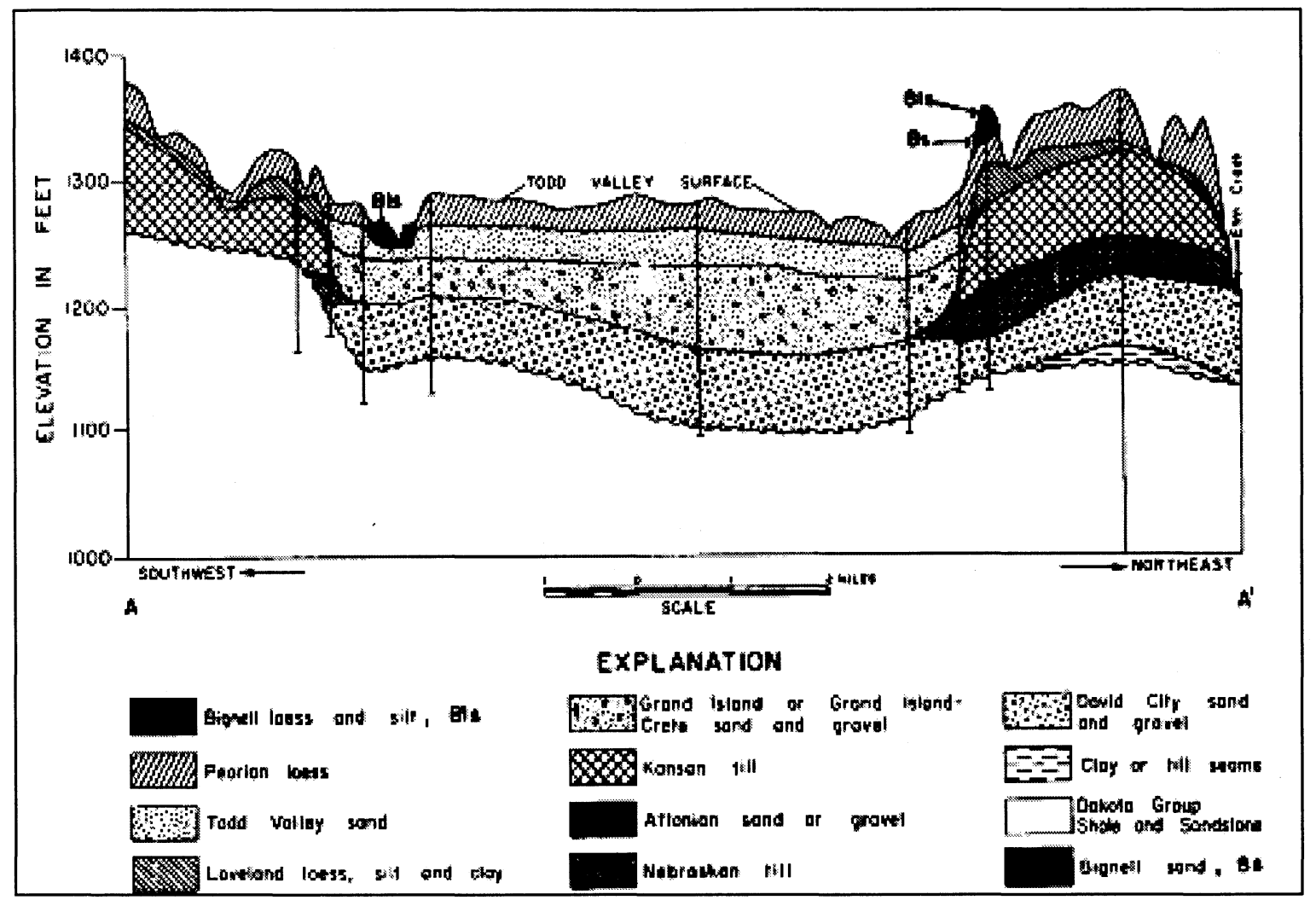

Figure 1. Cross-sectional view of the Todd Valley aquifer (modified from Condra et al. (1950) and Pisken (1971)).

\section{Geology of the Permanganate Injection Study Site}

Previous investigations of the permanganate injection site (N $41^{\circ} 9 " 24 ", \mathrm{~W}$ $\left.96^{\circ} 27^{\prime} 117^{\prime \prime}\right)$ were obtained from cross-sections and borehole logs (wells MW-31, MW-28, T63-1). Results from these investigations (Woodward-Clyde, 1995) indicated that approximately $6.1 \mathrm{~m}(20 \mathrm{ft})$ of Peoria Loess is mantled over the Todd Valley Formation, which is comprised of approximately $15.2 \mathrm{~m}(50 \mathrm{ft})$ of fine

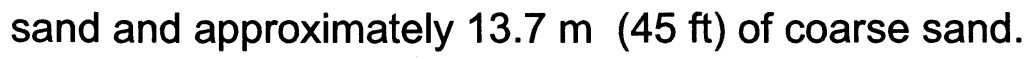


Data collected by our group utilizing soil core collection and soil electrical conductivity data analyses indicates roughly $5.5 \mathrm{~m}$ (18 ft) of Peoria Loess above at least $16.2 \mathrm{~m}$ (53 ft) of medium to fine sand (maximum soil core depth was $22.3 \mathrm{~m}$ (75 ft) below ground surface). Soil cores taken from the Todd Valley Formation were analyzed for grain-size analyses (Table 1). Soil electrical conductivity (SEC) was performed at the site via direct push technology (Geoprobe ${ }^{\circledR}$ Model 6610DT). SEC analysis showed changes in conductivity at approximately $5.5 \mathrm{~m}(18 \mathrm{ft}), 10.1$ $\mathrm{m}(33 \mathrm{ft})$, and $18.3 \mathrm{~m}(60 \mathrm{ft})$. The SEC data is in agreement with the grain-size

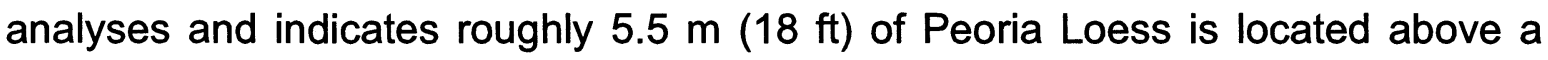
coarsening downward sand sequence (Fig. 2; Table 2)

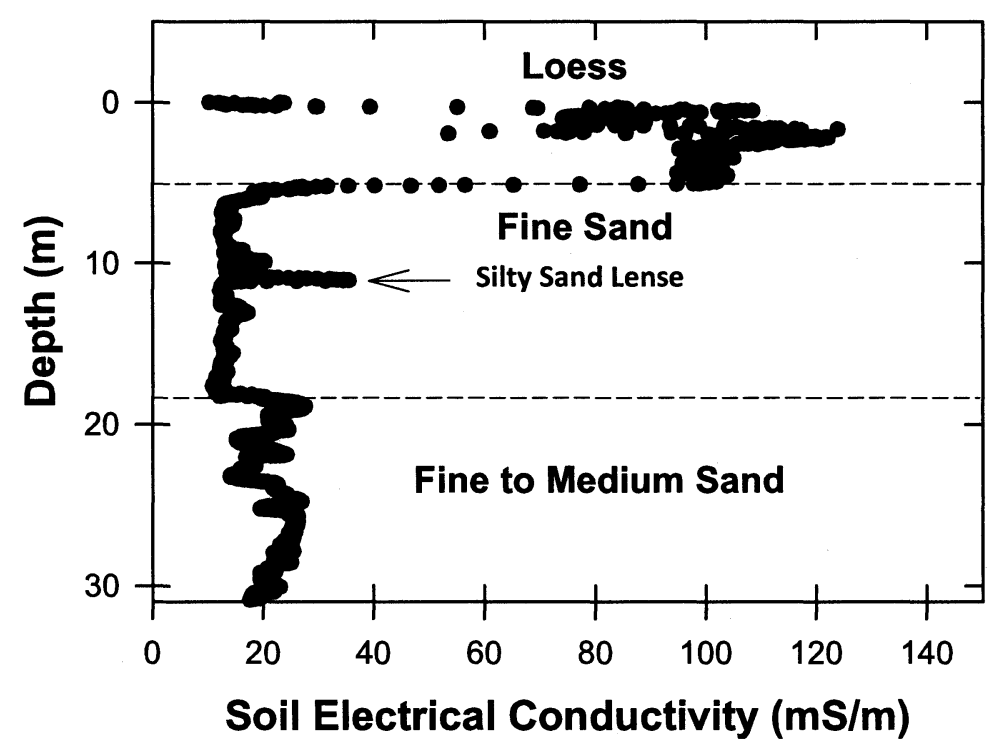

Figure 2. Soil electrical conductivity (SEC) measurements with depth at the permanganate injection site. 
Table 2.

Grain size analysis from soil cores taken at the permanganate injection site.

\begin{tabular}{|c|c|c|}
\hline Depth $(\mathrm{m})$ & Wentwoth Size Class & Sorting \\
\hline $6.7-7.6$ & Fine Sand & moderately sorted \\
$9.1-10.7$ & Medium-Fine Sand & moderately well sorted \\
$11.0-12.2$ & Fine Sand & moderately well sorted \\
$13.7-15.2$ & Fine Sand & moderately sorted \\
$15.2-16.2$ & Medium-Fine Sand & moderately well sorted \\
$18.3-19.2$ & Medium-Fine Sand & moderately sorted \\
$21.3-22.9$ & Medium-Fine Sand & moderately sorted \\
\hline
\end{tabular}

The sedimentology of a braided stream, such as the Platte River, is complex and encompasses several channels characterized by high width/depth ratios, steep slopes, and usually low sinuosities (Miall, 1977). According to Webb (1994), the parameters that describe fluid and sediment transport though braided stream systems include discharge, sediment load, width, depth, velocity, and bed roughness. All of which are controlled by the local geology and climate (Webb, 1994). These factors make quantifying the aquifer heterogeneity of braided stream depositional environments such as the Todd Valley Formation, even on a macro scale, a complicated task. Cardenas (2003) developed a three-dimensional model of a meandering stream using field observations. His data showed hydraulic conductivity measurements in his study site ranged from just over $3 \mathrm{~m} / \mathrm{d}$ to over 65 $\mathrm{m} / \mathrm{d}$. It is not unusual to lump these heterogeneities into an overall hydraulic conductivity, usually conducted by the pump test pioneered by Charles Vernon 
Theis (1935). However, in order to clearly address solute transport in a braided stream aquifer such as the Todd Valley, a finer scale quantification of heterogeneities must be obtained (Anderson et al., 1999).

Identifying the locations of the more hydraulically conductive zones, or preferential pathways, is key because these preferential pathways control the channeling of contaminants. While many researchers have used geostatistics to generate these preferential pathways (e.g., Thompson and Gelhar, 1990; MacQuarrie and Sudicky, 1990; Kitanidis, 1997), others have used geophysical techniques, such as ground-penetrating radar (GPR) to identify hydraulically conductive zones (e.g., Huggenberger et al, 1994; Rea and Knight, 1998) Anderson et al. (1999) used two approaches to quantify the heterogeneity of a braided stream aquifer. The first involved mapping a $50 \mathrm{~m}$ by $60 \mathrm{~m}$ section of a 3.3 $\mathrm{m}$ high out crop in Wisconsin utilizing field observations, photomosaics, and GPR profiles. The second study involved the creation of a $400 \mathrm{~m}$ by $400 \mathrm{~m}$ by $2.6 \mathrm{~m}$ thick synthetic aquifer using a computer model based on data collected from two similar braided stream systems in the Squamish River in British Columbia, Canada and the Ohau River, New Zealand. Both studies where able to create connected hydrofacies, which form preferential pathways in aquifer systems.

\section{Introduction to the Hydrogeology of Nebraska Ordnance Plant}

\section{Regional Hydrogeology of the Nebraska Ordnance Plant}

The two streams present at the NOP, namely, Johnson Creek and Silver Creek, provide drainage to Salt Creek, a tributary to the Platte River. Salt Creek 
discharges into the Platte River east of Ashland, NE near the southeastern corner of Saunders County. Drainage for Todd Valley is mainly southeast through Wahoo Creek located southwest of the NOP. The flat topography of Todd Valley supports a poorly defined drainage pattern (Woodward-Clyde, 1995). Supplemental manmade ditches were added to aid natural surface drainage. A man-made ditch created at Load Line 1 discharges into Silver Creek. Load lines 2 and 3 also had man-made ditches built that flowed through former high explosive storage areas. Man-made ditches built to drain Load Line 4 discharge into Johnson Creek. Drainage from the Burning Grounds discharges directly into Johnson Creek.

The Omadi Sandstone aquifer, Todd Valley aquifer, and the Platte River alluvial aquifer, Pennsylvanian shales, the Omadi shale make up the aquifer system at the former NOP site. The Todd Valley aquifer is hydraulically connected to the Platte River alluvial aquifer. The Platte River aquitard is the upper semiconfining layer that impedes flow beneath the ground surface and the aquifer. The Platte River aquitard consists of silts and clays. The Omadi Sandstone is hydraulically connected to the Todd Valley and Platte River alluvial aquifers where the Omadi shale is not present. The Todd Valley aquifer and the Platte River aquifer behave as a single aquifer system without hydraulic barriers.

The Omadi Sandstone aquifer is composed of fine to medium grained sandstone. Mineralogy of the Omadi Sandstone aquifer is dominantly quartz with ferrigeneous cement found locally (Piskin, 1971). Transmissivities of the Omadi Sandstone aquifer calculated by grain size range from $49.6 \mathrm{~m}^{2} / \mathrm{d}\left(4 \times 10^{3} \mathrm{gpd} / \mathrm{ft}\right)$ to 
$429 \mathrm{~m}^{2} / \mathrm{d}\left(3.46 \times 10^{4} \mathrm{gpd} / \mathrm{ft}\right)$ with a mean of $272.8 \mathrm{~m}^{2} / \mathrm{d}\left(2.20 \times 10^{4} \mathrm{gpd} / \mathrm{ft}\right)$ (Piskin, 1971).

The regional water table associated with the NOP slopes southeast with an average gradient of $2.27 \mathrm{~m} / \mathrm{km}$ (12 ft/mile) (Woodward-Clyde,1995). Depth to

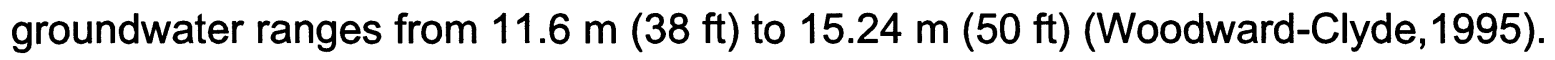
Historical data in relatively undisturbed conditions indicates water table elevations

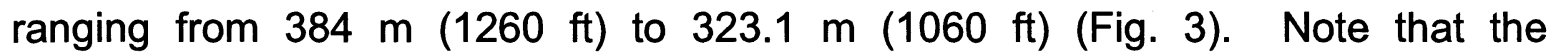
permanganate injection site used in this research is located between water table elevations $335.3 \mathrm{~m}(1100 \mathrm{ft})$ and $341.4 \mathrm{~m}(1120 \mathrm{ft})$.

The lower gravel layer of the Toddy Valley aquifer is mainly composed of fine gravel ( $2 \mathrm{~mm}$ to $4 \mathrm{~mm}$ ) with boulders occurring at the base (Piskin, 1971). The upper sand layer of the Toddy Valley aquifer consists of mostly medium sand but ranges from coarse sand to fine sand. The Todd Valley aquifer has a higher porosity and specific yield that the Omadi Sandstone aquifer and serves as the primary water bearing unit for water supply wells in the area. Average hydraulic conductivities for the Todd Valley aquifer are $14.9 \mathrm{~m} / \mathrm{d}$ in the fine sand unit and $48.3 \mathrm{~m} / \mathrm{d}$ the sand and gravel unit (Woodward-Clyde, 1995). 


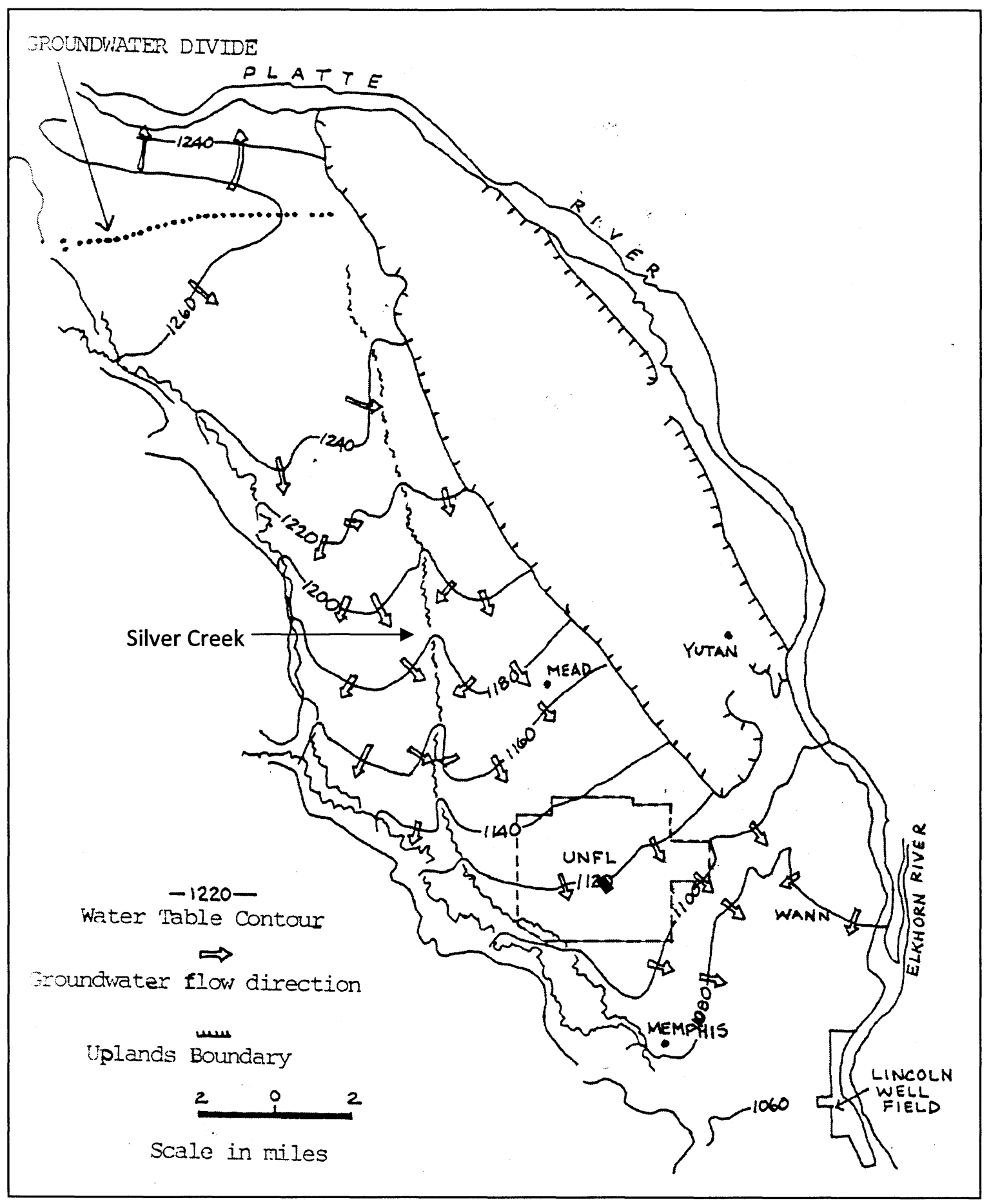

Figure 3. Regional water table elevations of the Todd Valley aquifer (modified from US Corps of Engineers, 1989 modified from Souders, 1967). Black rectangle indicates location of permanganate injection site. 


\section{Hydrogeology of the Permanganate Injection Site}

Wells gauged on October $5^{\text {th }}, 2006$ indicated that water levels ranged from $339.558 \mathrm{~m}(1113.75 \mathrm{ft})$ to $339.405 \mathrm{~m}(1113.25 \mathrm{ft})$ with an overall southeasterly hydraulic gradient of 0.0025 feet/foot (Fig. 4).

Pilot Study Site Water Table (feet above sea level)

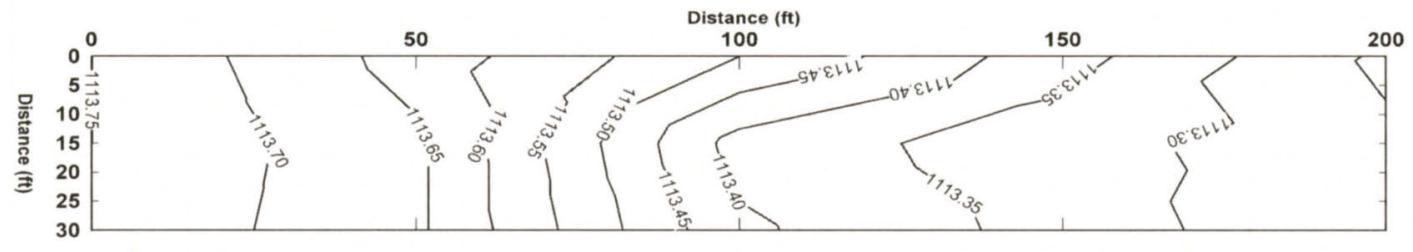

Figure 4. Water table elevations within the permanganate injection site.

To characterize hydraulic conductivities within the study site, pneumatic slug tests were conducted on 19 monitoring wells. These wells are screened in the upper fine sand layer of the Todd Valley aquifer. Slug tests results showed the average well horizontal hydraulic conductivity values $\left(K_{h}\right)$ ranged from $4 \mathrm{~m} /$ day to $20 \mathrm{~m} /$ day (Fig. 5). These values are in agreement with average hydraulic conductivity of the upper fine sand layer previously reported at $15 \mathrm{~m} /$ day by the Army Corp of Engineers (Woodward-Clyde, 1995).

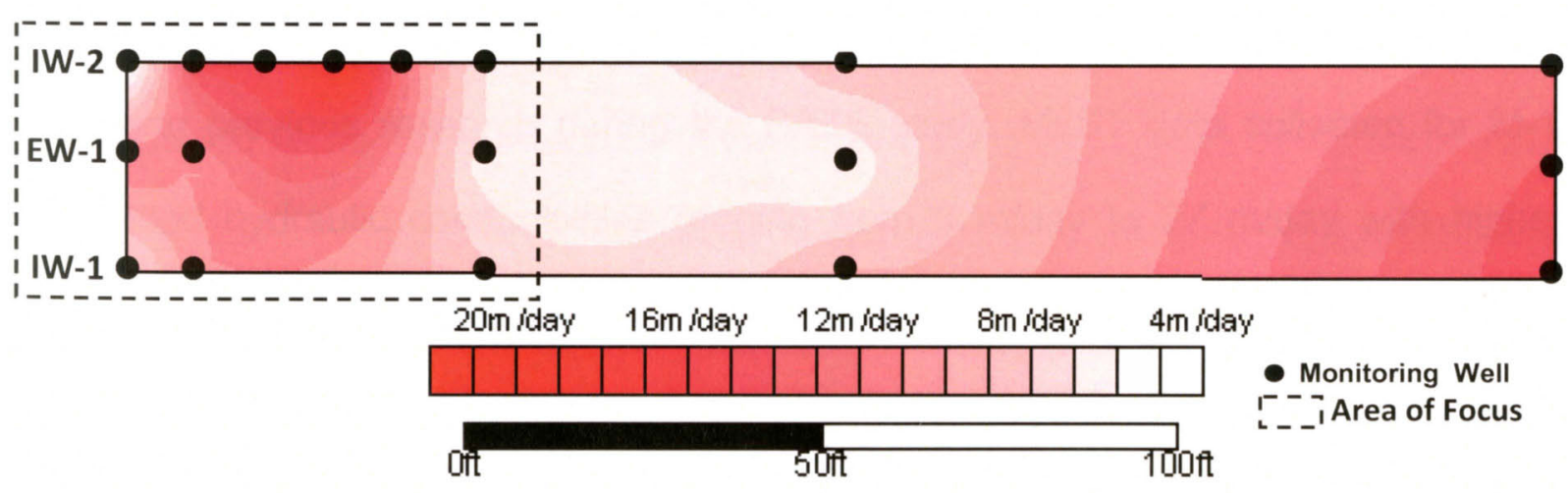

Figure 5. Hydraulic conductivities within the permanganate injection Site. 
Table 3.

Well construction parameters of wells located in the area of focus at the permanganate injection site.

\begin{tabular}{|ccccccc|}
\hline Well ID & Date Installed & $\begin{array}{c}\text { Bore } \\
\text { Hole } \\
\text { Diameter } \\
\text { (inhes) }\end{array}$ & $\begin{array}{c}\text { Casing } \\
\text { Diameter } \\
\text { (inches) }\end{array}$ & $\begin{array}{c}\text { Well } \\
\text { Depth } \\
\text { (ft) }\end{array}$ & $\begin{array}{c}\text { Screen } \\
\text { Interval } \\
\text { (ft) }\end{array}$ & Filter Pack Type \\
\hline EW-1 & $11 / 20 / 2003$ & 10 & 6 & 75 & $55-75$ & $16-30$ Silica Sand \\
IW-1 & $11 / 19 / 2003$ & 8 & 4 & 75 & $55-75$ & $16-30$ Silica Sand \\
IW-2 & $11 / 18 / 2003$ & 8 & 4 & 75 & $55-75$ & $16-30$ Silica Sand \\
MW-1 & $11 / 11 / 2003$ & 8.25 & 2 & 75 & $55-75$ & $20-40$ Silica Sand \\
MW-2 & $11 / 12 / 2003$ & 8.25 & 2 & 75 & $55-75$ & $20-40$ Silica Sand \\
MW-3 & $11 / 12 / 2003$ & 8.25 & 2 & 75 & $55-75$ & $20-40$ Silica Sand \\
MW-4 & $11 / 13 / 2003$ & 8.25 & 2 & 75 & $55-75$ & $20-40$ Silica Sand \\
MW-12 & $4 / 10 / 2007$ & 7.5 & 2 & 75 & $55-75$ & $20-40$ Best Sand \\
MW-13 & $4 / 10 / 2007$ & 7.5 & 2 & 75 & $55-75$ & $20-40$ Best Sand \\
MW-14 & $4 / 10 / 2007$ & 7.5 & 2 & 75 & $55-75$ & $20-40$ Best Sand \\
MW-15 & $4 / 10 / 2007$ & 11.5 & 4 & 75 & $55-75$ & $20-40$ Best Sand \\
MW-16 & $4 / 12 / 2007$ & 7.5 & 2 & 75 & $55-75$ & $20-40$ Best Sand \\
MW-17 & $4 / 12 / 2007$ & 7.5 & 2 & 75 & $55-75$ & $20-40$ Best Sand \\
\hline
\end{tabular}

In addition to the pneumatic slug tests, multi-level slug tests were performed on three 4 inch (10.16 cm diameter) wells, IW-1, IW-2, and MW-15, located within the study site in order to observe spatial differences in hydraulic conductivities within the well screen. Data obtained from IW-1 and IW-2 were unusable and indicated filter pack bridging. This may be attributed to poor well construction during previous research during the BAZE study. MLST data collected for M-15 yielded hydraulic conductivities ranging from $3 \mathrm{~m} /$ day to $27 \mathrm{~m} /$ day with highest

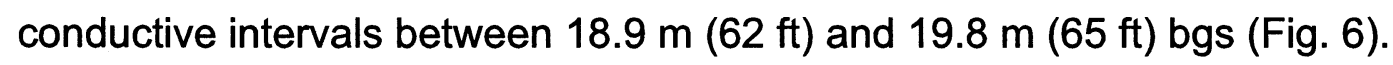




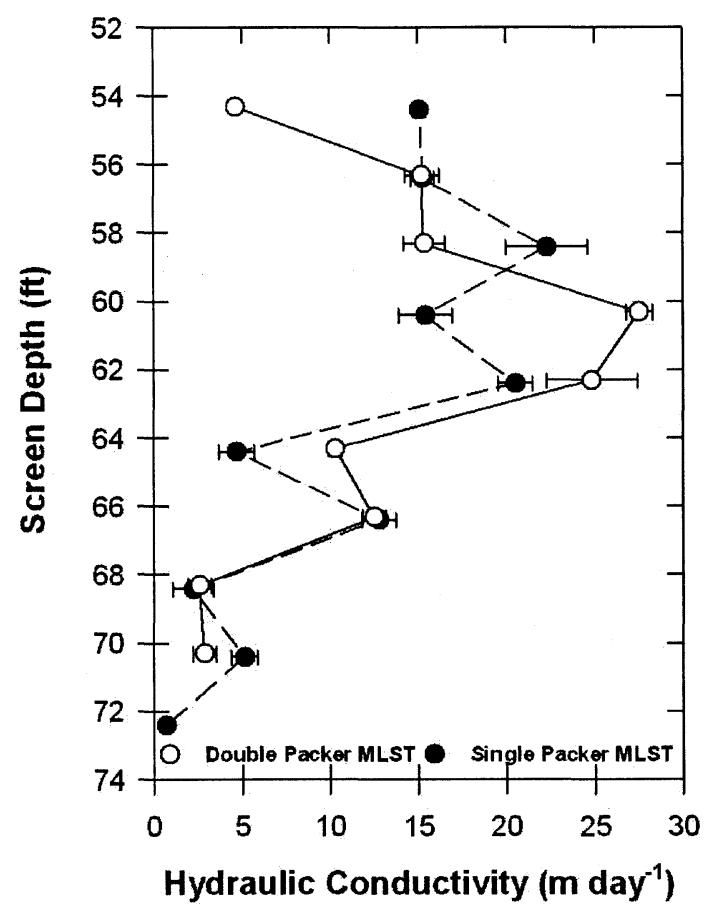

Figure 6. Hydraulic conductivity variations within MW-15 screened interval.

\section{Contaminants of Concern at the Former Nebraska Ordnance Plant}

Contaminated groundwater underlying the former Nebraska Ordnance Plant is believed to have originated from four sources. The first two are TCE plumes that originated at the Atlas Missile Area and the Air Force Tech Area at the north end of Load Line 1. The third plume contains explosives suspected of originating from Lines 2, 3, 4 and the North Burning Grounds Area east of Load Line 4. The fourth plume also contains explosives and believed to have originated from Load Line 1. TCE is the most commonly detected volatile organic compound (VOC) in the groundwater at the site. In 2005, the Army Corp of Engineers reported TCE 
concentrations at the site to range from no detection to over $800 \mu \mathrm{g} / \mathrm{L}$. RDX is the most common explosive found in the groundwater at the site with concentrations reported by the Army Corp of Engineers in 2005 to range from no detection to over $100 \mu \mathrm{g} / \mathrm{L}$.

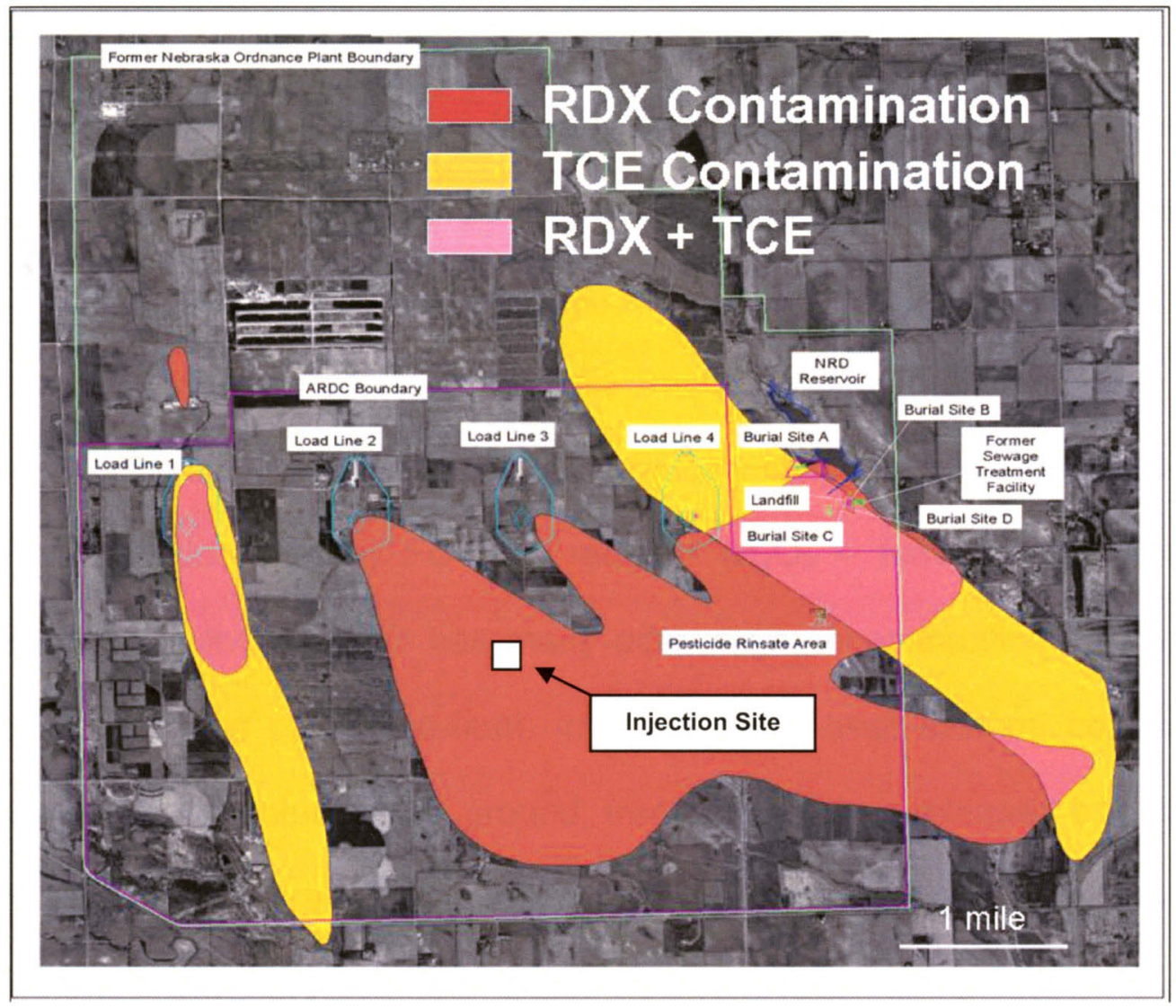

Figure 7. Aerial photograph of the former NOP and approximated RDX and TCE plume delineation.

Due to their frequent use and low soil adsorption coefficients, RDX and TCE are the most common and widespread contaminants (Fig. 7) and were used to estimate the extent of contamination, which was approximated at 23 billion gallons (Woodward-Clyde, 1995). 


\section{In Situ Chemical Oxidation}

In situ chemical oxidation (ISCO) is a remediation technique that delivers oxidants to the subsurface to degrade contaminants in soil and groundwater. ISCO has proven itself to be a successful method of soil and groundwater remediation (Schnarr et al., 1998). ISCO has the ability to react rapidly and extensively with organic contaminants and can be engineered to accommodate most treatment sites. Chemical oxidants can be deployed using methods such as deep soil mixing using augers, injection probes, hydraulic fracturing, and horizontal and vertical groundwater wells. Chemical oxidants commonly employed include: ozone $\left(\mathrm{O}_{3}\right)$, hydrogen peroxide $\left(\mathrm{H}_{2} \mathrm{O}_{2}\right)$, Fenton's reagent $\left(\mathrm{H}_{2} \mathrm{O}_{2}+\right.$ ferrous iron salts), and permanganate $\left(\mathrm{MnO}_{4}\right)$. ISCO has many advantages over traditional remediation techniques such as pump-and-treat. In a pump-and-treat system, contaminated groundwater is extracted above ground, treated, and then released back into the environment either by re-injection into groundwater, discharge to surface water, or disposal into a sewer system. Pump-and-treat is a costly and inefficient technique for remediation, especially if contaminants are strongly sorbed to aquifer media.

At the former NOP, eleven extraction wells are currently in place to hydraulically contain the spreading of the contaminated plume. This on site pump and treat facility currently treats four million gallons of groundwater per day using granular activated carbon (GAC). The annual operating costs for this method is 
approximately $\$ 800,000$ per year (Comfort 2005). The total treatment time proposed for the facilities is 125 years which would total $\$ 100,000,000$.

ISCO is recognized to be less expensive than long-term pump-and-treat (Cronk et al. 2004). ISCO does not require flushing of the contamination and therefore retardation is not an issue. Contaminants can be degraded in situ unlike surfactant flushing technologies which extracts contaminants from the subsurface for above ground treatment. In order for ISCO to be successful, field data must be collected to identify target contaminant levels as well as estimate additional possible oxidant sinks. The total oxidant demand (TOD) consists of many physical and chemical constituents. These include: dissolved phase contaminant, sorbed phase contaminant, free phase contaminant, dissolved phase reduced minerals, solid phase (or sorbed phase) reduced minerals, dissolved and sorbed phase natural organic matter (NOM) and thermal and chemical decomposition (Haselow et al., 2003). Methods for determining TOD include colormetric techniques, direct measurement, and push-pull techniques.

Colormetric techniques include titration and color change observation using a redox indicator. If the oxidant is permanganate, no indicator is needed due to the associated purple color. Direct measurements such as the Permanganate Soil Oxidant Demand (PSOD) take measurements spectrophotometrically $(525 \mathrm{~nm})$ before and after the test. Concentrations are then used to calculate the PSOD via the following equation:

$$
P S O D=\frac{V \times\left(C_{i}-C_{f}\right) \times 0.001}{W_{s}}
$$


where $V$ is the volume of solution added to the soil sample, $C_{i}$ is the initial concentration of potassium permanganate solution, $C_{f}$ is the final concentration of permanganate solution, and $W_{s}$ is the mass of the soil (ASTM Standard D 726207, 2007).

The Push-Pull technique measures oxidant demand directly in the aquifer as opposed to the previous laboratory techniques. The push-pull technique is comprised of three phases: the injection phase, the reaction or drift phase, and the extraction phase (Mumford et al. 2004). An oxidant solution and a non-reactive tracer with known concentration and injected volume is injected into the saturated zone and allowed to react. The non-reactive tracer serves to quantify the mass of the oxidant lost due to insufficient extraction verses the loss of mass due to subsurface reactions (i.e., consumption). Once the oxidant has had sufficient time to react with the subsurface, the oxidant is pumped out via the injection well. The recovered oxidant mass is subtracted by the initial injected mass. This serves as the change in mass. The change in mass is then divided by the mass of the contacted aquifer material yielding a mass of oxidant consumed per mass of aquifer reacted. The volume $\left(V_{c}^{i}\right)$ and mass $\left(m_{a q}^{i}\right)$, of aquifer contacted by the oxidant is calculated by the following equations (Mumford et al. 2004):

$$
V_{c}^{i}=\frac{V_{i n j}}{n}
$$

where $V_{i n j}$ is the volume of injected oxidant and $n$ is the effective porosity. 


$$
m_{a q}^{i}=\rho_{b} \times V_{c}^{i}
$$

where $\rho_{b}$ is the dry bulk density of the aquifer material

\section{ISCO Using Permanganate}

Permanganate has been used for years in waste water and drinking water treatment facilities to oxidize and remove organic contaminants. Permanganate is manufactured as a solid, potassium permanganate $\left(\mathrm{KMnO}_{4}\right)$, and liquid, sodium permanganate $\left(\mathrm{NaMnO}_{4}\right)$. Permanganate has been found to readily oxidize dissolved chlorinated alkenes and organic compounds with carbon-carbon double bonds, aldehyde groups, or hydroxyl groups. Permanganate is effective in typical groundwater temperatures and $\mathrm{pH}$ values ranging from 4 to 8 (Seol et. al. 2003.). Oak Ridge National Laboratory (West et al., 1998) noted that whenever permanganate was detected in groundwater wells, TCE concentrations dropped to non-detectable limits or low ppb levels. Struse et al. (2000) reported greater than $99 \%$ destruction of TCE within unconsolidated pebbles and gravels in a fine siltysand matrix. Oberle and Schroder (2000) reported complete destruction of 1,2DCE (dichloroethylene) $(81 \mu \mathrm{g} / \mathrm{L})$ within saturated sand and $99.9 \%$ destruction of PCE (perchloroethylene) $(60 \mathrm{mg} / \mathrm{kg})$ and TCE $(40 \mathrm{mg} / \mathrm{kg})$ in unsaturated sandy-clay.

Lowe et al. (2002) conducted a field evaluation where $\mathrm{NaMnO}_{4}$ was distributed via a recirculation system to degrade TCE with a concentration ranging from 133 to $2255 \mu \mathrm{g} / \mathrm{L}$. The system configuration consisted of one 6 -inch injection well, four 4-inch extraction wells, and nine 2-inch monitoring wells (Fig 8.). 


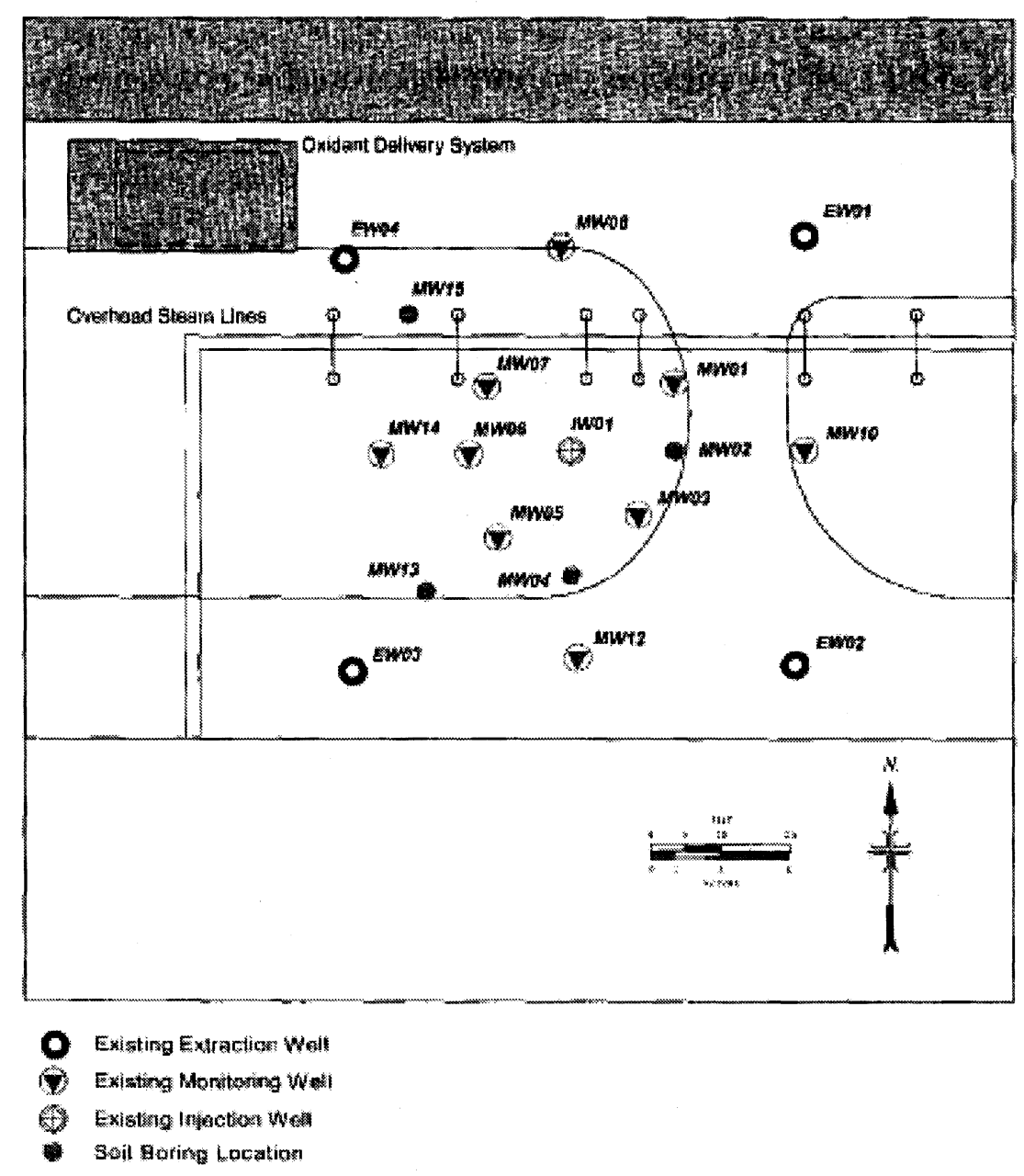

Figure 8. Schematic of the injection/extraction system configuration used by Lowe et al (2002).

Prior to $\mathrm{NaMnO}_{4}$ delivery, $1892 \mathrm{~L}$ of $1800 \mathrm{mg}-\mathrm{Br} / \mathrm{L}$ potassium bromide $(\mathrm{KBr})$ was delivered through the injection/extraction system as a conservative tracer. Upon completion of the tracer test, $295 \mathrm{~L} 40$ (w/w) $\mathrm{NaMnO}_{4}$ was mixed and injected at a concentration of $250 \mathrm{mg} / \mathrm{L}$. Groundwater was sampled throughout the injection/extraction process as well as periodically thereafter to monitor solvent rebound. 
After assuming a homogeneous aquifer, modeling efforts predicted that it would take approximately three days before the tracer would arrive at the extraction wells. Field results however, revealed heterogeneity throughout the study site with bromide reaching the extraction wells between five and 10 hours. This phenomena was previously described by Ibaraki and Schwartz (2001) who concluded that in a heterogeneous aquifer, preferential flow or high $\mathrm{K}$ regions, create hydraulic short circuits where uneven permanganate transport can occur from the injection well to the extraction well.

Results of the $\mathrm{NaMnO}_{4}$ injection indicated an overall TCE mass reduction between $99.5 \%$ and $98.8 \%$ and TCE remained below detection limits for one month before rebounding. Slug tests conducted at the site were conducted prior and post injection to monitor changes in aquifer hydraulic conductivity and/or well fouling with no significant changes noted. 


\section{Aquifer Permeability Impacts During Permanganate ISCO}

The oxidation of permanganate typically results in the production of one mole of manganese dioxide $\left(\mathrm{MnO}_{2}\right)$ for every mole of permanganate consumed. These solid $\mathrm{MnO}_{2}$ particles may be discrete and agglomerated in size and mobile in some settings (Siegrist et. al, 2002). These solids may coat grains, grow in size, and fill the porous media (Siegrist et. al, 2002). Schroth et al. (2001) found that in column studies, $\mathrm{MnO}_{2}$ had detrimental effects on relative permeability even at low permanganate concentrations. West et al. (1998) observed that permanganate reduced hydraulic conductivities at their treatment sites. West et al. (2000) observed both increased hydraulic conductivities and decreased hydraulic conductivities in monitoring wells screened in an aquifer treated with 2 to $4 \%$ potassium permanganate treatments. Lowe et al. (2002) found no change in aquifer hydraulic conductivities during a permanganate ISCO of TCE.

\section{Permanganate Transport Processes}

Permanganate moves through the subsurface by advection, molecular diffusion, mechanical dispersion, and by density gradients (Siegrist et. al, 2001). Advection flow via groundwater, is the primary transport process. Transport by mechanical dispersion results in microscopic variations in velocities within the porous medium that causes smearing of the permanganate front (Siegrist et. al, 2001). 
Molecular diffusion is a slow transport process that, according to Siegrist et al. (2001), cannot be relied on for distribution of permanganate more than a few decimeters from the point of release even after $30 \mathrm{~d}$ or more. Struse et al. (2002) concluded that diffusive transport of permanganate occurs in low permeable media and the rate depends on the permanganate's mass and concentration as well as aquifer properties. One dimensional transport of permanganate can be calculated using the equation (de Marsily, 1986):

$$
\left(\theta D^{*}+D\right) \frac{\partial^{2} C_{p}}{\partial x^{2}}-U \frac{\partial C_{p}}{\partial x}+r=\theta \frac{\partial C p}{\partial t}
$$

where $\theta$ is the porosity of the porous media, $D^{*}$ is the effective molecular diffusion coefficient, $D$ is the dispersion coefficient, $U$ is Darcy's velocity, $C_{p}$ is the permanganate concentration, $r$ is the rate of degradation or consumption of permanganate. When permanganate is continuously injected, $\frac{\partial C p}{\partial t}=0$, the following equation from Yan and Schwartz (1999) can be used to calculate the concentration of permanganate at any distance $x$.

$$
C_{P}=C_{P_{o}} \exp \left(\frac{-\theta k_{p}}{U} x\right)
$$

Where $k_{p}=2 \times 10^{-3} / \mathrm{s}$, the minimum degradation constant measured in solutions of potassium permanganate and natural organic matter obtained from a landfill leachate. 
Permanganate is denser than groundwater and will sink by density-induced advection. Bourne et al. (2004) conducted a field experiment in a sandy aquifer contaminated with DNAPL (PCE and TCE). The injection site was enclosed by sheet piling which created stagnant, velocity absent, aquifer conditions. Potassium permanganate $(40 \mathrm{~g} / \mathrm{L})$ was injected via DPT rods and allowed to redistribute passively along the DNAPL under density-driven advection. A series of multi-level bundle samplers were installed radially in which groundwater was analyzed for potassium permanganate, chloride, TCE, and other volatile organic contaminants. The geometry of the permanganate plume over the 11 week monitoring process is presented in Figure 9.
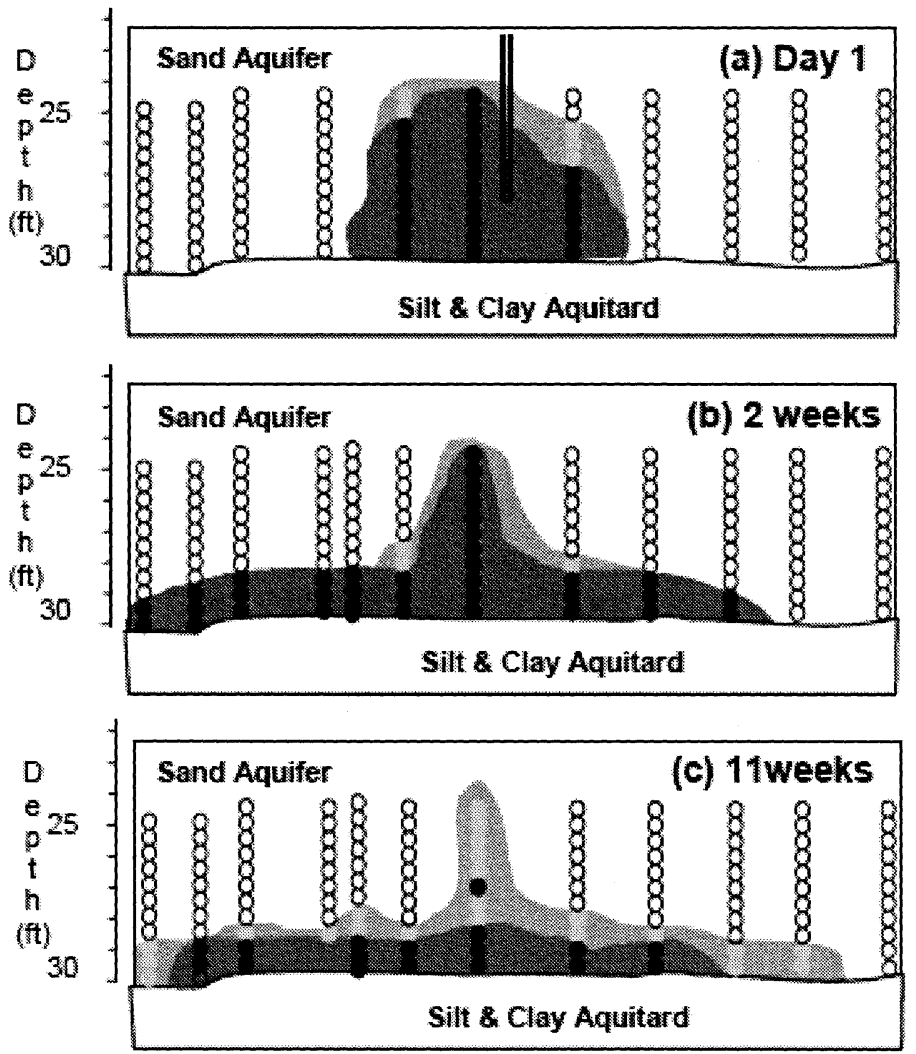

Figure 9. Changes in permanganate distribution with time (modified from Bourne et al., 2004) 
Wilson (2008) demonstrated the relationship between density-driven flow verse advection. Wilson was able to model how groundwater velocity affects the significance of density-driven flow. He showed that under isotropic conditions $\left(\frac{K_{z}}{K_{h}}=1\right)$ both density-driven flow and advection were possible at varying groundwater velocities. Wilson (2008) was also able to show that when horizontal hydraulic conductivity is 10 times larger than vertical hydraulic conductivity $\left(\frac{K_{z}}{K_{h}}=0.1\right)$, density-driven flow was secondary to advection and when horizontal hydraulic conductivity is 100 times higher than the vertical hydraulic conductivity $\left(\frac{K_{z}}{K_{h}}=0.01\right)$, density-driven flow was minor compared to advection with amendment densities up to $1.03 \mathrm{mg} / \mathrm{L}$.

\section{RDX Degradation Using Permanganate}

Permanganate has been used extensively to remediate TCE contaminated sites but only recently has permanganate been investigated to degrade RDX. Batch experiments with aqueous RDX conducted by Adam et al. (2004) showed $20,000 \mathrm{mg} / \mathrm{L}$ potassium permanganate degraded RDX from $2.8 \mathrm{mg} / \mathrm{L}$ to $0.1 \mathrm{mg} / \mathrm{L}$ in 11 d. Adam et al. (2004) found that batch experiments containing aquifer material decreased RDX degradation kinetics 0.67/day, however RDX concentrations were still reduced to $<50 \mu \mathrm{g} / \mathrm{L}$. Potassium permanganate was shown to degrade RDX at concentrations as low as $1000 \mathrm{mg} / \mathrm{L}$. Adam et al. (2004) 
determined RDX destruction rates in spiked soil slurries with vary potassium permanganate concentrations: $1000 \mathrm{mg} / \mathrm{L}(k=0.032 / \mathrm{d}), 2000 \mathrm{mg} / \mathrm{L}(k=0.185 / \mathrm{d})$, $4000 \mathrm{mg} / \mathrm{L}(k=0.080 / \mathrm{d})$, and $20000 \mathrm{mg} / \mathrm{L}(k=0.667 / \mathrm{d})$. Moreover, Adam et al. (2004) found $\mathrm{pH}(4.1-11.3)$ had little effect on RDX destruction rates by permanganate. Clayton et al. (2001) conducted laboratory batch studies using potassium permanganate concentrations of $400 \mathrm{mg} / \mathrm{L}, 4,000 \mathrm{mg} / \mathrm{L}, 20,000 \mathrm{mg} / \mathrm{L}$, and $48,000 \mathrm{mg} / \mathrm{L}$ to treat $2.5 \mathrm{mg} / \mathrm{L}$ aqueous RDX. Clayton et al. (2001) observed second order reactions (Table 3 ) and observed complete RDX degradation at approximately $90 \mathrm{~h}$ with $48,000 \mathrm{mg} / \mathrm{L}$ potassium permanganate.

\section{Table 4}

First and second order degradation rates of RDX by varying concentration of permanganate (Clayton et al. 2001)

\begin{tabular}{|c|c|c|}
\hline $\mathrm{KMnO}_{4}$ Concentration & $\operatorname{RDX~k}_{1}(1 / \mathrm{h})$ & $\mathrm{RDX} \mathrm{k}_{2}(\mathrm{~L} / \mathrm{mg} \mathrm{h})$ \\
\hline 48,000 & 0.0557 & $1.2 \times 10^{-6}$ \\
\hline 20,000 & 0.0206 & $1.0 \times 10^{-6}$ \\
\hline 4,000 & 0.0048 & $1.2 \times 10^{-6}$ \\
\hline 400 & 0.0005 & $1.3 \times 10^{-6}$ \\
\hline
\end{tabular}

Weeks et al. (2003) conducted batch studies using potassium permanganate to treat RDX in a treatabilty study at the Massachusetts Military Reservation (Cape Cod, MA). RDX contaminated groundwater from the site was treated with permanganate concentrations ranging from 400 to $10,000 \mathrm{mg} / \mathrm{L}$. They 
observed over $90 \%$ RDX degradation $(110 \mu \mathrm{g} / \mathrm{L}$ to $10 \mu \mathrm{g} / \mathrm{L})$ within 21 days at temperatures ranging between 9 and $12^{\circ} \mathrm{C}$ with $10,000 \mathrm{mg} / \mathrm{L}$ treatment. 


\section{REFERENCES}

Adam, M.L., Comfort, S.D., Snow, D.D., 2004. Remediating RDX-contaminated ground water with permanganate: Laboratory investigations for the Pantex perched aquifer. Journal Environmental Quality. 33, 2165-2173.

Anderson, M.P., Aiken, J.S., Webb, E.K., Mickelson, D.M., 1999. Sedimentology and hydrogeology of two braided stream deposits. Sedimentary Geology. 129, 187-199.

ASTM Standard D 7262-07. Standard Test Method for Estimating the Permanganate Natural Oxidant Demand of Soil and Aquifer Solids, ASTM International, West Conshohocken, PA, www.astm.org.

Bourne, C.S., Parker, B.L., Cherry, J.A., 2004. Destruction of TCE DNAPL using $\mathrm{KMnO}_{4}$ : Delivery with direct-push technology and distribution under density driven advection and diffusion. www.containment.fsu.edu/cd/content/pdf/315.pdf

Cardenas, M.B.R., Zlotnik, V.A., 2003. Three-dimentional model of modern channel bed deposits. Water Resources Research. 39(6), doi: 10.1029/2002WR001383.

Clayton, W.S., 2008. In situ chemical oxidation (basics, theory, design, and application). California DTSC Remediation Technology Symposium. May 1416.

Clayton, W.S., Harris, S.T., Marvin, B.K., and Struse, A.M., 2001. In-Situ oxidation treatment of high explosives in groundwater using potassium permanganate. In proceedings of the 2001 International Containment and Remediation 
Technology Conference, Institute for Cooperative Environmental Research, Florida State University.

Comfort, S. D., 2005. "Remediating RDX and HMX Contaminated Soil and Water" Bioremediation of Aquatic and Terrestrial Ecosystems. Ed. Fingerton, M. and Nagabhushanam, R. Enfield New Hampshire: Science Publishers.

Condra, G. E., Reed, E.C., 1943. The geological section of Nebraska: Nebraska Geol. Survey Bull. 14, 82.

Cronk, G., Marvin, B., 2004. “Economic Evaluation of Long-Term Pump and Treat Versus In Situ Chemical Oxidation", Remediation of Chlorinated and Recalcitrant Compounds. Ed. Gavaskar A.R. and Chen A.S.C., Proceedings of the Fourth International Conference on Remediation of Chlorinated and Recalcitrant Compounds Monterey, CA; Columbus, $\mathrm{OH}$ : Battelle Press.

de Marsily, G., 1986. Quantitative Hydrogeology: Groundwater Hydrology for Engineers. Academic Press, INC., Sand Diego, CA. Environmental Protection Agency, 2006. Standard Test Method for Determining the Permanganate Soil $\begin{array}{llll}\text { Oxidant Demand (Screening Phase, } & \text { PSOD-1). }\end{array}$ http://www.epa.gov/ada/research/waste/research_52.pdf

Environmental Protection Agency. 1998. In situ remediation technology: in situ chemical oxidation. EPA 542-R-98-008. Office of Solid Waste and Emergency Response. Washington, D.C.

Haselow, J. S., Siegrest, R. L., Crimi, M., and Jarosch, T., 2003. Estimating the total oxidant demand for in situ chemical oxidation design. Remediation. 13 (4), 5-16. 
Huggenberger, P., Meier, E., Pugin, A., 1994. Ground-probing radar as a tool for heterogeneity estimation in gravel deposits: advances in data-processing and facies analysis. Journal of Applied Geophysics. 31, 171-184.

Ibaraki, M. and Schwartz, F.W., 2001. Influence of natural heterogeneity on the efficiency of chemical floods in source zones. Ground Water. 39 (4), 660-666.

Kitanidis, P.K., 1997. Groundwater flow in heterogeneous formations. In: Dagan, G., Neuman, S.P. (Eds.), Subsurface Flow and Transport: A Stochastic Approach. Cambridge University Press, Cambridge, 83-91.

Lowe, K.S., Gardner, F.G., and Siegrist, R.L., 2002. Field evaluation of in situ chemical oxidation through vertical well-to-well recirculation of $\mathrm{NaMnO}_{4}$. Ground Water Monitoring and Remediation. winter. 106-115.

MacQuarrie, K.T.B., Sudicky, E.A., 1990. Simulation of biodegradable organic contaminants in groundwater, 2. Plume behavior in uniform and random flow fields. Water Resources Research. 26 (2), 223-239.

Mail, A.D., 1977. A review of the braided-river depositional environment: EarthScience Reviews, 13, 1-62.

Mumford, K.G., Lamarche, C.S., and Thomson, N.R., 2004. Natural oxidant demand of aquifer materials using the push-pull technique. Journal of Environmental Engineering, 130 (10), 1139-1146.

Oberle, D. W., and Schroder, D. L., 2000. Design consideration for in-situ chemical oxidation, in Proceedings of the Second International Conference on Remediation of Chlorinated and Recalcitrant Compounds, v. C2-6., Monterey, CA: Battelle Press, Columbus, $\mathrm{OH}, 397-403$. 
Piskin, R., 1971. Hydrogeology of the University of Nebraska field laboratory at Mead, Nebraska: University of Nebraska PhD Dissertation.

Rea, J., Knight, R., 1998. Geostatisitical analysis of ground-penetrating radar data: a means of describing spatial variation in the subsurface. Water Resources Research. 34 (3), 329-340.

Schnarr M., Truax C., Farquhar G., Hood E., Gonullu T., and Stickney B., 1998. Laboratory and controlled field experiments using potassium permanganate to remediate trichloroethylene and perchloroethylene DNAPLs in porous media. Journal of Contaminant Hydrology. 29 (3), 205-224.

Schuett, E. C., Jr., 1964. Petrology and the water mineral relationship of two Quaternary fills in eastern Nebraska: University of Nebraska, M. S. Thesis.

Schroth, M. H., Oostrom, M., Wietsma, T. W., and Istok, J. D., 2001. In-situ oxidation of trichloroethene by permanganate: effects on porous medium hydraulic properties. Journal of Contaminant Hydrology. 50, 79-98.

Seol, Y., Zhang, H., and Schwatz, F. W., 2003. A review of in situ chemical oxidation and heterogeneity. Environmental and Engineering Geoscience, 9 (1), $37-49$.

Siegrist, R. L., Urynowicz, M. A., West, O.R., Crimi, M. L., and Lowe, K. S., $2001 .$. Principles and practices of in situ chemical oxidation using permanganate. Battelle Press, Columbus, $\mathrm{OH}$.

Siegrist, R. L., Urynowicz, M. A., Crimi, M. L., and Lowe, K. S., 2002. Genesis and effects of particles produced during in situ chemical oxidation using permanganate. Journal of Environmental Engineering. 128 (11), 1068-1079. 
Souders, V.L., 1967. Availability of water in Saunders County, Nebraska, USGS Hydrologic Investigations, Atlas HA-266.

Stanley, K. O., 1971. The tectonic implications of Cenozoic gravel dispersal, Nebraska and adjoining Wyoming: North-Central Section Fifth Annual Meeting, Geol. Soc. Am. Abstr., 3 (4), 280.

Struse, A.M., Siegrist, R.L., Dawson, H.E., and Urynowicz, M.A., 2002. Diffusive transport of permanganate during in situ oxidation. Journal of Environmental Engineering. 128 (4), 327-334.

Struse, A.M., Siegrist, R.L., 2000. Permanganate transport and matrix interactions in silty clay soils. Chemical Oxidation and Reactive Barriers. Ed Wickramanayake, G.B., Gavaskar A.R., and Chen, A.S.C., Columbus, $\mathrm{OH}$, Battele Press.

Thompson, A.F.B., Gelhar, L.W., 1990. Numerical simulation of solute transport in three-dimensional, randomly heterogeneous porous medium. Water Resources Research. 26 (10), 2541-2562.

Theis, C.V., 1935. The relation between the lowering of the piezometric surface and the rate of discharge of a well using groundwater storage. Trans. Am. Geophys. Union 2, 519-524.

US Corps of Engineers, 1989. Former Nebraska Ordnance Works, Confirmation study, V. 1, Report and appendices A \& B, April 1989.

Webb, E.K., 1994. Simulating the three-dimensional distribution of sediment units in braided-stream deposits. Journal of Sediment. Res. B64 (2), 219-231. 
Weeks, K.R., Veenstra, S.C., Hill, D.L., and Gregson, B.P., 2003. A study of treatment options to remediate explosives and perchlorate in soils and groundwater at Camp Edwards, Massachusetts. Remediation Journal. 13 (2), 131-143.

West, O.R., Cline, S.R., Holden, W.L., Gardner, F.G., Schlosser, B.M., Thate, J.E., Pickering, D.A., and Houk, T.C., 1998. A field-scale demonstration of in situ chemical oxidation through recirculation at the X-701B site. Oak Ridge National Laboratory Report, ORNL/TM-13556.

West, O.R., Siegrist, R.L., Cline, S.R. and Gardner, F. G., 2000. The effects of in situ chemical oxidation through recirculation (ISCOR) on aquifer contamination, hydrogeology, and geochemistry. Oak Ridge national Laboratory, Internal report submitted to the Department of Energy, Office of Environmental Management, Subsurface Contaminants Focus Area.

Woodward-Clyde, 1995. Engineering evaluation/cost analysis for operable unit No. 2 (groundwater) former Nebraska Ordnance Plant, Mead, Nebraska DACA 4192-C-0023. Prepared for the Department of the Army, U.S. Army Engineers District, Kansas City District, Corps of Engineers, Kansas City, Missouri, May, 1995.

Yan, Y.E., and Schwartz, F.W., 1999. Oxidative degradation and kinetics of chlorinated ethenes by potassium permanganate. Journal of Contaminant Hydrology. 37, 343-365. 


\section{CHAPTER 3}

\section{IN SITU CHEMICAL OXIDATION OF RDX-CONTAMINATED GROUNDWATER WITH PERMANGANATE AT THE NEBRASKA ORDNANCE PLANT}

\section{Abstract}

Groundwater beneath the former Nebraska Ordnance Plant (NOP) is contaminated with the explosive hexahydro-1,3,5-trinitro-1,3,5-triazine (RDX). The current pump and treat facility, which is hydraulically preventing offsite migration, could potentially operate for the next 125 years and offers no short-term solution. The objective of this study was to demonstrate that permanganate can effectively degrade RDX in situ at the NOP. This was accomplished by performing treatability experiments, groundwater characterization, and a pilot-scale in situ chemical oxidation (ISCO) demonstration. The ISCO demonstration was performed by using an extraction-injection well configuration to create a curtain of permanganate between two injection wells. RDX destruction was quantified as the RDXpermanganate plume migrated down gradient through the well field. Electrical Resistivity Imaging (ERI) was also used to identify the location of the permanganate after injection. Results showed that RDX concentrations temporally decreased in wells closest to the injection wells by 70 to $80 \%$ with degradation rates of $0.12 \mathrm{~d}^{-1}$ and $0.087 \mathrm{~d}^{-1}$. These rates were lower than what was observed under batch conditions at $11.5^{\circ} \mathrm{C}\left(0.20 \mathrm{~d}^{-1}\right)$ and likely a result of a lower initial permanganate concentration (6000 versus $15000 \mathrm{mg} \mathrm{L}^{-1}$ ). ERI measurements and conductivity probe measurements of monitoring wells verified that permanganate 
distribution was not uniform throughout the 6.1-m well screen and that groundwater sampling likely captured treated and non-treated groundwater during pumping. Direct push measurements also verified that the permanganate migrated below the monitoring wells as it moved down gradient. Despite problems encountered in getting the permanganate curtain uniformly distributed and throughout the well screen interval, pilot-scale results provide proof-of-concept that permanganate can degrade RDX in situ and support permanganate as a possible remedial treatment for the RDX-contaminated groundwater.

Keywords: Permanganate; RDX; In situ chemical oxidation 


\section{INTRODUCTION}

The former Nebraska Ordnance Plant (NOP, Mead, NE) was a military loading, assembling, and packing facility that produced bombs, boosters, rockets, and shells during World War II and the Korean Conflict. Ordnances were routinely loaded with the high explosives TNT (2,4,6-trinitrotoluene) and RDX (hexahydro1,3,5-trinitro-1,3,5-triazine). To reduce chemical exposure to NOP workers during ordnance production, munitions residue that collected on floors, walls, and manufacturing equipment was rinsed with water and then deposited outside into unlined ditches and sumps. These ditches became grossly contaminated with TNT and RDX with soil concentrations exceeding $5000 \mathrm{mg} / \mathrm{kg}$ near the soil surface (Hundal et al., 1997). When rainfall exceeded infiltration rates, ponded water that formed in the drainage ditches literally became saturated with munitions residues (i.e., reached HE solubility limits) before percolating through the profile. Considering this process proceeded unabated for more than 50 years, ground water beneath the NOP eventually became contaminated. Further compromising NOP ground water was the extensive use of trichloroethene (TCE) to degrease and clean pipelines by the U.S. Air Force in the early 1960s. As a result, the RDX/TCE contaminant plume under the NOP facilities currently covers several square miles.

To prevent the contaminated plume from migrating offsite and in the direction of municipal well fields, an elaborate series of eleven extraction wells and 
piping networks were constructed to hydraulically contain the leading edge of the RDX/TCE plume. Currently this $\$ 33$ million dollar facility treats approximately 4 million gallons of ground water per day with granular activated carbon (GAC). Annual operating costs are approximately $\$ 800,000$ per year with an estimated treatment time of 125 years. As stated in EPA's Record of Decision (ROD) for treatment of NOP groundwater, additional cleanup efforts beyond the current GAC system will be required to remediate the groundwater.

The objective was to quantify RDX destruction via in situ chemical oxidation (ISCO) with permanganate at the Nebraska Ordnance Plant (NOP). This was accomplished by performing laboratory-based treatabilty experiments specific to NOP's geological and hydrological conditions, characterizing the groundwater at the test site, and conducting a field-scale ISCO demonstration with sodium permanganate on a section of RDX-contaminated groundwater at the Nebraska Ordnance Plant. 


\section{METHODS AND MATERIALS}

\section{Treatability Experiments}

\section{Soil Oxidant Demand}

Soil oxidant demand (SOD), which consists of oxidizable organic matter and inorganic solids, is one of the most important parameters that can be used to predict permanganate consumption in an aquifer (Seol et al. 2003). We conducted batch and column experiments to quantify the SOD of the Todd Valley aquifer where the pilot-scale ISCO injection was performed. Soils from depths of $16.7 \mathrm{~m}$ to $22.9 \mathrm{~m}$ were obtained via Direct Push Technologies (DPT) (Geoprobe ${ }^{\circledR}$ Model 6610DT) and allowed to air dry before determining soil oxidant demand. Soil analyses (Midwest Labs, Omaha, NE) indicated that the aquifer solids consisted of $90 \%$ sand, $4 \%$ silt, and $6 \%$ clay with an organic matter content of $0.4 \%$. Batch studies for SOD used the ASTM Standard Method D7262-07 (ASTM Standard, 2007) and were conducted by mixing $50 \mathrm{~g}$ of air-dried aquifer material with $100 \mathrm{~mL}$ of $\mathrm{NaMnO}_{4}$ in 250-mL Erlenmeyer flasks. Initial $\mathrm{NaMnO}_{4}$ concentrations used in the batch experiment included: $82,205,410,820,4100,8,200,12,300$, and 16,400 $\mathrm{mg} / \mathrm{L}$. Each concentration was performed in triplicate and experimental units were covered with Parafilm and aluminum foil during experimentation. Each flask was agitated twice a day by inverting. Temporal changes in permanganate concentrations were obtained by removing $1 \mathrm{~mL}$ aliquots at $1,6,12,24,48,120$, and $206 \mathrm{~h}$ and centrifuging at $19,481 \times \mathrm{g}$ for 10 minutes prior to analysis. Permanganate was quantified via a UV/Vis spectrophotometer (UV-2101 PC; 
Shimadzu, Kyoto, Japan) at a wavelength of $525 \mathrm{~nm}$. Standard calibrations showed a linear response by the UV/Vis detector up to concentrations of $70 \mathrm{mg} / \mathrm{L}$; therefore, all samples were diluted to within this concentration range before quantification.

Soil oxidant demand was calculated using the following equation (Eqn. 1; Huang et al., 2000)

$$
P S O D=\frac{V \times(C i-C f) \times 0.001}{W_{s}}
$$

where $P S O D$ is the Permanganate Soil Oxidant Demand $(\mathrm{g} / \mathrm{kg}), V$ is the volume of $\mathrm{NaMnO}_{4}$ added $(\mathrm{L}), C_{i}$ is the initial $\mathrm{NaMnO}_{4}$ concentration $(\mathrm{mg} / \mathrm{L}), C_{f}$ is the final $\mathrm{NaMnO}_{4}$ concentration $(\mathrm{mg} / \mathrm{L})$, and $W_{s}$ is the mass of the aquifer media $(\mathrm{kg})$.

Soil oxidant demand was also assessed during miscible displacement experiments where initial $\mathrm{NaMnO}_{4}$ concentrations ranged from 164 to $12,300 \mathrm{mg} / \mathrm{L}$. All transport experiments were conducted in $20-\mathrm{cm}(5-\mathrm{cm}$ diam) Plexiglas columns (Soil Measurement Systems, Tucson, AZ) using a similar system to that described by van Genuchten and Wierenga (1986, p. 1037). Soil columns were prepared by uniformly packing air-dried aquifer material into columns to yield bulk densities between 1.6 and $1.7 \mathrm{~g} / \mathrm{kg}$. The columns were equipped with two end caps secured with O-rings that fit closely inside the columns. The bottom end plate supported a porous plate and aluminum mesh; the top end cap secured the eluent delivery tube. Eluent was applied by a MaterFlex multichannel programmable peristaltic pump (Cole-Palmer Instruments, Vernon Hills, IL) that delivered $18 \mathrm{~mL} / \mathrm{h}$. Columns 
were placed over fraction collectors (Retriever II, ISCO, Lincoln, NE) that rotated every $30 \mathrm{~min}$ and collected approximately $9 \mathrm{~mL}$ of effluent in glass tubes.

Each soil column was saturated and conditioned with $3 \mathrm{mM} \mathrm{CaCl}_{2}$ for $24 \mathrm{~h}$ before receiving permanganate. Each permanganate concentration (i.e., pulse) was spiked with tritiated water $\left({ }^{3} \mathrm{H}_{2} \mathrm{O}\right)$, which served as a conservative tracer. After steady flow was established in the columns (determined by constant volume in the collection tubes), the effluent was switched from $3 \mathrm{mM} \mathrm{CaCl}_{2}$ to $\mathrm{NaMnO}_{4}-{ }^{3} \mathrm{H}_{2} \mathrm{O}$ for $8 \mathrm{~h}$ and then back to $3 \mathrm{mM} \mathrm{CaCl} 2$. Darcy flux was $19.44 \mathrm{~cm} / \mathrm{d}$ with a pore water velocity of $57.6 \mathrm{~cm} / \mathrm{d}$, which approximated the average groundwater velocity of the pilot-scale test site $(61 \mathrm{~cm} / \mathrm{d})$ as determined by the hydraulic gradient, hydraulic conductivity, and porosity data. Once the permanganate was flushed through the column, column effluent samples were weighed to determine the volume collected as a function of time and column pore volume. A 1-mL subsample of each effluent fraction was mixed with $6 \mathrm{~mL}$ of Ultima-Gold scintillation cocktail and ${ }^{3} \mathrm{H}$ activity determined on a Packard 1900TR liquid scintillation counter. Permanganate concentrations were determined as previously described.

Relative concentrations $\left(C / C_{0}\right)$ were calculated by dividing the concentrations of the permanganate and tritium by the initial concentrations of the $\mathrm{NaMnO}_{4}-{ }^{3} \mathrm{H}_{2} \mathrm{O}$ pulse. Both $\mathrm{NaMnO}_{4}$ and ${ }^{3} \mathrm{H}$ breakthrough curves (BTCs, C/C $)$ were plotted and integrated. The mass of $\mathrm{NaMnO}_{4}$ added to the columns was calculated from the total volume leached onto the column and the initial $\mathrm{NaMnO}_{4}$ concentration of the pulse. This mass was equated with the integrated area of the ${ }^{3} \mathrm{H}$ breakthrough curve. We then subtracted the integrated area of the $\mathrm{NaMnO}_{4}$ 
BTC from the ${ }^{3} \mathrm{H}$ BTC to determine the mass of $\mathrm{NaMnO}_{4}$ consumed. The mass of $\mathrm{NaMnO}_{4}$ consumed was divided by the aquifer media in the column to yield a SOD for the respective $\mathrm{NaMnO}_{4}$ concentrations.

\section{Aquifer Slurry Experiments}

RDX degradation kinetics were quantified in the presence of NOP aquifer solids (Todd Valley aquifer sand) and compared to previous aqueous and soil slurry investigations (Adam et al. 2004). Todd Valley aquifer sands contained $90 \%$ sand, $4 \%$ silt, and $6 \%$ clay with an organic matter content of $0.4 \%$. To quantify RDX transformation and mineralization in the presence of aquifer solids, $75 \mathrm{~g}$ (oven dry) of Todd Valley aquifer sand was combined with $150 \mathrm{~mL}$ of ${ }^{14} \mathrm{C}$-labeled RDX ( $\left.C_{0}=3.3 \mathrm{mg} / \mathrm{L}\right)$. Experimental units consisted of twelve 250-mL Erlenmeyer flasks (nine reaction flasks and three control flasks) filled with $84.975 \mathrm{~g}$ aquifer media (gravimetric water content $=13.3 \%$ ) and $140.025 \mathrm{~mL}$ of double deionized water. Crystalline $\mathrm{KMnO}_{4}$ was weighed and added to nine reaction flasks to produce the desired initial concentrations $(10000,15000$, and $20000 \mathrm{mg} / \mathrm{L})$. Once $\mathrm{KMnO}_{4}$ was added, all twelve flasks were placed on a gyrotory shaker (G-10: New Brunswick Scientific Company, New Brunswick, NJ) and spiked with $1 \mathrm{~mL}$ of 500 $\mathrm{mg} / \mathrm{L}$ RDX in acetone and $0.0463 \mathrm{~mL}$ of $30,000 \mathrm{dpm} / \mathrm{mL}{ }^{14} \mathrm{C}$-labeled RDX.

Temporal changes in RDX concentrations were quantified by withdrawing 1$\mathrm{mL}$ aliquots at $6,12,24,36,48,72,120,168,240$, and $336 \mathrm{~h}$. Each aliquot was placed in microcentrifuge vial and quenched with $150 \mu \mathrm{L}$ of $\mathrm{MnSO}_{4}(0.5 \mathrm{~g} / \mathrm{mL})$ to 
reduce $\mathrm{MnO}_{4}^{-}$to $\mathrm{MnO}_{2}$ and stop further RDX transformations by permanganate. The microcentrifuge vials were capped, shaken by hand, and centrifuged for 10 min at $19,481 \times g$ to settle out suspended silt, clay, and $\mathrm{MnO}_{2}$ colloids. Once centrifuged, $1 \mathrm{~mL}$ of supernatant was transferred to high performance liquid chromatography (HPLC) glass vials for analysis.

RDX was quantified at $220 \mathrm{~nm}$ by HPLC using a Keystone NA column (Keystone Scientific, Bellefonte, PA) with a 70:30 water:methanol mobile phase and a flow rate of $1 \mathrm{~mL} / \mathrm{min} .{ }^{14} \mathrm{C}$-activity was quantified by removing $0.5 \mathrm{~mL}$ aliquots from the permanganate-RDX mixtures at the same times RDX samples were obtained. ${ }^{14} \mathrm{C}$-aliquots were mixed with $0.5 \mathrm{~mL} 0.2 \mathrm{M} \mathrm{HNO}_{3}$ to acidify and release any dissolved ${ }^{14} \mathrm{CO}_{2}$. Six milliliters of Ultima Gold scintillation fluid (Perkin Elmer, Shelton, CT) was then added to each vial and stored in the dark for $48 \mathrm{~h}$ before analyzing on a liquid scintillation counter (Packard 1900TR, Meridian, CT)

\section{Treatment of Nebraska Ordnance Plant Groundwater with Permanganate}

Adam et al. (2004) previously showed that permanganate can effectively degrade and completely oxidize (i.e., mineralize) RDX. RDX concentrations at the NOP site are much lower than those used by Adam et al. (2004) and ranged from $\sim 300 \mu \mathrm{g} / \mathrm{L}$ to no detect. RDX-contaminated groundwater from the NOP was collected from a monitoring well upgradient from the pilot-scale injection site and treated with $15,000 \mathrm{mg} / \mathrm{L} \mathrm{KMnO}_{4}$ at room temperature $\left(23^{\circ} \mathrm{C}\right)$ under aerobic conditions. To accomplish this, $100 \mathrm{~mL}$ of the NOP groundwater $\left(C_{o}=210 \mu \mathrm{g} / \mathrm{L}\right)$ 
was added to $250 \mathrm{~mL}-$ Erlenmeyer flasks and placed on a gyrotory shaker (G-10: New Brunswick Scientific Company, New Brunswick, NJ). Each flask received 1.5 $\mathrm{g}$ of crystalline $\mathrm{KMnO}_{4}$ and was agitated on an orbital shaker. The crystalline $\mathrm{KMnO}_{4}$ was observed to dissolve within 4 min at $23^{\circ} \mathrm{C}$. Temporal changes in RDX concentrations were determined by removing $1.5 \mathrm{~mL}$ aliquots at selected times $(0$, $0.166,24,48,96,192$, and $288 \mathrm{~h}$ ) and quenched as previously described. Because of the low RDX concentrations present in the NOP groundwater $(\mu \mathrm{g} / \mathrm{L}$ versus $\mathrm{mg} / \mathrm{L}), \mathrm{RDX}$ was quantified by liquid chromatography/mass spectrometry (LC/MS) on a Thermoquest LCQ ion trap mass spectrometer. Details of this LC/MS procedure are described in Cassada et al. (1999).

\section{In situ Temperature Effect on RDX Degradation by Permanganate}

In-situ temperatures measured in monitoring wells at the field site ranged from 11 to $13^{\circ} \mathrm{C}$. Temperature effects on $\mathrm{MnO}_{4}{ }^{-} / \mathrm{RDX}$ reaction kinetics have not been previously reported. Thus, we compared destruction efficiencies at $11.5^{\circ} \mathrm{C}$ and $23^{\circ} \mathrm{C}$ by treating $150 \mathrm{~mL}$ of $3.3 \mathrm{mg} / \mathrm{L}$ RDX with $15,000 \mathrm{mg} / \mathrm{L} \mathrm{KMnO} 4$.

A cold water bath reciprocal shaker (BLUE M, New Columbia, PA) was used to maintain the experimental units at $11.5^{\circ} \mathrm{C}$. Twelve $250-\mathrm{mL}$ Erlenmeyer flasks were filled with $149 \mathrm{~mL}$ of double deionized water. Six flasks were used as treatment flasks and six as controls. Permanganate treatments received $2.235 \mathrm{~g}$ of $\mathrm{KMnO}_{4}$, which was allowed to completely dissolve. Once $\mathrm{KMnO}_{4}$ was dissolved, three treatment flasks and three control flasks were placed in a cold water bath 
shaker for $24 \mathrm{~h}$ and allowed to equilibrate at $11.5^{\circ} \mathrm{C}$. The remaining six flasks, three reaction vessels and three controls, were placed on a reciprocal shaker (Eberbach 6010, Ann Arbor, Ml) at room temperature $\left(23^{\circ} \mathrm{C}\right)$. After $24 \mathrm{~h}$ of acclimation, all flasks were spiked with $1 \mathrm{~mL}$ of $500 \mathrm{mg} / \mathrm{L}$ RDX in acetone and agitated on the shakers. Temporal changes in RDX concentrations were quantified by withdrawing $1-\mathrm{mL}$ aliquots at $0,6,12,24,36,48,72,120,192$, and $264 \mathrm{~h}$.

\section{Field-Scale ISCO Demonstration with Sodium Permanganate}

\section{Aquifer Characterization}

Permanganate transport in the subsurface is dictated by aquifer heterogeneities (Seol et al. 2003). In order to quantify aquifer heterogeneities within the injection site, full screen pneumatic slug tests (Zurbuchen et al., 2002) were conducted on 13 existing wells installed by Wani et al. (2007) during an earlier biodegradation demonstration as well as seven additional monitoring wells that were added for this study. All wells in the site are screened in the upper fine sand layer of the Todd Valley aquifer. Slug tests results showed the average well horizontal hydraulic conductivity values $\left(K_{h}\right)$ ranged from $4 \mathrm{~m} /$ day to $20 \mathrm{~m} /$ day. In addition to full screen pneumatic slug tests, multi-level pneumatic slug tests (Zlotnik and McGuire, 1998; Zlotnik and Zurbachen, 2003) were performed on a $10-\mathrm{cm}$ monitoring within the study site (MW-15) to quantify spatial differences in hydraulic conductivities across the well screen. 


\section{Permanganate Extraction-Injection Procedure}

An extraction-injection procedure was used to deliver the permanganate to the groundwater in an attempt to create a "curtain" of permanganate between injection wells. This involved a center extraction well and two lateral injection wells (Fig. 5). For modeling purposes, we assumed that the permanganate curtain would be complete as soon as the first permanganate molecules injected into IW-1 and IW-2 arrived at EW-1 after traveling distance I with local velocity $v(x)$. In the schematic diagram (Fig. 5), the center circle represents the extraction well (EW-1) at coordinate $x=0, y=0$, and is flanked by injection wells IW-1 and IW-2 with coordinates $x=-l, y=0$ and $x=+l, y=0$ (Fig. 5). To calculate the volume of water impacted by this delivery technique, we evaluated linear velocity along the $\mathrm{x}$-axis as follows:

$$
\begin{gathered}
q(x)=-\left[\frac{Q}{2 \pi b x}+\frac{Q / 2}{2 \pi(l-x) b}-\frac{Q / 2}{2 \pi(l+x) b}\right] \\
v(x)=\frac{q(x)}{n}=\frac{-Q}{2 \pi b n} \cdot\left[\frac{1}{x}+\frac{1}{2(l-x)}-\frac{1}{2(l+x)}\right]=\frac{-Q}{2 \pi b n} \cdot\left[\frac{1}{x}+\frac{l+x-(l-x)}{2\left(l^{2}-x^{2}\right)}\right] \\
=\frac{-Q}{2 \pi b n} \cdot\left[\frac{1}{x}+\frac{2 x}{2\left(l^{2}-x^{2}\right)}\right] \\
v(x)=\frac{-Q}{2 \pi b n} \cdot \frac{l^{2}-x^{2}+x^{2}}{x\left(l^{2}-x^{2}\right)}=\frac{-Q}{2 \pi b n} \cdot \frac{l^{2}}{x\left(l^{2}-x^{2}\right)}
\end{gathered}
$$


Time required for curtain completion was obtained as follows:

$$
\begin{gathered}
\text { time }=\int_{l}^{0} \frac{d x}{v(x)}=-\int_{l}^{0} \frac{d x}{Q / 2 \pi b n} \cdot \frac{x\left(l^{2}-x^{2}\right)}{l^{2}}=\frac{2 \pi b n}{Q l^{2}} \int_{0}^{l} x\left(l^{2}-x^{2}\right) d x \\
\text { time }=\frac{2 \pi b n}{Q l^{2}} \cdot\left[\frac{x^{2}}{2} l^{2}-\frac{x^{4}}{4}\right]_{0}^{l}=\frac{2 \pi b n}{Q l^{2}} \cdot\left[\frac{l^{4}}{2}-\frac{l^{4}}{4}\right]=\frac{2 \pi b n}{Q l^{2}} \cdot \frac{l^{4}}{4}=\frac{\pi b n l^{2}}{2 Q}
\end{gathered}
$$

Pumping with discharge rate $Q$ for this time produces the volume of groundwater that is impacted with permanganate.

$$
\text { volume }=Q \times \text { time }=\frac{\pi b n l^{2}}{2}
$$

The approximated volume required for creating a continuous curtain of permanganate was estimated using the following parameter estimates: $b$ is equal to well screen length ( $20 \mathrm{ft}$. or $6.096 \mathrm{~m}$ ), $n$ is equal to porosity (approximately 0.3 for sand), and $I$ is the distance between the extraction well and the injection well (15 ft. or $4.6 \mathrm{~m}$ ).

$$
\text { volume }=\frac{\pi b n l^{2}}{2}=\frac{\pi \cdot 6.096 m \cdot 0.3 \cdot 4.6^{2} \mathrm{~m}^{2}}{2}=60.9 \mathrm{~m}^{3}=60,900 \mathrm{~L}
$$

Sodium permanganate $\left(\mathrm{NaMnO}_{4}\right)$ was injected into the field via a proportional mixing-injection trailer system (Aquifer Solutions, Inc. Evergreen, CO). Groundwater was extracted from a center extraction well (EW-1) (Fig. 5.) via a 
submersible pump (Aermotor $A+75-500$, Delavan, $\mathrm{WI}$ ) at a rate of $151.6 \mathrm{~L} / \mathrm{min}(40$ gpm) and delivered to an intake manifold located onboard the trailer system. Approximately $1707.2 \mathrm{~L}(451 \mathrm{gal})$ of $40 \%(\mathrm{w} / \mathrm{w}) \mathrm{NaMnO}_{4}$, spiked with potassium bromide, was pumped at $3.79 \mathrm{~L} / \mathrm{min}(1 \mathrm{gpm})$ from $1041 \mathrm{~L}$ totes to an intake manifold where extracted groundwater and $\mathrm{NaMnO}_{4}$ were mixed at a ratio of 40:1. The mixed eluent was then gravity fed into each of two neighboring injection wells, IW-1 and IW-2 (Fig. 5.), at approximately $77.7 \mathrm{~L} / \mathrm{min}$ (20.5 gpm). $\mathrm{NaMnO}_{4}$ was continuously injected for 413 minutes with the exception of a 10 min interval at 260 min when $\mathrm{NaMnO}_{4}$ totes were switched. Following the $\mathrm{NaMnO}_{4}$ injection, extracted groundwater from EW-1 was recirculated to wells IW-1 and IW-2 for 42 min.

Sodium permanganate concentrations were periodically measured on site with a portable spectrophotometer (Hach model DR 2800, Loveland, CO) to monitor sodium permanganate concentration delivered to the injection wells and breakthrough at the extraction well. Specific conductivity was measured using a YSI 3000 T-L-C meter (Yellow Springs, OH) during each $\mathrm{NaMnO}_{4}$ measurement to establish a calibration curve, similar to that used by Cavé et al. (2007) to relate specific conductivity to $\mathrm{NaMnO}_{4}$ concentration.

To monitor groundwater levels and buildup of a permanganate head during the $8 \mathrm{~h}$ injection, $20 \mathrm{~m}$ of continuous PVC pipe $(3.8 \mathrm{~cm}$ diam.) was placed into each injection well to shield and dampen water level variations created by the cascading permanganate solution. A water level meter (Durham Geo Slope Indicator, Mukilteo, WA) was periodically lowered into the PVC pipes to record water levels. 


\section{Electrical Resistivity Imaging of Permanganate Injection}

To obtain electrical resistivity imaging of the test site before permanganate injection, ERI measurements were collected along 10 lines that crisscrossed the test area. ERI installation consisted of installing metal stakes (surface electrodes) approximately $15 \mathrm{~cm}$ into the ground every $3 \mathrm{~m}$. The electrodes were attached to a cable and the ERI data was collected with a 56 electrode array using an Advanced Geosciences, Inc., SuperSting R8 system that induced a current, measured the potential, and stored the data. Data was processed using a proprietary Halihan/Fenstemaker processing technique (Halihan and Fenstemaker, 2004). The electrode array generated a 165 meter (541 feet) long line that imaged approximately 33 meters (108 feet) deep. This arrangement was selected to vertically center the volumes surrounding the well screens within the injection site. This image depth also allowed the ERI to capture downward movement during injection. The ERI method measures apparent resistivity with a resolution equal to half the electrode spacing, in this case $1.5 \mathrm{~m}(4.9 \mathrm{ft})$ both horizontally and vertically.

Background images were obtained approximately one month prior to injection. During the permanganate injection, a 12-line ERI data set was collected. ERI measurements were also taken at later dates (i.e., 30, 60, 90 d) but results from these readings failed to provide readings that could be used to identify the permanganate in the groundwater. 


\section{Groundwater Sampling}

Groundwater was sampled from monitoring wells bi-weekly for eight weeks after injection. Prior to sampling, specific conductivity measurements were measured at $0.6 \mathrm{~m}$ intervals in each well and converted to permanganate concentrations (via regression) to estimate vertical stratifications of $\mathrm{NaMnO}_{4}$ entering the well screen. Groundwater samples were collected via a Grundfos Redi-flo2 submersible environmental pump (Olathe, KS) and variable frequency drive converter. A minimum of three well volumes were purged before taking two samples from each well, one for RDX and the other for $\mathrm{NaMnO}_{4}$ and bromide. RDX samples were placed in $250-\mathrm{mL}$ amber bottles and quenched with $\mathrm{MnSO}_{4}$ to precipitate sodium permanganate. All samples (i.e., $\mathrm{RDX}$ and $\mathrm{Br}^{-}$) were placed in a cooler and transferred to a laboratory refrigerator until analysis. Permanganate concentrations were determined as previously described. RDX analyses were conducted on LC/MS by the University of Nebraska Water Science Laboratory (Cassada et al., 1999).

Bromide was analyzed by transferring one milliliter of sampled groundwater to a $20-\mathrm{mL}$ scintillation vial. Thirty percent hydrogen peroxide was added in $10 \mu \mathrm{L}$ intervals to quench the permanganate. A $1 \mathrm{~mL}$ aliquot was then transferred to a micro-centrifuge tube and centrifuged for $10 \mathrm{~min}$ at $19,481 \times \mathrm{g}$ to separate $\mathrm{MnO}_{2}$ colloids and then transferred $0.5 \mathrm{~mL}$ of supernatant to a $0.5 \mathrm{~mL}$ ion chromatograph (IC) vial. Bromide was quantified by a Dionex Corporation DX 120 ion 
chromatograph (Sunnyvale, CA) with an lonpac ${ }^{\circledR}$ AS14 analytical column, lonpac ${ }^{\circledR}$ AG614 guard column, and AS40 Automated Sampler. A $3.5 \mathrm{mM} \mathrm{Na}_{2} \mathrm{CO}_{3}$ and 1.0 $\mathrm{mM} \mathrm{NaHCO}$ eluent was used as the mobile phase at a $1.2 \mathrm{~mL} / \mathrm{min}$ flow rate.

Groundwater samples at discrete 1.2-m intervals were also obtained via direct push technology (Geoprobe ${ }^{\circledR}$ Model 6610DT). Steel rods $(1.52 \mathrm{~m}$ ) were driven to depths 6 to $8 \mathrm{~m}$ below our monitoring well screens $(23 \mathrm{~m})$. Once the target depth was obtained, the interior of the steel rods were filled with water from the surface to produce a positive pressure and prevent subsurface sediments from entering the screen upon initial exposure to the aquifer. Once the screen was exposed and groundwater was allowed to enter the screen, a silicon tube equipped with a check ball valve was lowered into the screen. The tubing was repeatedly raised and lowered to pump the groundwater to the surface. Approximately three well volumes were purged into $18.9 \mathrm{~L}(5 \mathrm{gal})$ buckets. Once the groundwater samples were collected for a given depth interval, the steel rods and screen were raised approximately $1.22 \mathrm{~m}$ and a new groundwater sample was collected. This process was repeated until depth to groundwater was reached. 


\section{RESULTS AND DISCUSSION}

\section{Treatability Experiments}

\section{Soil Oxidant Demand}

Results from column and batch soil oxidant demand (SOD) experiments showed that permanganate consumption increased with increasing permanganate concentrations (Fig. 1, Table 1). A comparison of the two techniques showed SODs observed in column studies were lower than SODs observed in batch studies. Xu (2006) similarly observed that SODs in column studies were considerably less than SODs calculated from batch studies. This difference is attributed to lower permanganate-soil contact times during miscible displacement compared to a well mixed batch reactor. During batch experiments with the Todd Valley aquifer material, we were unable to quantify permanganate consumption above $5,000 \mathrm{mg} / \mathrm{L} \mathrm{NaMnO}_{4}$ because dilution effects and variability offset the minute changes in permanganate concentrations observed before and after exposure to aquifer solids. Because column experiments utilized more soil mass than the batch experiments $(50 \mathrm{~g}$ vs. $\sim 755 \mathrm{~g}$ ), higher initial permanganate concentrations could be used and an exponential increase in permanganate consumption with increased influent concentrations was observed (Fig. 1). Regardless of the SOD technique, both batch and column studies confirmed that the Todd Valley aquifer had a very low SOD (generally $<1 \mathrm{~g} / \mathrm{kg}$ ). These results are consistent with Hønning et al. (2007) who observed SOD's of 0.5 to $2.0 \mathrm{~g} \mathrm{MnO}_{4}{ }^{-1} / \mathrm{kg}$ 
soil for glacial melt water sands. Low SOD are also generally observed when aquifers have very low organic content (Mumford et al. ,2005).

Previous research (Siegrist et al. 2002; Le and Schwartz 2000; Schroth et al. 2001) has shown that permanganate reactions with natural organic mater and organic contaminants can produce $\mathrm{MnO}_{2}$ colloids that may clog pore spaces and reduce hydraulic conductivity. In order to quantify the mass of $\mathrm{MnO}_{2}$ that would form during treatment of RDX-contaminated groundwater during the extractioninjection procedure, $2 \mathrm{~L}$ of groundwater from the test site (RDX concentration $\sim 100$ $\mu / L)$ was treated with $1.78 \mathrm{~g}, 6.23 \mathrm{~g}$, and $35.6 \mathrm{~g}$ of permanganate. Results showed very little mass of $\mathrm{MnO}_{2}$ would form during treatment of the extracted groundwater ( 0.07 to $0.25 \%$ by weight)

\section{Aquifer Slurry Experiments}

Including Todd Valley aquifer material in the permanganate-RDX batch reactor had no effect on RDX destruction kinetics. A >99 percent RDX degradation was observed within $14 \mathrm{~d}$ (Fig. 2a) for each treatment. Moreover, $\sim 90 \%$ of ${ }^{14} \mathrm{C}$ RDX was removed by 15,000 and $20,000 \mathrm{mg} / \mathrm{L} \mathrm{KMnO}_{4}$ treatments, indicating a high degree of mineralization (Fig. 2b). RDX degradation rates varied from $0.387 / \mathrm{d}$ to $0.656 / \mathrm{d}$ for the three initial $\mathrm{KMnO}_{4}$ concentrations. These data are similar to that reported by Adam et al. (2004) who reported a RDX (initial concentration of 2.8 $\mathrm{mg} / \mathrm{L}$ ) degradation constant of $k=0.667 / \mathrm{d}$ in the presence of aquifer media $(91 \%$ 
sand, $3 \%$ silt, $6 \%$ clay, and an organic content of $0.1 \%$ ) treated with $20,000 \mathrm{mg} / \mathrm{L}$ $\mathrm{KMnO}_{4}$.

\section{Permanganate Treatment of Nebraska Ordnance Plant Groundwater}

Complete RDX degradation was observed within $8 \mathrm{~d}$ following treatment of NOP groundwater $\left(C_{0}=210 \mu \mathrm{g} / \mathrm{L}\right)$ with $15,000 \mathrm{mg} / \mathrm{L} \mathrm{KMnO}_{4}$ (Fig. 3). RDX degradation kinetics were similar to our aquifer slurry batch experiment $(k=$ $0.598 / \mathrm{d}$ for NOP groundwater vs. $0.544 / \mathrm{d}$ in slurry experiment). Adam et al. (2004) also observed no appreciable change in RDX degradation kinetics in batch experiments where RDX initial concentrations ranged from 1.3 to $10.4 \mathrm{mg} / \mathrm{L}$.

\section{In Situ Temperature Effect on RDX Degradation by Permanganate}

Ambient groundwater temperatures observed at the NOP were found to strongly influence RDX destruction kinetics. A comparison of room versus groundwater temperature $\left(23\right.$ vs $\left.11.5^{\circ} \mathrm{C}\right)$ showed that destruction kinetics were nearly three-fold slower at the lower temperature $\left(0.587 / \mathrm{d}\right.$ at $23^{\circ} \mathrm{C}$ versus $0.205 / \mathrm{d}$ at $11.5^{\circ} \mathrm{C}$; Fig. 4). Complete RDX degradation was observed within $8 \mathrm{~d}$ at room temperature while RDX-permanganate solutions at $11.5^{\circ} \mathrm{C}$ still maintained approximately 20 percent RDX. Although permanganate/RDX degradation kinetics at low temperatures have not previously been reported, batch studies involving permanganate and chlorinated ethenes have shown decreased kinetics with 
decreased temperatures (Dai and Reitsma, 2004; Yan and Shwartz (2000). Weeks et al. (2003) conducted a treatment study for the Massachusetts Military Reservation using permanganate to treat RDX. Their study showed that 10,000 $\mathrm{mg} / \mathrm{L}$ permanganate could effectively degrade $110 \mu \mathrm{g} / \mathrm{L}$ to $10 \mu \mathrm{g} / \mathrm{L}$ at $11^{\circ} \mathrm{C}$ within 27 days.

Field-Scale ISCO Demonstration with Sodium Permanganate

Based on our modeling efforts of the extraction-injection well configuration (Eqn 6 and 8), and assuming piston-type flow (i.e., no dispersion), approximately 7 $\mathrm{h}$ of pumping (extraction-injection) would have been needed to complete the permanganate curtain. Initial permanganate breakthrough at the extraction well, however, was observed within 77 min. Once all the permanganate had been injected into IW-1 and IW-2 $(t \sim 7.15 \mathrm{~h})$, the sodium permanganate concentration in EW-1 had only reached $2386 \mathrm{mg} / \mathrm{L}$, indicating that a uniform curtain of permanganate was not established across the injection wells.

Electrical resisitivty imaging (ERI) results indicated that only differencing between pre-injection and immediately post-injection showed any discernable changes. The majority of these changes were observed on lines placed over the injection wells (IW1, IW2) (Fig. 6) and down gradient of the injection plane (Fig. 7). At these locations, both positive and negative changes occurred. The changes ranged from $-13 \%$ to $13 \%$. Although these changes were consistent with a conductive injectate being placed in the aquifer, the observed changes were much 
smaller than expected. The location of the changes indicates that significant changes occurred above the water table. The other change occurred upgradient of the injection wells and vertically below and to the southwest of the injection wells as shown by the composite ERI (Fig. 8). These results signify that the permanganate followed some preferential flow paths that were not congruent with the location of the monitoring wells. ERI conducted during the injection process also indicated that the permanganate curtain failed to develop with the injection well locations having ERI signals approximately twice as high as the extraction well location (Fig. 8).

Another contributing factor to the observed permanganate distribution was the observed head buildups in the injection wells during the permanganate injection. IW-1 had a maximum buildup of $3 \mathrm{~m}$ of permanganate while IW-2 was at $7 \mathrm{~m}(23 \mathrm{ft})$ near the end of the injection. IW-1 and IW-2 head differences were previously encountered during a 30 min pre-injection test using water but not to the extent observed during the permanganate injection. The differential head buildup observed between injection wells also likely contributed to a less than uniform distribution of permanganate.

RDX concentrations temporally decreased in wells closest to the injection wells (IW-1, IW-2, Fig. 9) as the permanganate migrated down gradient. RDX degradation rates of $0.12 / \mathrm{d}$ in $\mathrm{MW}-12$ and $0.087 / \mathrm{d}$ in $\mathrm{MW}-14$ were observed. These rates were lower than what was observed under batch conditions at $11.5^{\circ} \mathrm{C}$ (Fig. 4, 0.20/d) and likely a result of a lower initial permanganate concentration (6000 versus $15000 \mathrm{mg} / \mathrm{L}$ ). RDX concentrations decreased nearly $80 \%$ (from 64.6 
to $13.1 \mu \mathrm{g} / \mathrm{L}$ ) in $\mathrm{MW}-12,70 \%$ in $\mathrm{MW}-14$ (from 54.3 to $16.2 \mu \mathrm{g} / \mathrm{L}$ ), $73 \%$ in $\mathrm{MW}-15$ (from 87.3 to $23.5 \mu \mathrm{g} / \mathrm{L}$ ), and $75 \%$ (from over 45 to $11 \mu \mathrm{g} / \mathrm{L}$ ) in $\mathrm{MW}-16$ before permanganate breakthrough was complete. We observed a slight decrease in RDX in MW-17 and MW-4 (data not shown). The permanganate concentrations sampled in MW-17 and MW-4 did not show a true breakthrough, which corresponds to the scattering RDX concentrations measured in both wells.

When permanganate and bromide breakthrough curves were normalized to the maximum concentrations observed, the $\mathrm{MnO}_{4}{ }^{-} / \mathrm{Br}^{-} \mathrm{BTC}$ in wells $\mathrm{MW}-12$, $M W-14$, and MW-15 were nearly identical and indicated that permanganate consumption by native SOD was minimal (Fig. 10). Using the same integration technique described in the soil column experiments (Sec. 2.1.1.), we calculated permanganate consumption was $0.25 \%$ to $0.76 \%$ for wells $M W-12, M W-14$, and MW-15 indicating low permanganate consumption after a linear distance of $6 \mathrm{~m}$ (20 ft). The low consumption of permanganate under in situ conditions is also supported by the fact while multilevel sampling (via DPT), permanganate concentrations $>900 \mathrm{mg} / \mathrm{L}$ were observed $72 \mathrm{~d}$ after injection at a linear distance of $>14.5 \mathrm{~m}$ from IW-2. The low oxidant demand of both aquifer and groundwater (i.e., RDX concentration) indicate that permanganate could potentially oxidize a large volume of RDX-contaminated groundwater within the Todd Valley aquifer.

Permanganate breakthrough was observed in all wells within the field site except MW-2 and MW-3. Electrical conductivity measurements conducted prior to groundwater sampling indicated that the permanganate plume did not uniformly enter the monitoring well screens (Fig. 11) but followed preferential flow paths 
found during multi-level slug testing of MW-15 prior to permanganate injection (Fig. 12). Calculated hydraulic conductivities $\left(K_{h}\right)$ for $M W-15$ range from $3 \mathrm{~m} /$ day to 27 $\mathrm{m} /$ day with highest conductive intervals between $18.9 \mathrm{~m}$ and $19.8 \mathrm{~m}$ below ground surface (bgs). Groundwater sampling conducted via DPT at 24, 56, and 72 days verified permanganate plume bifurcation, or plume fingering within the site. This bifurcation may be due to preferential pathways caused by the depositional nature of the Todd Valley sands, which were deposited in a braided stream system similar to the current Platte River near Ashland, Nebraska. The sedimentology of a braided stream is complex and encompasses several channels characterized by high width/depth ratios, steep slopes, and usually low sinuosities (Miall, 1977). Because of this stratification, monitoring wells only captured fingers of permanganate that was mixed with non-treated groundwater during pumping, thereby diluting permanganate/bromide concentrations within the well and artificially inflating RDX concentrations due to mixing within the well casing. Despite problems encountered in getting the permanganate curtain uniformly distributed and throughout the well screen interval, the observed RDX destruction rates from this pilot-scale demonstration provide proof-of-concept that permanganate can degrade RDX in situ and support permanganate as a possible remedial treatment for the RDX-contaminated groundwater. 


\section{References}

Adam, M.L., Comfort, S.D., Snow, D.D., 2004. Remediating RDX-contaminated ground water with permanganate: Laboratory investigations for the Pantex perched aquifer. Journal Environmental Quality, 33, 2165-2173.

ASTM Standard, 2007. Standard Test Method for Estimating the Permanganate Natural Oxidant Demand of Soil and Aquifer Solids (Method D72262-07), ASTM International, West Conshohocken, PA, www.astm.org.

Cassada, D.A., Monson, S.J., Snow, D.D., Spalding, R.F., 1999. Sensitive determination of RDX, nitroso-RDX metabolites, and other munitions in ground water by solid-phase extraction and isotope dilution liquid chromatographyatmospheric pressure electro-spray ionization mass spectrometry. J. Chromatography. A, 844, 87-95.

Cavé, L., Hartog, N., Al, T., Parker, B., Mayer, K.U., Cogswell, S., 2007. Electrical monitoring of in situ chemical oxidation by permanganate. Ground Water Monitoring and Remediation, 27(2), 77-84.

Dai, Q., Reitsma, S., 2004. Kinetic study of permanganate oxidation of tetrachlorethylene at a high $\mathrm{pH}$ under acidic conditions. Remediation Journal. 14(4), 67-79.

Halihan, T., Fenstemaker, T., 2004. Proprietary Electrical Resitivity Imaging Method. 2.0 ed. Oklahoma State University Office of Intellectual Property, Stillwater, OK. 
Hønning, J., Broholm, M. M., Bjerg, P. L., 2007. Quantification of potassium permanganate consumption and PCE oxidation in subsurface materials. Journal of Contaminant Hydrology. 90, 221-239.

Huang, K., Hoag, G. A., Chheda, P., Woody, B. A., Dobbs, G.M., 2000. Soil oxidant demand during chemical oxidation of trichloroethylene by permanganate in soil media. Hazard. Ind. Waste 32, 617-626.

Hundal, L. S., Singh, J., Bier, E. L., Shea, P. J., Comfort, S. D., Powers, W. L., 1997. Removal of TNT and RDX from water and soil using iron metal. Environmental Pollution. 97, 55-64.

Le, X. D., Schwartz, F., 2000. Efficiency problems related to permanganate oxidation schemes. U.S. Environmental Protection Agency, Washington, D.C.

Miall, A.D., 1977. A review of the braided-river depositional environment: EarthScience Reviews, 13, 1-62.

Mumford, K. G., Thomson, N. R., Allen-King, R. M., 2005. Bench scale investigation of permanganate natural oxidant demand kinetics. Environ. Sci. Technol. 39, 2835-2840.

Schroth, M. H., Oostrom, M., Wietsma, T. W., Istok, J. D., 2001. In-situ oxidation of trichloroethene by permanganate: effects on porous medium hydraulic properties. Journal of Contaminant Hydrology, 50, 79-98. 
Seol, Y., Zhang, H., Schwatz, F. W., 2003. A review of in situ chemical oxidation and heterogeneity. Environmental and Engineering Geoscience, 9 (1), 37-49.

Siegrist, R. L., Urynowicz, M. A., Crimi, M. L., Lowe, K. S., 2002. Genesis and effects of particles produced during in situ chemical oxidation using permanganate. Journal of Environmental Engineering, 128 (11), 1068-1079.

Wani, A.H., Wade, R., Davis, J.L., 2007. Field demonstration of biologically active zone enhancement using acetate as a sole carbon source for in situ reductive transformation of RDX in groundwater. Practical Periodical of Hazardous, Toxic, and Radioactive Waste Management. 11 (2), 83-91.

van Genuchten, M. Th., Wierenga, P. J., 1986. Solute dispersion coefficients and retardation factors. In: A. Klute (ed.), Methods of Soil Analysis, part 1, Physical and Mineralogical Methods, Agronomy 9 (1): 1025-1054. 2nd ed., Am. Soc. Agron., Madison, WI.

Weeks, K.R., Veenstra, S.C., Hill, D.L., Gregson, B.P., 2003. A study of treatment options to remediate explosives and perchlorate in soils and groundwater at Camp Edwards, Massachusetts. Remediation Journal. 13 (2), 131-143.

Xu, X., 2006. Interaction of Chemical Oxidants with Aquifer Materials. Masters Thesis, University of Waterloo, Waterloo, Ontario, Canada

Zlotnik, V.A., McGuire, V.L., 1998. Multi-level slug tests in highly permeable formations: 1. Modification of the Springer-Gelhar (SG) model, J. of Hydrology, $204,271-282$. 
Zlotnik, V.A., Zurbuchen, B.R., 2003. Field study of hydraulic conductivity in a heterogeneous aquifer: Comparison of single-borehole measurements using different instruments. Water Resour. Res. 39 (4), doi: 10.1029/2002WR001415

Zurbuchen, B.R., Zlotnik, V.A., Butler, J.J., 2002. Dynamic interpretation of slug tests in highly permeable aquifers, Water Resour. Res. 38 (3), 1-18. 


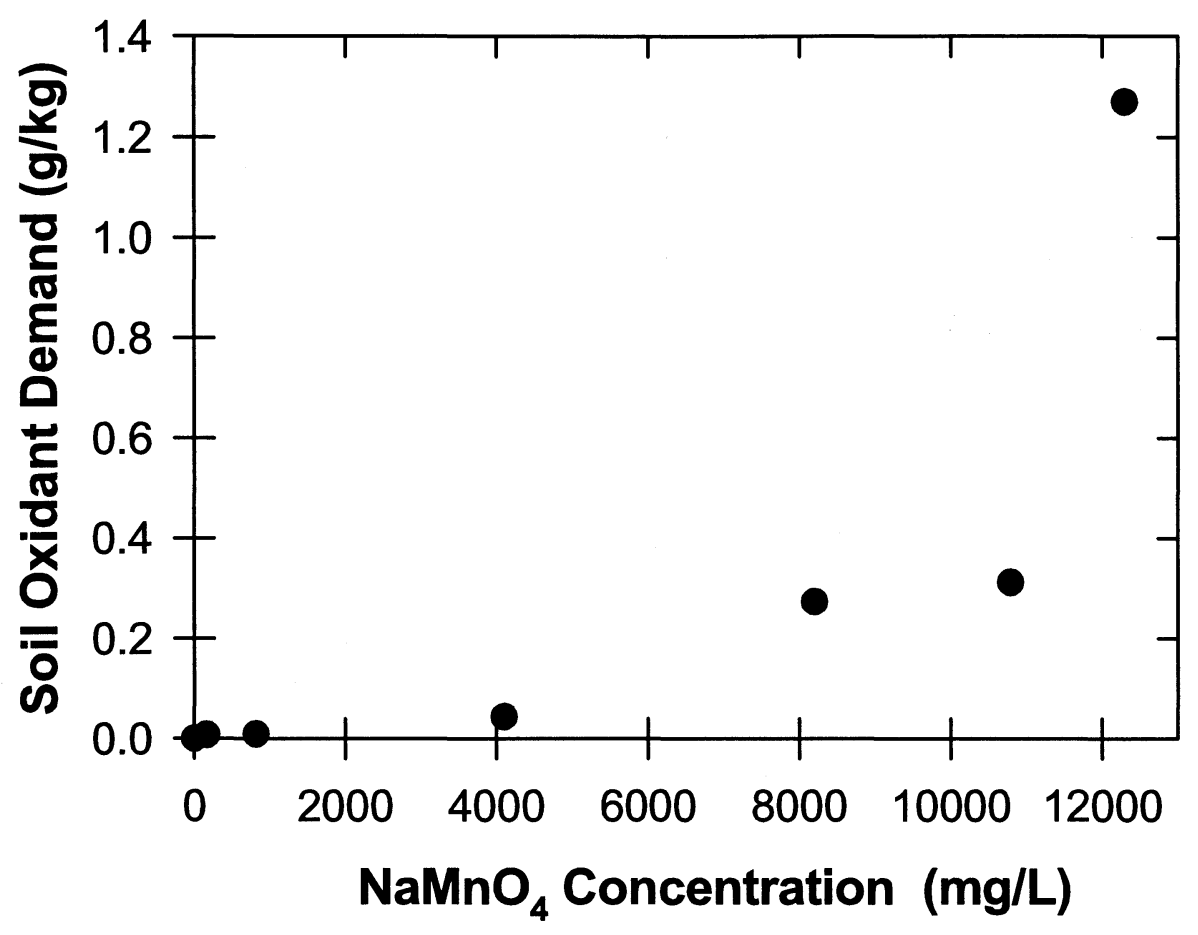

Figure 1. Soil oxidant demand determined from column studies conducted with Todd Valley Aquifer solids. 


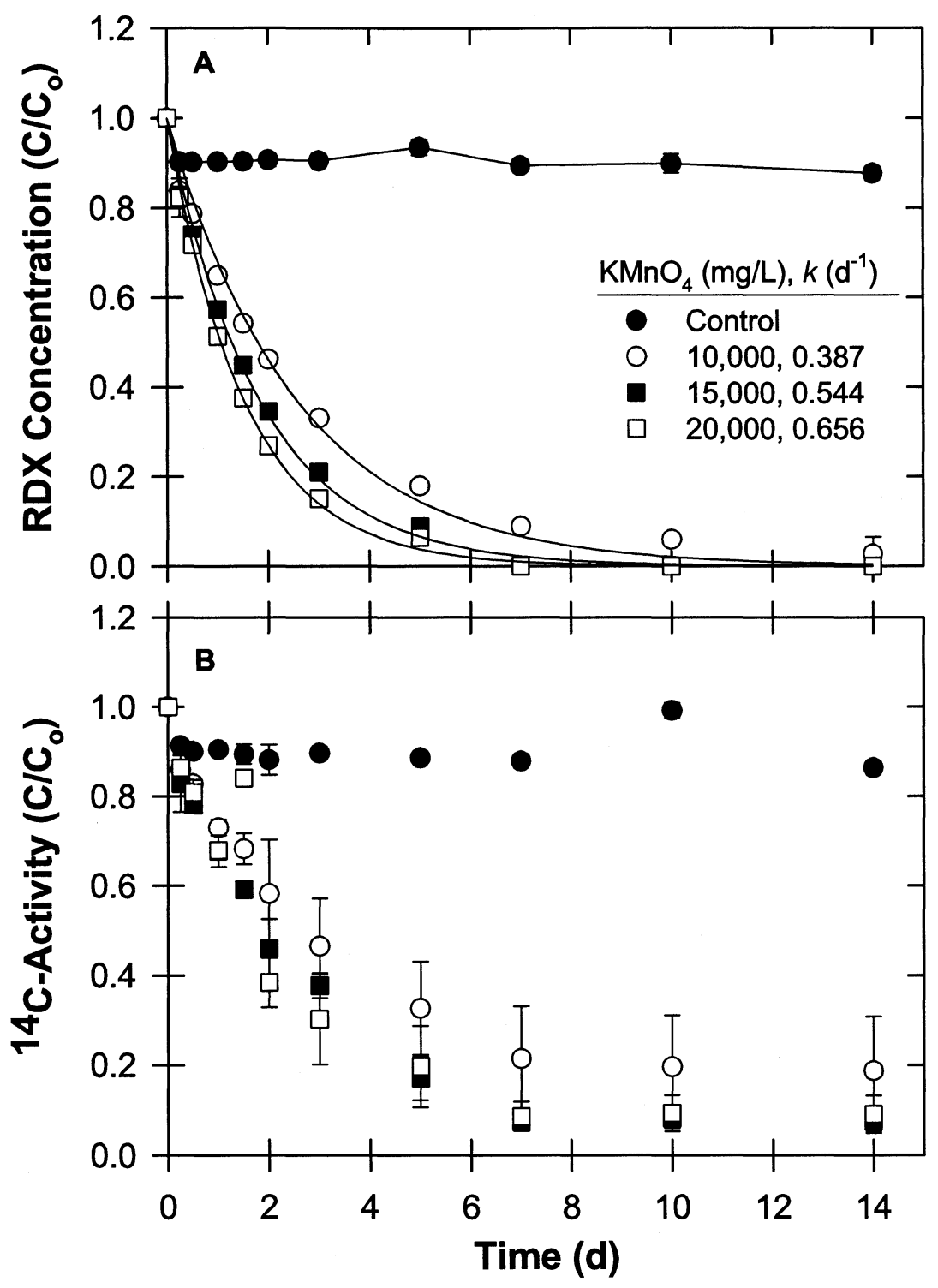

Figure 2. Temporal changes in RDX and ${ }^{14} \mathrm{C}$ concentrations following treatment with three initial permanganate concentrations. Error bars represent standard deviation of means $(n=3)$; where absent, bars fall within symbols. 


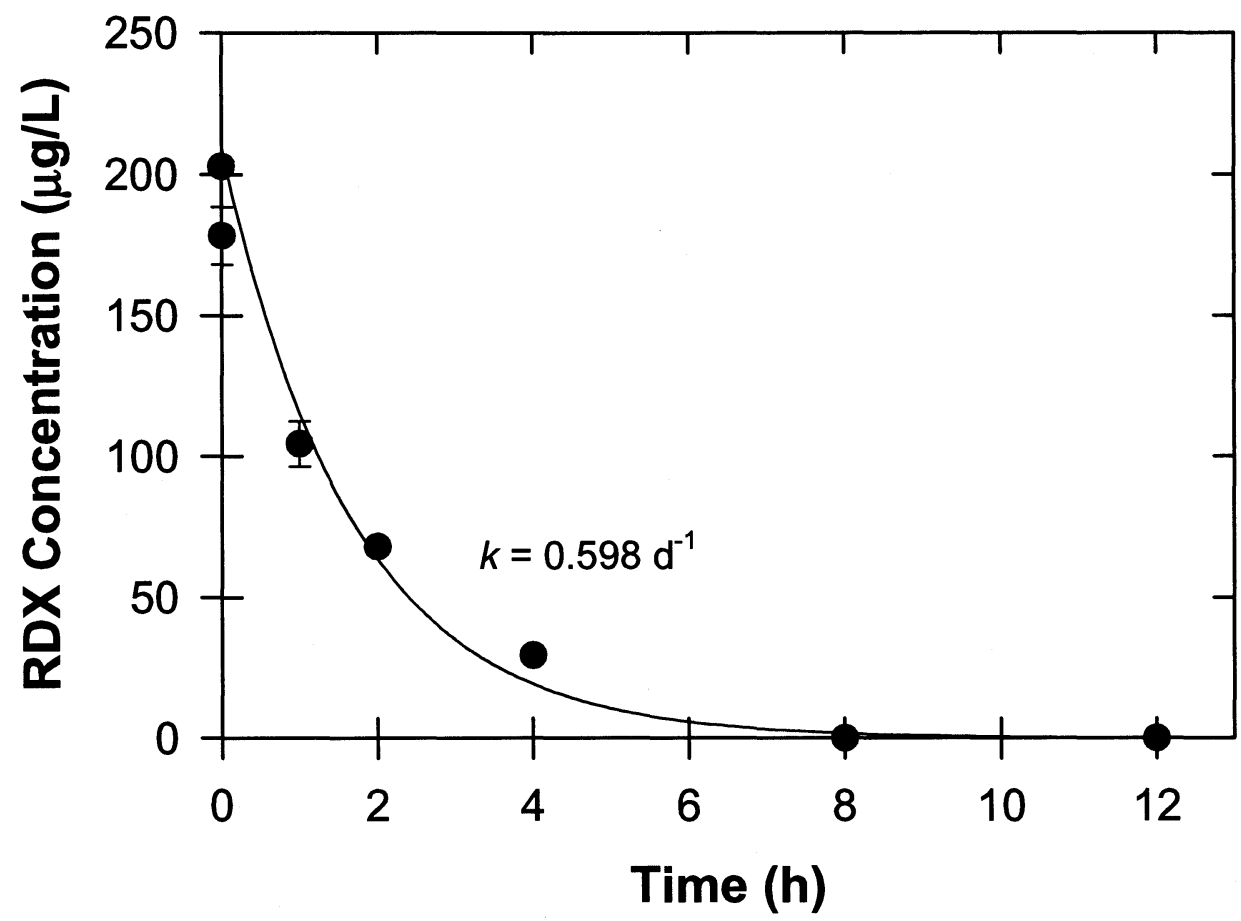

Figure 3. Treatment of NOP groundwater with $15000 \mathrm{mg} / \mathrm{L} \mathrm{KMnO} \mathrm{K}_{4}\left(\mathrm{C}_{o}=210 \mu \mathrm{g} / \mathrm{L}\right)$. Error bars represent standard deviation of means ( $n=3)$; where absent, bars fall within symbols. 


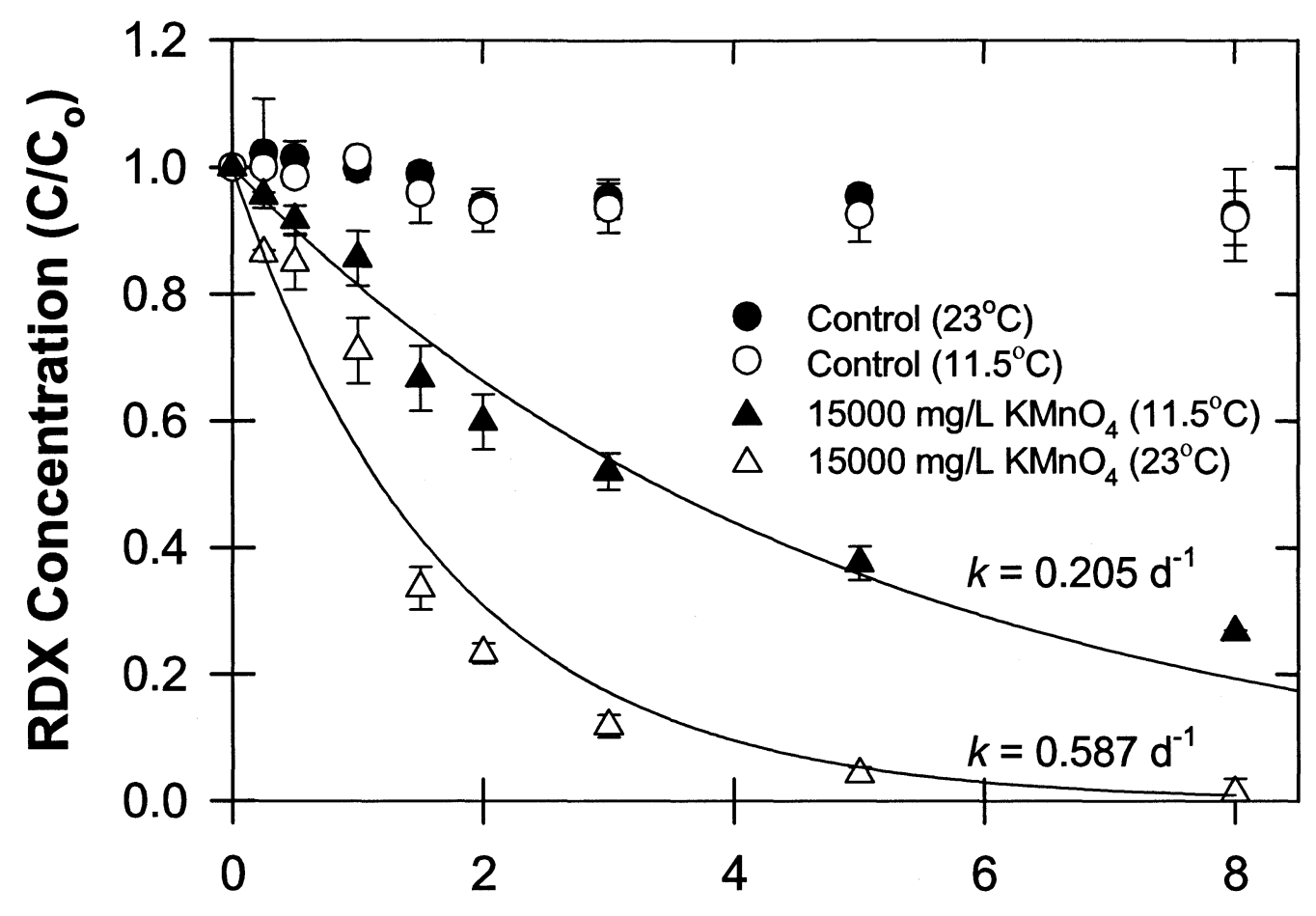

Time (d)

Figure 4. Temporal changes in $R D X$ concentration $\left(C_{o}=3.5 \mathrm{mg} R D X / L\right)$ in an aqueous solution treated with $15000 \mathrm{mg} / \mathrm{L} \mathrm{KMnO}_{4}$ at $11.5^{\circ} \mathrm{C}$ and room temperature $\left(23^{\circ} \mathrm{C}\right)$. Error bars represent standard deviation of means $(n=3)$; where absent, bars fall within symbols. 


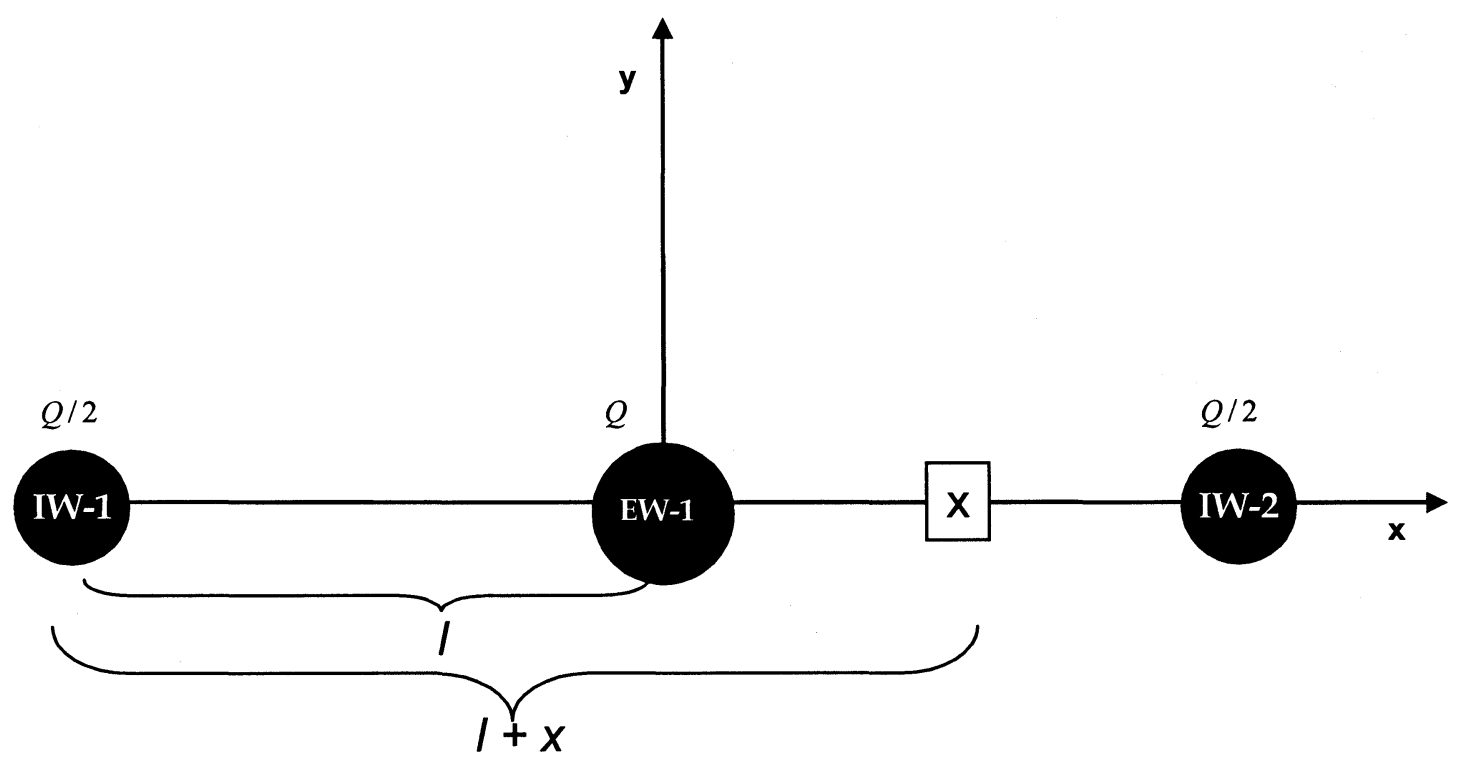

Figure 5. Schematic of injection curtain with variables used in volume calculations (Eqns. 1-6). 


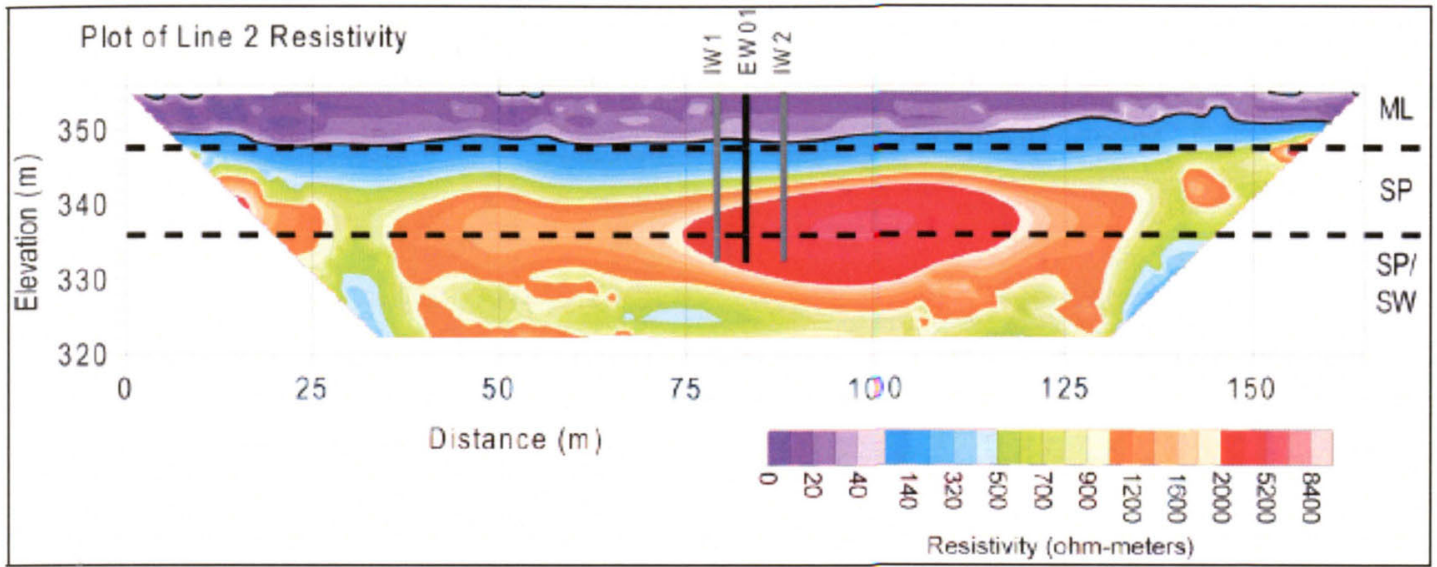

B)

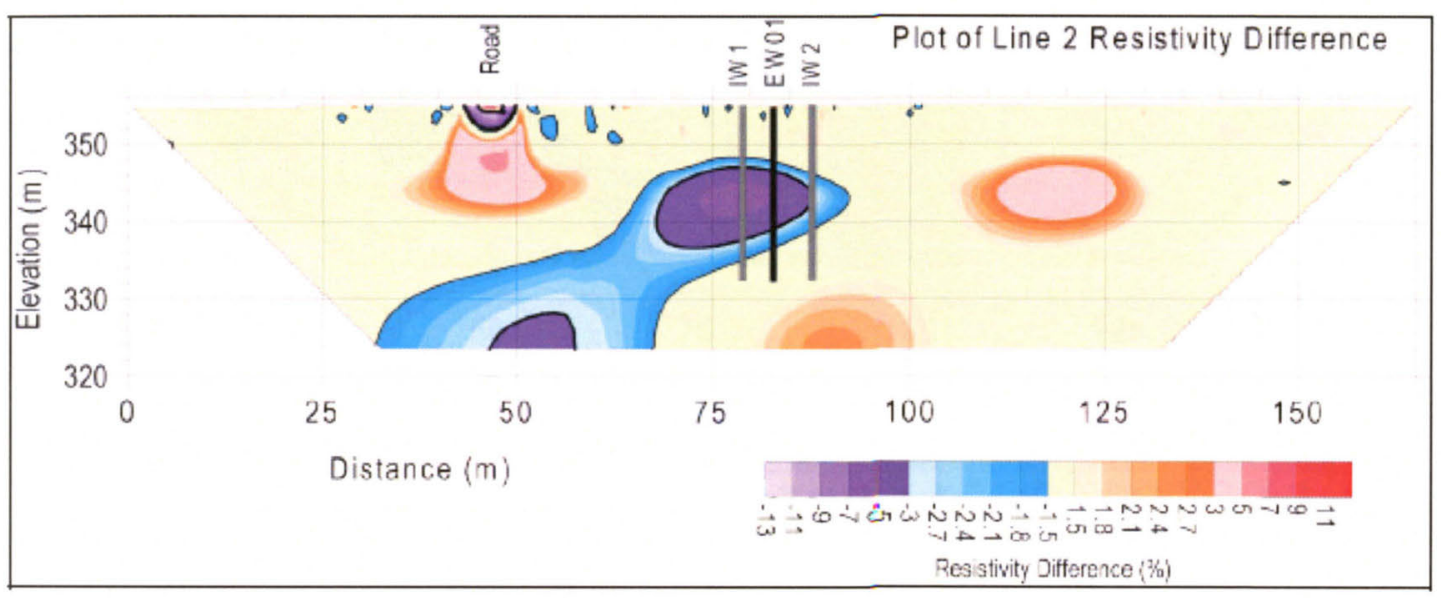

Figure 6. A) Resistivity of ERI line parallel to injection plane showing location of extraction and injection wells used to develop permanganate curtain and monitoring wells. B) Resistivity difference after injection (used with permission from Todd Halihan). 


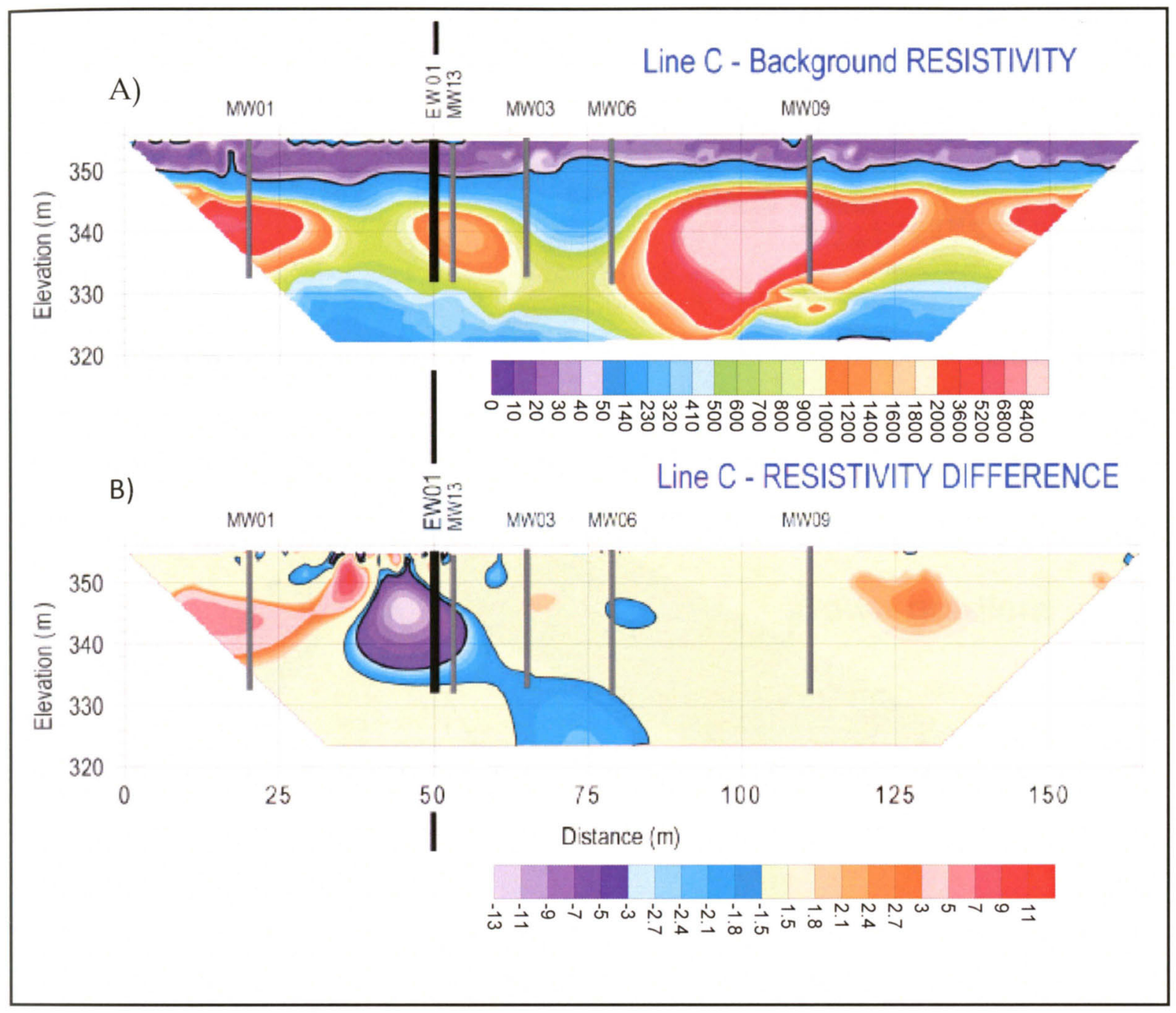

Figure 7. A) Resistivity of ERI line along down gradient centerline of the injection plane showing location of extraction well and down gradient monitoring wells. B) Resistivity difference after injection (used with permission from Todd Halihan). 


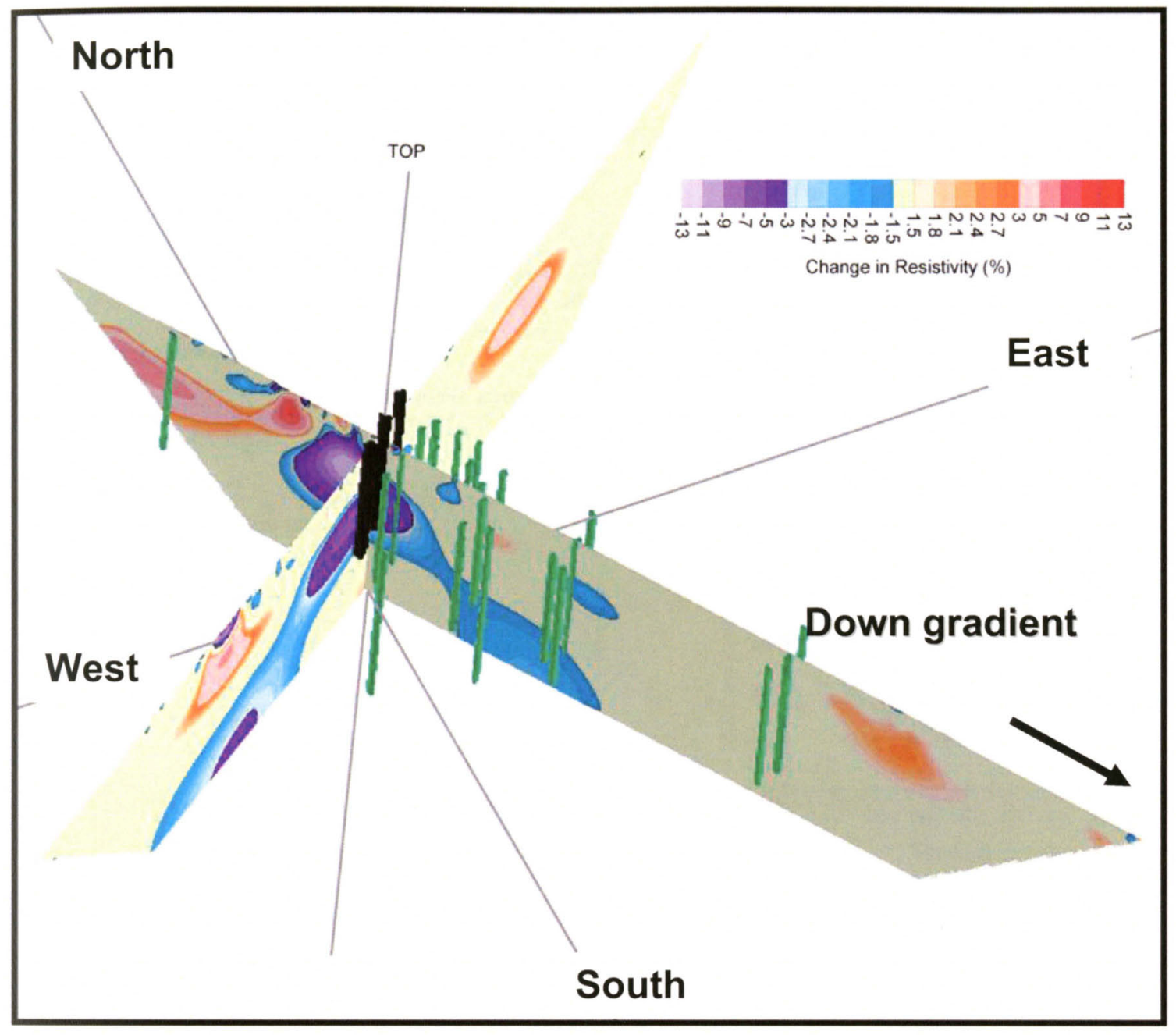

Figure 8. ERI composite of resistivity differences after injection with locations of wells used to develop permanganate curtain (black) and monitoring wells (green) (used with permission from Todd Halihan). 

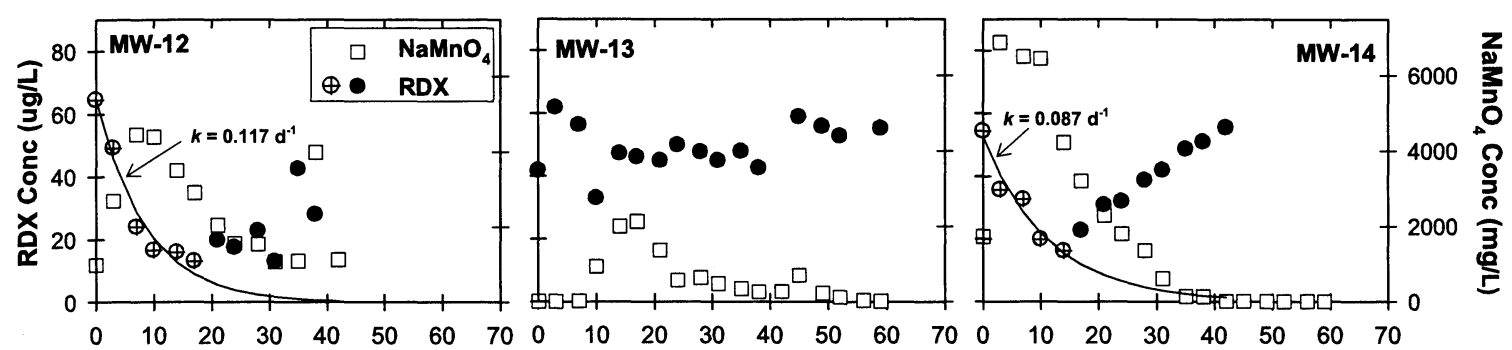

Monitoring Well Network
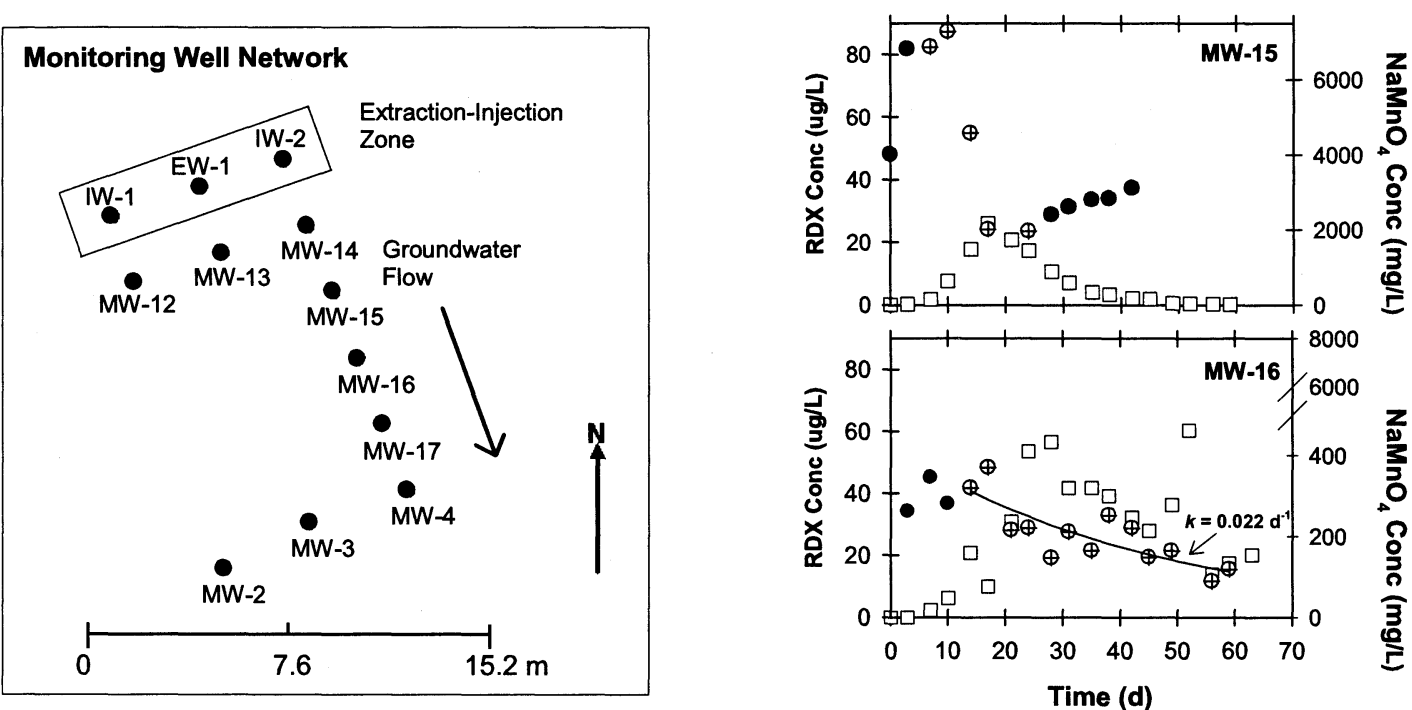

Figure 9. RDX and permanganate breakthrough curves observed in field monitoring wells. Open circle symbols with crosses were used in calculation of RDX degradation kinetics (i.e. fitted lines). 


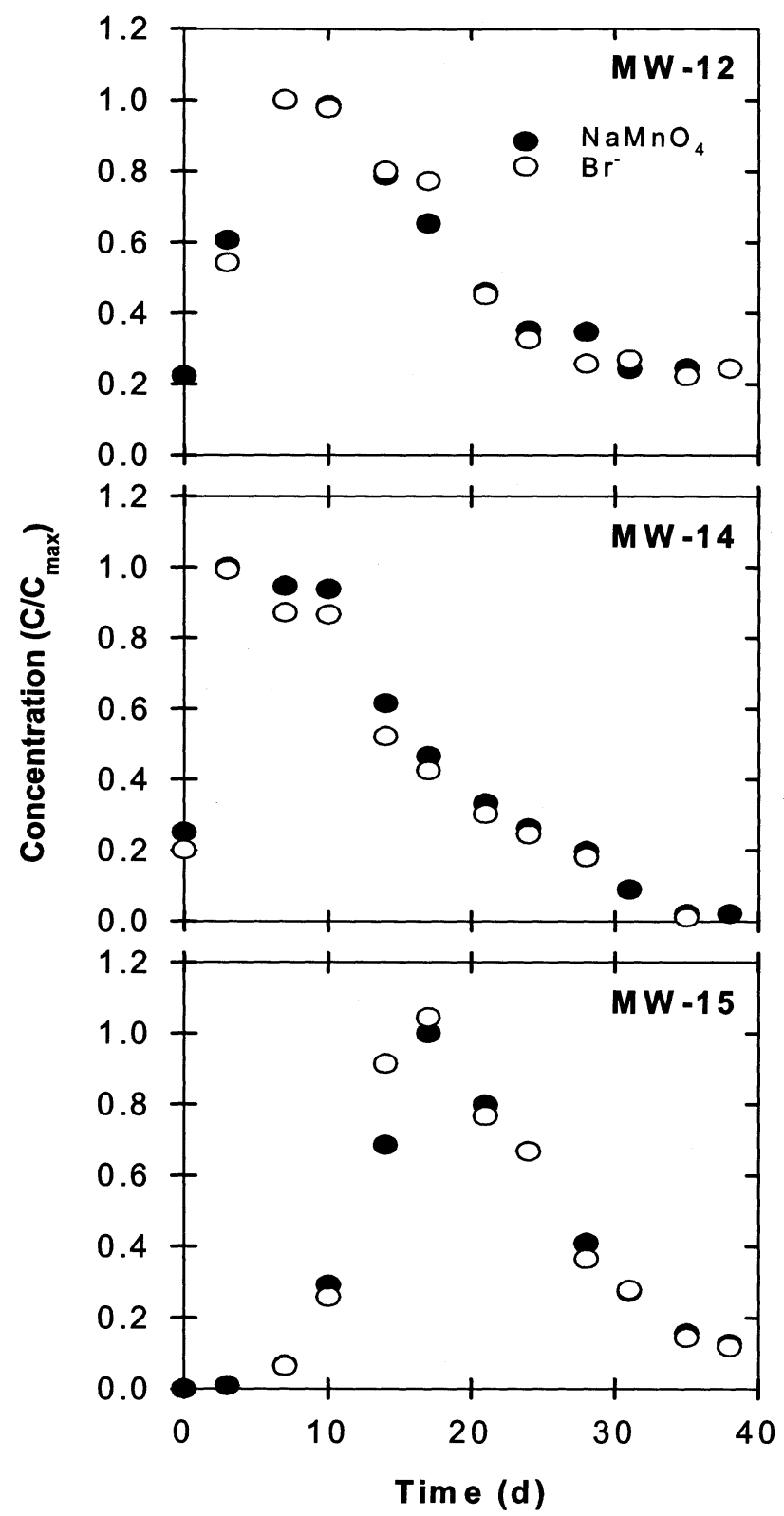

Figure 10. Sodium permanganate and $B r^{-}$breakthrough curves obtained from $\mathrm{MW}$ 12, $M W-14$, and $M W-15$. 
TEMPORAL CHANGES IN PERMANGANATE PROFILE

(by EC conversion)
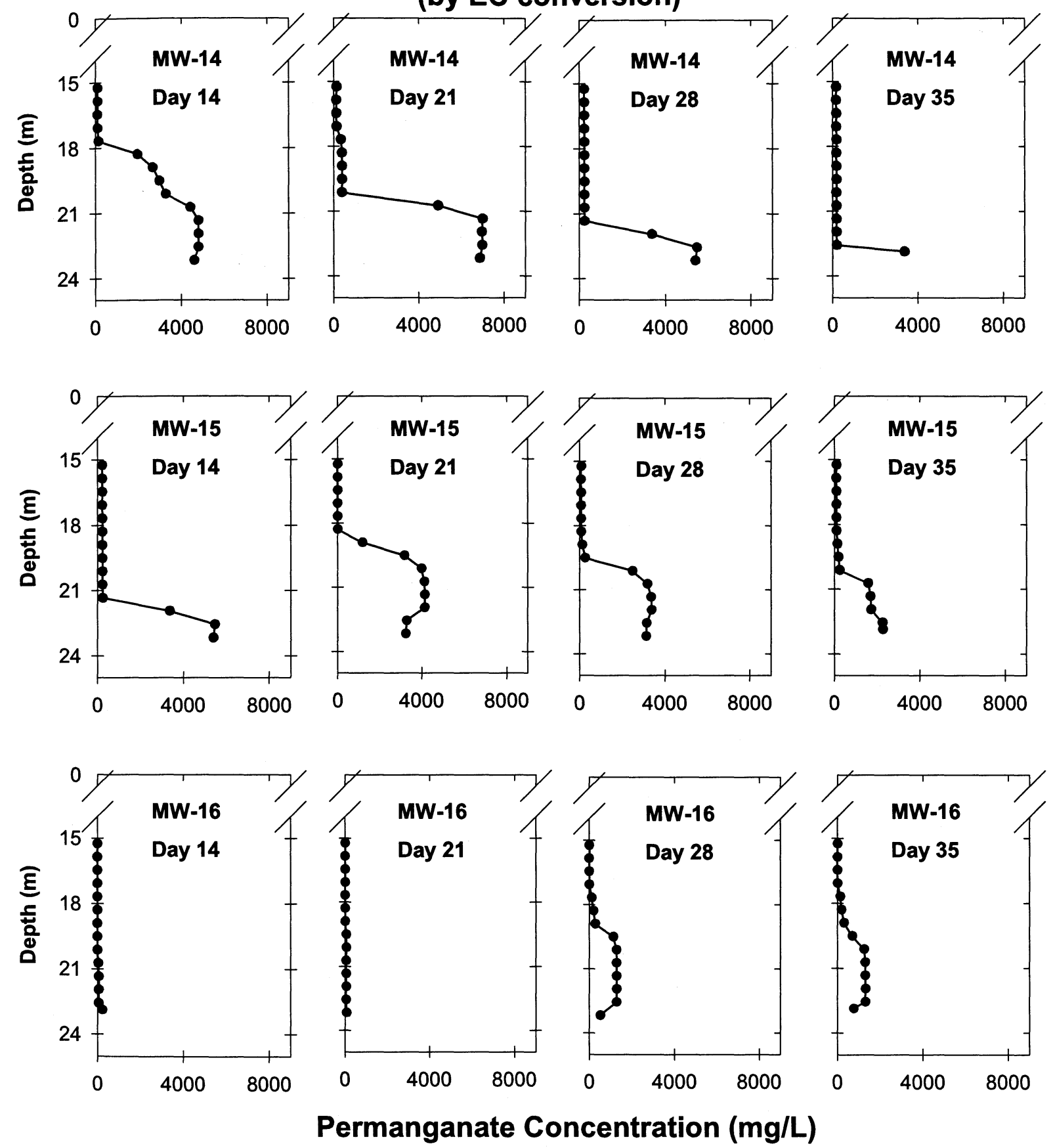

Figure 11. A comparison of permanganate profile concentrations determined by spatial conductivity measurements. 


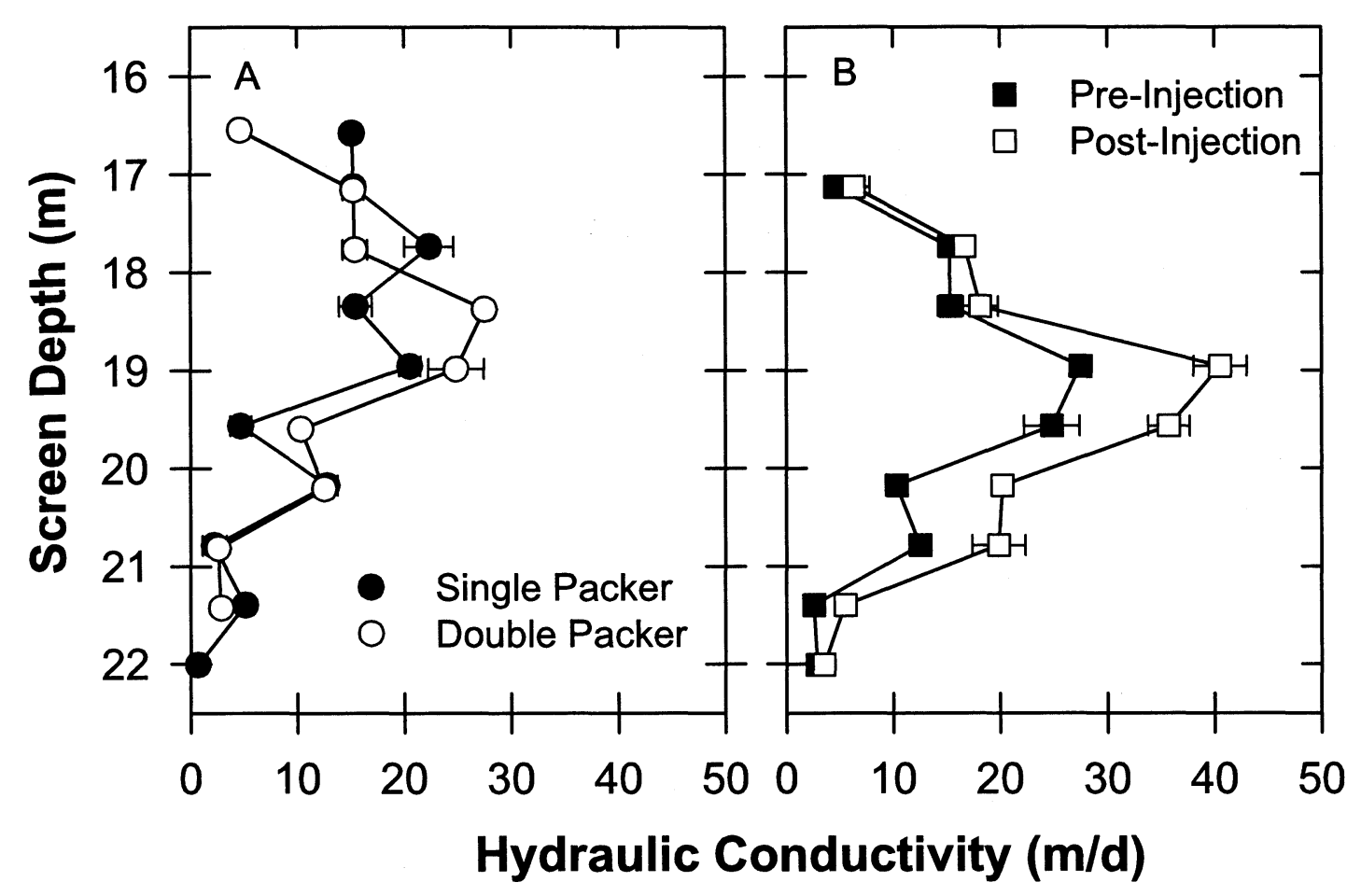

Figure 12. (A) Hydraulic conductivities throughout the screened interval of MW-15 obtained by multi-level slug testing indicating depths of preferential flow. (B) Hydraulic conductivities taken before and after permanganate injection. 


\section{Table 1}

Soil oxidant demand (SOD) of Todd Valley aquifer determined by batch experiments.

Initial $\mathrm{NaMnO}_{4}$
Concentration $(\mathrm{mg} / \mathrm{L})$

$\begin{array}{ll}100 & 0.121 \\ & (0.01) \\ & 0.166\end{array}$

250

0.345

500

0.205

1000

0.711

5000

$(0.69)$

$\dagger$ Average value $(n=3)$ calculated after $216 h$ of contact time. Parenthetic values indicate sample standard deviations. 


\section{APPENDIX A \\ Three-Dimensional Permanganate Transport Modeling}

\section{INTRODUCTION}

One concern associated with in situ chemical oxidation treatments is the possibility of off-site migration of the chemical oxidants. Because ISCO using permanganate had not been previously performed at the Nebraska Ordnance Plant, EPA and Army Corps of Engineering personnel were concerned about the possibility of permanganate moving into downgradient wells. Consequently, we used a 3-dimensional (3-D) transport model (Baetslé,1969) to predict the migration of permanganate following injection at the study site (the former BAZE site (Wani et. al, 2007). This was accomplished using the most conservative input parameters to produce a "worst case scenario" for the off-site movement of permanganate.

\section{METHODS AND MATERIALS}

The Baetslé (1969) (Eqn. 1) is a model that predicts chemical concentrations as a function of distance traveled in the $x, y, z$ directions and time. Parameters included in the model are as follows: the initial concentration of the constituent $\left(\mathrm{C}_{0}\right)\left[\mathrm{mg} / \mathrm{ft}^{3}\right]$, the initial volume added $\left(\mathrm{V}_{0}\right)\left[\mathrm{ft}^{3}\right]$, time $(\mathrm{t})$ [day], linear groundwater velocity $(v)[f t / d a y]$, longitudinal and transverse dispersion $\left(D_{x}, D_{y}, D_{z}\right)$ $\left[\mathrm{ft}^{2} / \mathrm{day}\right]$, and decay constant $(\lambda)[1 / \mathrm{day}]$. 


$$
C(x, y, z, t)=\left[\frac{C_{0} V_{0}}{8(\pi \cdot t)^{3 / 2}\left(D_{x} D_{y} D_{z}\right)^{1 / 2}}\right] \exp \left[-\frac{(x-v t)^{2}}{4 D_{x} t}-\frac{y^{2}}{4 D_{y} t}-\frac{z^{2}}{4 D_{z} t}-\lambda t\right]
$$

To predict the worst case scenario, we treated permanganate as a conservative tracer (i.e., no degradation, $\lambda=0$ ). Linear groundwater velocities were estimated at $2.0 \mathrm{ft} /$ day from previous research conducted at the study site (Wani et al., 2007). Longitudinal dispersion $\left(D_{x}\right)$ was obtained by the product of an approximated dispersivity coefficient $\left(A_{L}\right)$ and the estimated site groundwater velocity (V) (Eqn. 2). We approximated $A_{L}$ to be $9.5 \mathrm{ft}$ which was obtained from a similar type aquifer of unconsolidated sand and gravel with average aquifer thickness of 88.5 feet (Gelhar et al., 1992). Transverse dispersion in both the $y$ and $z$ direction was estimated at 10 -fold less than the longitudinal dispersion $\left(D y=\frac{D x}{10}\right.$ and $D z=\frac{D x}{10}$ ), which is commonly assumed in transport modeling

$$
D_{x}=A_{L} * V=9.5 \mathrm{ft}^{*} 2 \mathrm{ft} / \text { day }=19 \mathrm{ft}^{2} / \text { day }
$$

For input concentration, an initial permanganate concentration of $\mathrm{C}_{0}=$ $15,000 \mathrm{mg} / \mathrm{L}$ with a total injection volume of $V_{0}=61,000 \mathrm{~L}$ was used. The model was run in an Excel spreadsheet for 8 years using two different values of $x$, $x=3168$ ( 0.6 miles $)$ and $x=7022 \mathrm{ft}(1.33$ miles $)$, which corresponded to the nearest downgradient wells (Fig 1). Because only wells directly down gradient were of interest, we set $y$ at 0 and $z$ at 0 . Examples of corresponding functions for 1570 days and 2690 days are shown below in equations (3) and (4) respectively. 


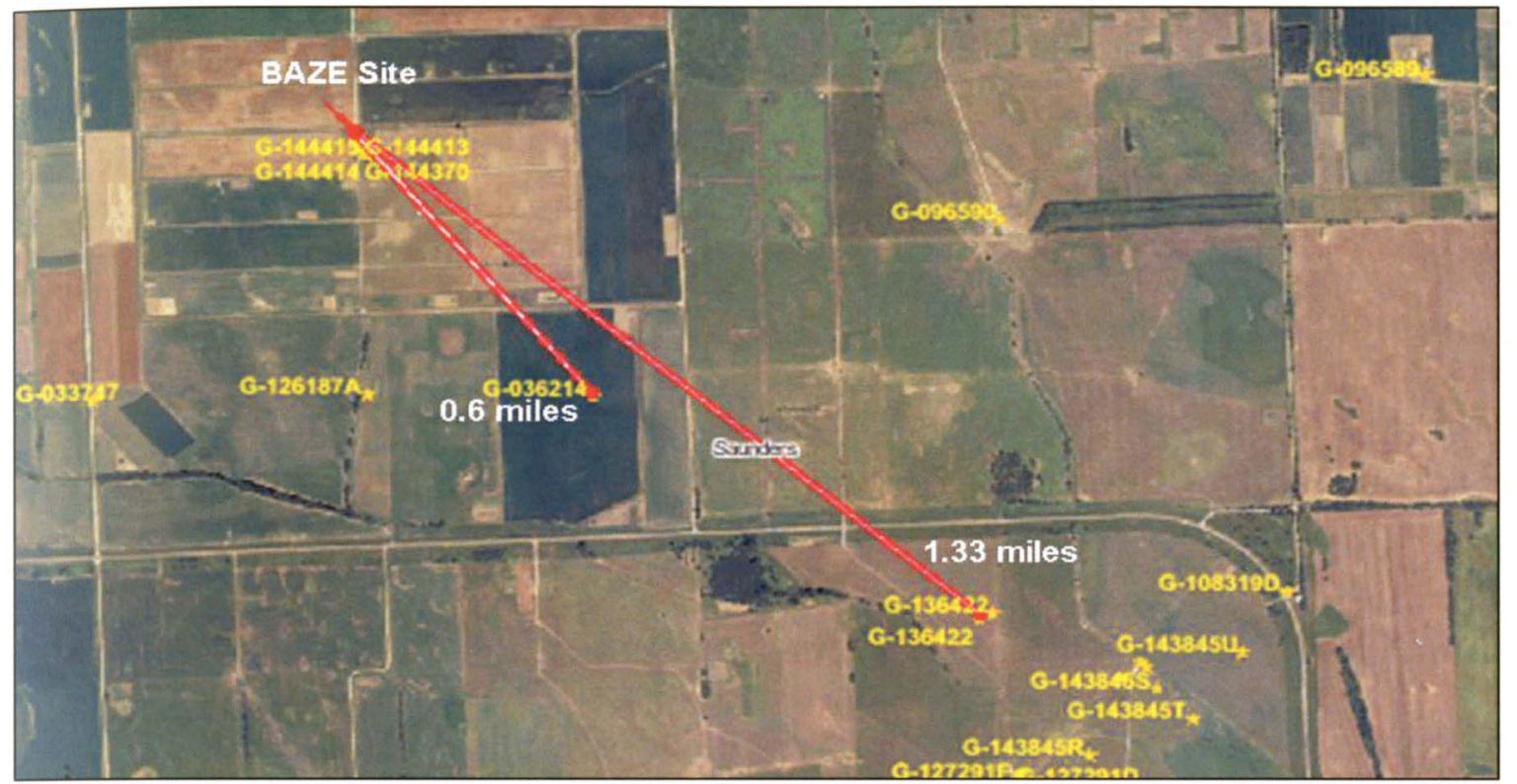

Figure 1. Location of wells (G-036214 at $x=3168 \mathrm{ft}$ (0.6 miles) and G-136422 at $x=7022 \mathrm{ft}(1.33$ miles)) and their proximity to the pilot study site. 


$$
\begin{aligned}
& C(3168,0,0,1570)=\left[\frac{(15000)(61000)}{8(\pi \cdot 1570)^{3 / 2}((19.0)(1.9)(1.9))^{1 / 2}}\right] \exp \left[-\frac{(3168-(2)(1570))^{2}}{4(19)(1570)}\right]=39.64 \mathrm{mg} / L \\
& C(7022,0,0,3490)=\left[\frac{(15000)(61000)}{8(\pi \cdot 3490)^{3 / 2}((19.0)(1.9)(1.9))^{1 / 2}}\right] \exp \left[-\frac{(9240-(2)(3490))^{2}}{4(19)(3490)}\right]=11.96 \mathrm{mg} / L
\end{aligned}
$$

\section{RESULTS AND DISCUSSION}

Results from the Baetslé modeling efforts indicated that travel time to the well closest to the study site ( $3168 \mathrm{ft}$ or 0.6 miles down gradient) would be 4.3 years and that peak concentrations observed would be $39.64 \mathrm{mg} / \mathrm{L}$ (Fig. 2a). Complete breakthrough of the permanganate would take approximately two years to complete. Likewise, the peak permanganate concentration observed in the extraction wells locited $7022 \mathrm{ft}$ (1.33 miles) downgradient from the injection site would be less than $12 \mathrm{mg} / \mathrm{L}$ (Fig. 2b). Permanganate would begin to enter the well approximately 8.25 years and breakthrough would take over three years to complete. Again, this assumes that permanganate will not degrade, nor be consumed by native organic matter, and that advection and dispersion alone was the mechanism affecting permanganate transport. 

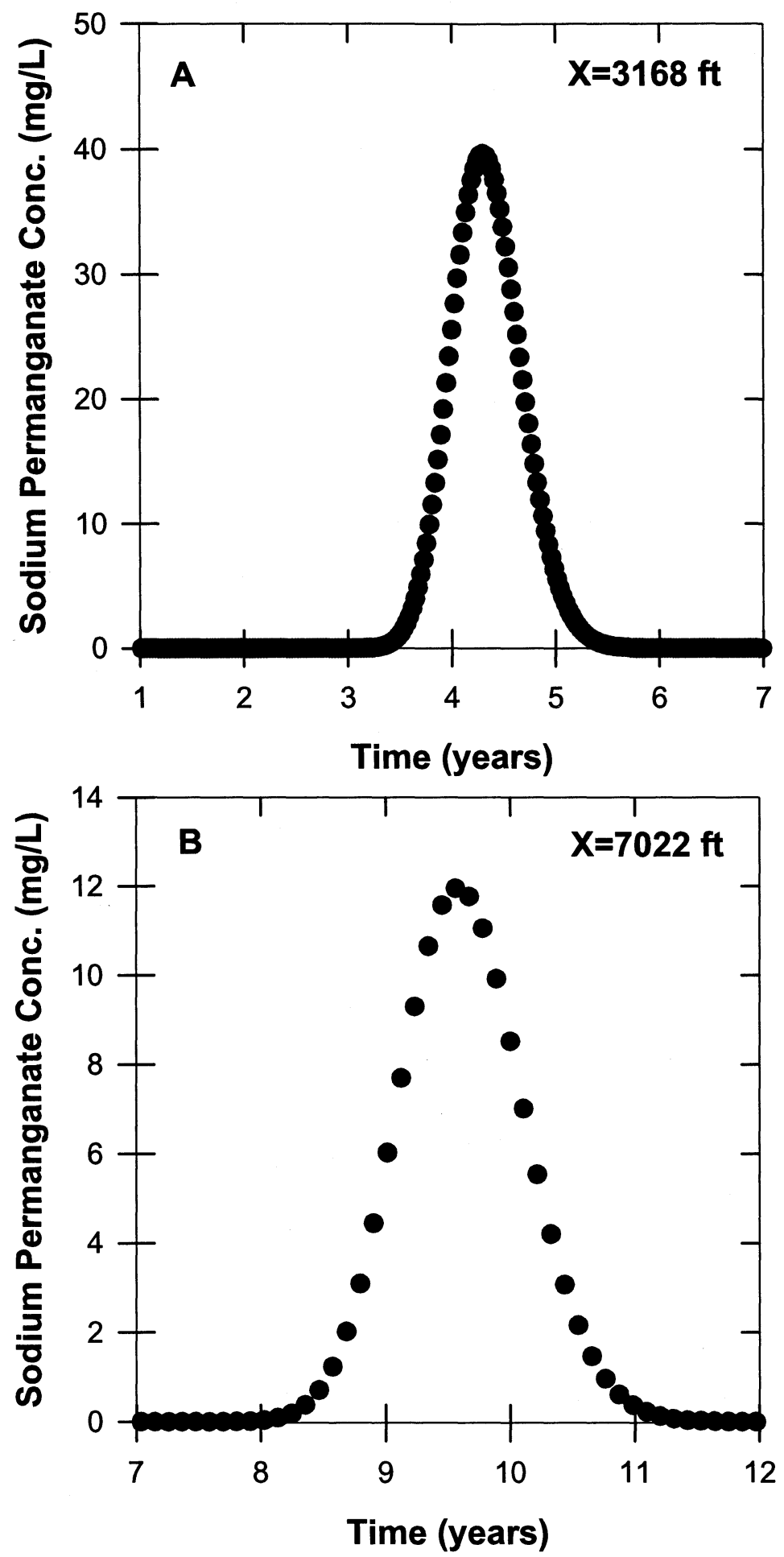

Figure 2. Sodium permanganate breakthrough curves modeled at $X=3168 \mathrm{ft}$ and $X=7022 \mathrm{ft}$ using the Baetalé 1969 Point Source Model 


\section{CONCLUSION}

The Baetslé (1969) model of instantaneous point source contamination was used to predict permanganate concentrations in two wells located downgradient from the injection site. The first well is located $3168 \mathrm{ft}$ down gradient and the second well $7022 \mathrm{ft}$ (1.33 miles) down gradient. In this model, we predicted "worst case scenarios" by assuming that there would be no permanganate consumption via the aquifer constituents and that only dispersion was reducing the initial concentration.

Even with zero permanganate consumption, dispersion alone would reduce peak sodium permanganate concentrations by $99.74 \%$ in the well located $3168 \mathrm{ft}$ ( 0.6 miles) downgradient and by $99.92 \%$ in the extraction well located $7022 \mathrm{ft}$ ( 1.33 miles) down gradient. The reality is that permanganate will be consumed by the aquifer and aquifer constituents (as demonstrated by laboratory experiments) and that the possibility of observing any permanganate in the downgradient wells is extremely remote. 


\section{References}

Baetslé, L. H. 1969 Migration of radionuclides in porous media. In A.M.F. Duhamel (ed.), Progress in Nuclear Energy Series XII, Health Physics, Pergamon Press, Elmsford, N.Y., 707-730.

Gelhar, L. W., Welty, C., Rehfeldt, K. R. 1992. A critical review of data on fieldscale dispersion in aquifers. Water Resources Research. V. 28 (7) 19551974.

Wani, A.H., Wade, R., Davis, J.L., 2007. Field demonstration of biologically active zone enhancement using acetate as a sole carbon source for in situ reductive transformation of RDX in groundwater. Practical Periodical of Hazardous, Toxic, and Radioactive Waste Management. V. 11 (2), 83-91. 


\section{APPENDIX B \\ Pneumatic Slug Testing}

\section{INTRODUCTION}

Accurate measurements of hydraulic conductivity $(K)$ is an essential facet of aquifer characterization and paramount for implementing a remedial treatment. For in situ chemical oxidation treatment, it is important to identify heterogeneities within the aquifer so that the trajectory of the added chemical amendment can be predicted.

Horizontal hydraulic conductivity $\left(\mathrm{K}_{\mathrm{r}}\right)$ at our remediation test site was quantified by performing pneumatic slug tests on 9 two-inch-diameter wells, one six-inch well, and two 4-inch wells. Slug tests were conducted over the full length of the well screens (16.74 to $22.86 \mathrm{~m}$ ) on each well. In addition to fully screened slug tests, multi-level slug tests (MLSTs) were conducted on injection and extraction wells (IW-1, IW-2, and EW-1) and monitoring well MW-15 using a packer assembly with a single packer and double packer (straddle packer) configuration. The objectives were twofold: (i) to identify heterogeneities within the permanganate injection site and (ii) determine if changes in $\mathrm{K}_{\mathrm{r}}$ occurred following permanganate injection as a result of manganese dioxide $\left(\mathrm{MnO}_{2}\right)$ production. 


\section{MATERIALS AND METHODS}

\section{Fully Screened Pneumatic Slug Testing}

Pneumatic slug tests across the entire well screen of the injection and monitoring wells were performed before and after permanganate treatment. Hydraulic conductivities $\left(\mathrm{K}_{\mathrm{r}}\right)$ were quantified using a pneumatic water level depressor, PTX-161 pressure transducer (In-Situ Inc, Ft. Collins, Co), hand-held bicycle pump, and a Hermit $1000 \mathrm{C}$ datalogger (In-Situ Inc, Ft. Collins, Co)(Fig.1). The pneumatic level depressor consisted of a ball valve, a transducer feed connector, a pressure gauge, and an air valve (Fig. 2). The pneumatic water level depressor was attached to the well casing via one rubber coupling and adjustable hose clamps that secured the coupling to both well casing and pneumatic water level depressor. To measure $\mathrm{K}_{\mathrm{r}}$ in the three types of wells present at the test site, three different size couplings were used: one two-two inch coupling was used for the ten two inch monitoring wells, one two-four inch coupling was used for the two four inch injection wells, and one four-six inch coupling was used for the one six inch extraction well.

Step-by-step procedures used to measure $\mathrm{K}_{\mathrm{r}}$ were to first determine water levels in each well so we could determine at what depth to place the pressure transducer. Once the depth to groundwater had been verified, the pneumatic level depressor was mounted on the well casing and the pressure transducer was fed through the transducer feed connector and lowered no more than 0.5 meters below the measured water level (depths $>0.5 \mathrm{~m}$ are outside the pressure transducer 
calibration). Once the pressure transducer was at the desired depth, the transducer feed connector was tightened to secure pressure transducer and seal the system. The transducer was then connected to a Hermit 1000c datalogger using the following parameters: type-TOC, rate-Log with sample rate set to the lowest setting of 0 , and DSP-SI meters. A bicycle pump was then attached to the pneumatic level depressor via the air valve and air was manually pumped into the well to depress the static water level within the well. A pressure gauge mounted on the pneumatic level depressor with units of inches of $\mathrm{H}_{2} \mathrm{O}$ was used to verify that the system was air tight. Once the well was pressurized, the pressure transducer was referenced to $0 \mathrm{~m}$ (i.e., zero) and the data logger was started. Immediately after initiation of the data logger, pressure was instantaneously released to the atmosphere via the ball valve on the pneumatic water level depressor. All tests were conducted in triplicate and upon test completion, raw datalogger data was uploaded to a field computer for analysis using Aqtesolv Windows Pro (HydroSOLVE Inc, Reston, VA) where it was processed using Bouwer-Rice algorithm (1976) to calculate $\mathrm{K}_{\mathrm{r}}$. 


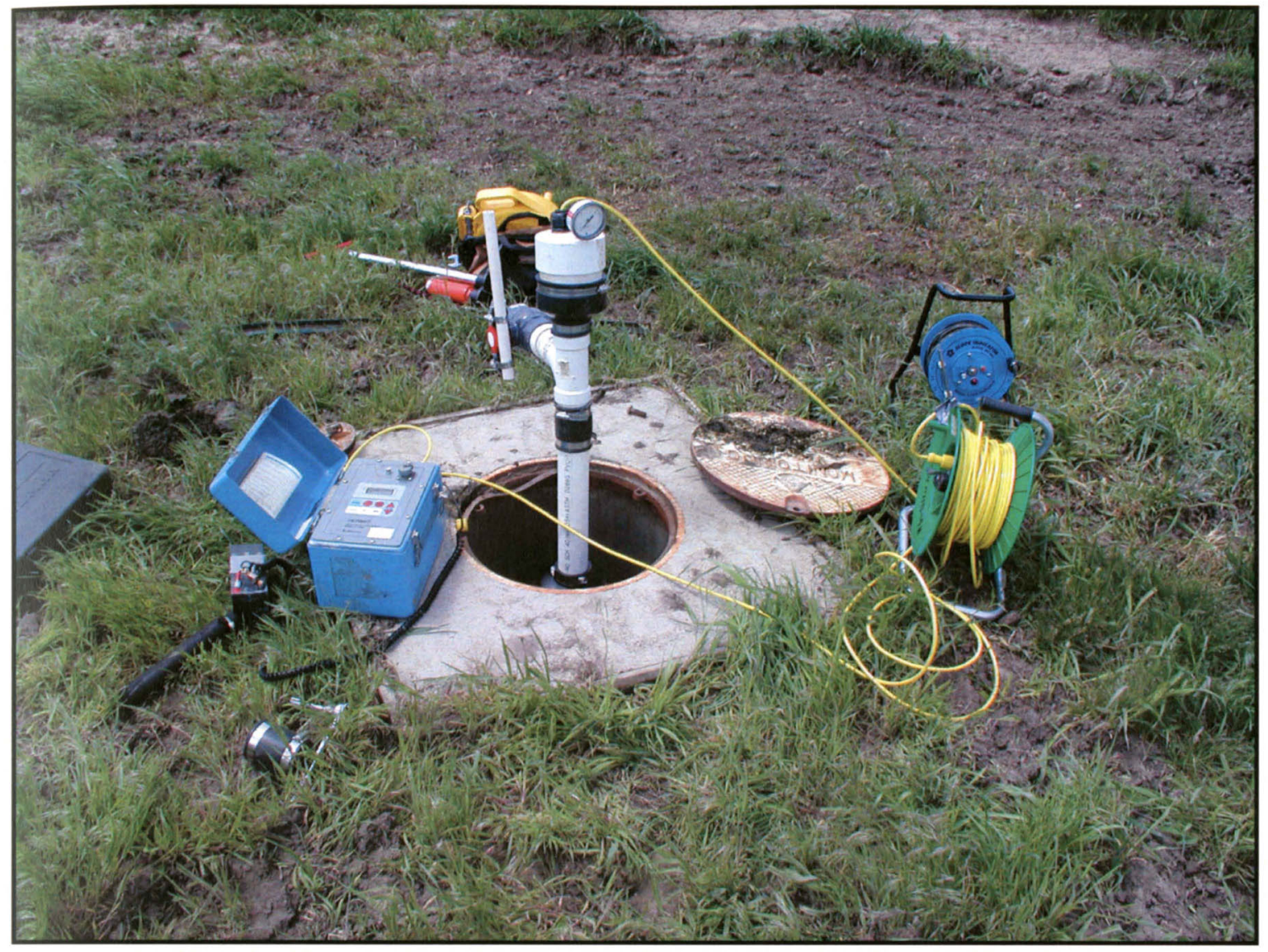

Figure 1. Overview of pneumatic slug test equipment without packer along full screen. 


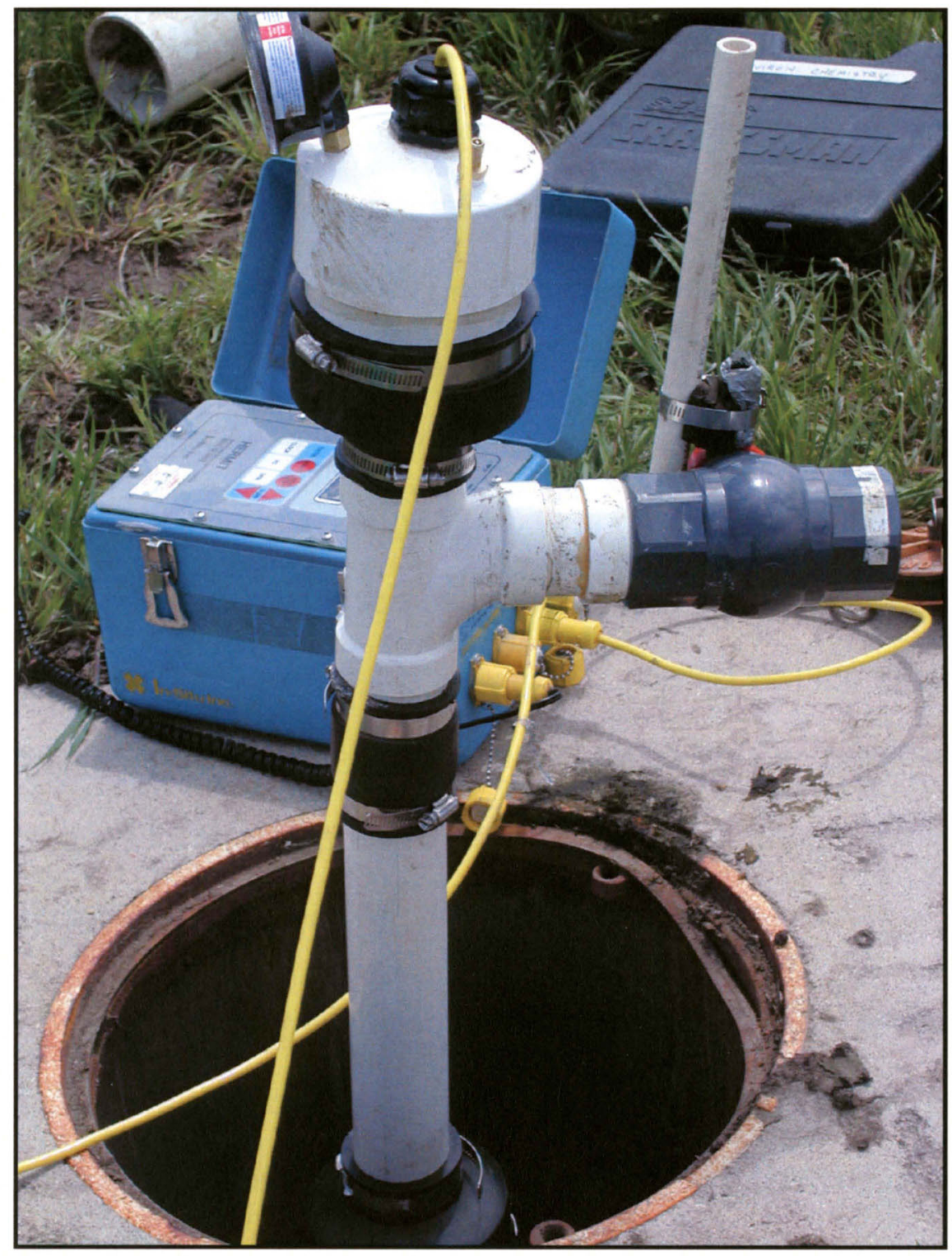

Figure 2. Overview of pneumatic water level depressor components. 


\section{Multi-Level Slug Tests}

Multi-level slug tests (MLSTs) were conducted to observe vertical heterogeneities within the screened interval of three 4-inch monitoring wells at the ISCO test site (IW-1, IW-2, and MW-15). Two MLST methods were conducted; a double-packer (straddle packer) configuration and a single-packer configuration. The double packer configuration, described in detail by Zlotnik et al. (2003) and Zlotnik and McGuire (1998) (Fig. 3) consists of an upper packer (0.63 m) connected to a lower packer $(0.62 \mathrm{~m})$ by three stainless steel rods. The stainless steel rods serve as the liaison between the well screen and pressure transducer. When both packers are inflated to approximately 50 PSI the sealed interval length is $0.62 \mathrm{~m}$. The single-packer configuration is a modified double-packer configuration in which the lower packer is removed leaving the upper packer and steel rods (Figs. 4 and Fig. 5).

The MLST was conducted by suspending the packer assembly from a tripod with a stainless steel cable attached to a wench pulley system (Fig 6). The packers were inflated by an air hose that was connected to an air compressor. The packer assembly was pressurized and checked for system air leaks and packer integrity before two-inch PVC risers were mounted on the packer assembly. Once the system was checked for leaks, the packer assembly was depressurized and lowered into the well until packer(s) were just below the top of the well casing. The packer assembly was pressurized to secure it before threading a $3.05 \mathrm{~m}$ (10ft) 2inch PVC riser to the top of the assembly. Once the first riser was mounted to the assembly, packer(s) were depressurized and lowered approximately $3 \mathrm{~m}$ before 
mounting an additional PVC riser using a 2 inch by 2 inch rubber coupling. This process continued until the packer assembly reached the bottom of the well.

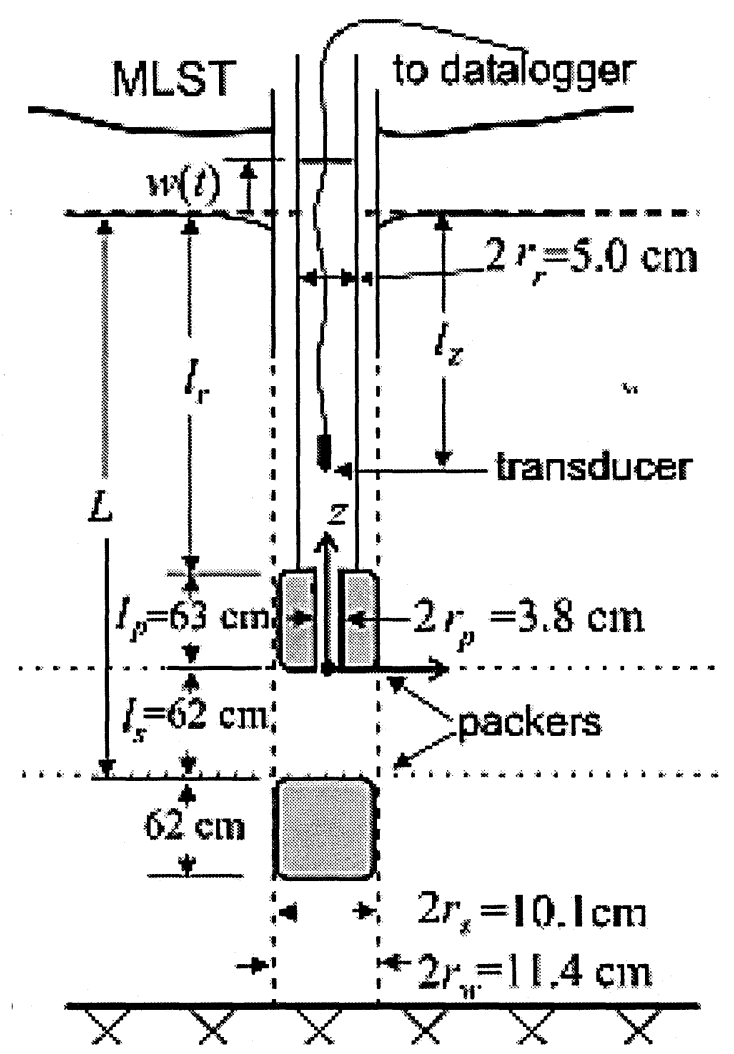

Figure 3. Schematic of the double packer configuration with dimensions (modified from by Zlotnik et al. (2003)).

Once the packer assembly was in position, the packer(s) were pressurized to seal off the desired portion of the well screen and the pneumatic slug test was conducted as previously described in Chapter 2 "Regional Geology". Once the screen interval was tested three times, the packers were depressurized and the packer assembly was raised $0.61 \mathrm{~m}(2 \mathrm{ft})$. This process continued until the full screened interval was tested. 
The single packer multi-level slug test, not yet described in the literature, was developed to support $K_{r}$ values obtained from the double packer MLST. The singlepacker method is more practical since there is not a set test interval in which $\mathrm{Kr}$ can be measured unlike the double-packer configuration which has a constant test interval ( $I_{s}$ in Fig. 3).

Hydraulic conductivity calculations for the tested interval using the single packer configuration differed from the calculations used in the double packer configuration. The double packer configuration maintained a constant screen length after every tested interval while the single packer screen length increased

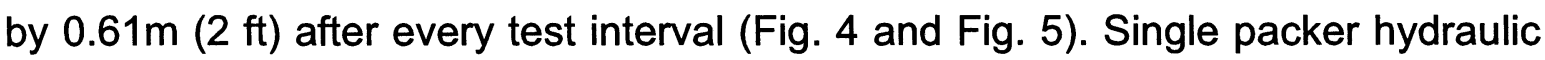
conductivity was calculated using equation (1).

$$
K_{n+1}=\left[\left(K_{A V G}\right)_{n+1}(n+1)-\left(K_{A V G}\right)_{n} \times n\right]
$$

Where $K_{n}$ is horizontal hydraulic conductivity of $n$th aquifer layer between elevations $z=(n-1) \Delta z$ and $z=n \Delta z . \quad \Delta z$ is the interval that separates two different positions of the packer. $n$ is packer position: $n=1$ corresponds to the lowest tested interval $\Delta z$ between elevations $z=0$ and $z=\Delta z$. In this case, the packer bottom is at the elevation $\Delta z$. $n=2$ corresponds to the tested interval $2 \Delta z$ (when the packer isolates interval between bottom $z=0$ and $z=2 \Delta z)$, etc. $\left(K_{A V}\right)_{n}$ is hydraulic conductivity of all tested interval between packer at $z=n \Delta z$ and bottom $z=0$. 


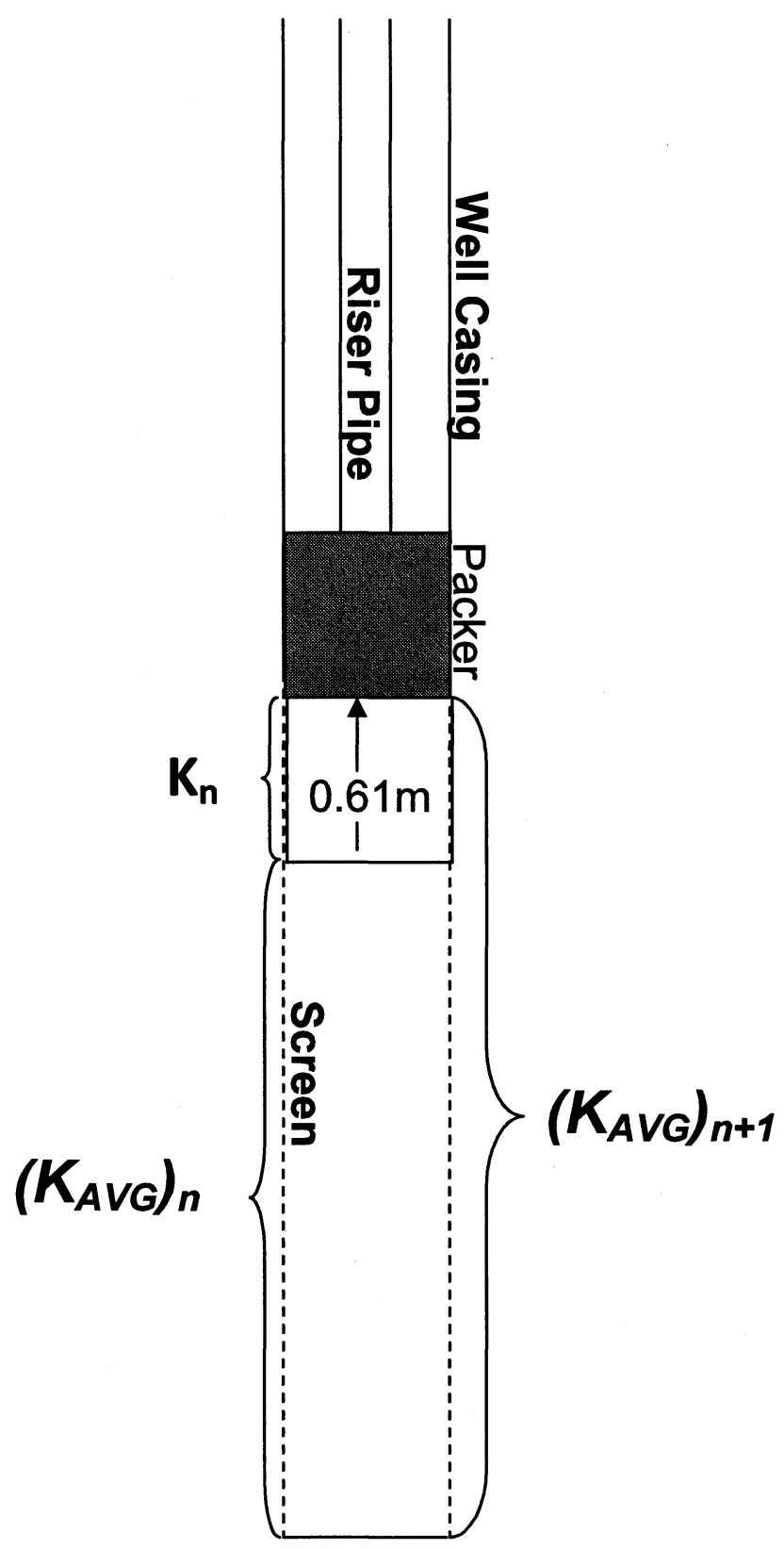

Figure 4. Representation of single-packer configuration and origin of associated $K$ parameters used in equation 1. 


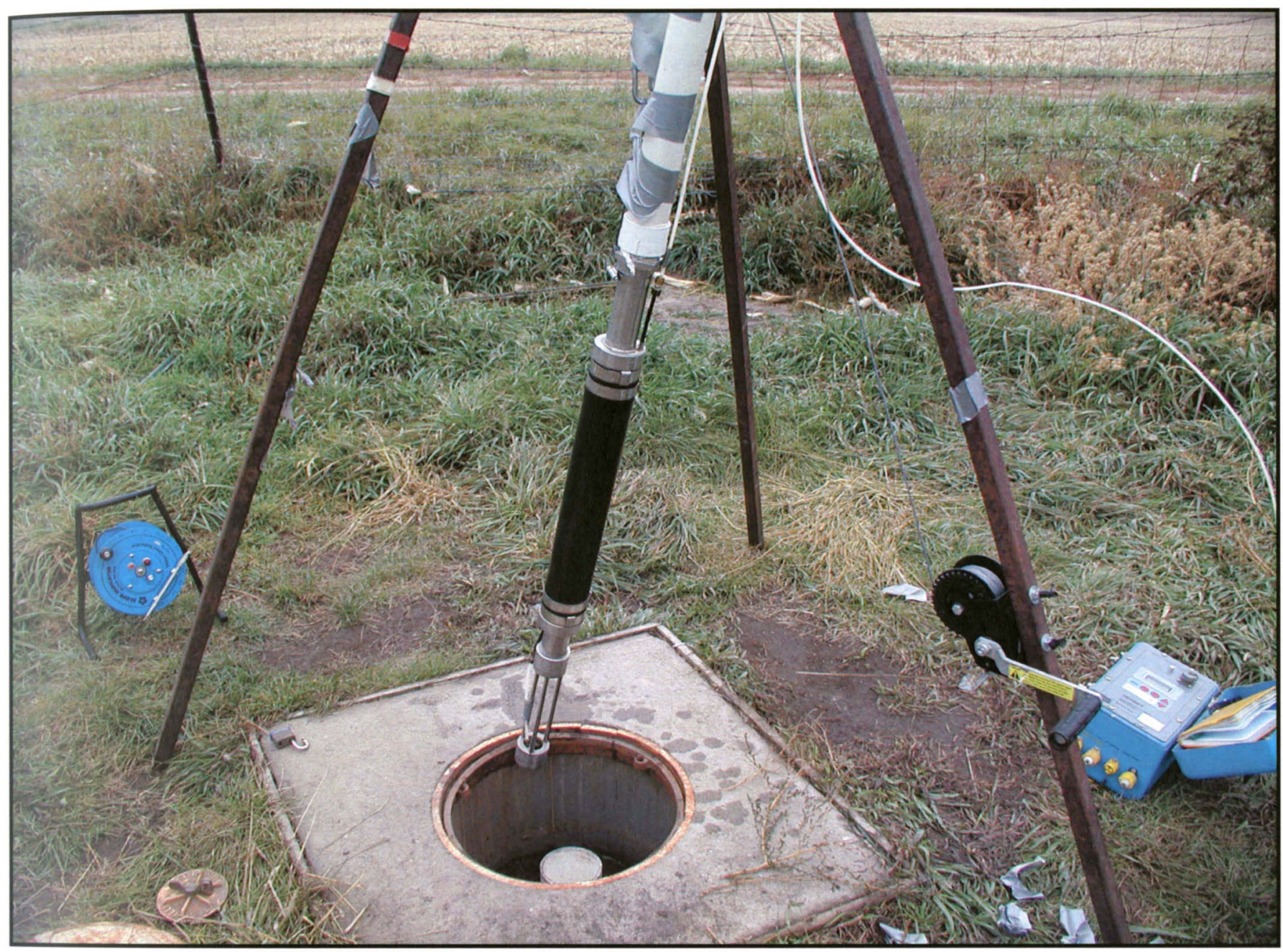

Figure 5. Photograph of single-packer configuration. 


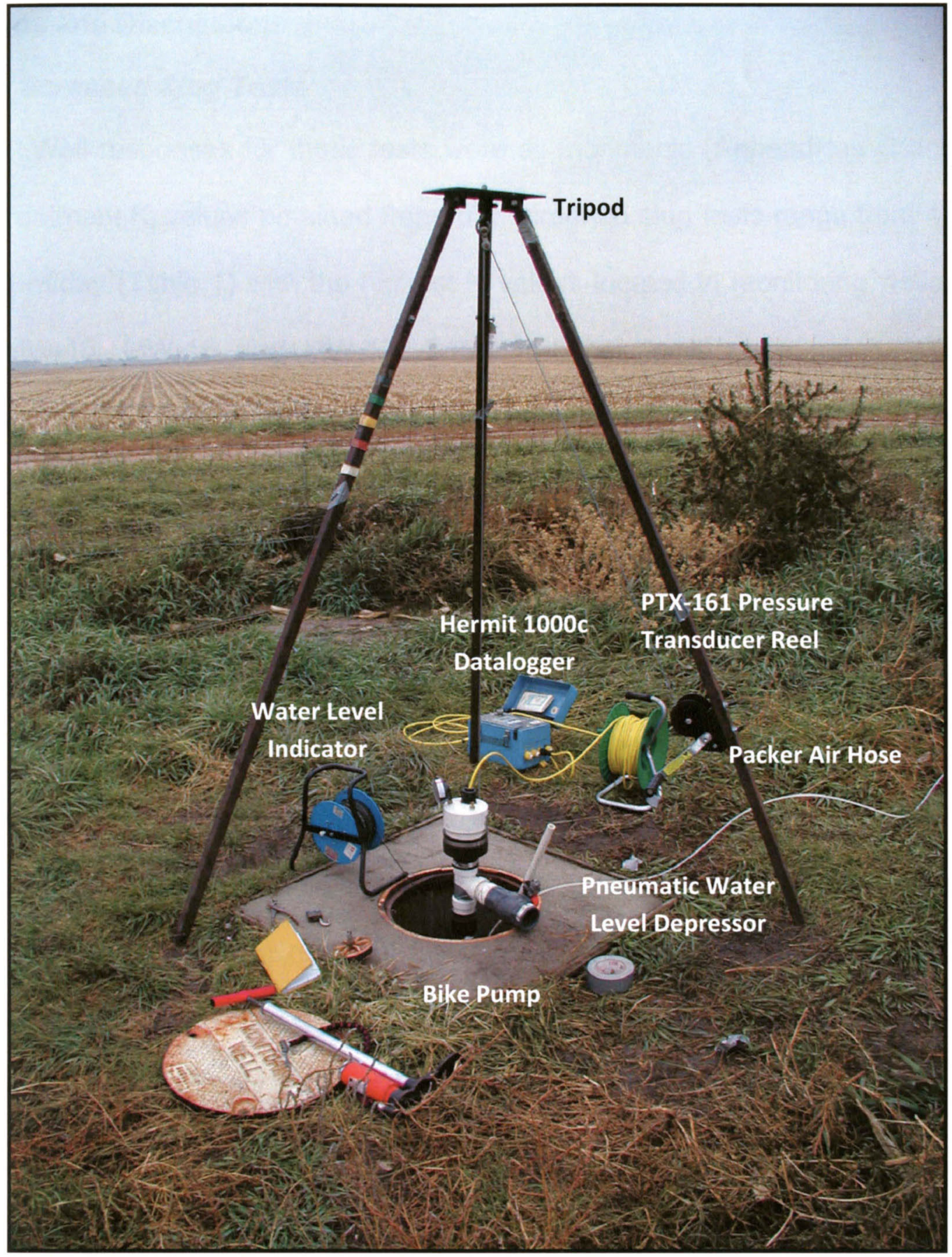

Figure 6. Photograph of MLST equipment and setup. 


\section{Results and Discussion}

\section{Fully Screened Slug Tests}

Well responses for these tests were all monotonic (Appendices $C$ and D.). Pre-treatment $K_{r}$ values obtained from fully screened slug tests range from 4.95 to $23.53 \mathrm{~m} /$ day (Table 1 ) with the highest $\mathrm{K}_{\mathrm{r}}$ values located in monitoring wells $\mathrm{MW}$ 14, MW-15, MW-16 and MW-17. Some changes in $K_{r}$ were noted following permanganate injection and analysis of $\mathrm{K}_{\mathrm{r}}$ values before and after injection showed $K_{r}$ ratios (i.e., Pre/Post) ranged from 0.17 to 3.14 (Table 1). Wells in which $K_{r}$ were reduced included two of the three wells used in the injection-extraction zone (i.e., IW-2, EW-1). Considering all wells in the injection zone (IW-1, IW-2, and EW-1) received high concentrations of permanganate $(20,000 \mathrm{mg} / \mathrm{L}$ in $\mathrm{IW}-1$ and $\mathrm{IW}-2)$ and that IW-1 and IW-2 showed considerable permanganate buildup (i.e., head) during the injection process, some loss in conductivity was expected. Most of the other wells demonstrated little change in conductivities following the permanganate injection. This is likely a result of lower $\mathrm{MnO}_{4}{ }^{-}$concentrations, the fact that the permanganate plume moved downward (i.e., sunk) as it moved downgradient, and the monitoring wells only captured fingers of the permanganate plume.

The lone significant increase in hydraulic conductivity observed in MW-4 (Table 1) is most likely due to the intense sampling regime. MW-4 was installed during a prior demonstration (Wani et al., 2007) and may have gone stagnant when initial slug tests were conducted. 
Table 1. Pre and post permanganate injection hydraulic conductivities ( $m /$ day) calculate in wells within the pilot study site

\begin{tabular}{|c|c|c|c|}
\hline \multirow{2}{*}{ Well ID } & \multicolumn{3}{|c|}{ Ratio (Post K /Pre K) } \\
\cline { 2 - 4 } & Average Pre K & Average Post K & Post K/Pre K \\
\hline EW-1 & 9.15 & 1.60 & 0.17 \\
IW-1 & 4.39 & 5.02 & 1.14 \\
IW-2 & 2.50 & 4.95 & 1.98 \\
MW-2 & 6.99 & 6.93 & 0.99 \\
MW-3 & 5.40 & 7.74 & 1.43 \\
MW-4 & 4.08 & 12.82 & 3.14 \\
MW-12 & 9.42 & 9.50 & 1.01 \\
MW-13 & 10.93 & 9.97 & 0.91 \\
MW-14 & 16.68 & 20.85 & 1.25 \\
MW-15 & 12.51 & 12.93 & 1.03 \\
MW-16 & 26.55 & 23.53 & 0.89 \\
MW-17 & 11.25 & 17.56 & 1.56 \\
\hline
\end{tabular}

\section{Multi-Level Slug Tests}

All observed well responses were monotonic (Appendix C). Both single packer and double packer data were processed by Aqtesolv Windows Pro (HydroSOLVE Inc, Reston, VA) with $\mathrm{K}_{\mathrm{r}}$ interpreted using Bouwer-Rice algorithm (1976). Single-packer $K_{r}$ values coincided very well to values obtained the doublepacker assembly which indicates that the single-packer slug test could be an effective technique

MLSTs conducted on the two injection wells, IW-1 and IW-2, showed inconsistent and abnormally high $\mathrm{K}_{\mathrm{r}}$ values and is believed to be caused by poor gravel pack integrity leading to water short circuiting (i.e. depressed water entering gravel pack voids instead of formation). Nonetheless, pre-permanganate treatment data obtained from MW-15 was replicable and the data obtained by both packer configurations indicates variations in $\mathrm{K}_{\mathrm{r}}$ throughout the $6.1 \mathrm{~m}(20 \mathrm{ft})$ screen. The 
single packer configuration was able to capture an additional measurement at the bottom of the well screen due to the elimination of the bottom packer. Prepermanganate treatment hydraulic conductivities observed in $\mathrm{MW}-15$ range from below $1 \mathrm{~m} /$ day to over $25 \mathrm{~m} /$ day and peak between 17.5 and $19.5 \mathrm{~m}$ below the ground surface (Fig. 7).

Because plume movement will concentrate on high $\mathrm{K}$ zones (preferential flow paths) and tend to refract from low $K$ zones, implications of these $K_{r}$ variations could be permanganate plume bifurcation, incomplete permanganate mass recovery, and inadequate permanganate plume delineation.

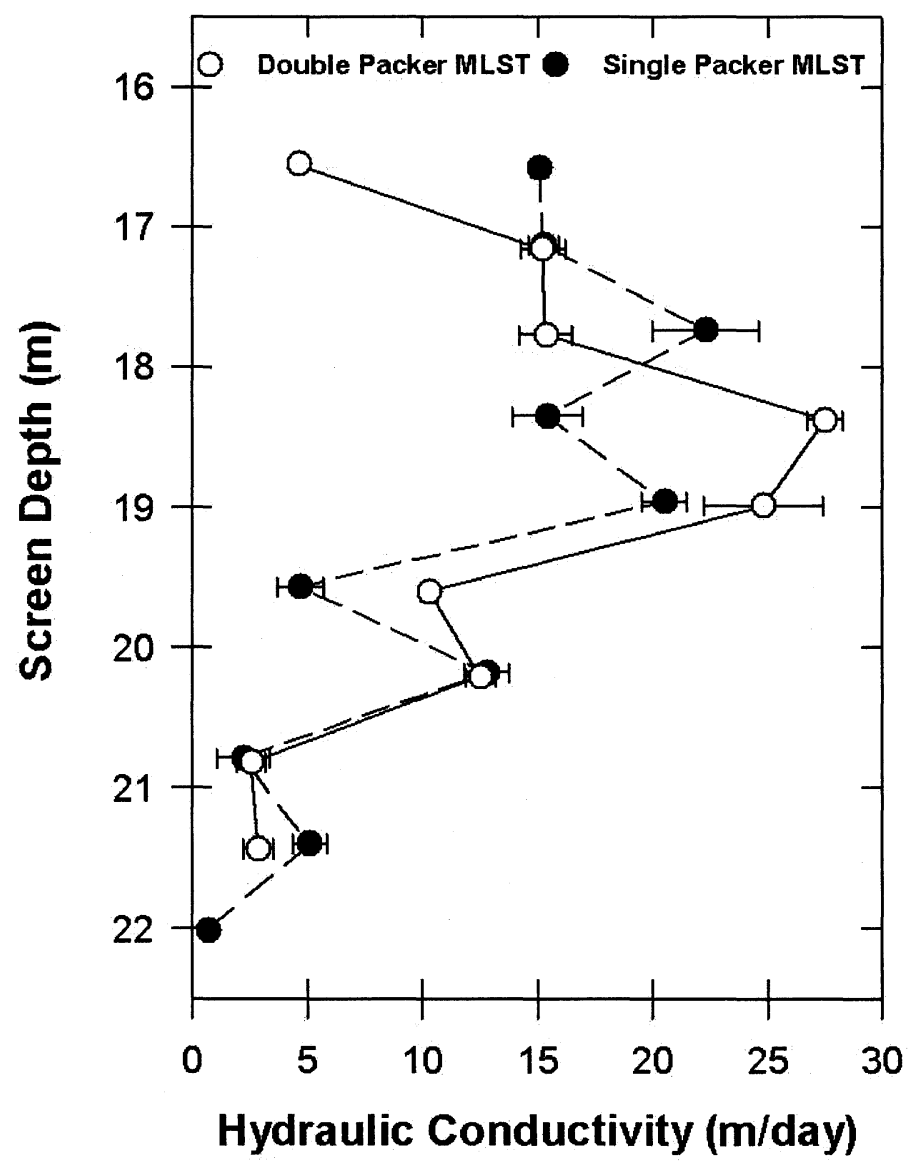

Figure 7 Hydraulic conductivities observed in MW-15 using single and double packer multi-level slug test configurations. 
Multilevel slug testing following permanganate injection in MW-15 (Fig. 8) indicated no reduced hydraulic conductivities due to $\mathrm{MnO}_{2}$ colloids. This was somewhat expected based on the very low natural oxidant demand of the aquifer $(<1 \%$ consumption of permanganate) and very low RDX concentrations present in the aquifer $(<300 \mu \mathrm{g} / \mathrm{L})$. A comparison of pre-versus post-injection showed that hydraulic conductivities were higher at each depth interval following the permanganate injection (Fig. 8). This is different than results obtained from the full screen slug tests where we observed a slight decrease in hydraulic conductivity (Table 1). One explanation for an increase in hydraulic conductivities in $\mathrm{MW}-15$ is that we used an intensive bi-weekly sampling regime (purging 3 to 4 well volume twice a week) to monitor RDX destruction and this intense sampling may have continued well development (removing fine grains), and therefore, increased hydraulic conductivity within all portions of the well screen but especially the more conductive zones (i.e., 19-20 m). 


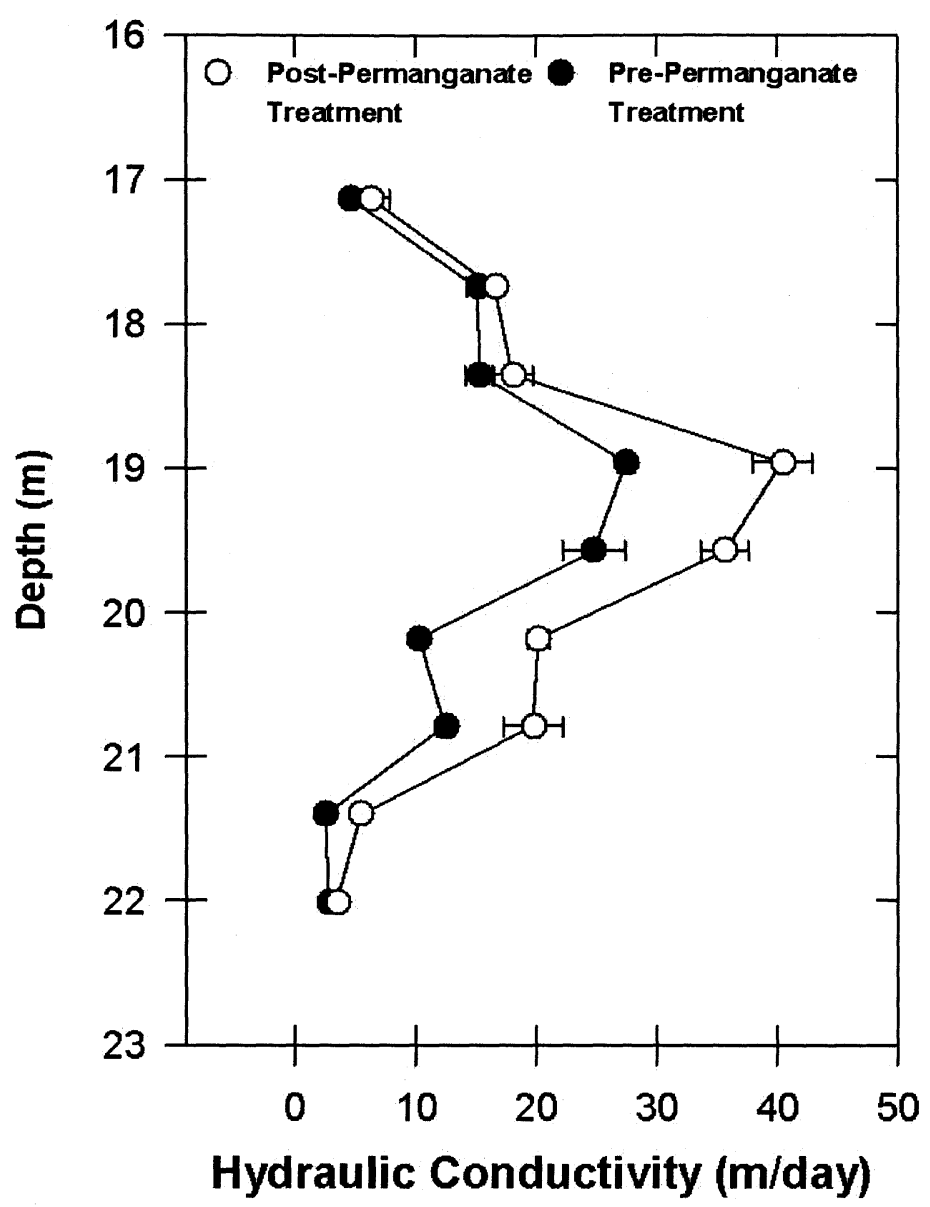

Fig.8. Hydraulic conductivities calculated from pre and postpermanganate double packer multi-level slug tests.

\section{Conclusions}

Pre-permanganate treatment site hydraulic conductivities were calculated using pneumatic slug tests and multi-level slug tests. These data indicate heterogeneities both spatially within the test site and vertically throughout the well screens. These heterogeneities could cause plume movement to deviate from the interpreted hydraulic gradient and concentrate in high $\mathrm{K}$ zones (preferential flow 
paths). This type of preferential flow behavior made permanganate plume delineation using site monitoring wells to be incomplete or inaccurate.

With the exception of perhaps the injection zone, we do not believe the byproduct of permanganate oxidation (i.e., $\mathrm{MnO}_{2}$ ) led to decreases in hydraulic conductivities. Any variability between pre and post-permanganate injection hydraulic conductivity could be attributed to intense groundwater sampling that occurred throughout the test site and likely increased well development. 


\section{REFERENCES}

Bouwer, H., Rice, R.C.,1976. A slug test for determining hydraulic conductivity of unconfined aquifers with completely or partially penetrating wells, Water Resources Research. 12 (3), 423-428.

Wani, A.H., Wade, R., Davis, J.L., 2007. Field Demonstration of Biologically ActiveZone Enhancement Using Acetate as a Sole Carbon Source for In Situ Reductive Transformation of RDX in Groundwater. Practical Periodical of Hazardous, Toxic, and Radioactive Waste Management. 11 (2), 83-91.

Zlotnik, V.A., Zurbuchen, B.R., 2003. Estimation of hydraulic conductivity from the borehole flowmeter tests considering non-linear effects in highly permeable aquifers, Journal of Hydrology. 281 (1-2), 115-128

Zlotnik, V.A., McGuire, V.L., 1998. Multi-level slug tests in highly permeable formations: 1. Modification of the Springer-Gelhar (SG) model, Journal of Hydrology. 204, 271-282.

Zlotnik, V.A., McGuire, V.L., 1998. Multi-level slug tests in highly permeable formations: 2. Hydraulic conductivity identification, method verification, and field applications, Journal of Hydrology, 204, 283-296. 


\section{APPENDIX C}

Full Screen Pneumatic Slug Test Results

Pre Sodium Permanganate Injection 


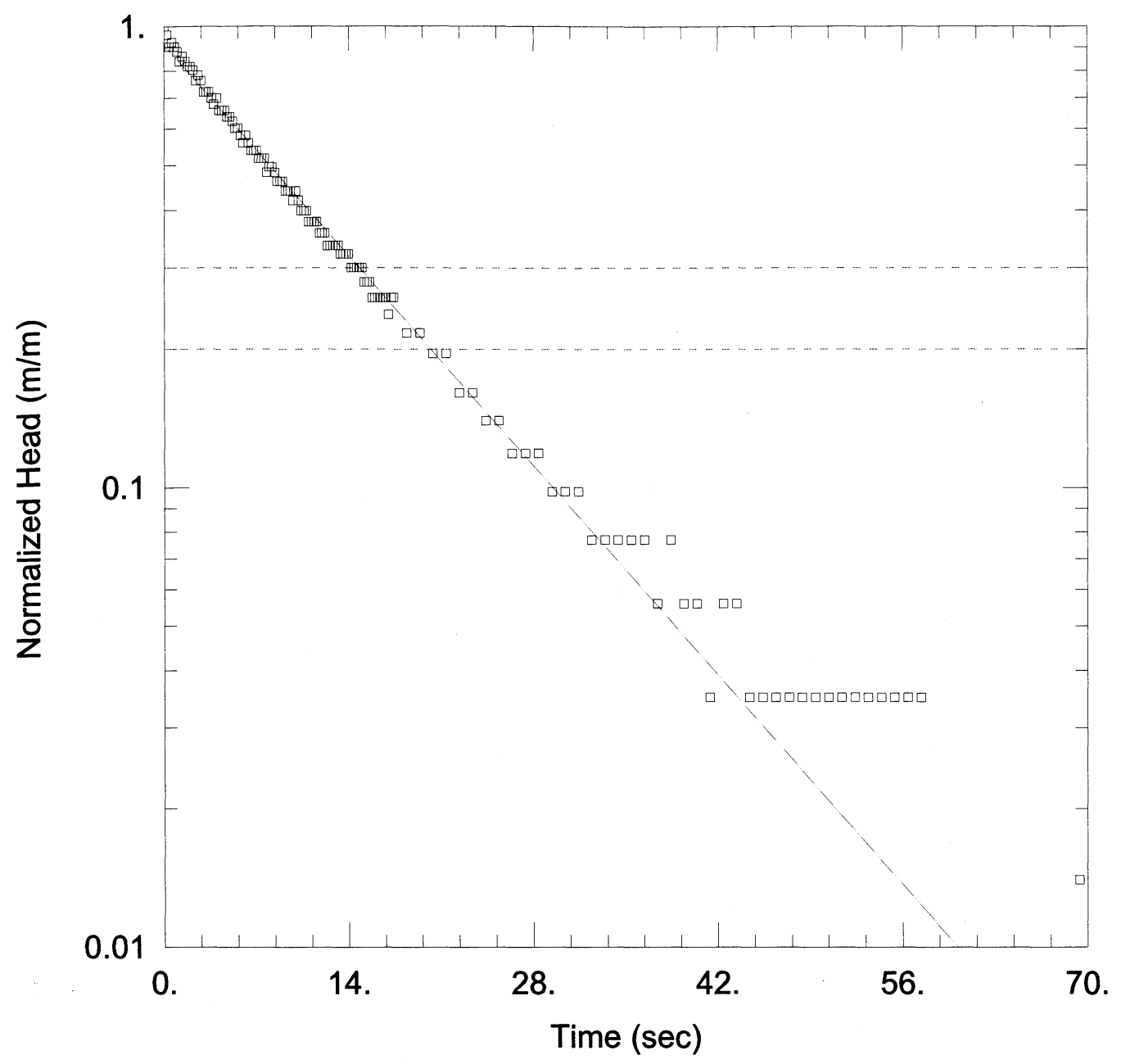

WELL TEST ANALYSIS

Data Set: E:I...IEW1_1.aqt

Date: $09 / 14 / 08$

Time: 15:09:15

\section{PROJECT INFORMATION}

Company: University of Nebraska

Location: Injection Pilot Study

Test Well: EW-1

\section{AQUIFER DATA}

Saturated Thickness: $15.24 \mathrm{~m}$

Anisotropy Ratio (Kz/Kr): 1.

WELL DATA (EW-1)

Initial Displacement: $1 . \mathrm{m}$

Total Well Penetration Depth: $7.616 \mathrm{~m}$

Casing Radius: $0.0762 \mathrm{~m}$

Static Water Column Height: $6.096 \mathrm{~m}$

Screen Length: $6.096 \mathrm{~m}$

Well Radius: $0.0762 \mathrm{~m}$

\section{SOLUTION}

Aquifer Model: Unconfined

Solution Method: Bouwer-Rice

$\mathrm{K}=9.517 \mathrm{~m} /$ day

y0 $=0.9118 \mathrm{~m}$ 


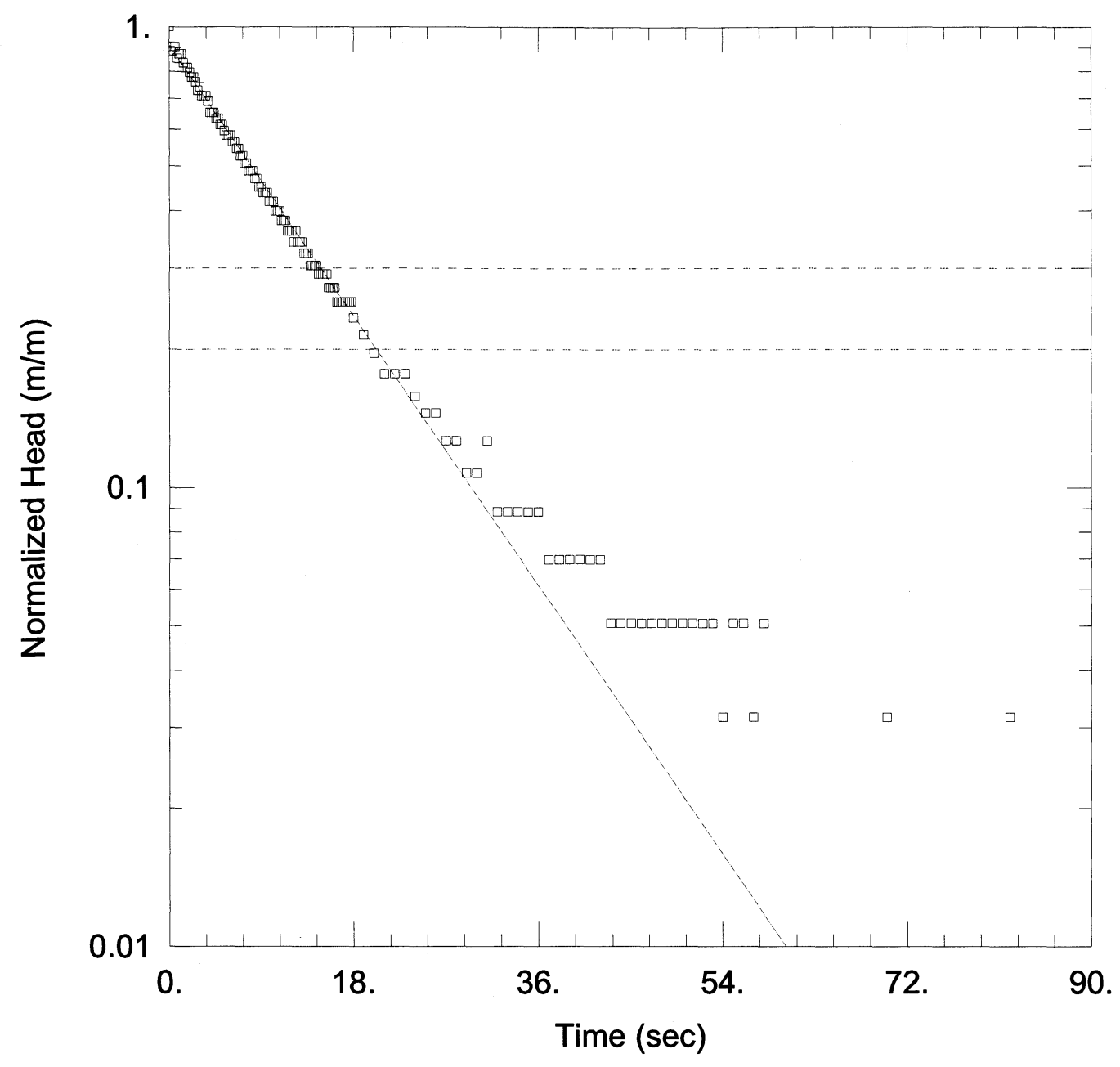

\section{WELL TEST ANALYSIS}

Data Set: E:I...IEW1_2.aqt

Date: 09/14/08

Time: 15:09:55

\section{PROJECT INFORMATION}

Company: University of Nebraska

Location: Injection Pilot Study

Test Well: EW-1

\section{AQUIFER DATA}

Saturated Thickness: 15.24 m

Anisotropy Ratio (Kz/Kr): 1.

\section{WELL DATA (EW-1)}

Initial Displacement: 1. m

Total Well Penetration Depth: $7.616 \mathrm{~m}$

Casing Radius: $0.0762 \mathrm{~m}$
Static Water Column Height: $6.096 \mathrm{~m}$ Screen Length: $6.096 \mathrm{~m}$

Well Radius: $0.0762 \mathrm{~m}$

\section{SOLUTION}

Aquifer Model: Unconfined

Solution Method: Bouwer-Rice

$\mathrm{K}=9.517 \mathrm{~m} / \mathrm{day}$ y0 $=0.9118 m$ 


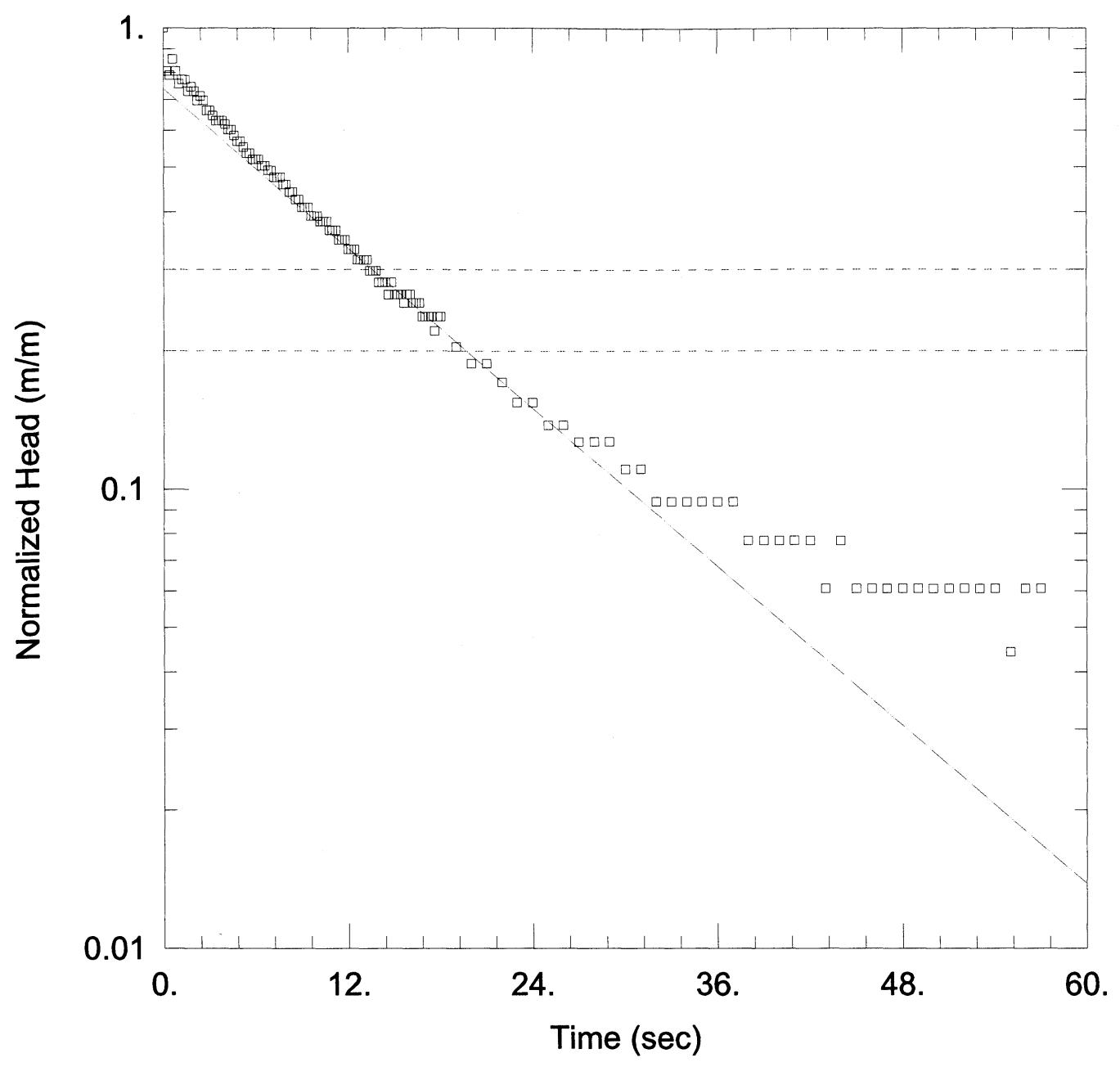

WELL TEST ANALYSIS

Data Set: E:I...IEW1_3.aqt

Date: $09 / 14 / 08$

Time: 15:10:38

PROJECT INFORMATION

Company: University of Nebraska

Location: Injection Pilot Study

Test Well: EW-1

\section{AQUIFER DATA}

Saturated Thickness: $15.24 \mathrm{~m}$

Anisotropy Ratio $(\mathrm{Kz} / \mathrm{Kr}): 1$.

\section{WELL DATA (EW-1)}

Initial Displacement: 1. m

Total Well Penetration Depth: $7.616 \mathrm{~m}$

Casing Radius: $0.0762 \mathrm{~m}$
Static Water Column Height: $6.096 \mathrm{~m}$ Screen Length: $6.096 \mathrm{~m}$

Well Radius: $0.0762 \mathrm{~m}$

\section{SOLUTION}

Aquifer Model: Unconfined

Solution Method: Bouwer-Rice

$\mathrm{K}=8.418 \mathrm{~m} /$ day

$\mathrm{y} 0=0.7385 \mathrm{~m}$ 


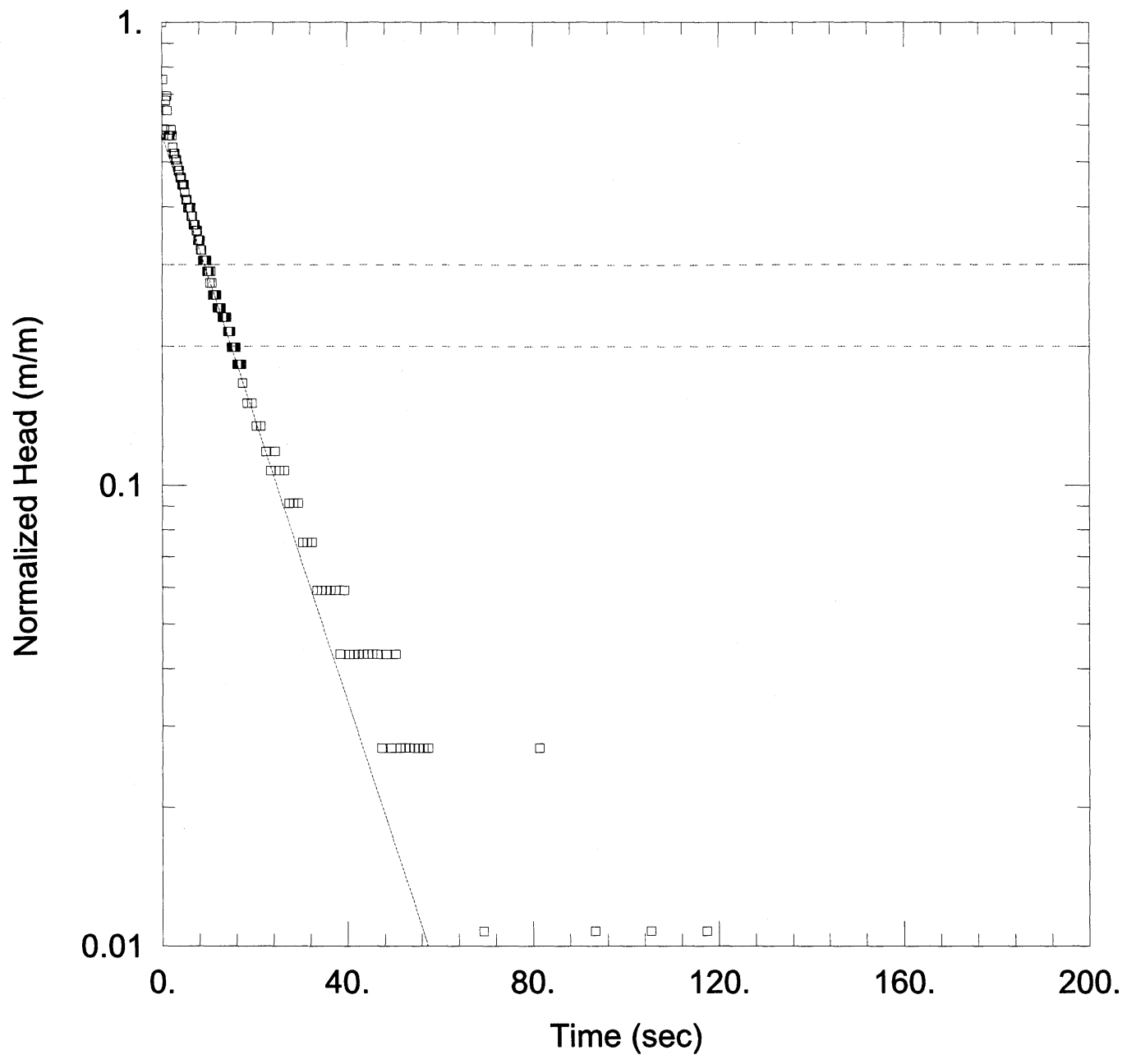

\section{WELL TEST ANALYSIS}

Data Set: E:I...IVW-1_1.aqt

Date: $09 / 14 / 08$

Time: 15:11:21

\section{PROJECT INFORMATION}

Company: University of Nebraska

Location: Injection Pilot Study

Test Well: IW-1

\begin{tabular}{|c|c|}
\hline \multicolumn{2}{|c|}{ AQUIFER DATA } \\
\hline Saturated Thickness: $15.24 \mathrm{~m}$ & Anisotropy Ratio (Kz/Kr): 1. \\
\hline \multicolumn{2}{|c|}{ WELL DATA (IW-1) } \\
\hline $\begin{array}{l}\text { Initial Displacement: } 1 . \mathrm{m} \\
\text { Total Well Penetration Depth: } \underline{7.616} \mathrm{~m} \\
\text { Casing Radius: } 0.0508 \mathrm{~m}\end{array}$ & $\begin{array}{l}\text { Static Water Column Height: } 6.096 \mathrm{~m} \\
\text { Screen Length: } 6.096 \mathrm{~m} \\
\text { Well Radius: } 0.0508 \mathrm{~m}\end{array}$ \\
\hline \multicolumn{2}{|c|}{ SOLUTION } \\
\hline Aquifer Model: Unconfined & Solution Method: Bouwer-Rice \\
\hline $\mathrm{K}=4.389 \mathrm{~m} / \mathrm{day}$ & $\mathrm{y} 0=0.5704 \mathrm{~m}$ \\
\hline
\end{tabular}




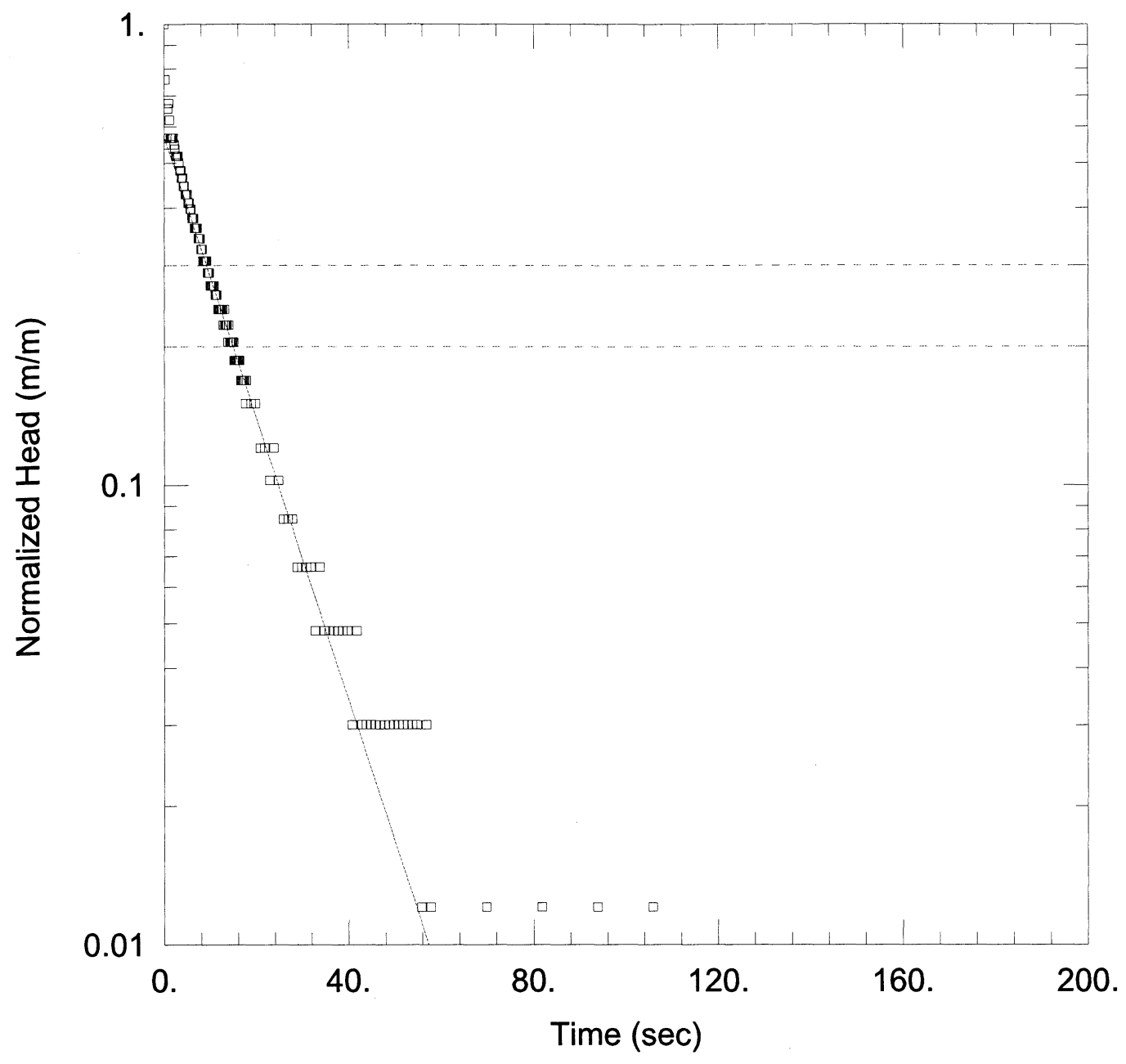

\section{WELL TEST ANALYSIS}

Data Set: E:I...IIW-1_2.aqt

Date: $09 / 14 / 08$

Time: 15:12:02

\section{PROJECT INFORMATION}

Company: University of Nebraska

Location: Injection Pilot Study

Test Well: IW-1

\section{AQUIFER DATA}

Saturated Thickness: $15.24 \mathrm{~m}$

Anisotropy Ratio $(\mathrm{Kz} / \mathrm{Kr})$ : 1.

WELL DATA (IW-1)

Initial Displacement: 1. m

Total Well Penetration Depth: $7.616 \mathrm{~m}$

Casing Radius: $0.0508 \mathrm{~m}$
Static Water Column Height: $6.096 \mathrm{~m}$

Screen Length: $6.096 \mathrm{~m}$

Well Radius: $0.0508 \mathrm{~m}$

\section{SOLUTION}

Aquifer Model: Unconfined

$\mathrm{K}=\underline{4.389} \mathrm{~m} /$ day
Solution Method: Bouwer-Rice

y0 $=0.5704 \mathrm{~m}$ 


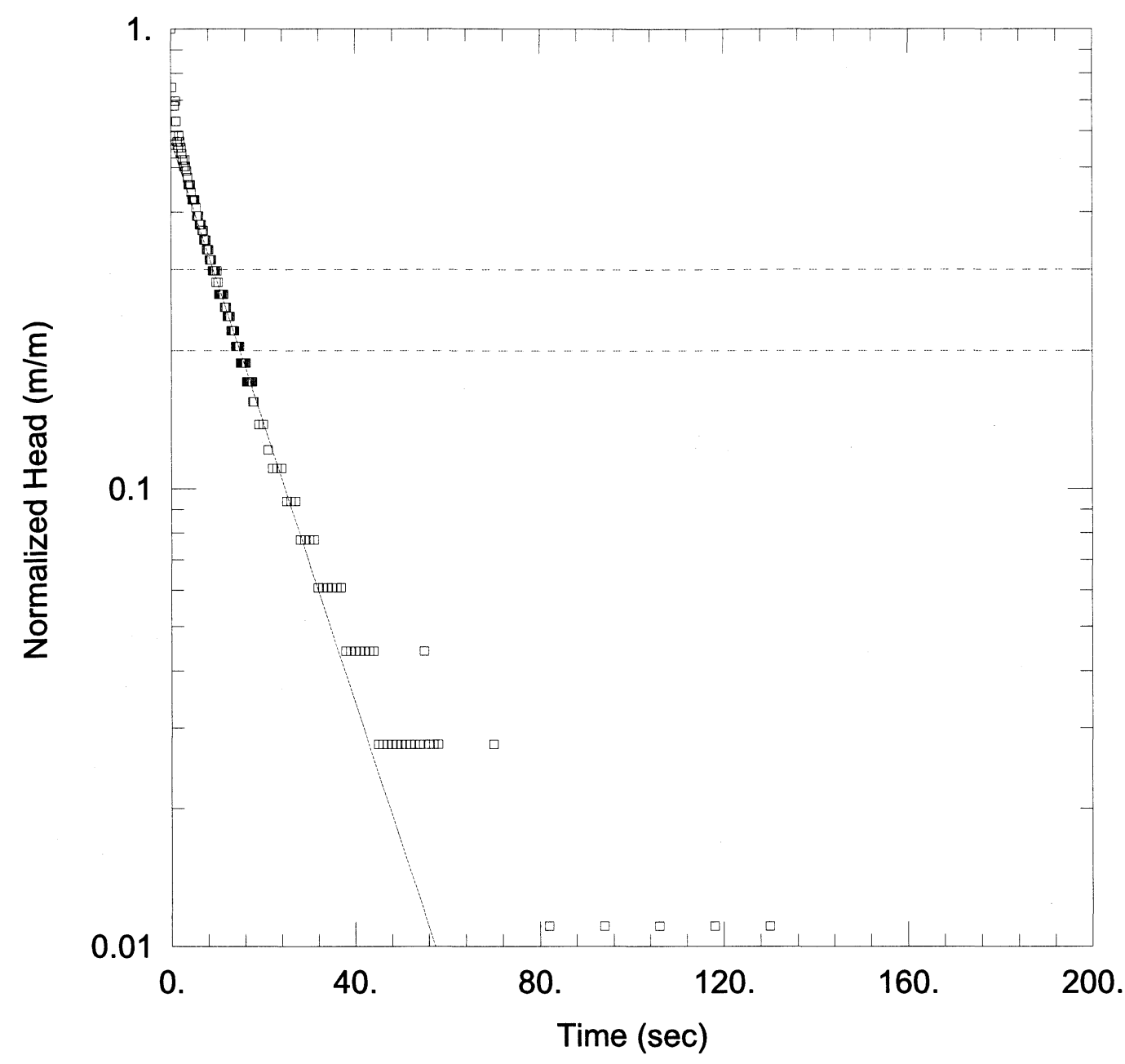

\begin{tabular}{|c|c|}
\hline \multicolumn{2}{|c|}{ WELL TEST ANALYSIS } \\
\hline $\begin{array}{l}\text { Data Set: E:I...IWW-1_3.aqt } \\
\text { Date: } 09 / 14 / 08\end{array}$ & Time: $15: 12: 44$ \\
\hline \multicolumn{2}{|c|}{ PROJECT INFORMATION } \\
\hline \multicolumn{2}{|l|}{$\begin{array}{l}\text { Company: University of Nebraska } \\
\text { Location: Injection Pilot Study } \\
\text { Test Well: IW-1 }\end{array}$} \\
\hline \multicolumn{2}{|c|}{ AQUIFER DATA } \\
\hline Saturated Thickness: $15.24 \mathrm{~m}$ & Anisotropy Ratio (Kz/Kr): 1 . \\
\hline \multicolumn{2}{|c|}{ WELL DATA (IW-1) } \\
\hline $\begin{array}{l}\text { Initial Displacement: } 1 . \mathrm{m} \\
\text { Total Well Penetration Depth: } \underline{7.616 \mathrm{~m}} \\
\text { Casing Radius: } \underline{0.0508 \mathrm{~m}}\end{array}$ & $\begin{array}{l}\text { Static Water Column Height: } \underline{6.096 \mathrm{~m}} \\
\text { Screen Length: } 6.096 \mathrm{~m} \\
\text { Well Radius: } \underline{0.0508 \mathrm{~m}}\end{array}$ \\
\hline \multicolumn{2}{|c|}{ SOLUTION } \\
\hline Aquifer Model: Unconfined & Solution Method: Bouwer-Rice \\
\hline $\mathrm{K}=4.389 \mathrm{~m} / \mathrm{day}$ & $\mathrm{y} 0=0.5704 \mathrm{~m}$ \\
\hline
\end{tabular}




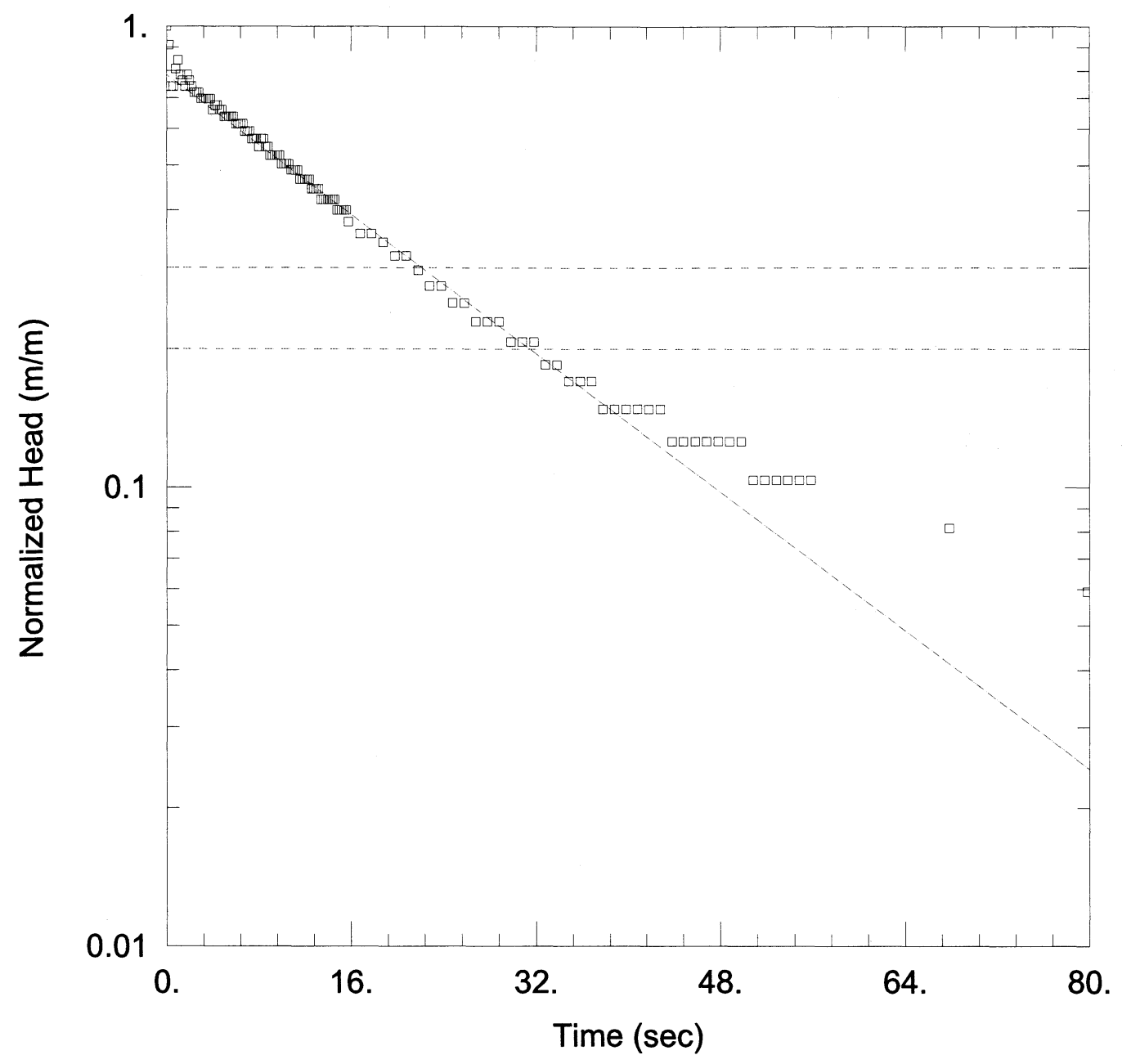

\section{WELL TEST ANALYSIS}

Data Set: E:I...IVW-2_1.aqt

Date: $09 / 14 / 08$

Time: $15: 13: 17$

\section{PROJECT INFORMATION}

Company: University of Nebraska

Location: Injection Pilot Study

Test Well: IW-2

\section{AQUIFER DATA}

Saturated Thickness: $15.24 \mathrm{~m}$ Anisotropy Ratio $(\mathrm{Kz} / \mathrm{Kr})$ : 1.

WELL DATA (IW-2)

Initial Displacement: 1. m

Total Well Penetration Depth: $7.616 \mathrm{~m}$

Casing Radius: $0.0508 \mathrm{~m}$

Static Water Column Height: $6.096 \mathrm{~m}$ Screen Length: $6.096 \mathrm{~m}$

Well Radius: $0.0508 \mathrm{~m}$

\section{SOLUTION}

Aquifer Model: Unconfined

Solution Method: Bouwer-Rice

$\mathrm{K}=2.703 \mathrm{~m} /$ day y0 $=0.7835 \mathrm{~m}$ 


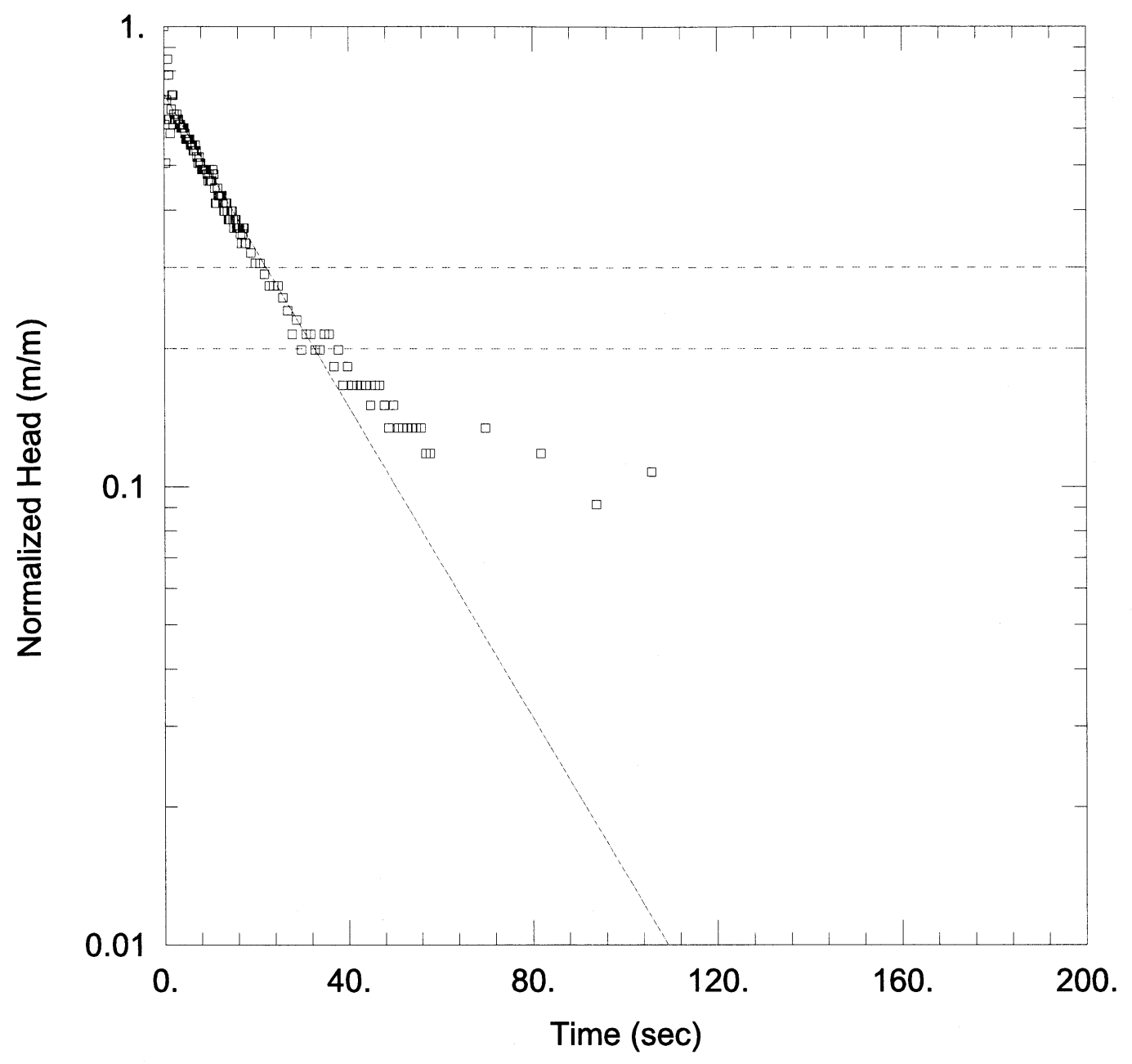

\section{WELL TEST ANALYSIS}

Data Set: E:I...IIW-2_2.aqt

Date: $09 / 14 / 08$

Time: 15:14:09

\section{PROJECT INFORMATION}

Company: University of Nebraska

Location: Injection Pilot Study

Test Well: IW-2

\section{AQUIFER DATA}

Saturated Thickness: $15.24 \mathrm{~m}$

Anisotropy Ratio (Kz/Kr): 1.

\section{WELL DATA (IW-2)}

Initial Displacement: 1. m

Total Well Penetration Depth: $7.616 \mathrm{~m}$

Casing Radius: $0.0508 \mathrm{~m}$
Static Water Column Height: $6.096 \mathrm{~m}$ Screen Length: $6.096 \mathrm{~m}$

Well Radius: $0.0508 \mathrm{~m}$

\section{SOLUTION}

Aquifer Model: Unconfined

Solution Method: Bouwer-Rice

$\mathrm{K}=2.431 \mathrm{~m} /$ day

y0 $=0.713 m$ 


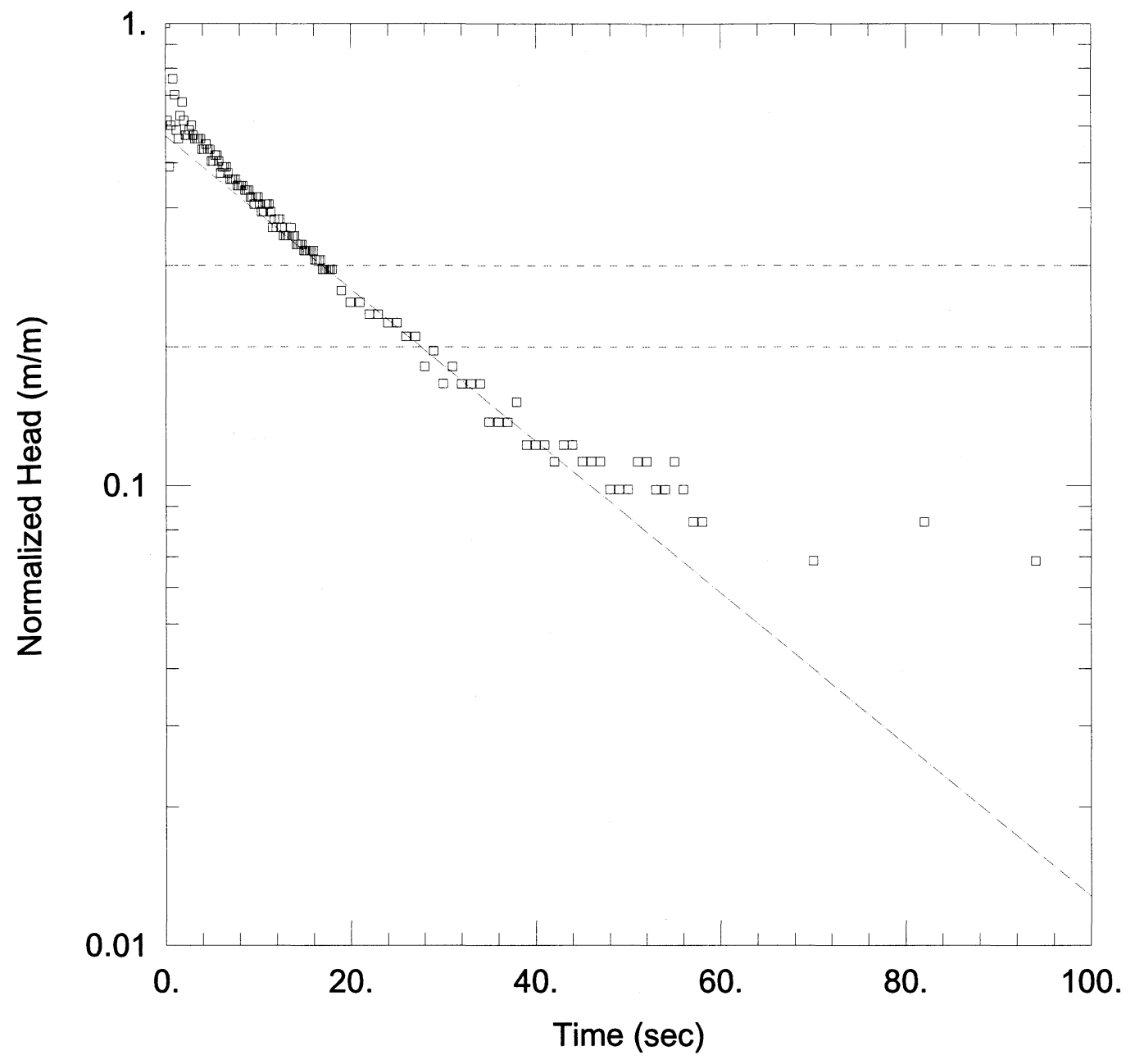

\section{WELL TEST ANALYSIS}

Data Set: E:I...IIW-2_3.aqt

Date: $09 / 14 / 08$

Time: 15:14:55

PROJECT INFORMATION

Company: University of Nebraska

Location: Injection Pilot Study

Test Well: IW-2

\section{AQUIFER DATA}

Saturated Thickness: $15.24 \mathrm{~m}$

Anisotropy Ratio (Kz/Kr): 1.

WELL DATA (IW-2)

Initial Displacement: 1. m

Total Well Penetration Depth: $7.616 \mathrm{~m}$

Casing Radius: $0.0508 \mathrm{~m}$
Static Water Column Height: $6.096 \mathrm{~m}$ Screen Length: $6.096 \mathrm{~m}$ Well Radius: $0.0508 \mathrm{~m}$
Aquifer Model: Unconfined

$\mathrm{K}=2.365 \mathrm{~m} /$ day
Solution Method: Bouwer-Rice

y0 $=0.5704 \mathrm{~m}$ 


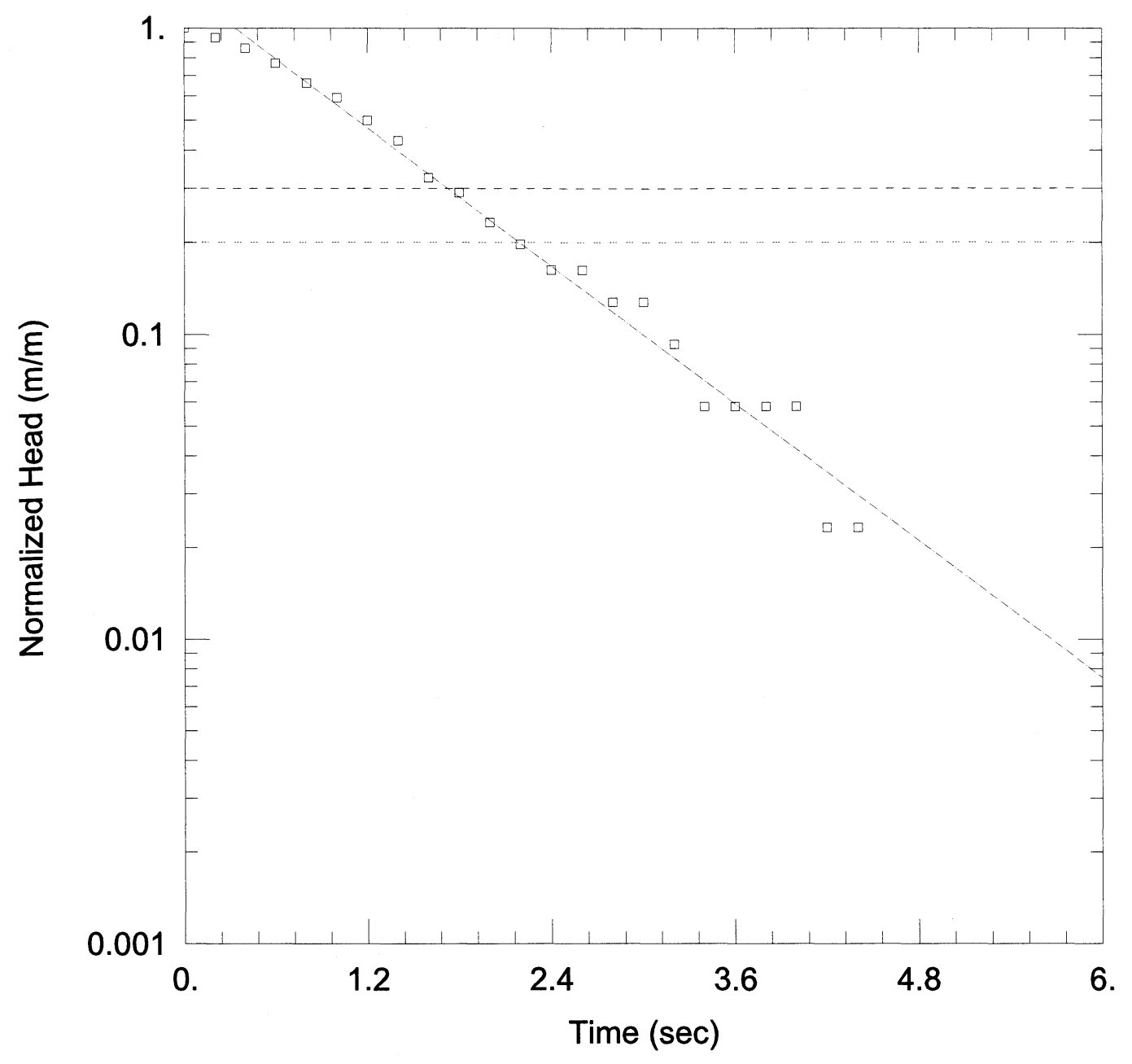

\section{WELL TEST ANALYSIS}

Data Set: E:I...IMW1_1.aqt

Date: $09 / 14 / 08$

Time: $12: 40: 38$

\section{PROJECT INFORMATION}

Company: University of Nebraska

Location: Injection Pilot Study

Test Well: MW-1

\section{AQUIFER DATA}

Saturated Thickness: $15.24 \mathrm{~m}$

Anisotropy Ratio $(\mathrm{Kz} / \mathrm{Kr})$ : 1 .

\section{WELL DATA (MW-1)}

Initial Displacement: $1 . \mathrm{m}$

Total Well Penetration Depth: $7.616 \mathrm{~m}$

Casing Radius: $0.0254 \mathrm{~m}$
Static Water Column Height: $6.096 \mathrm{~m}$ Screen Length: $6.096 \mathrm{~m}$

Well Radius: $0.0254 \mathrm{~m}$

\section{SOLUTION}

Aquifer Model: Unconfined

Solution Method: Bouwer-Rice

$\mathrm{K}=15.71 \mathrm{~m} / \mathrm{day}$ $\mathrm{y} 0=1.334 \mathrm{~m}$ 


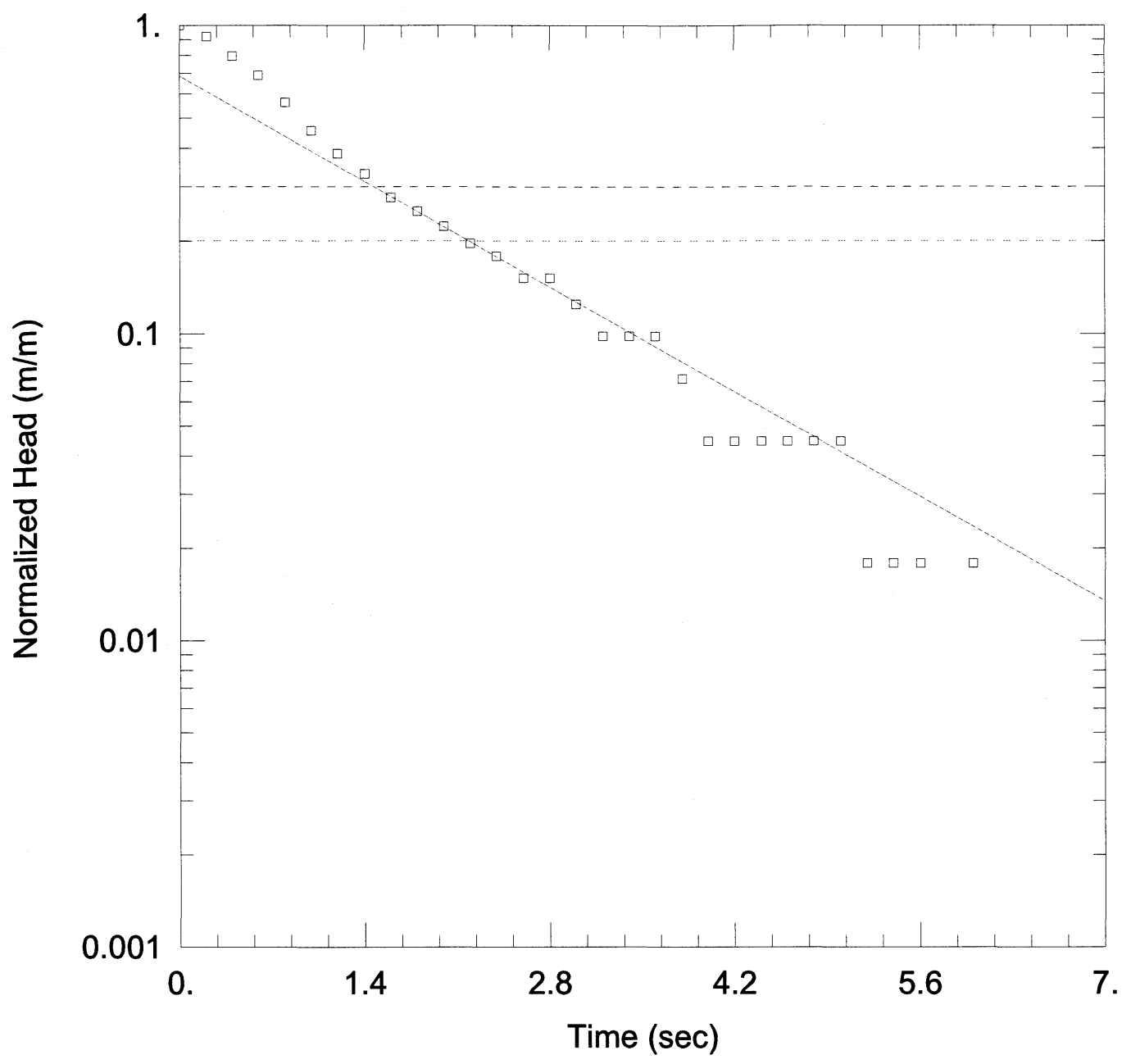

WELL TEST ANALYSIS

Data Set: E:I...IMW1_2.aqt

Date: $09 / 14 / 08$

Time: $12: 41: 13$

PROJECT INFORMATION

Company: University of Nebraska

Location: Injection Pilot Study

Test Well: MW-1

\section{AQUIFER DATA}

Saturated Thickness: $15.24 \mathrm{~m}$

Anisotropy Ratio (Kz/Kr): 1.

WELL DATA (MW-1)

Initial Displacement: 1. m

Total Well Penetration Depth: $7.616 \mathrm{~m}$

Static Water Column Height: $6.096 \mathrm{~m}$

Casing Radius: $0.0254 \mathrm{~m}$ Screen Length: $6.096 \mathrm{~m}$

Well Radius: $0.0254 \mathrm{~m}$

\section{SOLUTION}

Aquifer Model: Unconfined

Solution Method: Bouwer-Rice

$\mathrm{K}=10.21 \mathrm{~m} / \mathrm{day}$

yo $=0.685 \mathrm{~m}$ 


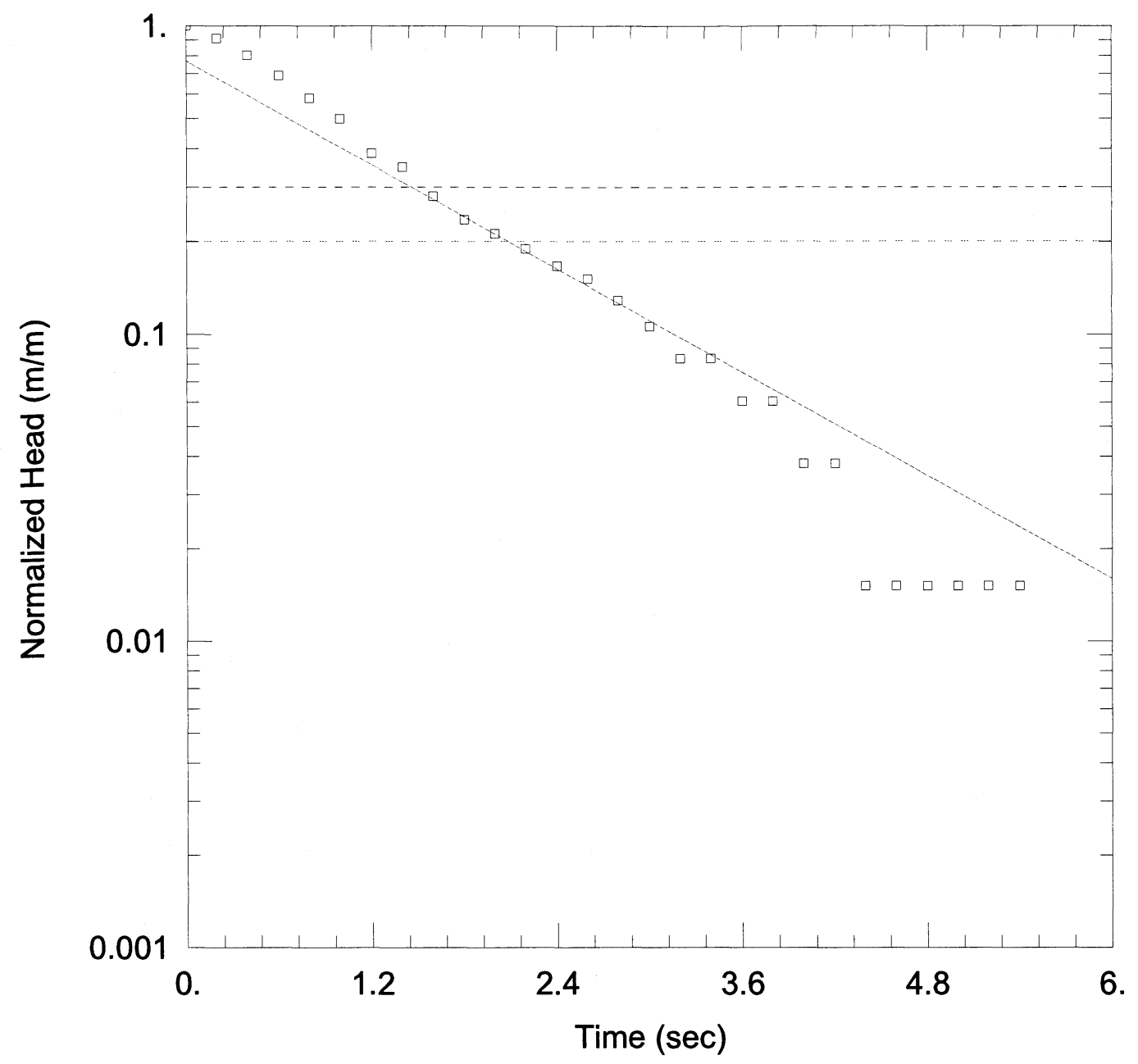

WELL TEST ANALYSIS

Data Set: E:I...IMW1_3.aqt

Date: $09 / 14 / 08$

Time: $12: 41: 44$

\section{PROJECT INFORMATION}

Company: University of Nebraska

Location: Injection Pilot Study

Test Well: MW-1

\section{AQUIFER DATA}

Saturated Thickness: $15.24 \mathrm{~m}$

Anisotropy Ratio (Kz/Kr): 1.

WELL DATA (MW-1)

Initial Displacement: 1. m

Total Well Penetration Depth: $7.616 \mathrm{~m}$

Casing Radius: $0.0254 \mathrm{~m}$
Static Water Column Height: $6.096 \mathrm{~m}$ Screen Length: $6.096 \mathrm{~m}$

Well Radius: $0.0254 \mathrm{~m}$
Aquifer Model: Unconfined

$\mathrm{K}=11.74 \mathrm{~m} /$ day
Solution Method: Bouwer-Rice

$\mathrm{y} 0=\underline{0.7684 \mathrm{~m}}$ 


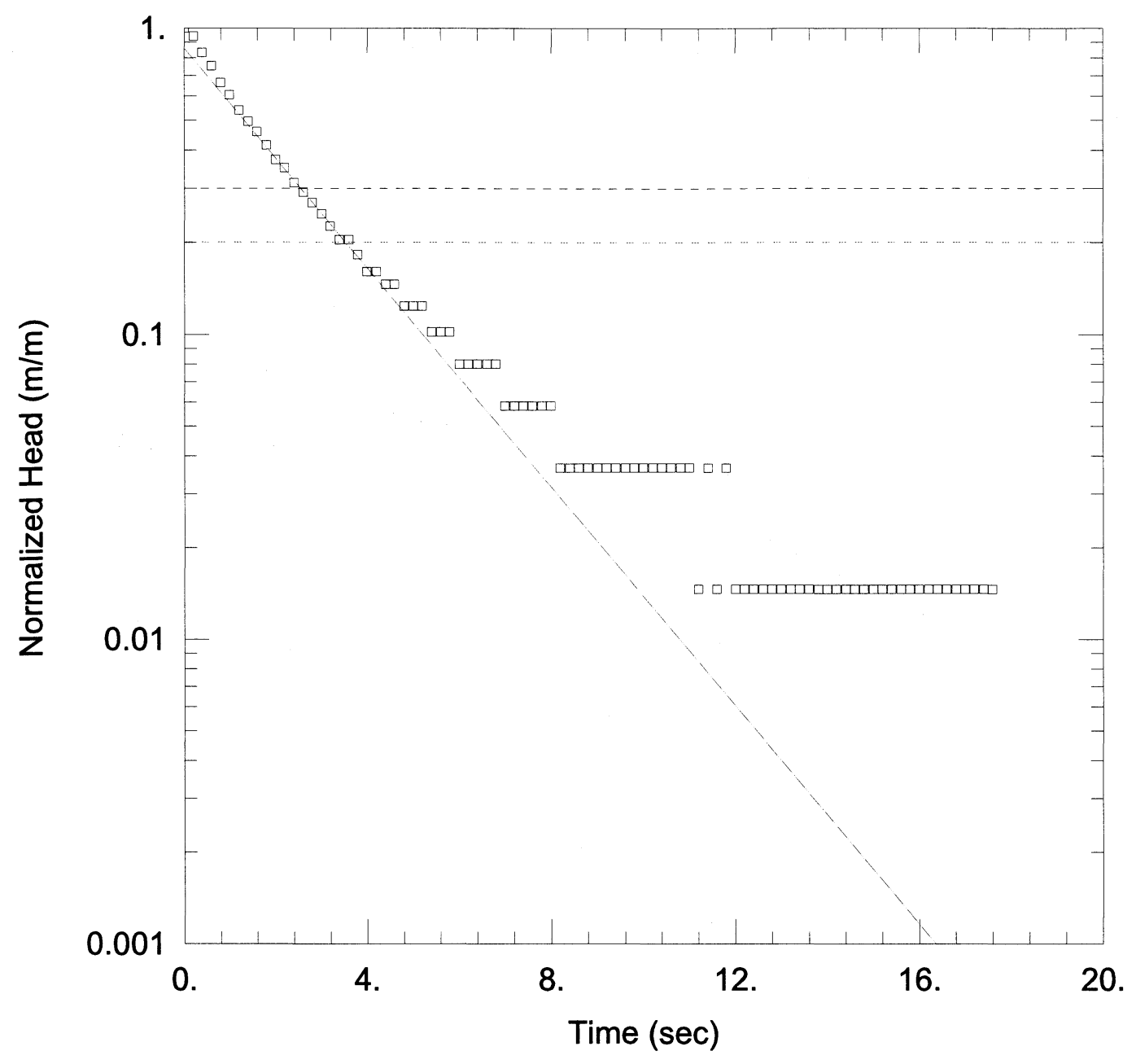

WELL TEST ANALYSIS

Data Set: E:I...MWW2_1.aqt

Date: $09 / 14 / 08$

Time: 15:15:42

\section{PROJECT INFORMATION}

Company: University of Nebraska

Location: Injection Pilot Study

Test Well: MW-2

\section{AQUIFER DATA}

Saturated Thickness: $15.24 \mathrm{~m}$

Anisotropy Ratio $(\mathrm{Kz} / \mathrm{Kr})$ : 1.

WELL DATA (MW-2)

Initial Displacement: $1 . \mathrm{m}$

Total Well Penetration Depth: $7.616 \mathrm{~m}$

Casing Radius: $0.0254 \mathrm{~m}$

Static Water Column Height: $6.096 \mathrm{~m}$ Screen Length: $6.096 \mathrm{~m}$

Well Radius: $0.0254 \mathrm{~m}$

\section{SOLUTION}

Aquifer Model: Unconfined

Solution Method: Bouwer-Rice

$\mathrm{K}=\underline{7.509} \mathrm{~m} / \mathrm{day}$ $\mathrm{y} 0=0.8594 \mathrm{~m}$ 


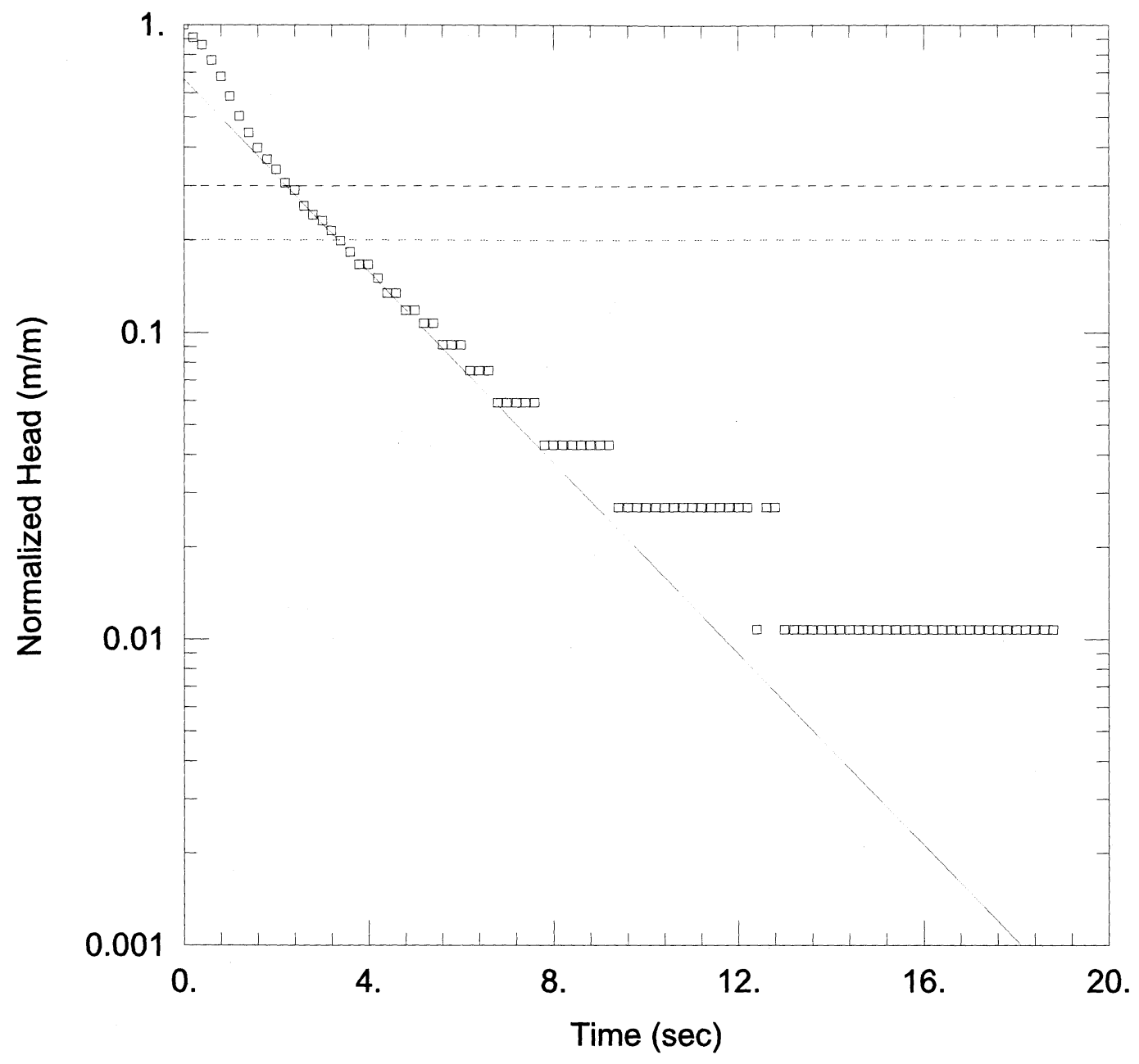

\section{WELL TEST ANALYSIS}

Data Set: E:1...MWW2_2.aqt

Date: $09 / 14 / 08$

Time: $15: 16: 24$

\section{PROJECT INFORMATION}

Company: University of Nebraska

Location: Injection Pilot Study

Test Well: MW-2

\section{AQUIFER DATA}

Saturated Thickness: $15.24 \mathrm{~m}$

Anisotropy Ratio $(\mathrm{Kz} / \mathrm{Kr}): 1$.

\section{WELL DATA (MW-2)}

Initial Displacement: $1 . \mathrm{m}$

Total Well Penetration Depth: $7.616 \mathrm{~m}$

Casing Radius: $0.0254 \mathrm{~m}$
Static Water Column Height: $6.096 \mathrm{~m}$ Screen Length: $6.096 \mathrm{~m}$

Well Radius: $0.0254 \mathrm{~m}$

\section{SOLUTION}

Aquifer Model: Unconfined

Solution Method: Bouwer-Rice

$\mathrm{K}=6.528 \mathrm{~m} / \mathrm{day}$

y0 $=0.6651 \mathrm{~m}$ 


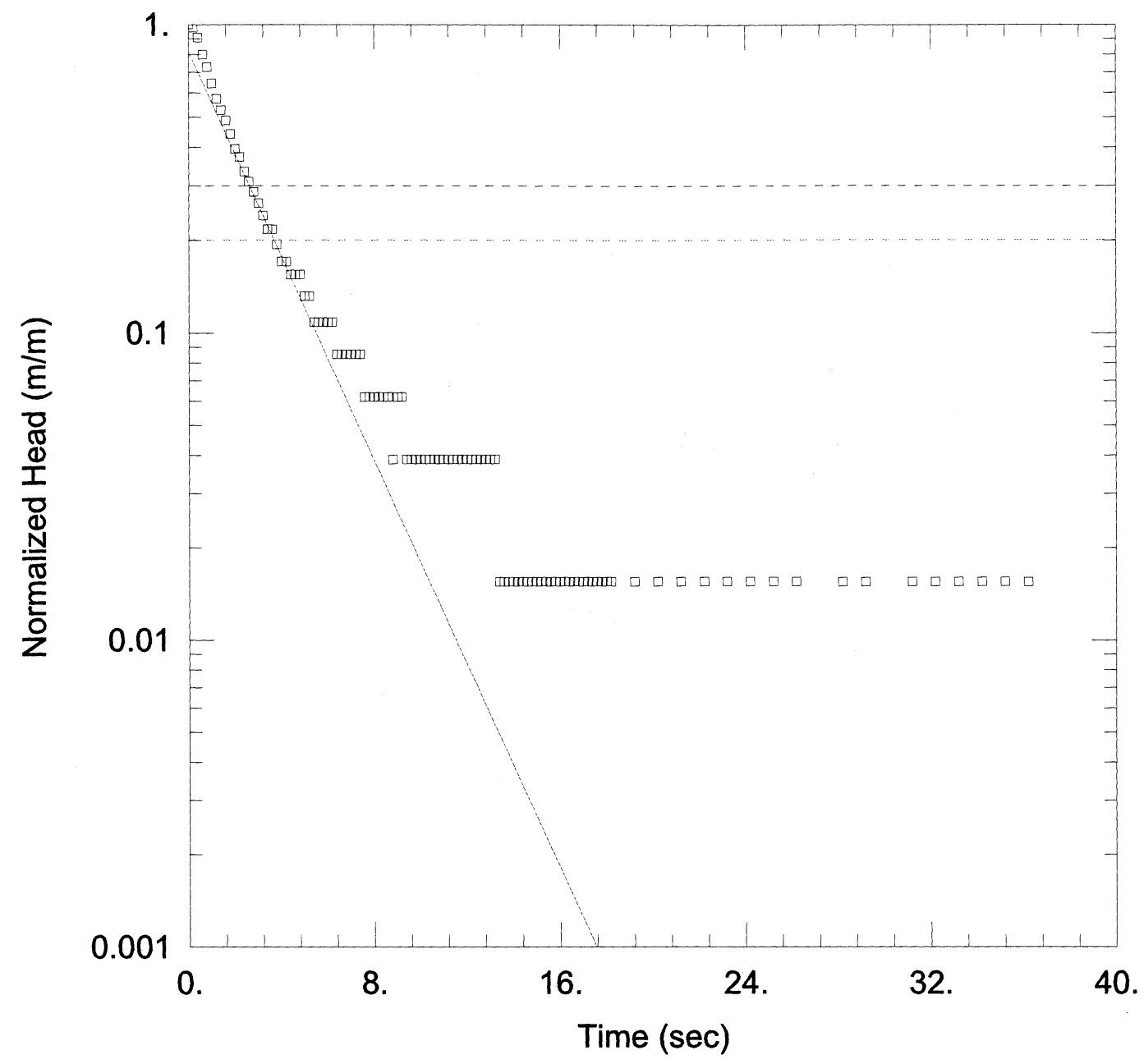

\section{WELL TEST ANALYSIS}

Data Set: E:I...MW2_3.aqt

Date: $09 / 14 / 08$

Time: 12:39:57

\section{PROJECT INFORMATION}

Company: University of Nebraska

Location: Injection Pilot Study

Test Well: MW-1

\section{AQUIFER DATA}

Saturated Thickness: $15.24 \mathrm{~m}$

Anisotropy Ratio (Kz/Kr): 1.

\section{WELL DATA (MW-2)}

Initial Displacement: 1. m

Total Well Penetration Depth: $7.616 \mathrm{~m}$

Casing Radius: $0.0254 \mathrm{~m}$
Static Water Column Height: $6.096 \mathrm{~m}$

Screen Length: $6.096 \mathrm{~m}$

Well Radius: $0.0254 \mathrm{~m}$

\section{SOLUTION}

Aquifer Model: Unconfined

Solution Method: Bouwer-Rice

$\mathrm{K}=\underline{6.943} \mathrm{~m} / \mathrm{day}$

$\mathrm{y} 0=0.8134 \mathrm{~m}$ 


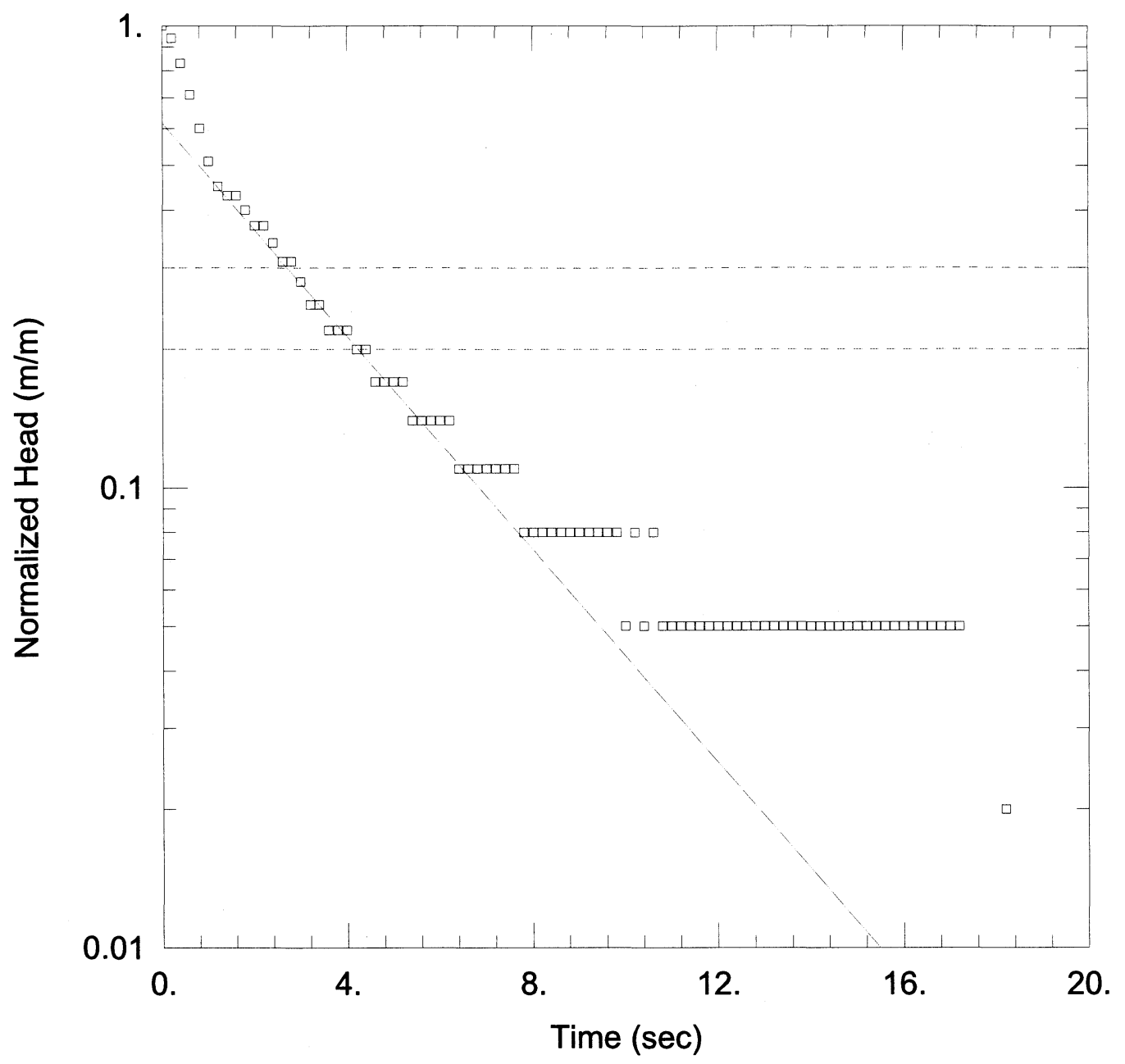

WELL TEST ANALYSIS

Data Set: E:I...IMW3_1.aqt

Date: $09 / 14 / 08$

Time: 15:17:04

\section{PROJECT INFORMATION}

Company: University of Nebraska

Location: Injection Pilot Study

Test Well: MW-3

\section{AQUIFER DATA}

Saturated Thickness: $15.24 \mathrm{~m}$

Anisotropy Ratio (Kz/Kr): 1.

WELL DATA (MW-3)

Initial Displacement: 1. m

Total Well Penetration Depth: $7.616 \mathrm{~m}$

Casing Radius: $0.0254 \mathrm{~m}$
Static Water Column Height: $6.096 \mathrm{~m}$ Screen Length: $6.096 \mathrm{~m}$

Well Radius: $0.0254 \mathrm{~m}$

\section{SOLUTION}

Aquifer Model: Unconfined

Solution Method: Bouwer-Rice

$\mathrm{K}=4.838 \mathrm{~m} /$ day

y0 $=\underline{0.6162} \mathrm{~m}$ 


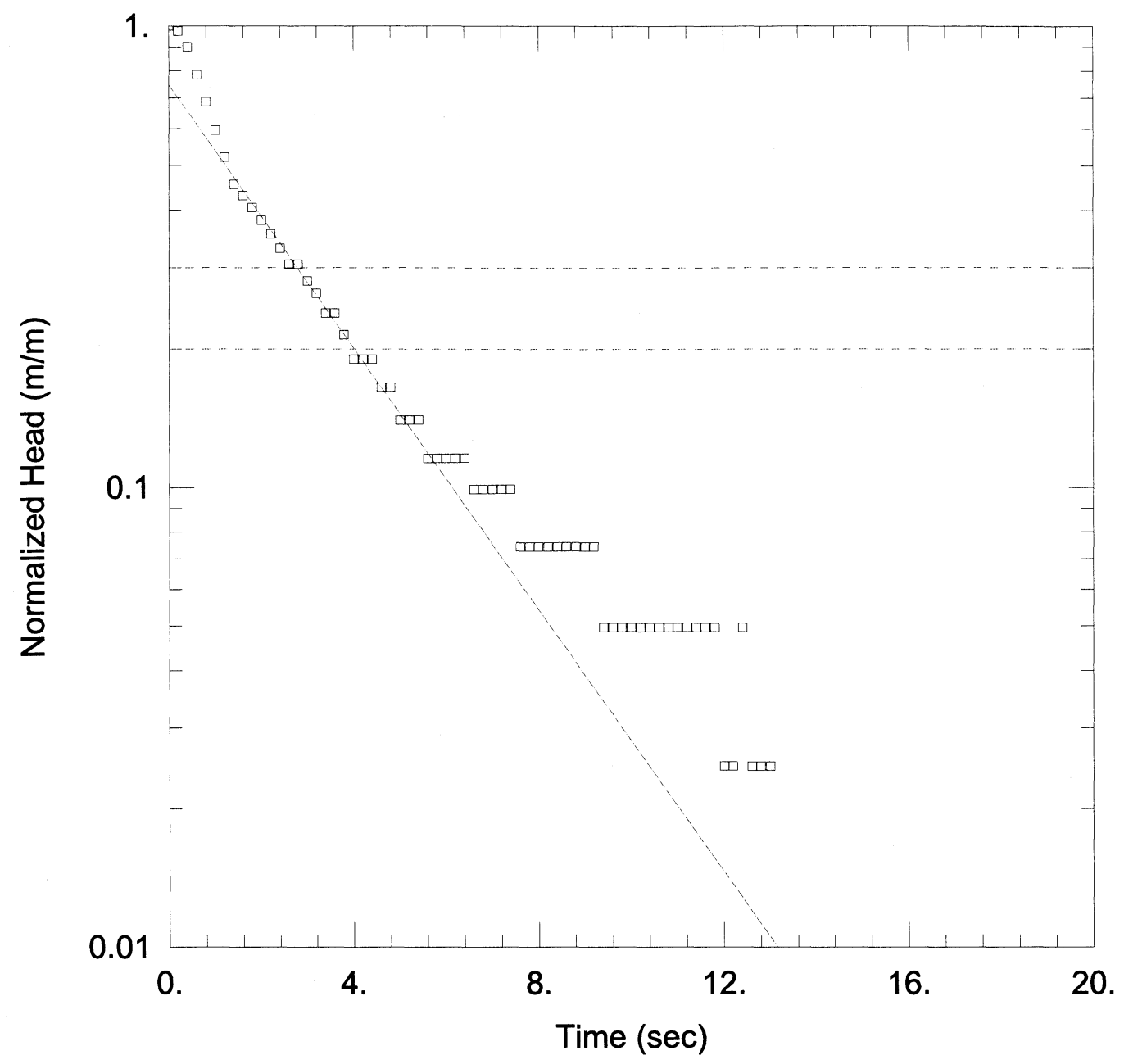

\section{WELL TEST ANALYSIS}

Data Set: E:I...IMW3_2.aqt

Date: $09 / 14 / 08$

Time: 15:17:55

\section{PROJECT INFORMATION}

Company: University of Nebraska

Location: Injection Pilot Study

Test Well: MW-3

\section{AQUIFER DATA}

Saturated Thickness: $15.24 \mathrm{~m}$

Anisotropy Ratio (Kz/Kr): 1.

WELL DATA (MW-3)

Initial Displacement: 1. m

Total Well Penetration Depth: $7.616 \mathrm{~m}$

Casing Radius: $0.0254 \mathrm{~m}$
Static Water Column Height: $6.096 \mathrm{~m}$

Screen Length: $6.096 \mathrm{~m}$

Well Radius: $0.0254 \mathrm{~m}$

Aquifer Model: Unconfined

Solution Method: Bouwer-Rice

$\mathrm{K}=5.96 \mathrm{~m} / \mathrm{day}$

y0 $=0.7458 \mathrm{~m}$ 


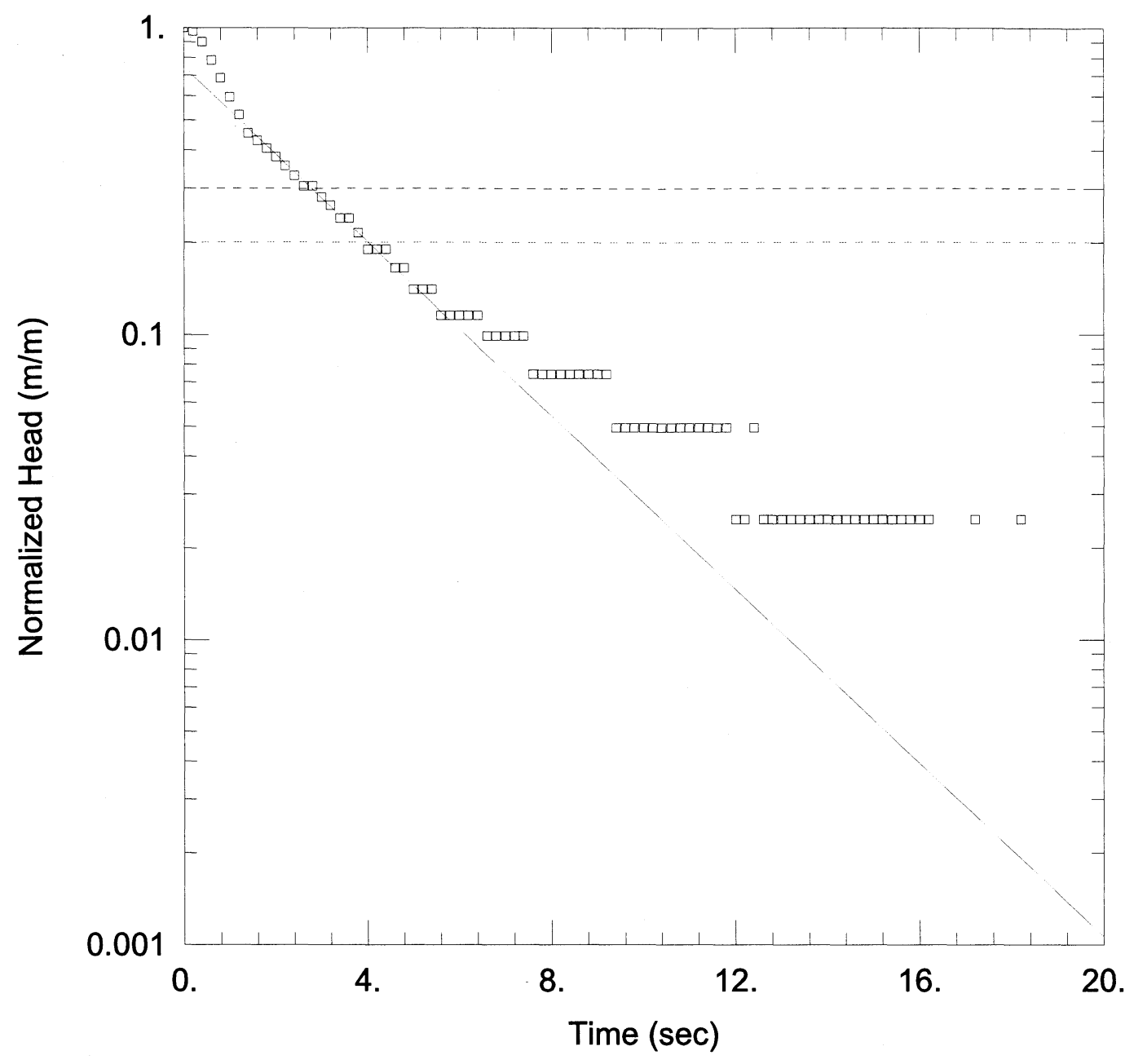

WELL TEST ANALYSIS

Data Set: E:I...MW3_3.aqt

Date: $09 / 14 / 08$

Time: 15:18:36

PROJECT INFORMATION

Company: University of Nebraska

Location: Injection Pilot Study

Test Well: MW-3

\section{AQUIFER DATA}

Saturated Thickness: $15.24 \mathrm{~m}$

Anisotropy Ratio (Kz/Kr): 1.

WELL DATA (MW-3)

Initial Displacement: $1 . \mathrm{m}$

Total Well Penetration Depth: $7.616 \mathrm{~m}$

Static Water Column Height: $6.096 \mathrm{~m}$

Casing Radius: $0.0254 \mathrm{~m}$ Screen Length: $6.096 \mathrm{~m}$

Well Radius: $0.0254 \mathrm{~m}$

\section{SOLUTION}

Aquifer Model: Unconfined

Solution Method: Bouwer-Rice

$\mathrm{K}=5.96 \mathrm{~m} /$ day

$\mathrm{y} 0=0.7458 \mathrm{~m}$ 


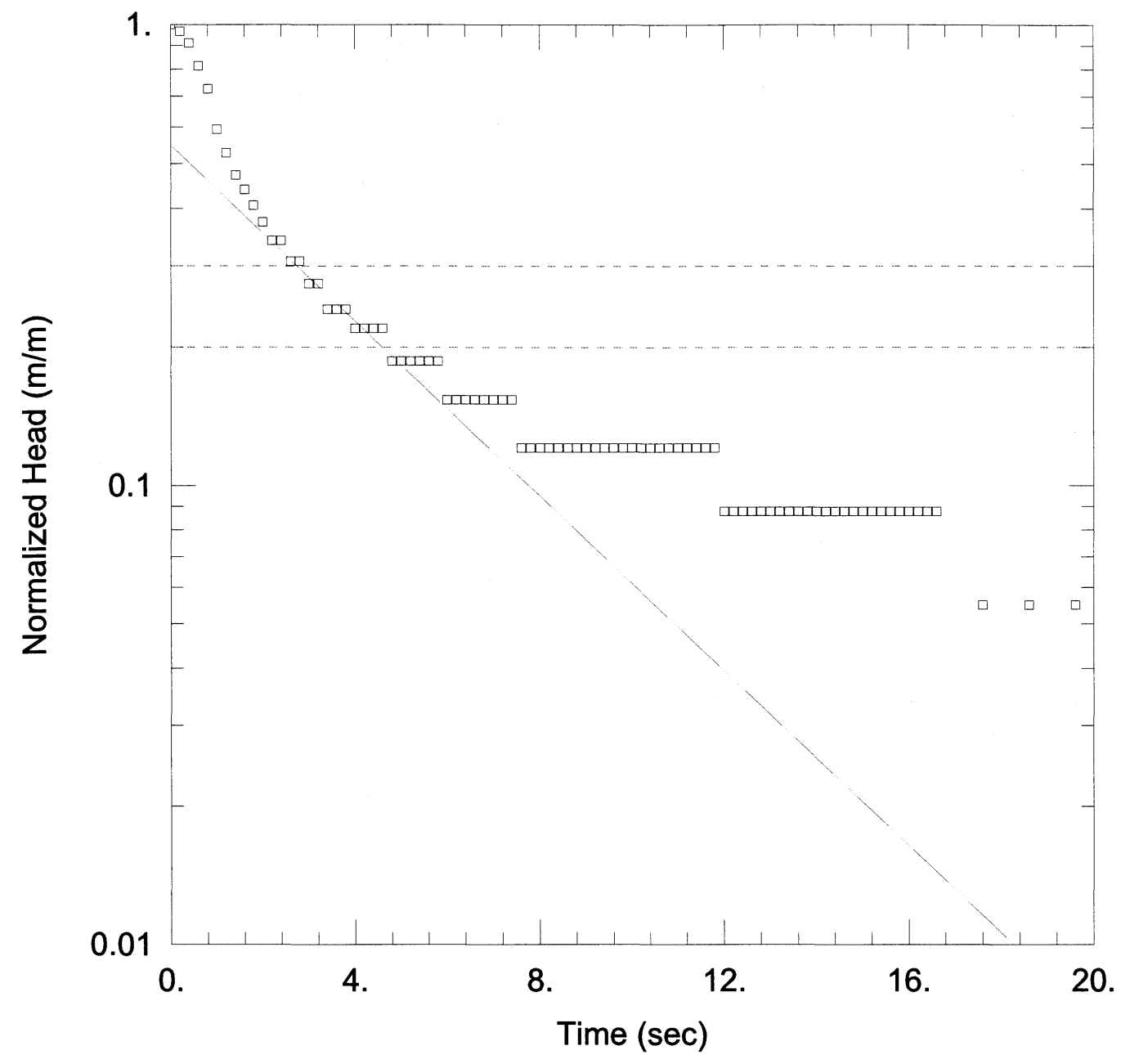

\section{WELL TEST ANALYSIS}

Data Set: E:I...IMW4_1.aqt

Date: $09 / 14 / 08$

Time: 15:19:07

\section{PROJECT INFORMATION}

Company: University of Nebraska

Location: Injection Pilot Study

Test Well: MW-4

\section{AQUIFER DATA}

Saturated Thickness: $15.24 \mathrm{~m}$

Anisotropy Ratio (Kz/Kr): 1.

\section{WELL DATA (MW-4)}

Initial Displacement: 1. m

Total Well Penetration Depth: $7.616 \mathrm{~m}$

Casing Radius: $0.0254 \mathrm{~m}$
Static Water Column Height: $6.096 \mathrm{~m}$

Screen Length: $6.096 \mathrm{~m}$

Well Radius: $0.0254 \mathrm{~m}$

\section{SOLUTION}

Aquifer Model: Unconfined

Solution Method: Bouwer-Rice

$\mathrm{K}=3.985 \mathrm{~m} /$ day

y0 $=0.5477 \mathrm{~m}$ 


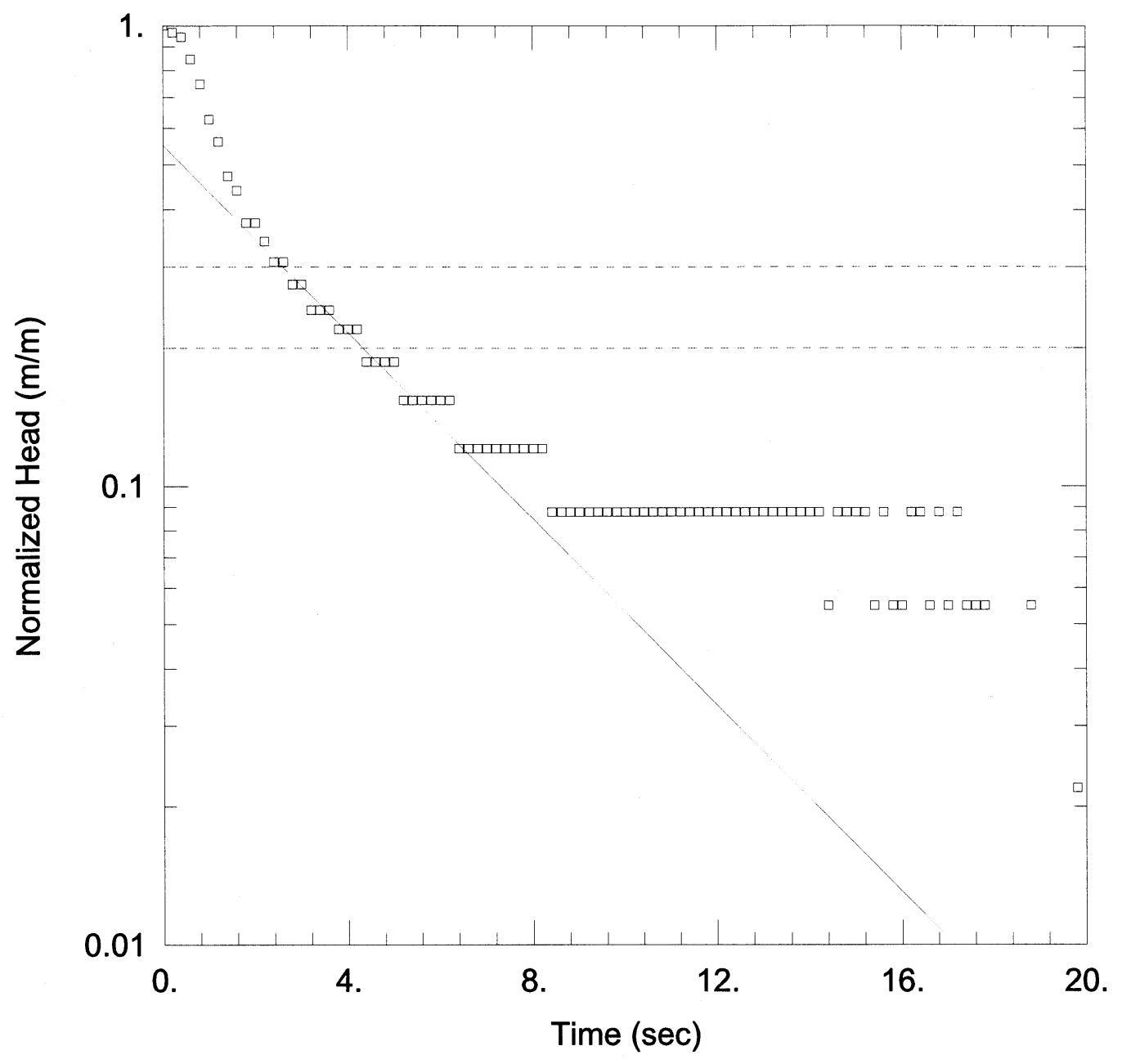

Data Set: E:I...MW4_2.aqt

Date: $09 / 14 / 08$

WELL TEST ANALYSIS

Time: 15:19:52

\section{PROJECT INFORMATION}

Company: University of Nebraska

Location: Injection Pilot Study

Test Well: MW-4

\section{AQUIFER DATA}

Saturated Thickness: $15.24 \mathrm{~m}$

Anisotropy Ratio (Kz/Kr): 1.

WELL DATA (MW-4)

Initial Displacement: 1. m

Total Well Penetration Depth: $7.616 \mathrm{~m}$

Casing Radius: $0.0254 \mathrm{~m}$
Static Water Column Height: $6.096 \mathrm{~m}$ Screen Length: $6.096 \mathrm{~m}$

Well Radius: $0.0254 \mathrm{~m}$

\section{SOLUTION}

Aquifer Model: Unconfined

Solution Method: Bouwer-Rice

$\mathrm{K}=4.251 \mathrm{~m} /$ day

$\mathrm{y} 0=0.5505 \mathrm{~m}$ 


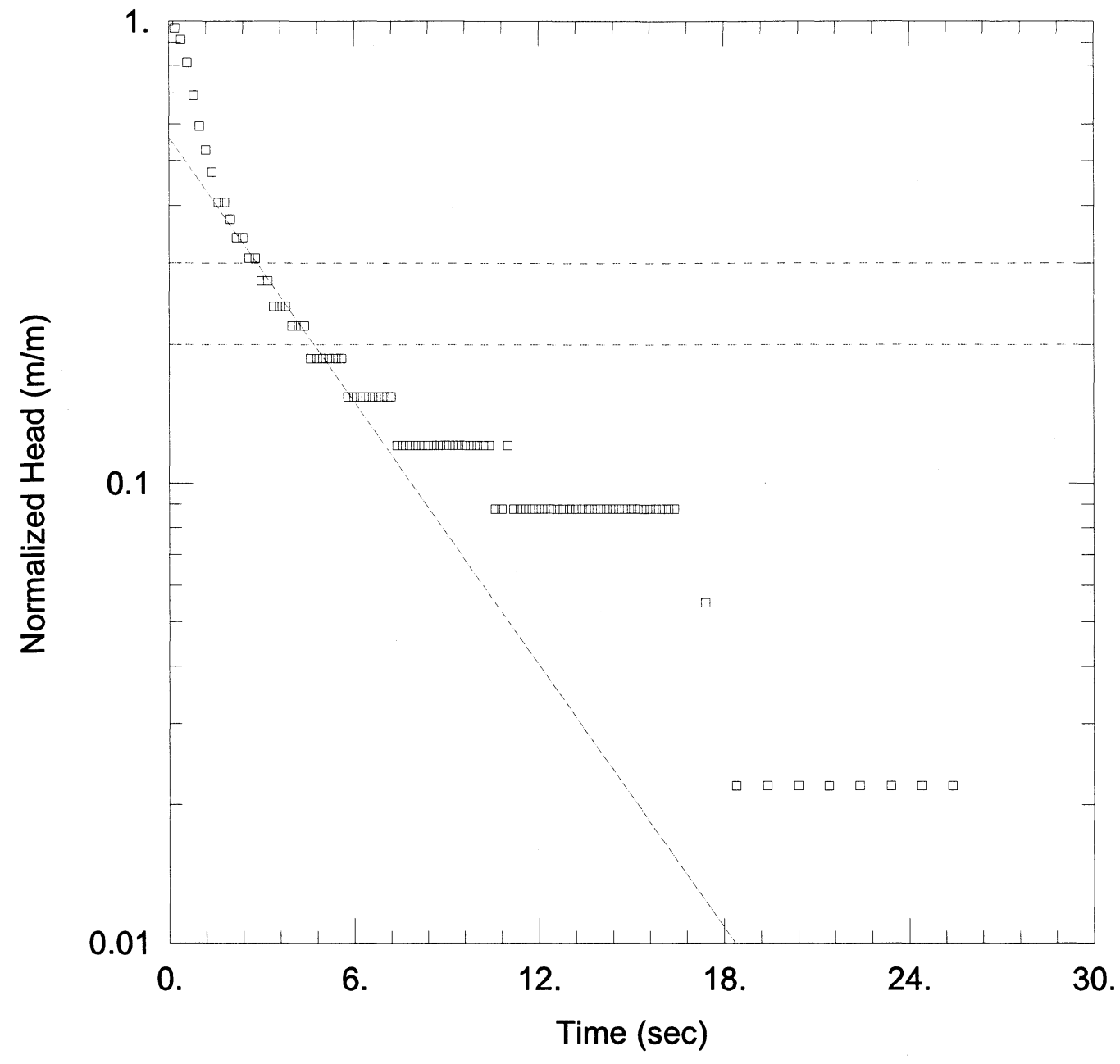

\section{WELL TEST ANALYSIS}

Data Set: E:I...IMW4_3.aqt

Date: $09 / 14 / 08$
Time: $15: 20: 48$

\section{PROJECT INFORMATION}

Company: University of Nebraska

Location: Injection Pilot Study

Test Well: MW-4

\section{AQUIFER DATA}

Saturated Thickness: $15.24 \mathrm{~m}$

Anisotropy Ratio $(\mathrm{Kz} / \mathrm{Kr})$ : 1.

\section{WELL DATA (MW-4)}

Initial Displacement: $1 . \mathrm{m}$

Total Well Penetration Depth: $7.616 \mathrm{~m}$

Casing Radius: $0.0254 \mathrm{~m}$
Static Water Column Height: $6.096 \mathrm{~m}$

Screen Length: $6.096 \mathrm{~m}$

Well Radius: $0.0254 \mathrm{~m}$

\section{SOLUTION}

Aquifer Model: Unconfined

$\mathrm{K}=3.988 \mathrm{~m} / \mathrm{day}$
Solution Method: Bouwer-Rice

$\mathrm{y} 0=0.5608 \mathrm{~m}$ 


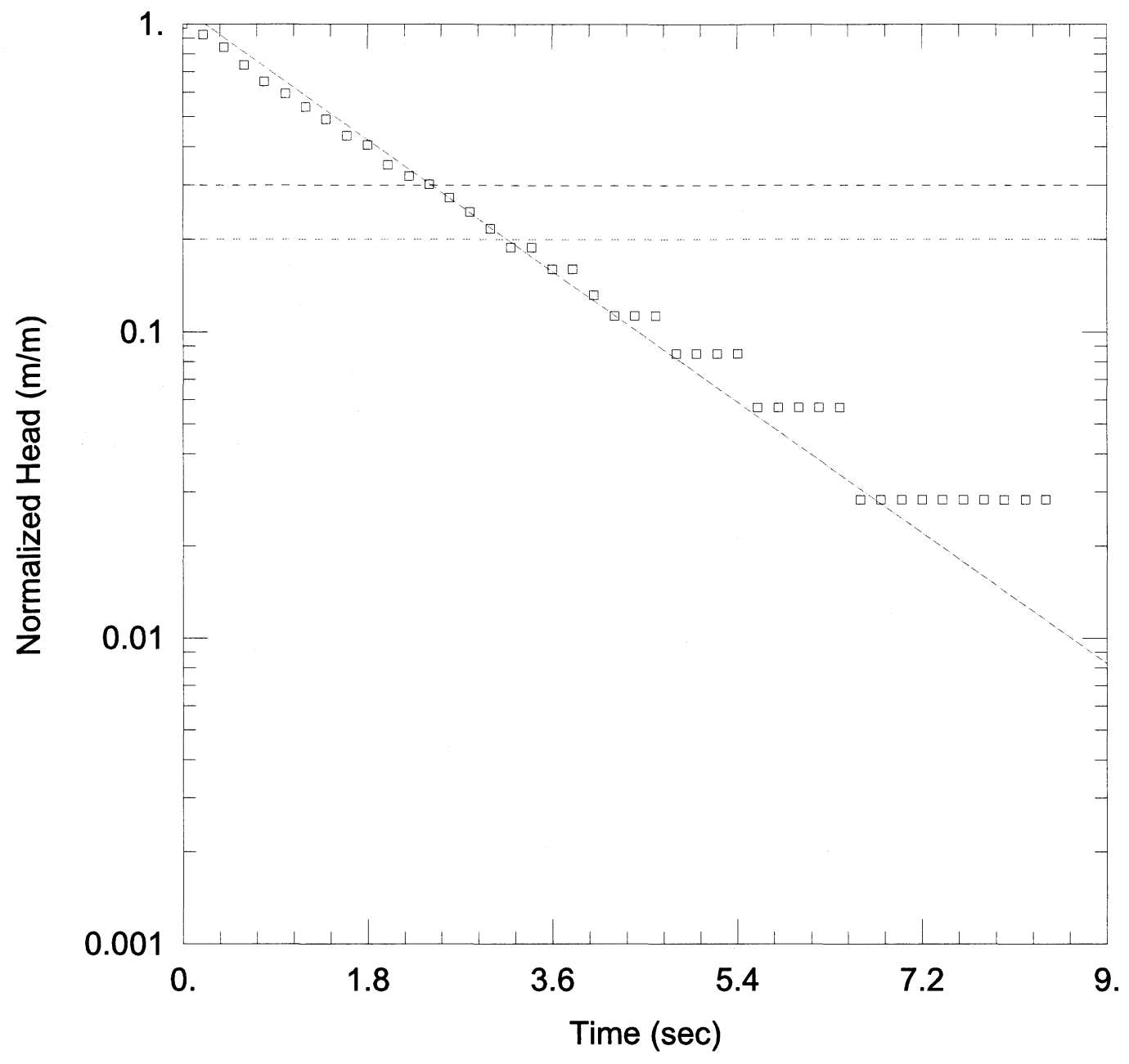

WELL TEST ANALYSIS

Data Set: E:I...IMW5_1.aqt

Date: $09 / 14 / 08$

Time: $15: 21: 34$

PROJECT INFORMATION

Company: University of Nebraska

Location: Injection Pilot Study

Test Well: MW-5

\section{AQUIFER DATA}

Saturated Thickness: $15.24 \mathrm{~m}$

Anisotropy Ratio (Kz/Kr): 1.

WELL DATA (MW-5)

Initial Displacement: 1. m

Total Well Penetration Depth: $7.616 \mathrm{~m}$

Static Water Column Height: $6.096 \mathrm{~m}$

Screen Length: $6.096 \mathrm{~m}$

Casing Radius: $0.0254 \mathrm{~m}$

Well Radius: $0.0254 \mathrm{~m}$

\section{SOLUTION}

Aquifer Model: Unconfined

Solution Method: Bouwer-Rice

$\mathrm{K}=9.933 \mathrm{~m} / \mathrm{day}$

$\mathrm{y} 0=1.128 \mathrm{~m}$ 


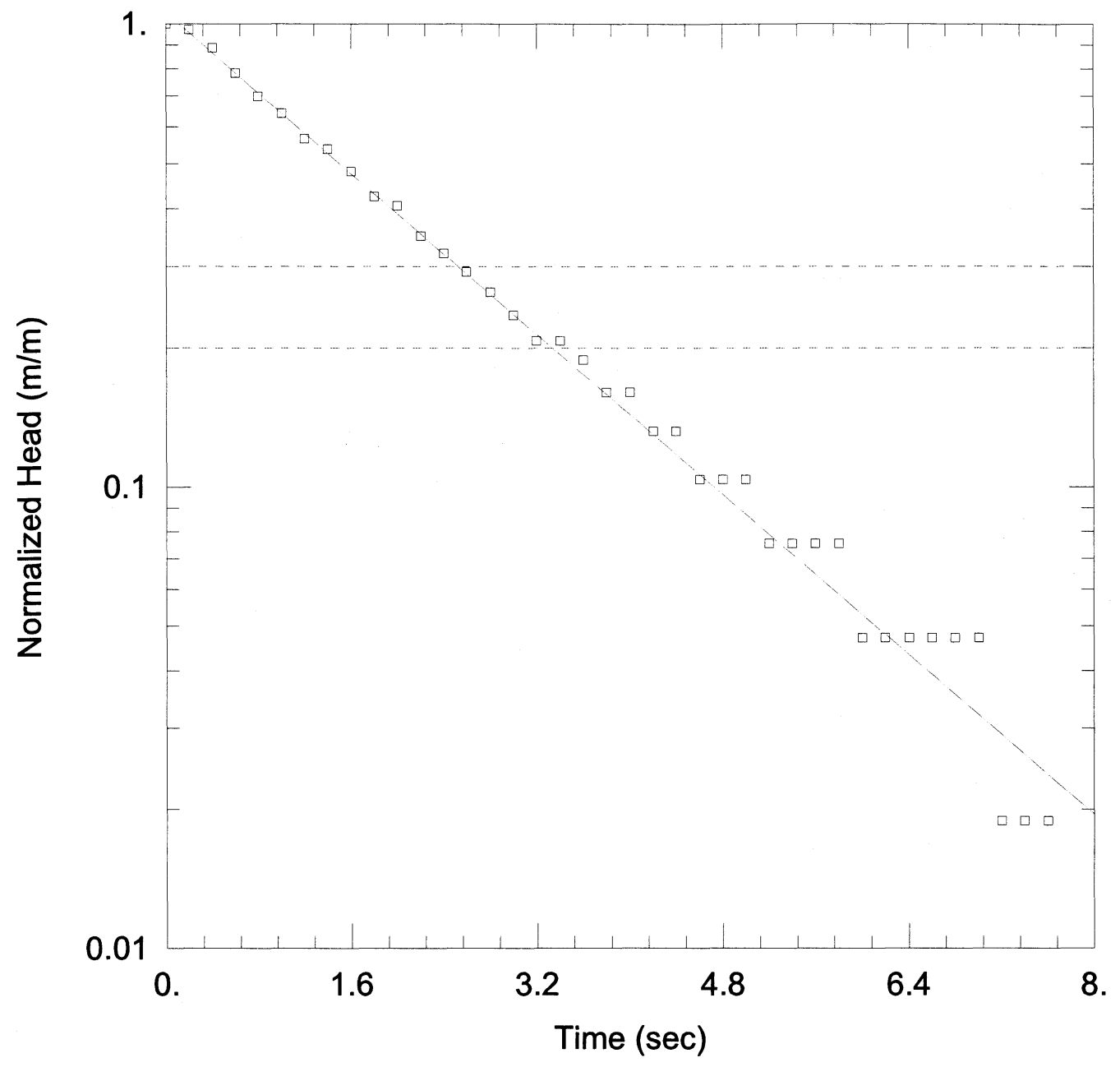

\section{WELL TEST ANALYSIS}

Data Set: E:I...IMW5 2.aqt

Date: $09 / 14 / 08$

Time: 15:22:07

\section{PROJECT INFORMATION}

Company: University of Nebraska

Location: Injection Pilot Study

Test Well: MW-5

\section{AQUIFER DATA}

Saturated Thickness: $15.24 \mathrm{~m}$

Anisotropy Ratio (Kz/Kr): 1.

WELL DATA (MW-5)

Initial Displacement: 1. m

Total Well Penetration Depth: $7.616 \mathrm{~m}$

Casing Radius: $0.0254 \mathrm{~m}$
Static Water Column Height: 6.096 m Screen Length: $6.096 \mathrm{~m}$

Well Radius: $0.0254 \mathrm{~m}$
Aquifer Model: Unconfined

$K=9.073 \mathrm{~m} / \mathrm{day}$
Solution Method: Bouwer-Rice

$\mathrm{y} 0=1.057 \mathrm{~m}$ 


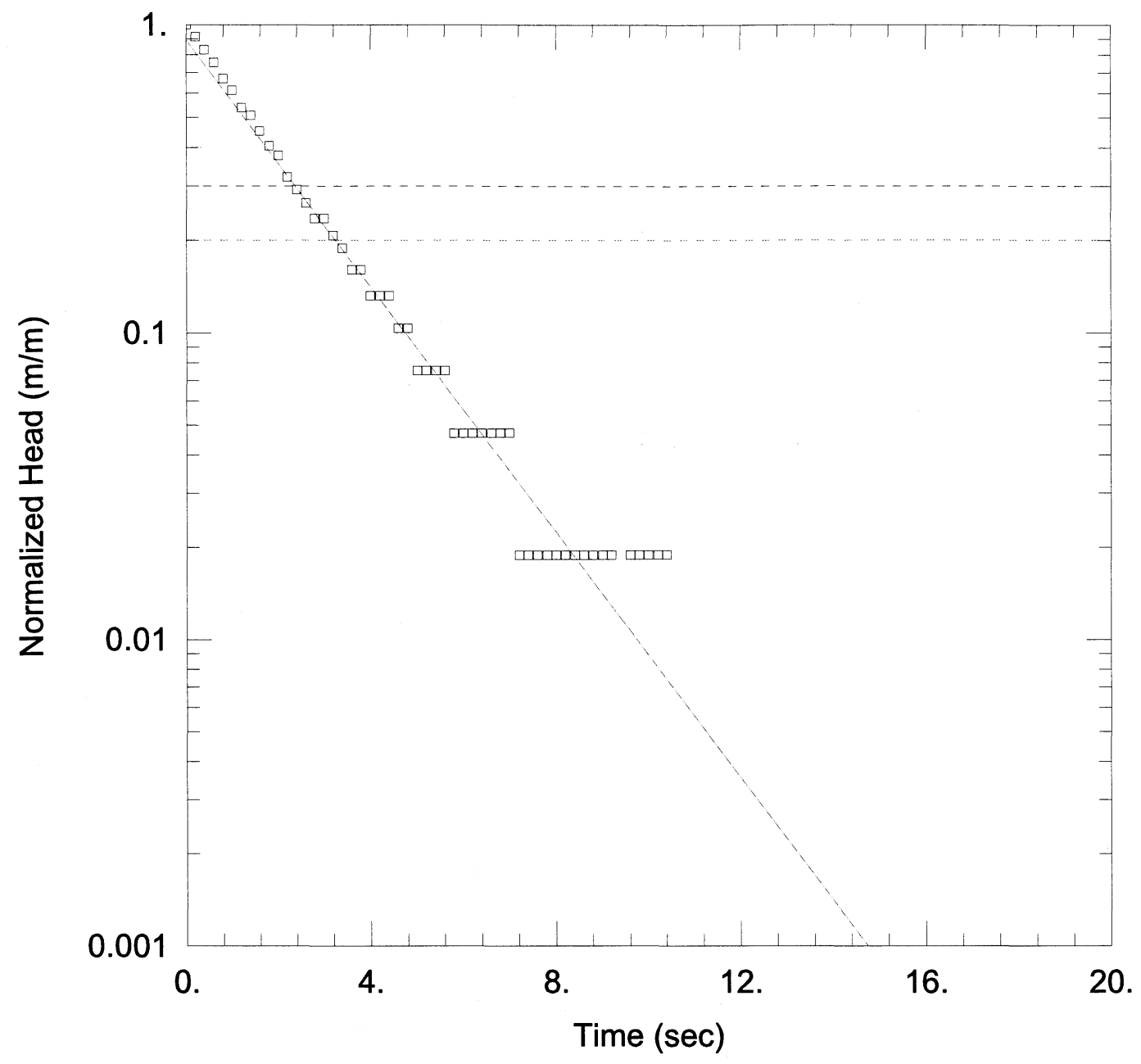

\section{WELL TEST ANALYSIS}

Data Set: E:I...IMW5_3.aqt

Date: 09/14/08
Time: 15:23:50

\section{PROJECT INFORMATION}

Company: University of Nebraska Location: Injection Pilot Study

Test Well: MW-5

\section{AQUIFER DATA}

Saturated Thickness: $15.24 \mathrm{~m}$

Anisotropy Ratio (Kz/Kr): 1.

WELL DATA (MW-5)

Initial Displacement: 1. m

Total Well Penetration Depth: $7.616 \mathrm{~m}$

Casing Radius: $0.0254 \mathrm{~m}$
Static Water Column Height: $6.096 \mathrm{~m}$

Screen Length: $6.096 \mathrm{~m}$

Well Radius: $0.0254 \mathrm{~m}$

\section{SOLUTION}

Aquifer Model: Unconfined

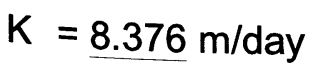

Solution Method: Bouwer-Rice

y0 $=0.8913 \mathrm{~m}$ 


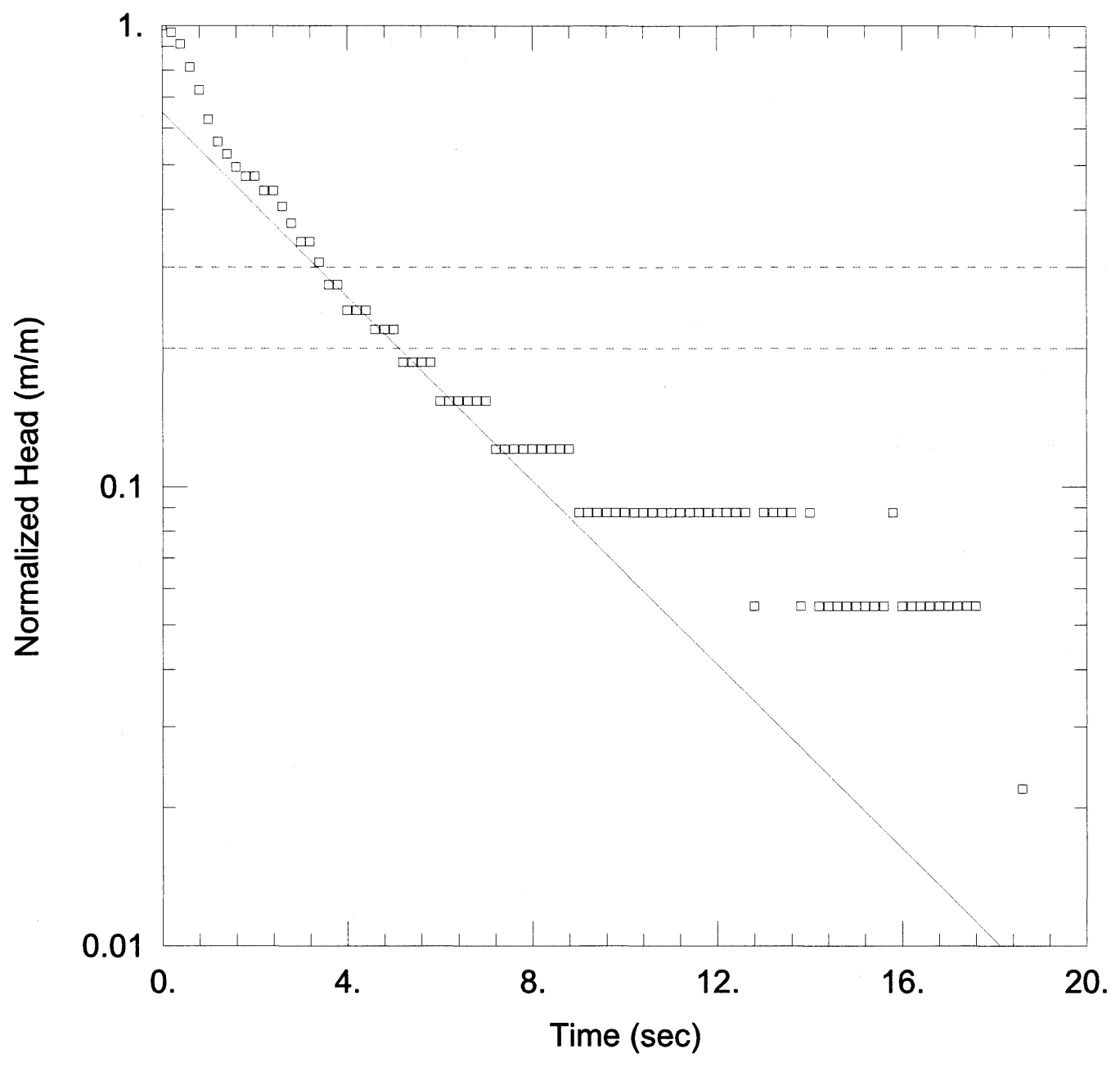

\section{WELL TEST ANALYSIS}

Data Set: E:I...IMW6_1.aqt

Date: $09 / 14 / 08$

Time: 15:24:34

\section{PROJECT INFORMATION}

Company: University of Nebraska

Location: Injection Pilot Study

Test Well: MW-6

\section{AQUIFER DATA}

Saturated Thickness: $15.24 \mathrm{~m}$

Anisotropy Ratio (Kz/Kr): 1.

WELL DATA (MW-6)

Initial Displacement: 1. m

Total Well Penetration Depth: $7.616 \mathrm{~m}$

Casing Radius: $0.0254 \mathrm{~m}$
Static Water Column Height: $6.096 \mathrm{~m}$ Screen Length: $6.096 \mathrm{~m}$

Well Radius: $0.0254 \mathrm{~m}$

\section{SOLUTION}

Aquifer Model: Unconfined

Solution Method: Bouwer-Rice

$\mathrm{K}=4.188 \mathrm{~m} / \mathrm{day}$

$\mathrm{y} 0=\underline{0.6494 \mathrm{~m}}$ 


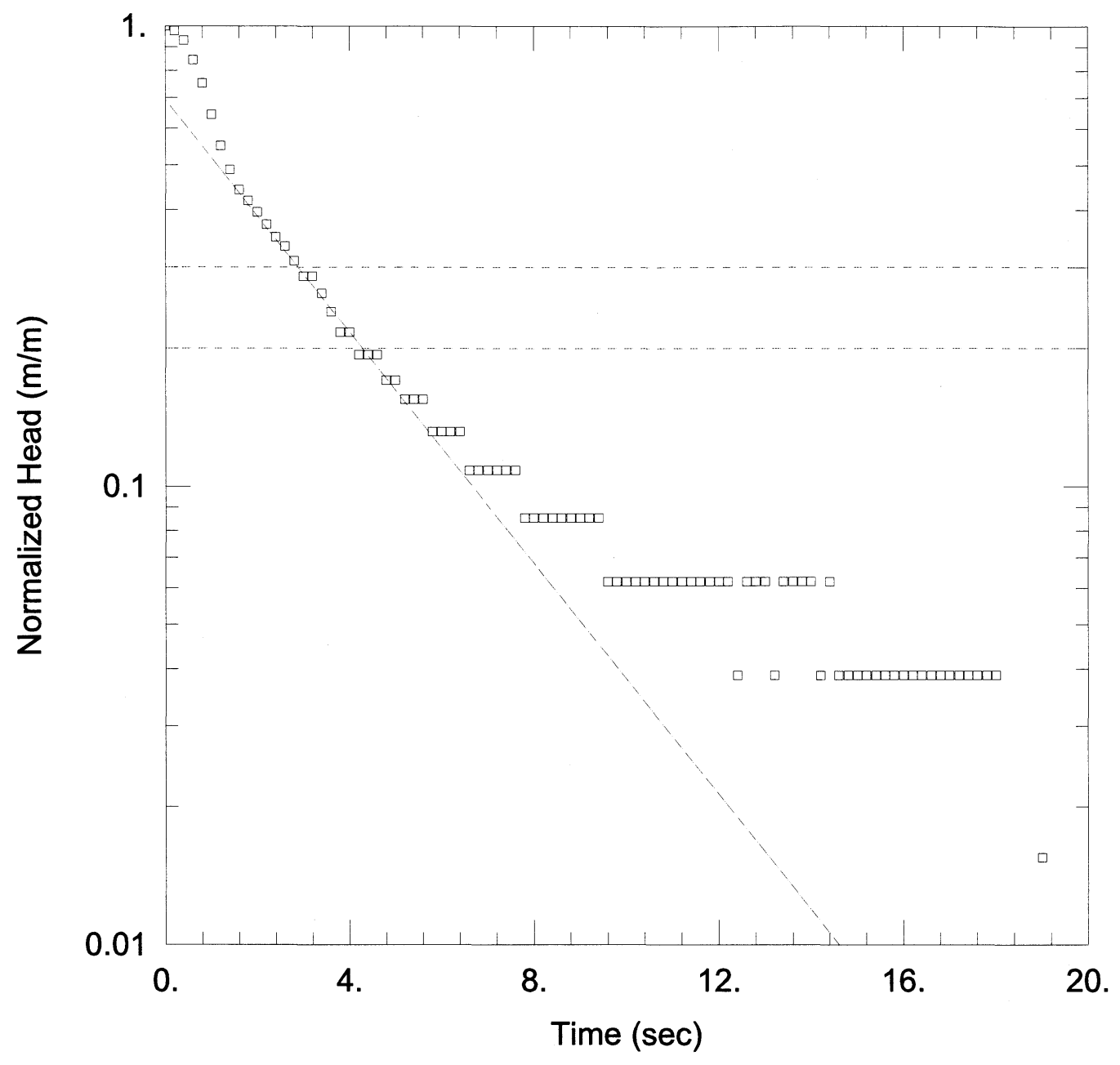

WELL TEST ANALYSIS

Data Set: E:I...IMW6_2.aqt

Date: 09/14/08

Time: $15: 25: 29$

PROJECT INFORMATION

Company: University of Nebraska

Location: Injection Pilot Study

Test Well: MW-6

\section{AQUIFER DATA}

Saturated Thickness: $15.24 \mathrm{~m}$

Anisotropy Ratio (Kz/Kr): 1.

WELL DATA (MW-6)

Initial Displacement: $1 . \mathrm{m}$

Total Well Penetration Depth: $\underline{7.616} \mathrm{~m}$

Static Water Column Height: $6.096 \mathrm{~m}$

Casing Radius: $0.0254 \mathrm{~m}$

Screen Length: $6.096 \mathrm{~m}$

Well Radius: $0.0254 \mathrm{~m}$

\section{SOLUTION}

Aquifer Model: Unconfined

Solution Method: Bouwer-Rice

$\mathrm{K}=5.273 \mathrm{~m} /$ day

y0 $=0.6915 \mathrm{~m}$ 


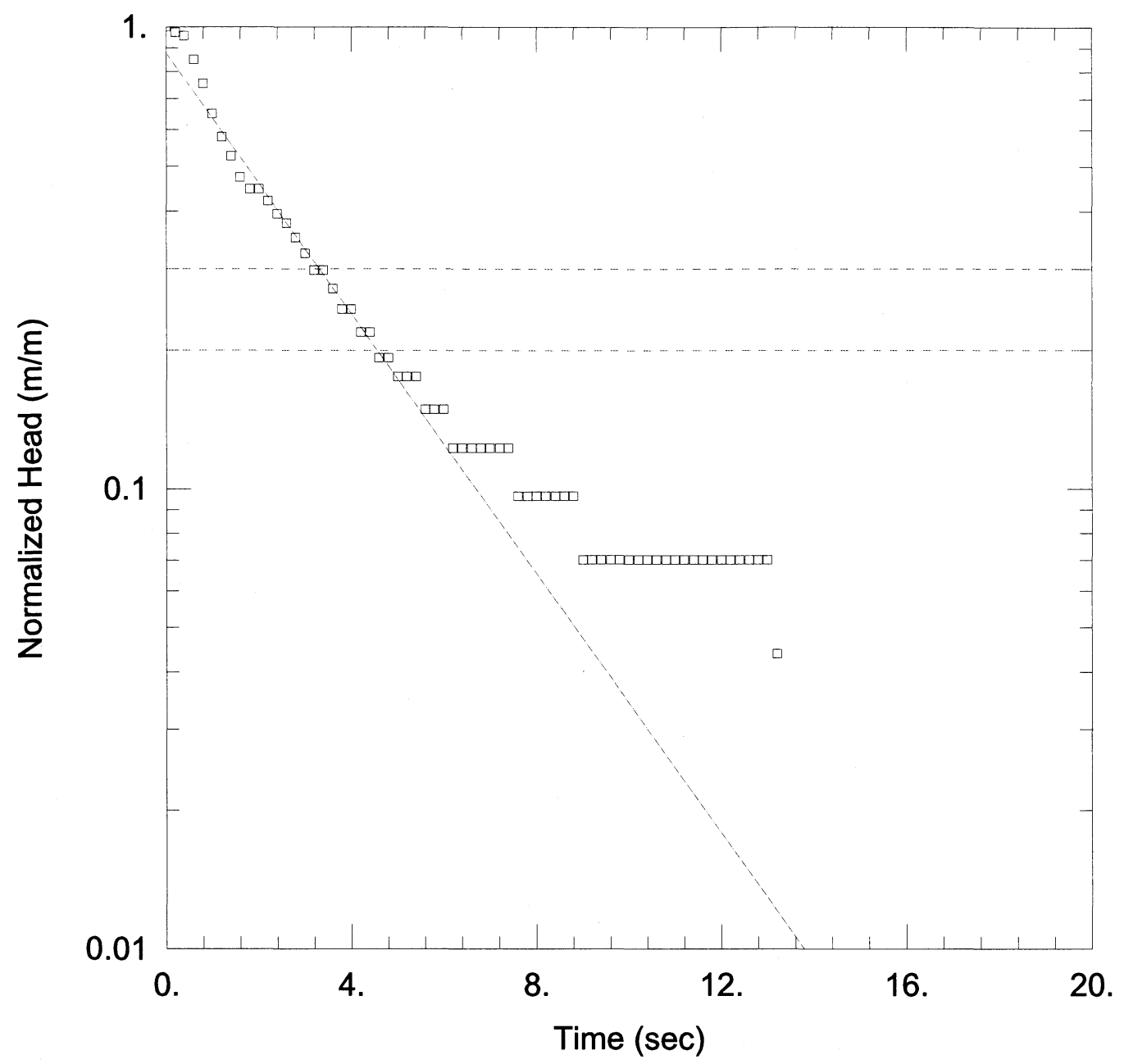

\section{WELL TEST ANALYSIS}

Data Set: E:I...MW6_3.aqt

Date: $09 / 14 / 08$

Time: 15:26:09

\section{PROJECT INFORMATION}

Company: University of Nebraska

Location: Injection Pilot Study

Test Well: MW-6

\section{AQUIFER DATA}

Saturated Thickness: $15.24 \mathrm{~m}$

Anisotropy Ratio (Kz/Kr): 1.

\section{WELL DATA (MW-6)}

Initial Displacement: 1. m

Total Well Penetration Depth: $7.616 \mathrm{~m}$

Casing Radius: $0.0254 \mathrm{~m}$
Static Water Column Height: $6.096 \mathrm{~m}$ Screen Length: $6.096 \mathrm{~m}$

Well Radius: $0.0254 \mathrm{~m}$

\section{SOLUTION}

Aquifer Model: Unconfined

$\mathrm{K}=5.901 \mathrm{~m} / \mathrm{day}$
Solution Method: Bouwer-Rice

y0 $=0.8778 \mathrm{~m}$ 


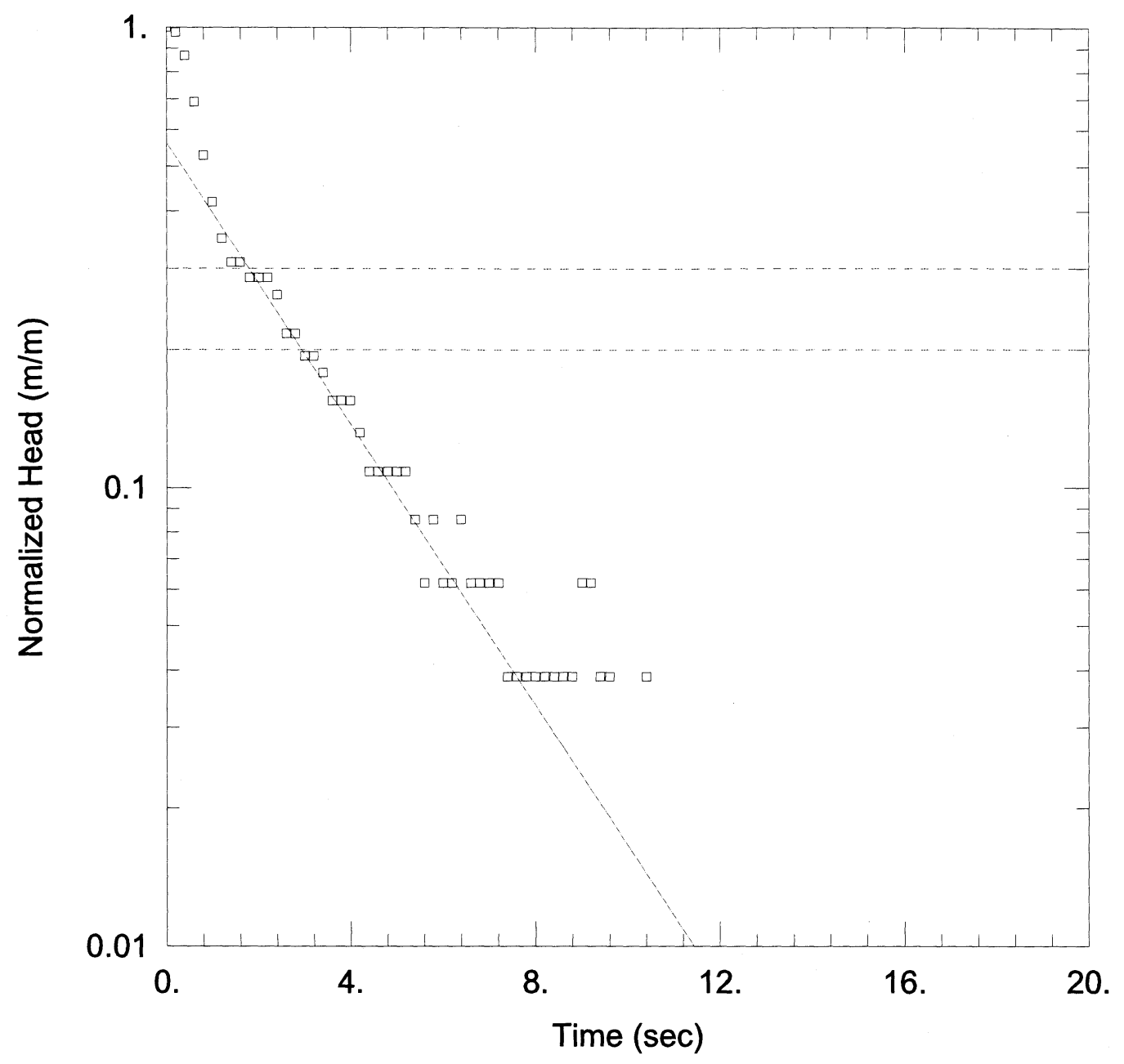

WELL TEST ANALYSIS

Data Set: E:I...MW7_1.aqt

Date: $09 / 14 / 08$

Time: $15: 26: 48$

\section{PROJECT INFORMATION}

Company: University of Nebraska

Location: Injection Pilot Study

Test Well: MW-7

\section{AQUIFER DATA}

Saturated Thickness: $15.24 \mathrm{~m}$

Anisotropy Ratio (Kz/Kr): 1.

\section{WELL DATA (MW-7)}

Initial Displacement: 1. m

Total Well Penetration Depth: $7.616 \mathrm{~m}$

Casing Radius: $0.0254 \mathrm{~m}$
Static Water Column Height: $6.096 \mathrm{~m}$ Screen Length: $6.096 \mathrm{~m}$ Well Radius: $0.0254 \mathrm{~m}$

\section{SOLUTION}

Aquifer Model: Unconfined

Solution Method: Bouwer-Rice

$\mathrm{K}=6.409 \mathrm{~m} / \mathrm{day}$ y0 $=0.5625 \mathrm{~m}$ 


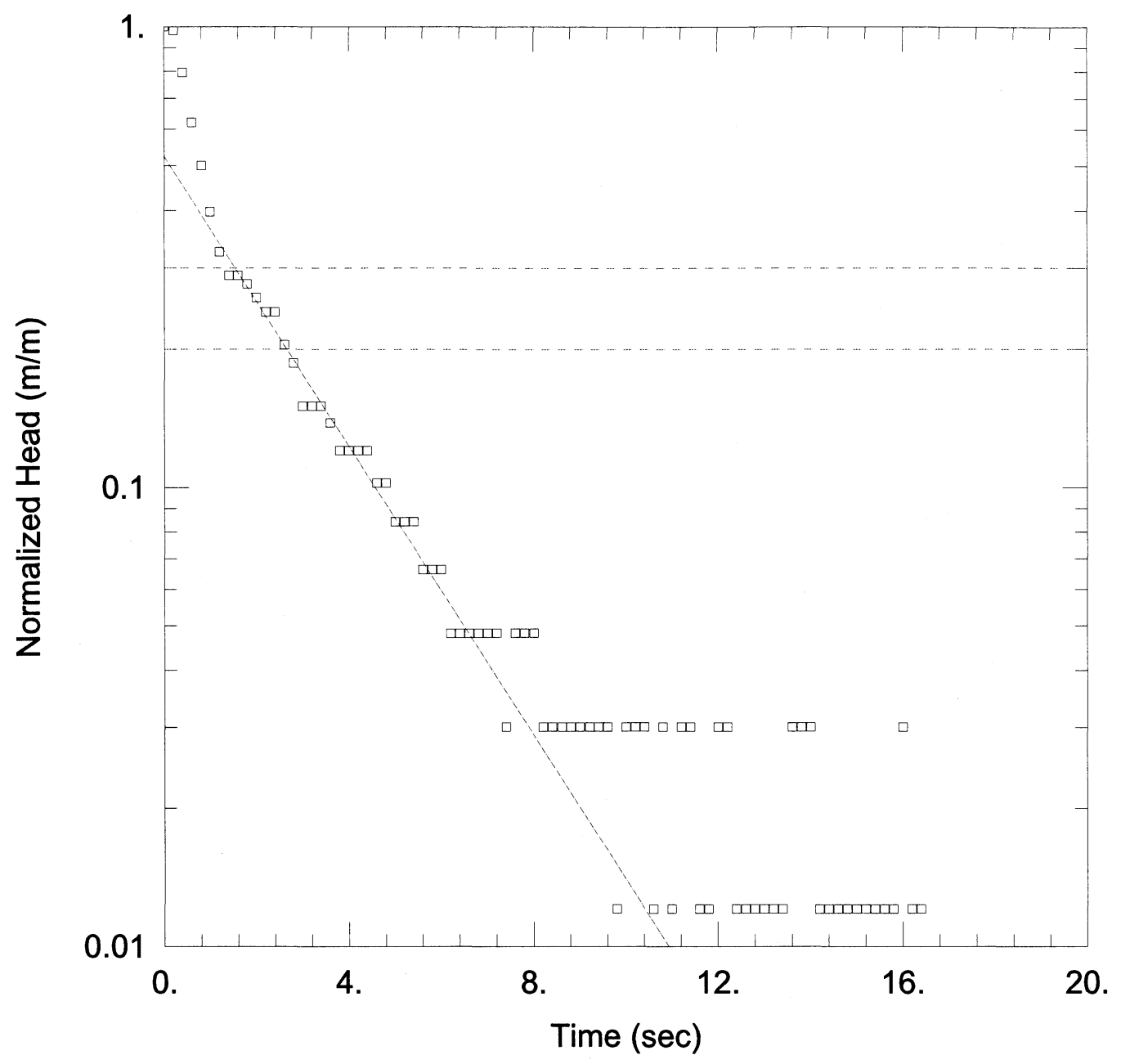

WELL TEST ANALYSIS

Data Set: E:I...IMW7_2.aqt

Date: $09 / 14 / 08$

Time: $15: 27: 33$

PROJECT INFORMATION

Company: University of Nebraska

Location: Injection Pilot Study

Test Well: MW-7

\section{AQUIFER DATA}

Saturated Thickness: $15.24 \mathrm{~m}$

Anisotropy Ratio (Kz/Kr): 1.

WELL DATA (MW-7)

Initial Displacement: $1 . \mathrm{m}$

Total Well Penetration Depth: $7.616 \mathrm{~m}$

Casing Radius: $0.0254 \mathrm{~m}$
Static Water Column Height: $6.096 \mathrm{~m}$

Screen Length: $6.096 \mathrm{~m}$

Well Radius: $0.0254 \mathrm{~m}$

\section{SOLUTION}

Aquifer Model: Unconfined

Solution Method: Bouwer-Rice

$\mathrm{K}=6.581 \mathrm{~m} / \mathrm{day}$

y0 $=0.5229 \mathrm{~m}$ 


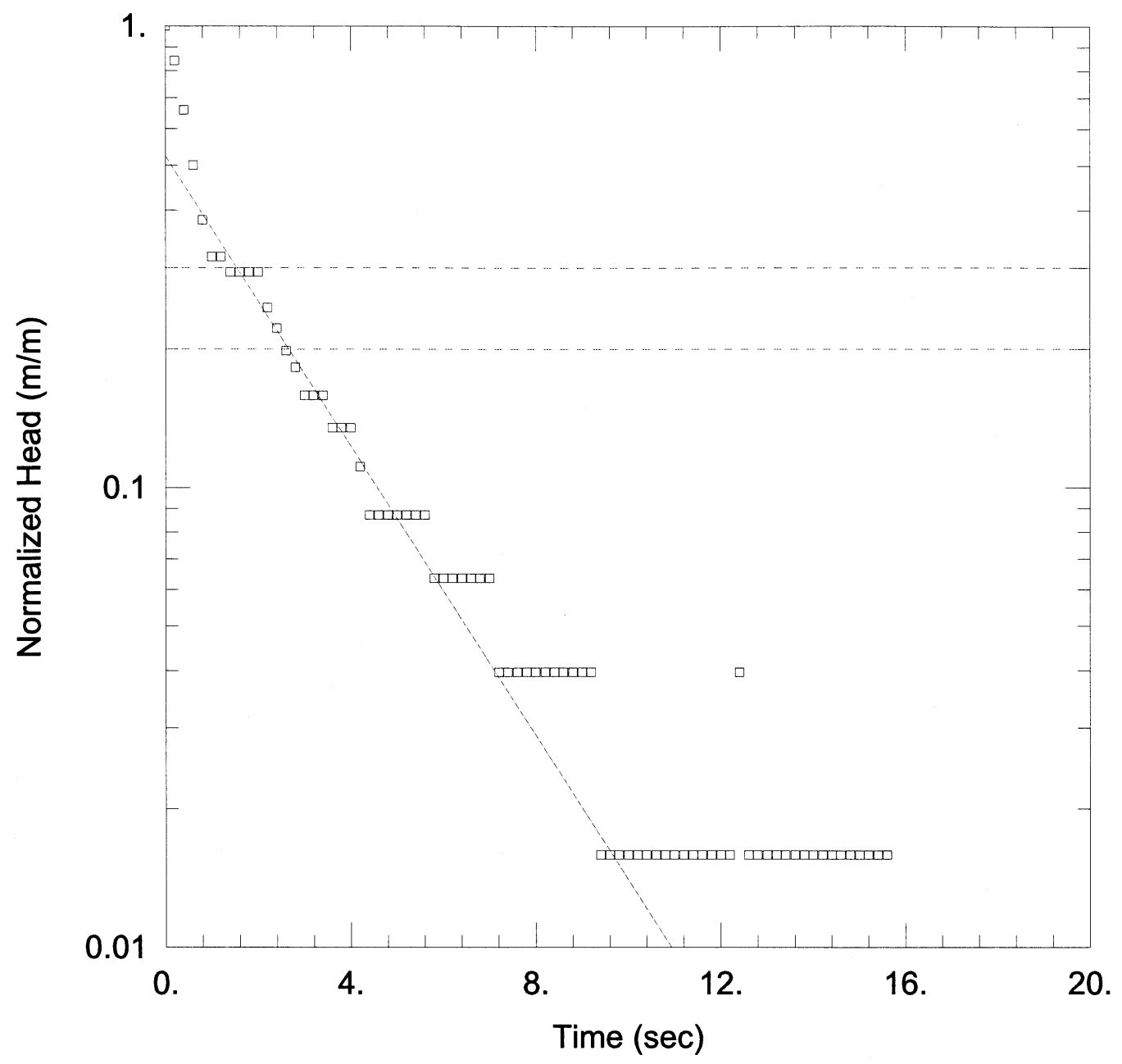

WELL TEST ANALYSIS

Data Set: E:I...MW7_3.aqt

Date: $09 / 14 / 08$

Time: $15: 28: 15$

PROJECT INFORMATION

Company: University of Nebraska

Location: Injection Pilot Study

Test Well: MW-7

\section{AQUIFER DATA}

Saturated Thickness: $15.24 \mathrm{~m}$

Anisotropy Ratio (Kz/Kr): 1 .

WELL DATA (MW-7)

Initial Displacement: 1. m

Total Well Penetration Depth: $7.616 \mathrm{~m}$

Static Water Column Height: $6.096 \mathrm{~m}$

Casing Radius: $0.0254 \mathrm{~m}$ Screen Length: $6.096 \mathrm{~m}$

Well Radius: $0.0254 \mathrm{~m}$

\section{SOLUTION}

Aquifer Model: Unconfined

Solution Method: Bouwer-Rice

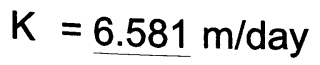

$\mathrm{y} 0=0.5229 \mathrm{~m}$ 


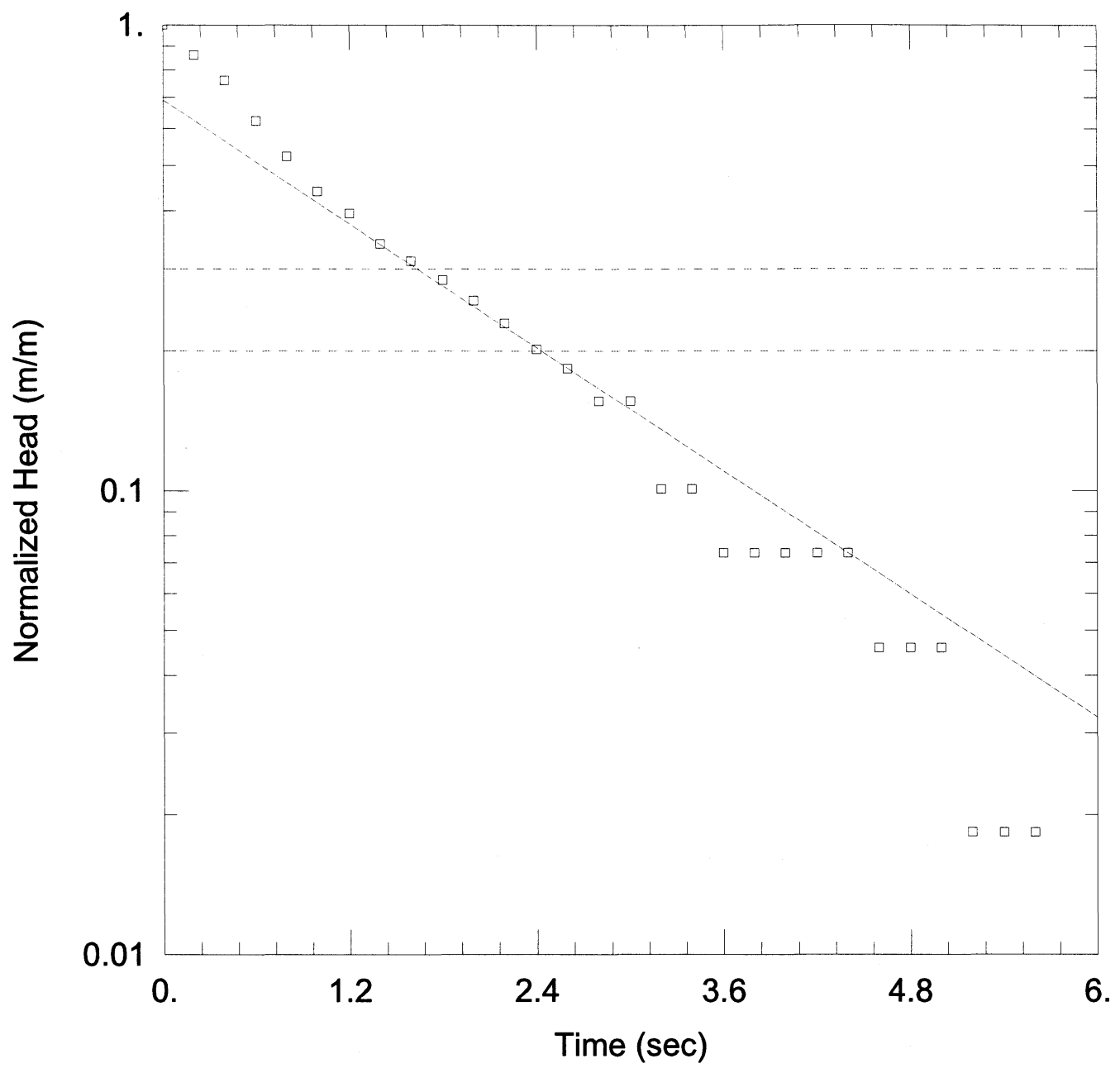

\section{WELL TEST ANALYSIS}

Data Set: E:I...IMW8_1.aqt

Date: $09 / 14 / 08$

Time: $15: 28: 57$

\section{PROJECT INFORMATION}

Company: University of Nebraska

Location: Injection Pilot Study

Test Well: MW-8

\section{AQUIFER DATA}

Saturated Thickness: $15.24 \mathrm{~m}$

Anisotropy Ratio (Kz/Kr): 1.

WELL DATA (MW-8)

Initial Displacement: 1. $\mathrm{m}$

Total Well Penetration Depth: $7.616 \mathrm{~m}$

Casing Radius: $0.0254 \mathrm{~m}$
Static Water Column Height: $6.096 \mathrm{~m}$

Screen Length: $6.096 \mathrm{~m}$

Well Radius: $0.0254 \mathrm{~m}$

\section{SOLUTION}

Aquifer Model: Unconfined

Solution Method: Bouwer-Rice

$\mathrm{K}=9.261 \mathrm{~m} / \mathrm{day}$

y0 $=0.69 \mathrm{~m}$ 


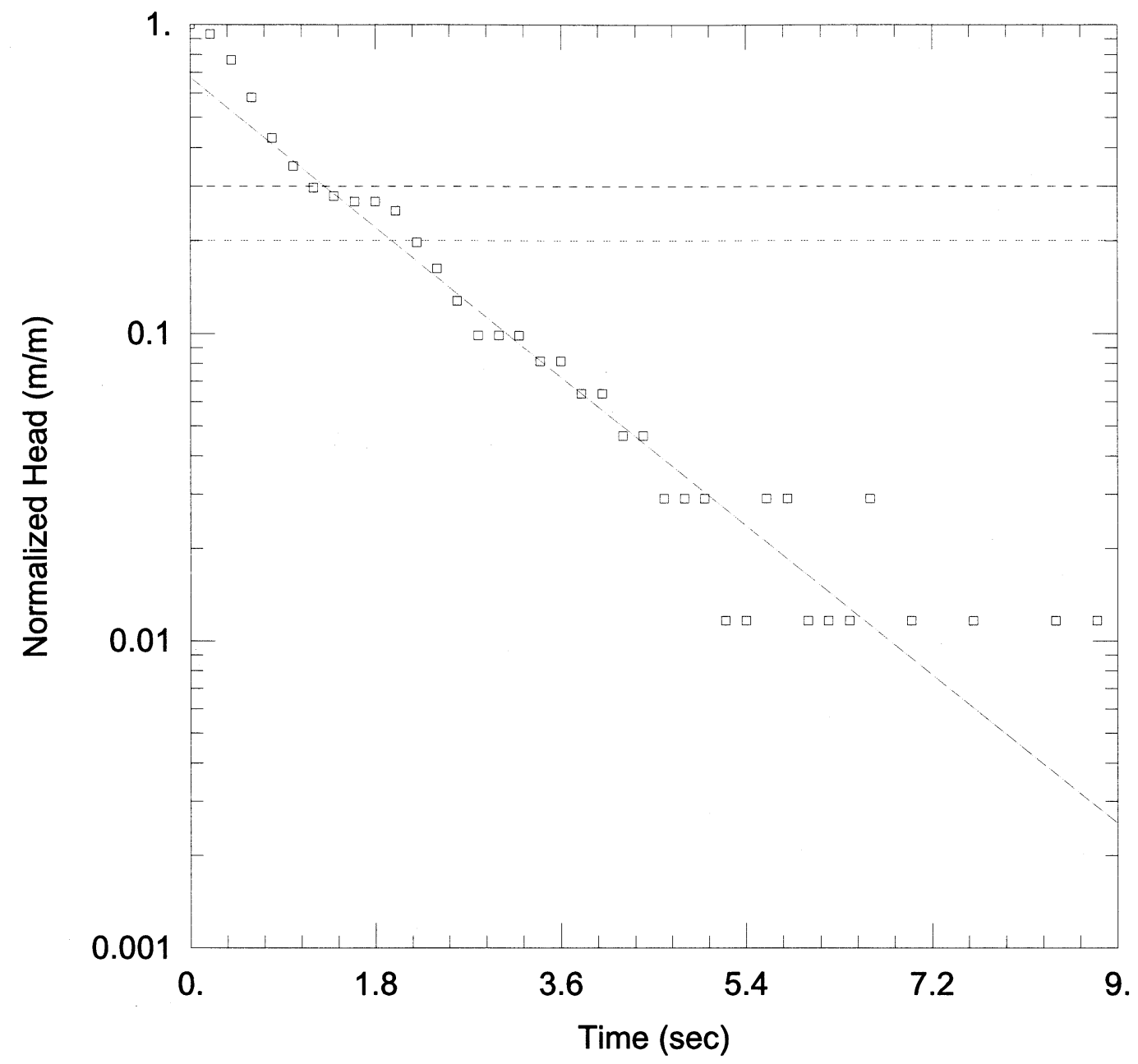

\section{WELL TEST ANALYSIS}

Data Set: E:I...IMW8_2.aqt

Date: $09 / 14 / 08$

Time: $15: 29: 35$

\section{PROJECT INFORMATION}

Company: University of Nebraska

Location: Injection Pilot Study

Test Well: MW-8

\section{AQUIFER DATA}

Saturated Thickness: $15.24 \mathrm{~m}$

Anisotropy Ratio $(\mathrm{Kz} / \mathrm{Kr}): 1$.

WELL DATA (MW-8)

Initial Displacement: 1. m

Total Well Penetration Depth: $7.616 \mathrm{~m}$

Static Water Column Height: $6.096 \mathrm{~m}$

Screen Length: $6.096 \mathrm{~m}$

Casing Radius: $0.0254 \mathrm{~m}$

Well Radius: $0.0254 \mathrm{~m}$ 


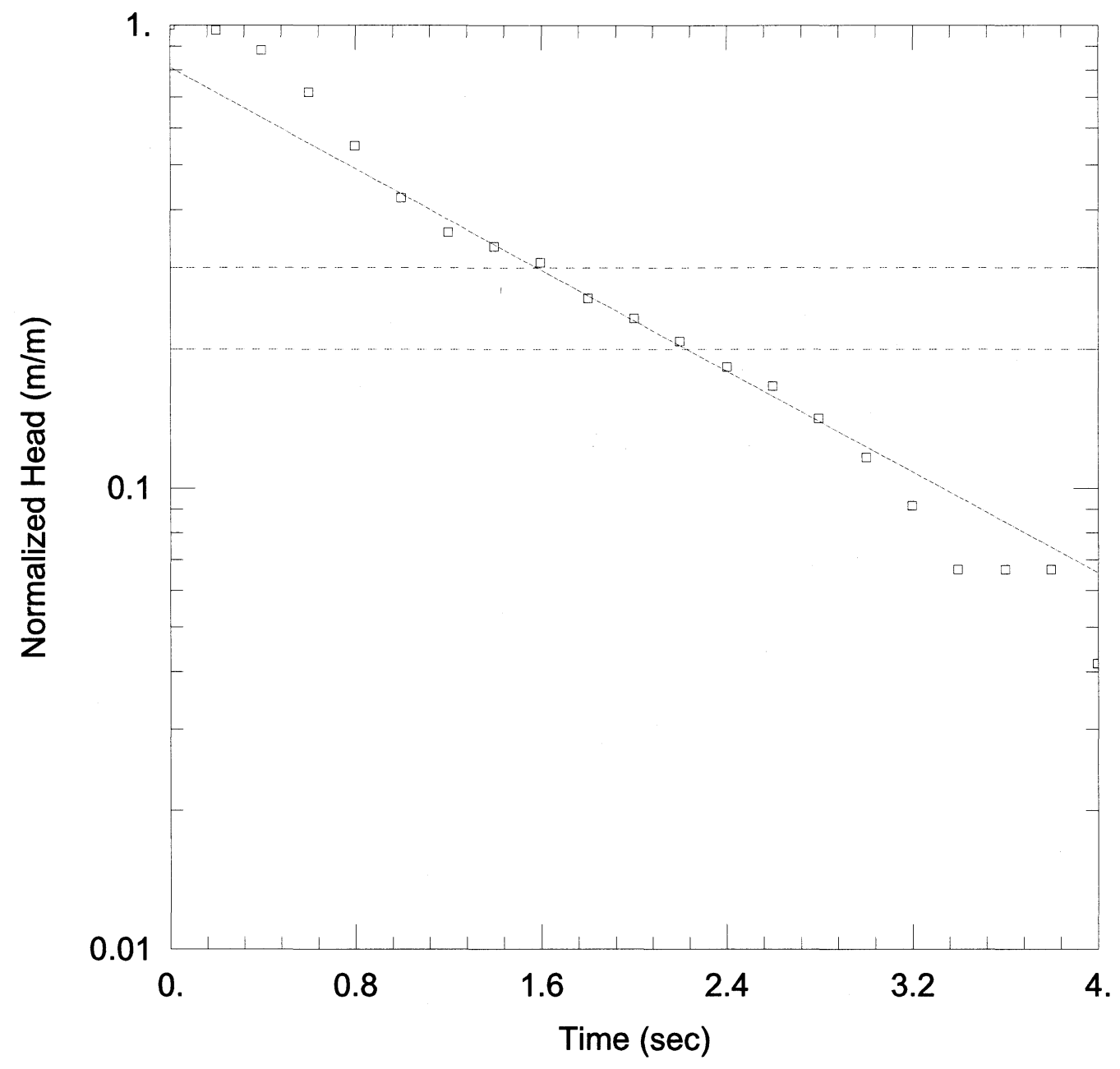

\section{WELL TEST ANALYSIS}

Data Set: E:1...IMW8_3.aqt

Date: $09 / 14 / 08$
Time: $15: 30: 17$

\section{PROJECT INFORMATION}

Company: University of Nebraska

Location: Injection Pilot Study

Test Well: MW-8

\section{AQUIFER DATA}

Saturated Thickness: $15.24 \mathrm{~m}$

Anisotropy Ratio (Kz/Kr): 1.

WELL DATA (MW-8)

Initial Displacement: 1. m

Total Well Penetration Depth: $7.616 \mathrm{~m}$

Casing Radius: $0.0254 \mathrm{~m}$
Static Water Column Height: $6.096 \mathrm{~m}$

Screen Length: $6.096 \mathrm{~m}$

Well Radius: $0.0254 \mathrm{~m}$

\section{SOLUTION}

Aquifer Model: Unconfined

Solution Method: Bouwer-Rice

$\mathrm{K}=11.43 \mathrm{~m} /$ day

$\mathrm{y} 0=0.8112 \mathrm{~m}$ 


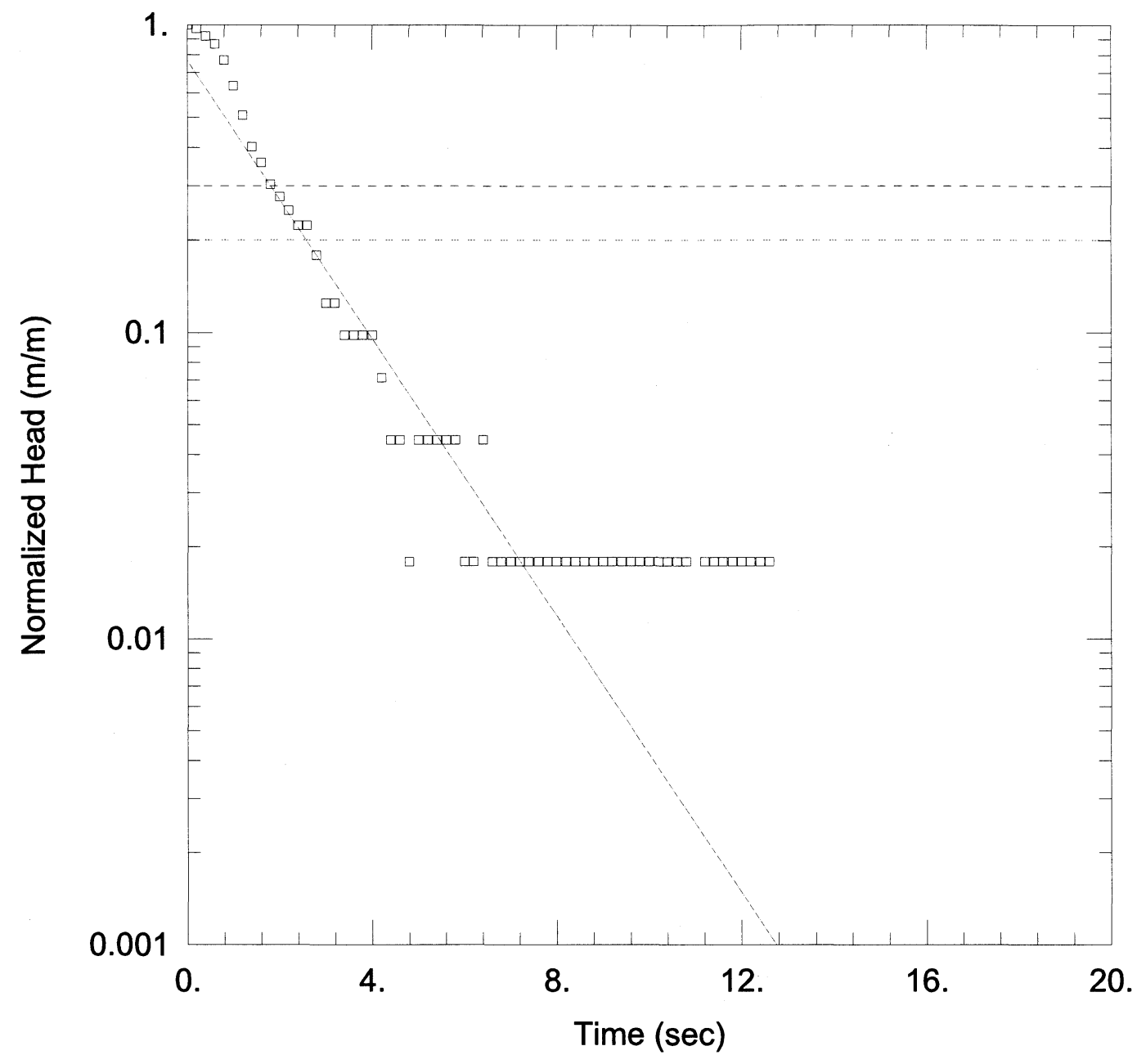

\section{WELL TEST ANALYSIS}

Data Set: E:I...IMW9_1.aqt

Date: 09/14/08

Time: 15:31:05

\section{PROJECT INFORMATION}

Company: University of Nebraska

Location: Injection Pilot Study

Test Well: MW-9

\section{AQUIFER DATA}

Saturated Thickness: $15.24 \mathrm{~m}$

Anisotropy Ratio (Kz/Kr): 1.

\section{WELL DATA (MW-9)}

Initial Displacement: $1 . \mathrm{m}$

Total Well Penetration Depth: $7.616 \mathrm{~m}$

Casing Radius: $0.0254 \mathrm{~m}$
Static Water Column Height: $6.096 \mathrm{~m}$ Screen Length: $6.096 \mathrm{~m}$

Well Radius: $0.0254 \mathrm{~m}$
Aquifer Model: Unconfined

$\mathrm{K}=9.472 \mathrm{~m} / \mathrm{day}$
Solution Method: Bouwer-Rice

$\mathrm{y} 0=0.7656 \mathrm{~m}$ 


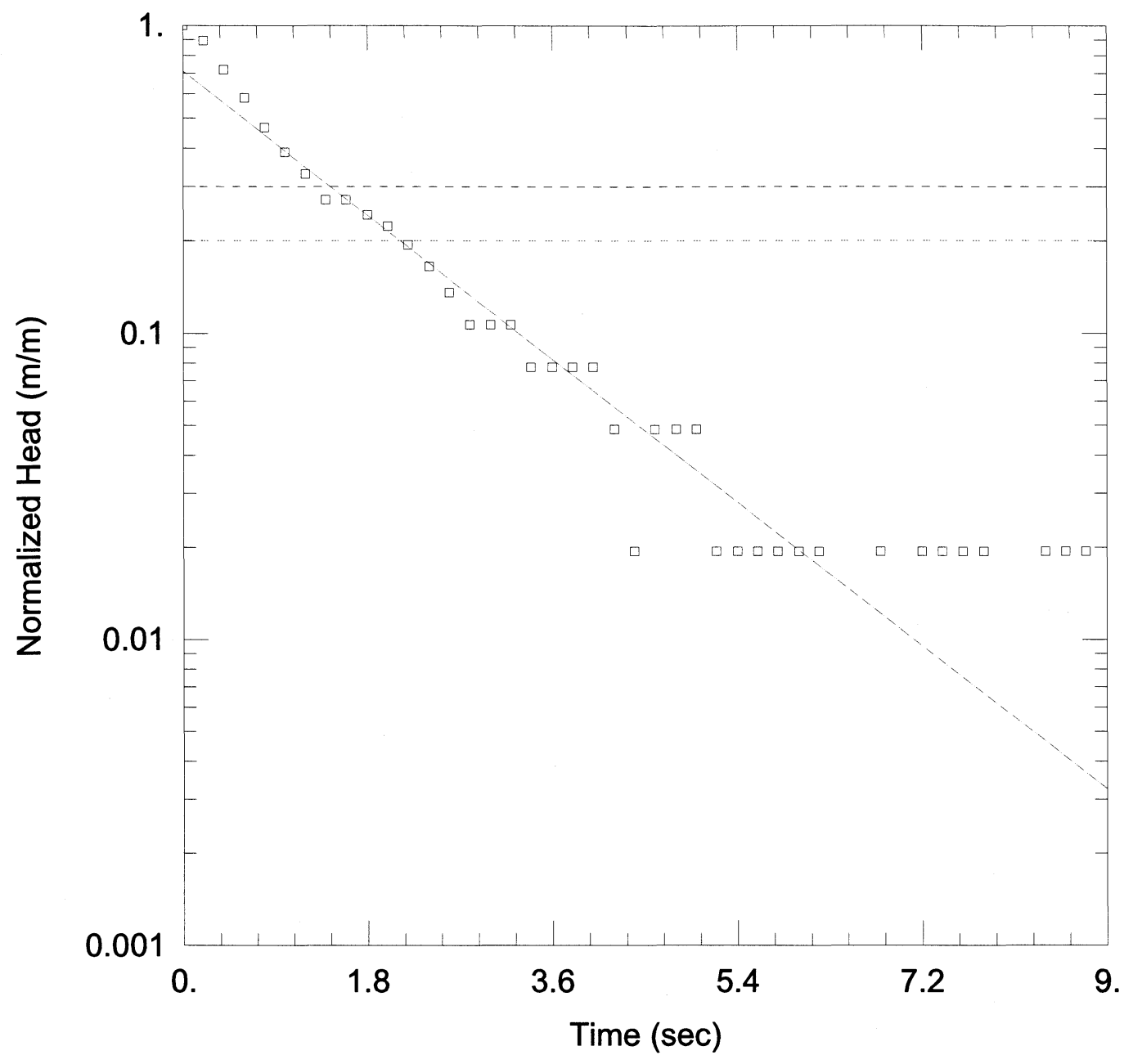

\section{WELL TEST ANALYSIS}

Data Set: E:I...MW9_2.aqt

Date: $09 / 14 / 08$

Time: 15:31:46

PROJECT INFORMATION

Company: University of Nebraska

Location: Injection Pilot Study

Test Well: MW-9

\section{AQUIFER DATA}

Saturated Thickness: $15.24 \mathrm{~m}$

Anisotropy Ratio (Kz/Kr): 1 .

WELL DATA (MW-9)

Initial Displacement: $1 . \mathrm{m}$

Total Well Penetration Depth: $7.616 \mathrm{~m}$

Casing Radius: $0.0254 \mathrm{~m}$
Static Water Column Height: $6.096 \mathrm{~m}$

Screen Length: $6.096 \mathrm{~m}$

Well Radius: $0.0254 \mathrm{~m}$

Aquifer Model: Unconfined

Solution Method: Bouwer-Rice

$\mathrm{K}=10.89 \mathrm{~m} /$ day

yo $=0.711 \mathrm{~m}$ 


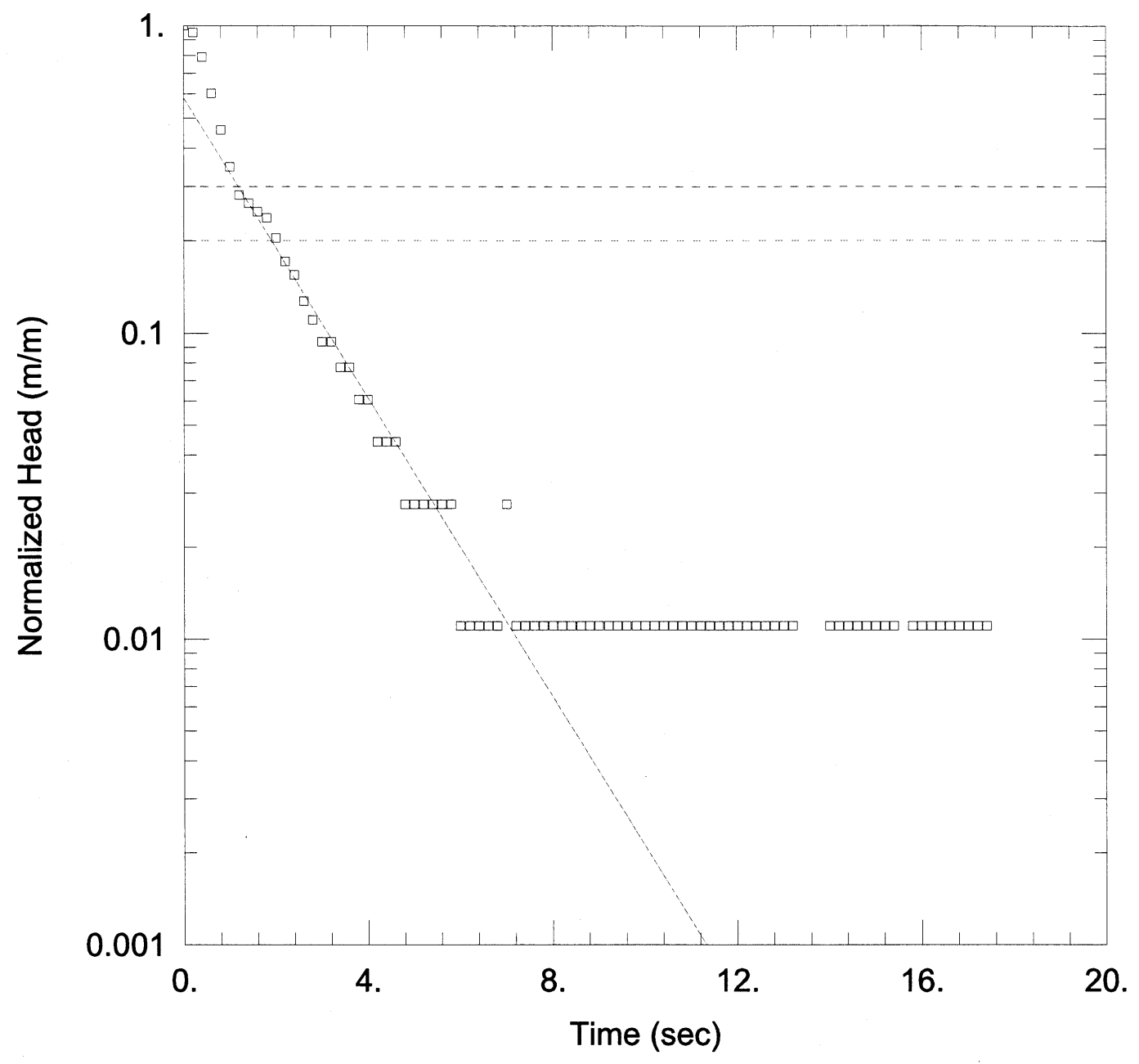

\section{WELL TEST ANALYSIS}

Data Set: E:I...IMW9_3.aqt

Date: $09 / 14 / 08$

Time: $15: 32: 38$

\section{PROJECT INFORMATION}

Company: University of Nebraska

Location: Injection Pilot Study

Test Well: $\mathrm{MW}-9$

\section{AQUIFER DATA}

Saturated Thickness: $15.24 \mathrm{~m}$

Anisotropy Ratio (Kz/Kr): 1.

WELL DATA (MW-9)

Initial Displacement: 1. m

Total Well Penetration Depth: $7.616 \mathrm{~m}$

Casing Radius: $0.0254 \mathrm{~m}$
Static Water Column Height: $6.096 \mathrm{~m}$ Screen Length: $6.096 \mathrm{~m}$ Well Radius: $0.0254 \mathrm{~m}$

\section{SOLUTION}

Aquifer Model: Unconfined

Solution Method: Bouwer-Rice

$\mathrm{K}=10.22 \mathrm{~m} /$ day

y0 $=0.5827 \mathrm{~m}$ 


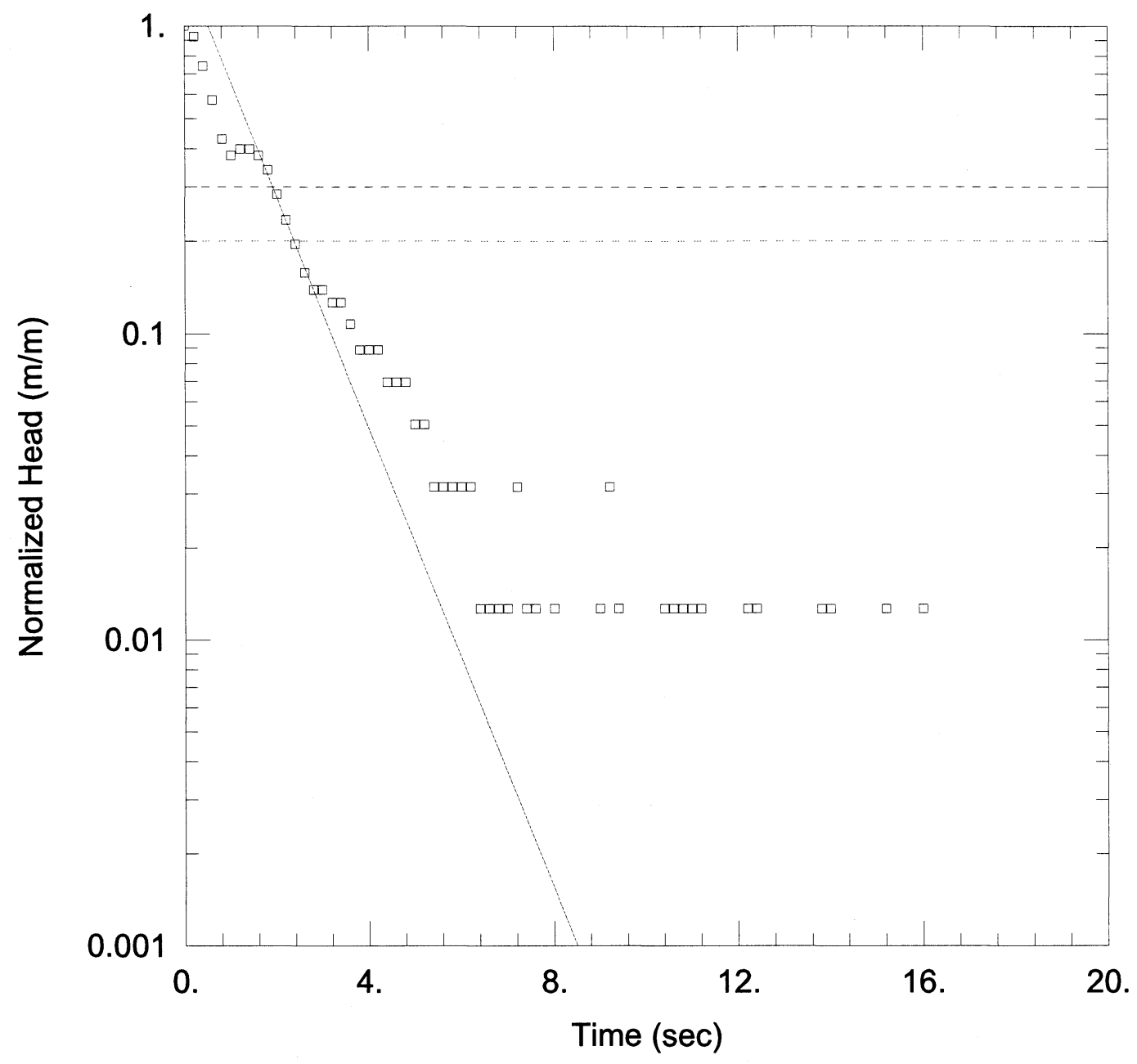

\section{WELL TEST ANALYSIS}

Data Set: E:I...IMW10_1.aqt

Date: $09 / 14 / 08$

Time: 15:33:23

\section{PROJECT INFORMATION}

Company: University of Nebraska

Location: Injection Pilot Study

Test Well: MW-10

\section{AQUIFER DATA}

Saturated Thickness: $15.24 \mathrm{~m}$

Anisotropy Ratio (Kz/Kr): 1.

\section{WELL DATA (MW-10)}

Initial Displacement: $1 . \mathrm{m}$

Total Well Penetration Depth: $7.616 \mathrm{~m}$

Casing Radius: $0.0254 \mathrm{~m}$
Static Water Column Height: 6.096 m

Screen Length: $6.096 \mathrm{~m}$

Well Radius: $0.0254 \mathrm{~m}$
Aquifer Model: Unconfined

$\mathrm{K}=15.74 \mathrm{~m} / \mathrm{day}$
Solution Method: Bouwer-Rice

y0 $=1.571 \mathrm{~m}$ 


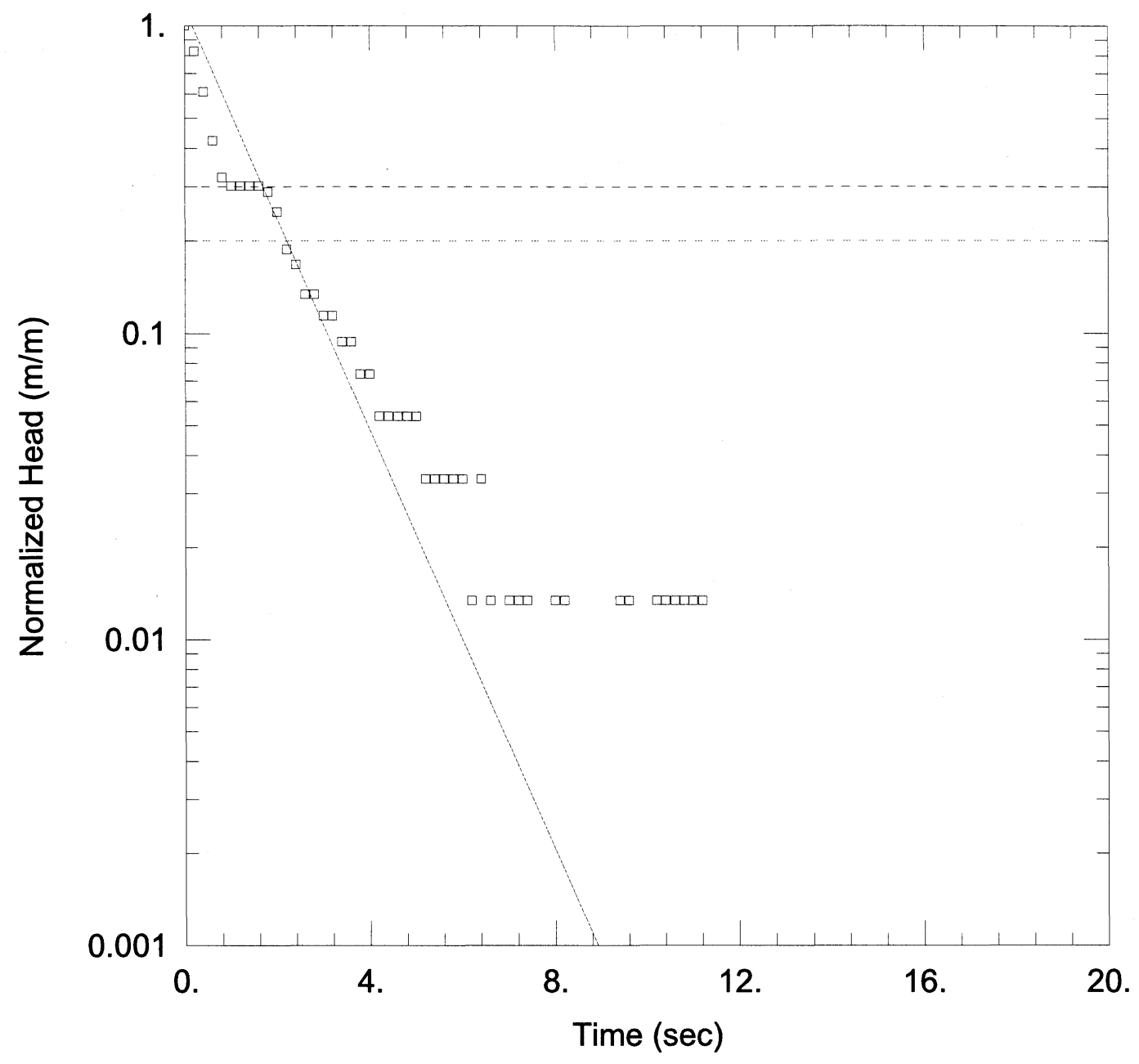

\section{WELL TEST ANALYSIS}

Data Set: E:I...IMW10_2.aqt

Date: $09 / 14 / 08$

Time: 15:33:55

\section{PROJECT INFORMATION}

Company: University of Nebraska

Location: Injection Pilot Study

Test Well: MW-10

\section{AQUIFER DATA}

Saturated Thickness: $15.24 \mathrm{~m}$

Anisotropy Ratio (Kz/Kr): 1.

\section{WELL DATA (MW-10)}

Initial Displacement: $1 . \mathrm{m}$

Total Well Penetration Depth: $7.616 \mathrm{~m}$

Casing Radius: $0.0254 \mathrm{~m}$
Static Water Column Height: $6.096 \mathrm{~m}$

Screen Length: $6.096 \mathrm{~m}$

Well Radius: $0.0254 \mathrm{~m}$

\section{SOLUTION}

Aquifer Model: Unconfined

Solution Method: Bouwer-Rice

$\mathrm{K}=14.36 \mathrm{~m} / \mathrm{day}$

$\mathrm{y} 0=\underline{1.144 \mathrm{~m}}$ 


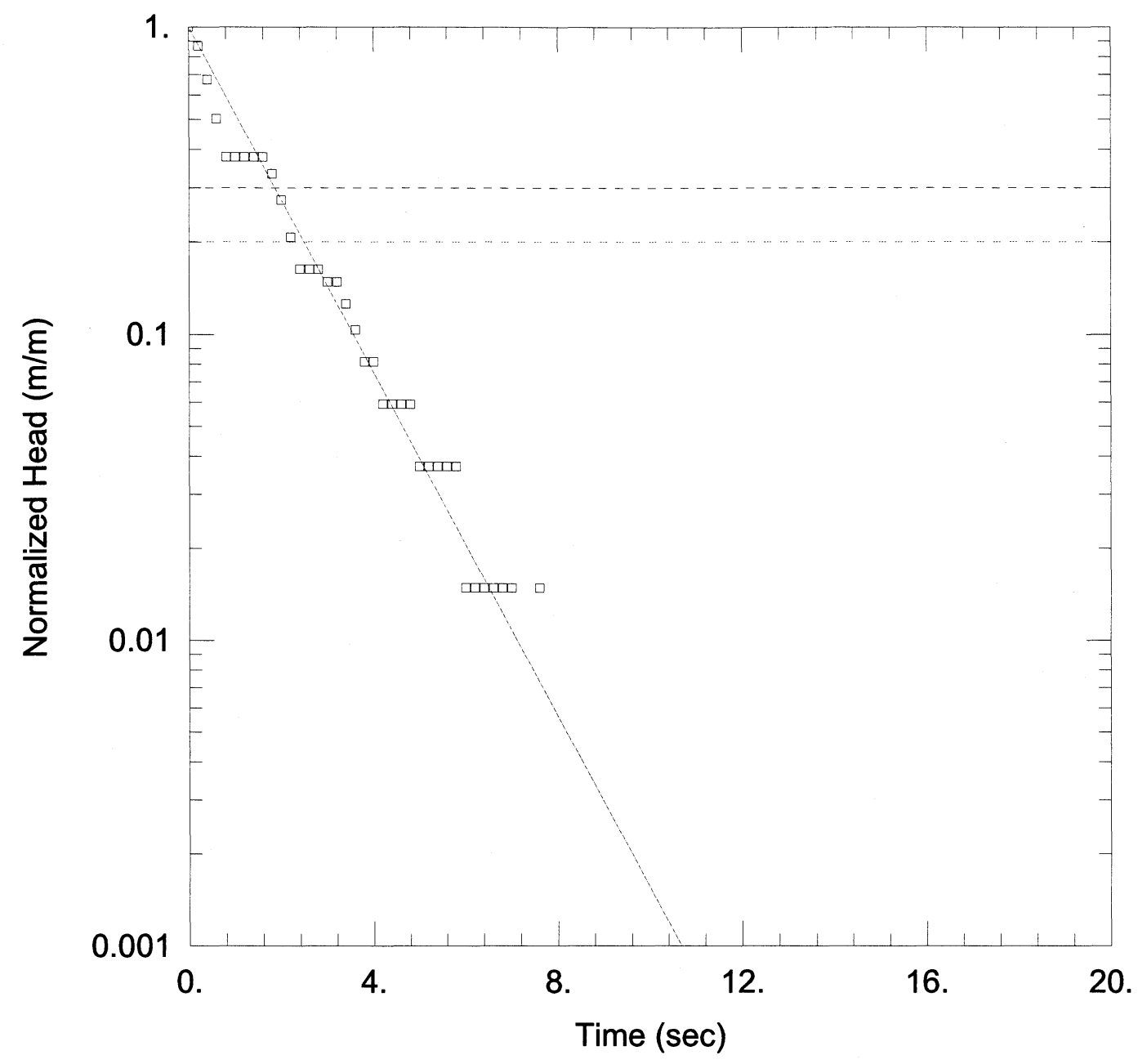

\section{WELL TEST ANALYSIS}

Data Set: E:I...IMW10_3.aqt

Date: $09 / 14 / 08$

Time: 15:34:34

\section{PROJECT INFORMATION}

Company: University of Nebraska

Location: Injection Pilot Study

Test Well: MW-10

\section{AQUIFER DATA}

Saturated Thickness: $15.24 \mathrm{~m}$

Anisotropy Ratio (Kz/Kr): 1.

\section{WELL DATA (MW-10)}

Initial Displacement: $1 . \mathrm{m}$

Total Well Penetration Depth: $7.616 \mathrm{~m}$

Casing Radius: $0.0254 \mathrm{~m}$
Static Water Column Height: $6.096 \mathrm{~m}$

Screen Length: $6.096 \mathrm{~m}$

Well Radius: $0.0254 \mathrm{~m}$

\section{SOLUTION}

Aquifer Model: Unconfined

Solution Method: Bouwer-Rice

$\mathrm{K}=11.77 \mathrm{~m} / \mathrm{day}$

$\mathrm{y} 0=1.003 \mathrm{~m}$ 


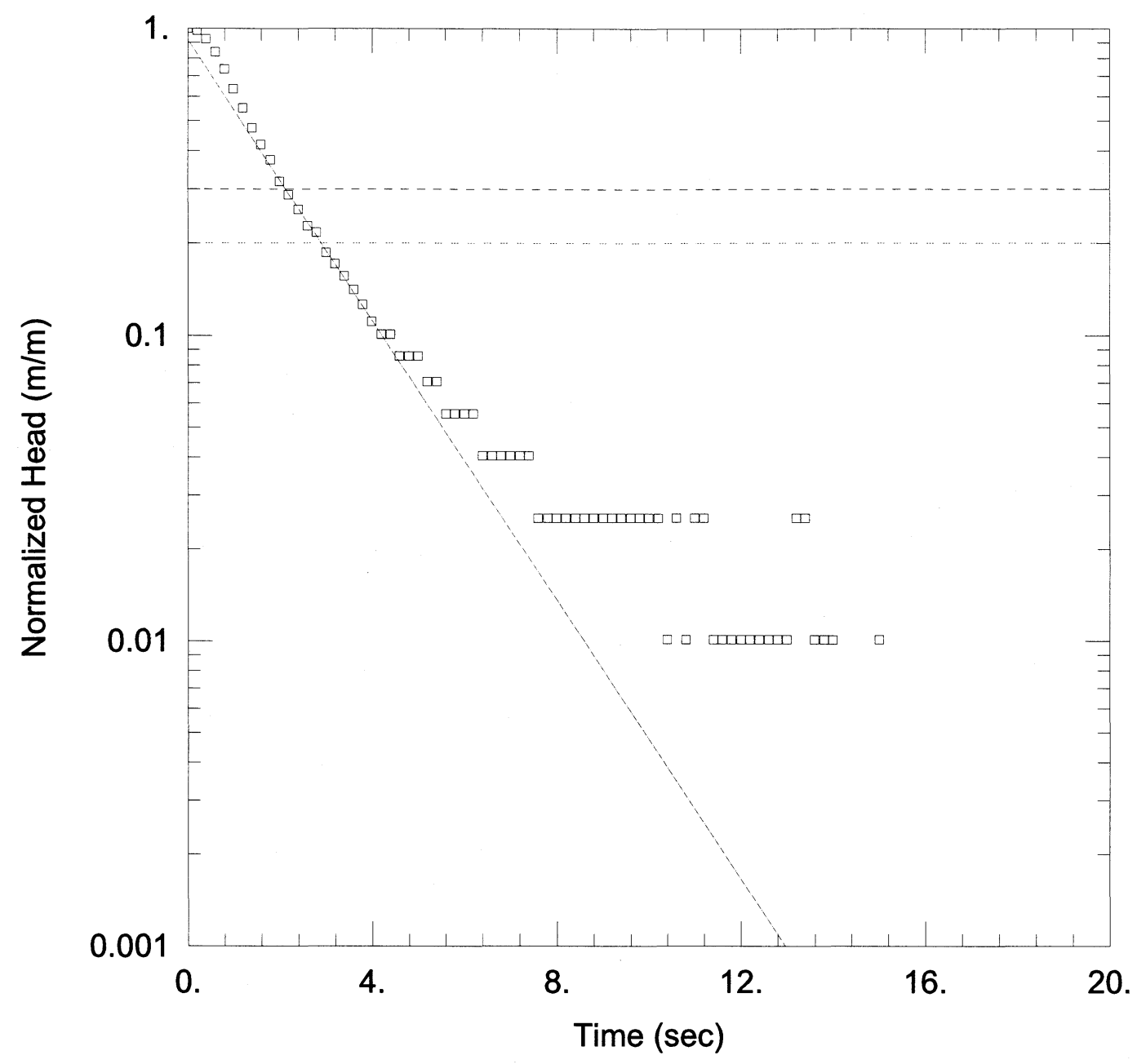

\section{WELL TEST ANALYSIS}

Data Set: E:I...IMW12_1.aqt

Date: $09 / 14 / 08$

Time: $15: 35: 24$

\section{PROJECT INFORMATION}

Company: University of Nebraska

Location: Injection Pilot Study

Test Well: MW-12

\section{AQUIFER DATA}

Saturated Thickness: $15.24 \mathrm{~m}$

Anisotropy Ratio (Kz/Kr): 1.

WELL DATA (MW-12)

Initial Displacement: 1. m

Total Well Penetration Depth: $7.616 \mathrm{~m}$

Casing Radius: $0.0254 \mathrm{~m}$
Static Water Column Height: $6.096 \mathrm{~m}$ Screen Length: $6.096 \mathrm{~m}$

Well Radius: $0.0254 \mathrm{~m}$

\section{SOLUTION}

Aquifer Model: Unconfined

Solution Method: Bouwer-Rice

$\mathrm{K}=9.572 \mathrm{~m} / \mathrm{day}$

$\mathrm{y} 0=0.9185 \mathrm{~m}$ 


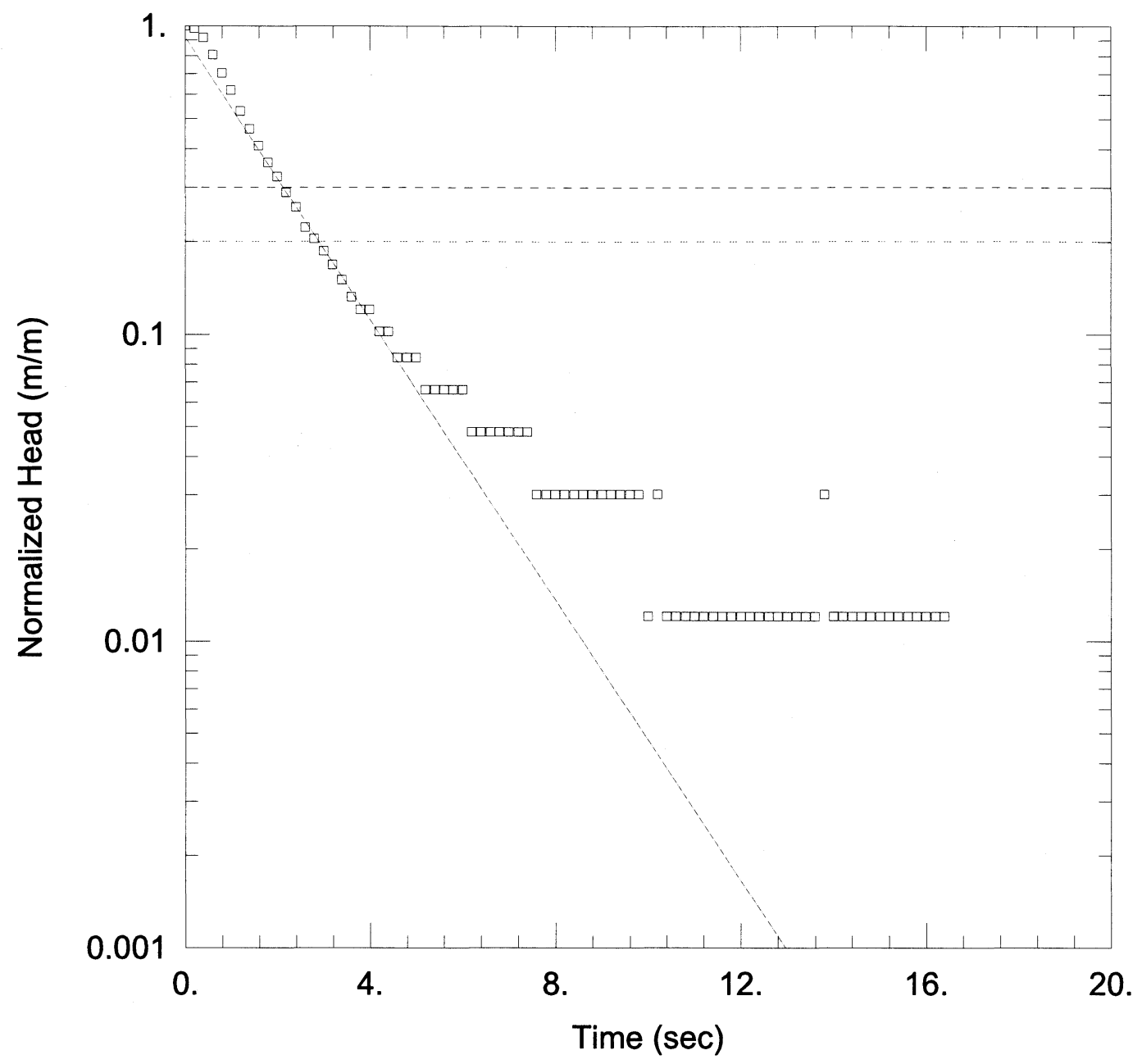

\section{WELL TEST ANALYSIS}

Data Set: E:I...IMW12_2.aqt

Date: $09 / 14 / 08$

Time: $15: 35: 55$

\section{PROJECT INFORMATION}

Company: University of Nebraska

Location: Injection Pilot Study

Test Well: MW-12

\section{AQUIFER DATA}

Saturated Thickness: $15.24 \mathrm{~m}$

Anisotropy Ratio $(\mathrm{Kz} / \mathrm{Kr}): 1$.

\section{WELL DATA (MW-12)}

Initial Displacement: 1. m

Total Well Penetration Depth: $7.616 \mathrm{~m}$

Casing Radius: $0.0254 \mathrm{~m}$
Static Water Column Height: $6.096 \mathrm{~m}$

Screen Length: $6.096 \mathrm{~m}$

Well Radius: $0.0254 \mathrm{~m}$

\section{SOLUTION}

Aquifer Model: Unconfined

Solution Method: Bouwer-Rice

$\mathrm{K}=9.572 \mathrm{~m} / \mathrm{day}$

$\mathrm{y} 0=0.9185 \mathrm{~m}$ 


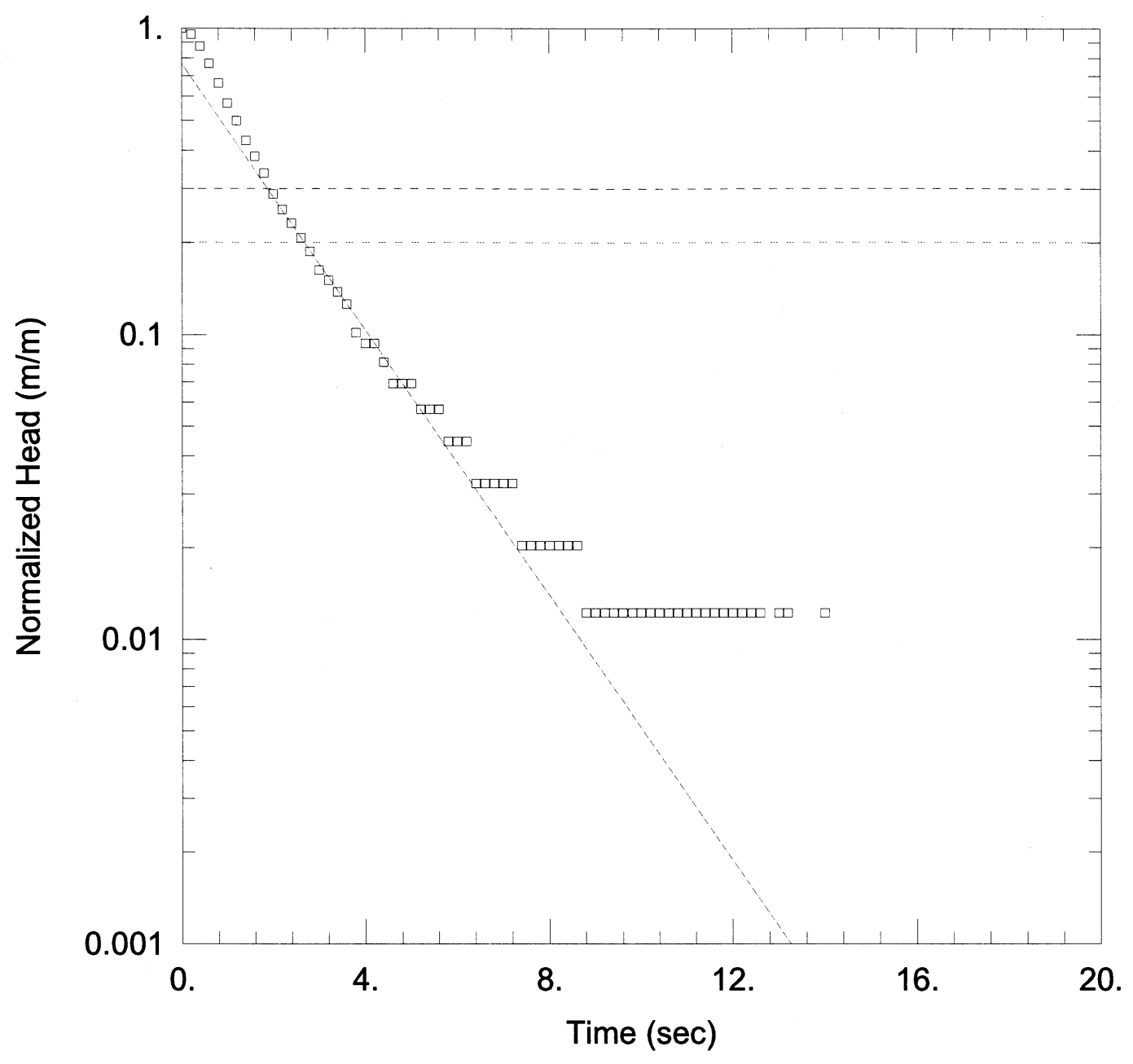

WELL TEST ANALYSIS

Data Set: E:I...IMW12_3.aqt

Date: $09 / 14 / 08$

Time: $15: 36: 27$

\section{PROJECT INFORMATION}

Company: University of Nebraska

Location: Injection Pilot Study

Test Well: MW-12

\section{AQUIFER DATA}

Saturated Thickness: $15.24 \mathrm{~m}$

Anisotropy Ratio $(\mathrm{Kz} / \mathrm{Kr}): 1$.

\section{WELL DATA (MW-12)}

Initial Displacement: 1. m

Total Well Penetration Depth: $7.616 \mathrm{~m}$

Casing Radius: $0.0254 \mathrm{~m}$
Static Water Column Height: $6.096 \mathrm{~m}$ Screen Length: $6.096 \mathrm{~m}$ Well Radius: $0.0254 \mathrm{~m}$

\section{SOLUTION}

Aquifer Model: Unconfined

Solution Method: Bouwer-Rice

$\mathrm{K}=9.108 \mathrm{~m} / \mathrm{day}$

$\mathrm{y} 0=0.7666 \mathrm{~m}$ 


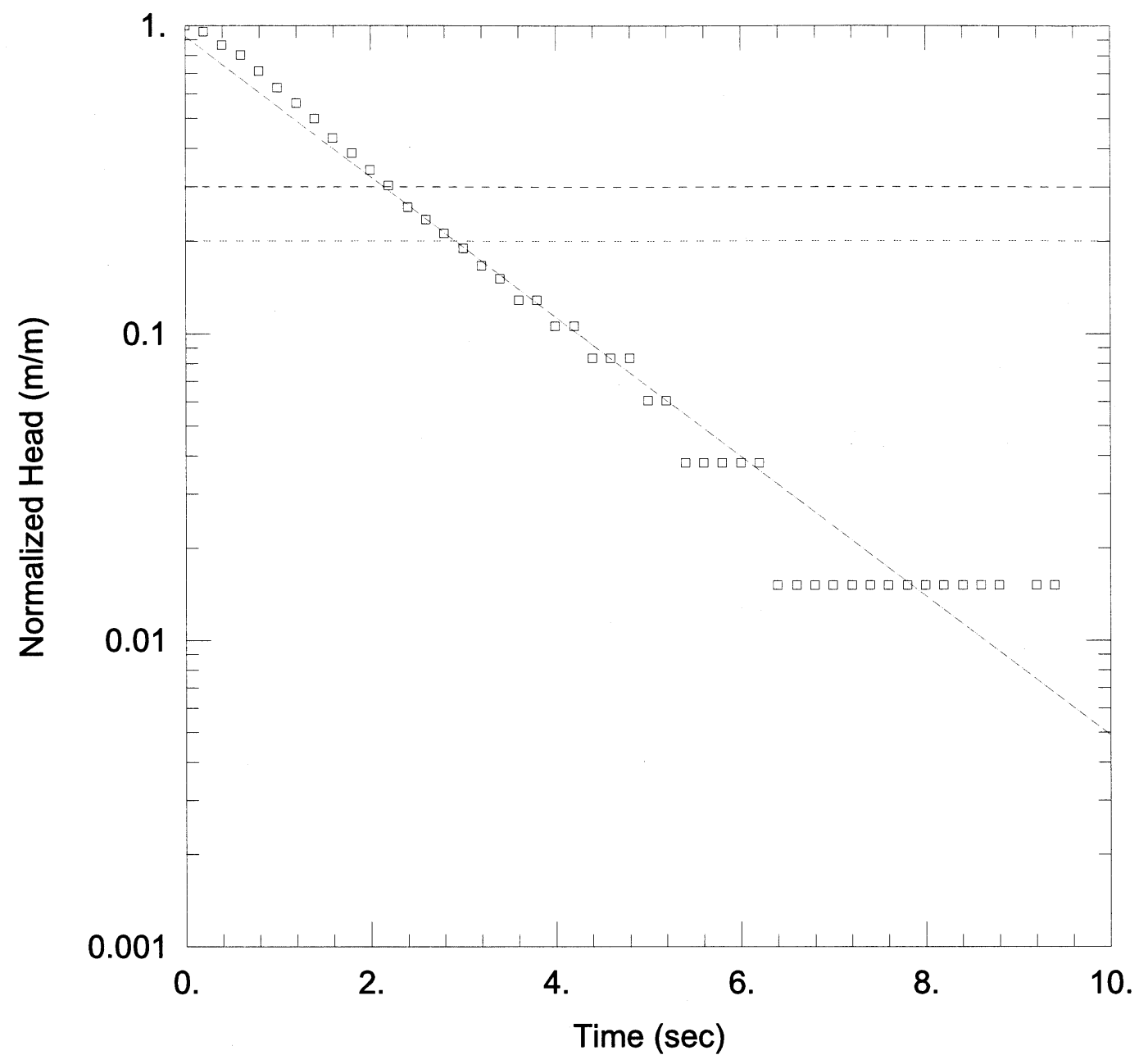

\section{WELL TEST ANALYSIS}

Data Set: E:I...IMW13_1.aqt

Date: $09 / 14 / 08$

Time: 15:37:57

PROJECT INFORMATION

Company: University of Nebraska

Location: Injection Pilot Study

Test Well: MW-13

\section{AQUIFER DATA}

Saturated Thickness: $15.24 \mathrm{~m}$

Anisotropy Ratio $(\mathrm{Kz} / \mathrm{Kr}): 1$.

WELL DATA (MW-13)

Initial Displacement: 1. m

Total Well Penetration Depth: $7.616 \mathrm{~m}$

Casing Radius: $0.0254 \mathrm{~m}$
Static Water Column Height: $6.096 \mathrm{~m}$

Screen Length: $6.096 \mathrm{~m}$

Well Radius: $0.0254 \mathrm{~m}$

\section{SOLUTION}

Aquifer Model: Unconfined

Solution Method: Bouwer-Rice

$\mathrm{K}=9.518 \mathrm{~m} / \mathrm{day}$

y0 $=0.9209 \mathrm{~m}$ 


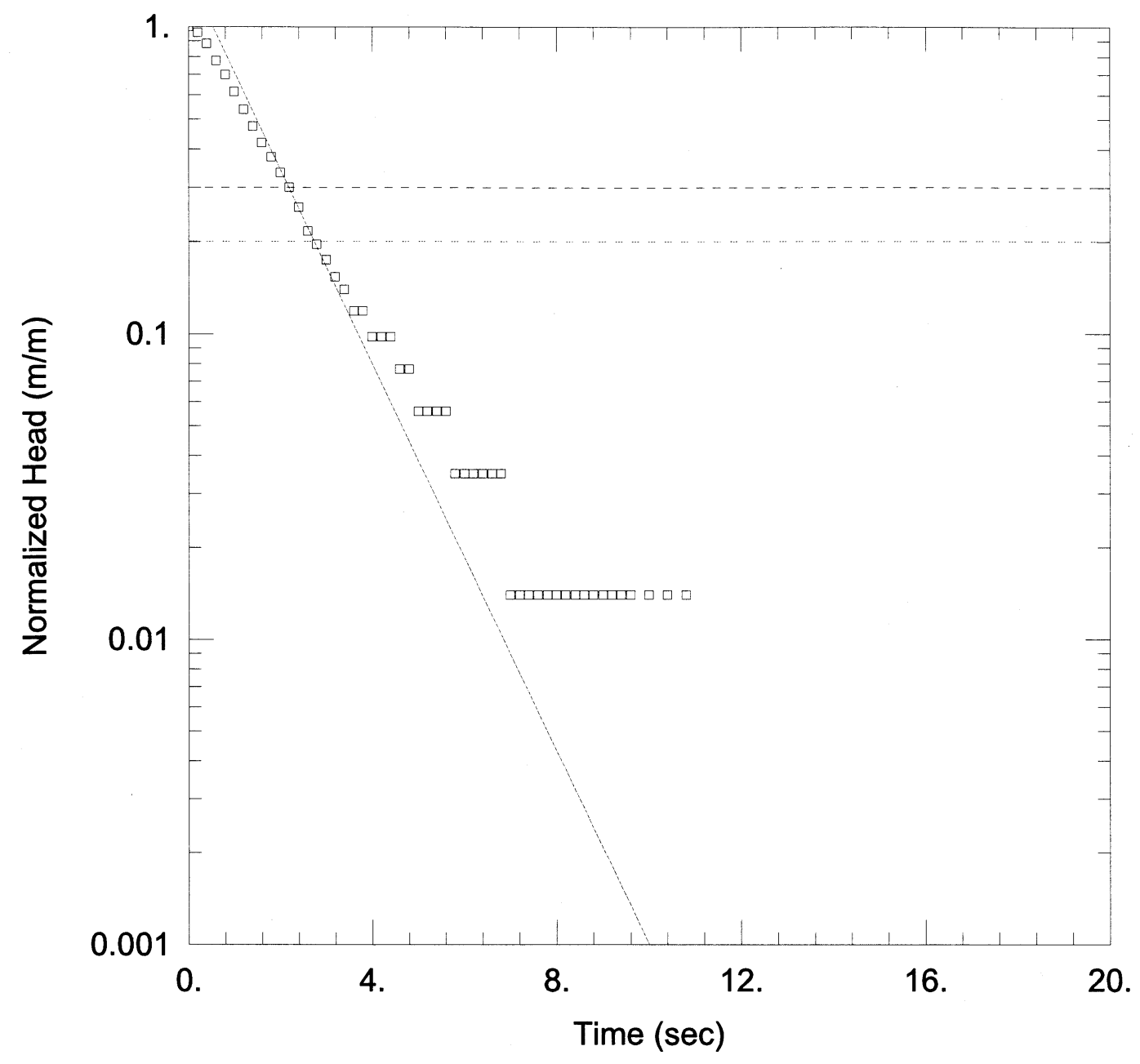

\section{WELL TEST ANALYSIS}

Data Set: E:I...IMW13_2.aqt

Date: $09 / 14 / 08$

Time: 15:38:31

\section{PROJECT INFORMATION}

Company: University of Nebraska

Location: Injection Pilot Study

Test Well: MW-13

\section{AQUIFER DATA}

Saturated Thickness: $15.24 \mathrm{~m}$

Anisotropy Ratio (Kz/Kr): 1.

\section{WELL DATA (MW-13)}

Initial Displacement: $1 . \mathrm{m}$

Total Well Penetration Depth: $7.616 \mathrm{~m}$

Casing Radius: $0.0254 \mathrm{~m}$
Static Water Column Height: $6.096 \mathrm{~m}$ Screen Length: $6.096 \mathrm{~m}$ Well Radius: $0.0254 \mathrm{~m}$

\section{SOLUTION}

Aquifer Model: Unconfined

Solution Method: Bouwer-Rice

$\mathrm{K}=13.26 \mathrm{~m} / \mathrm{day}$ yo $=1.475 \mathrm{~m}$ 


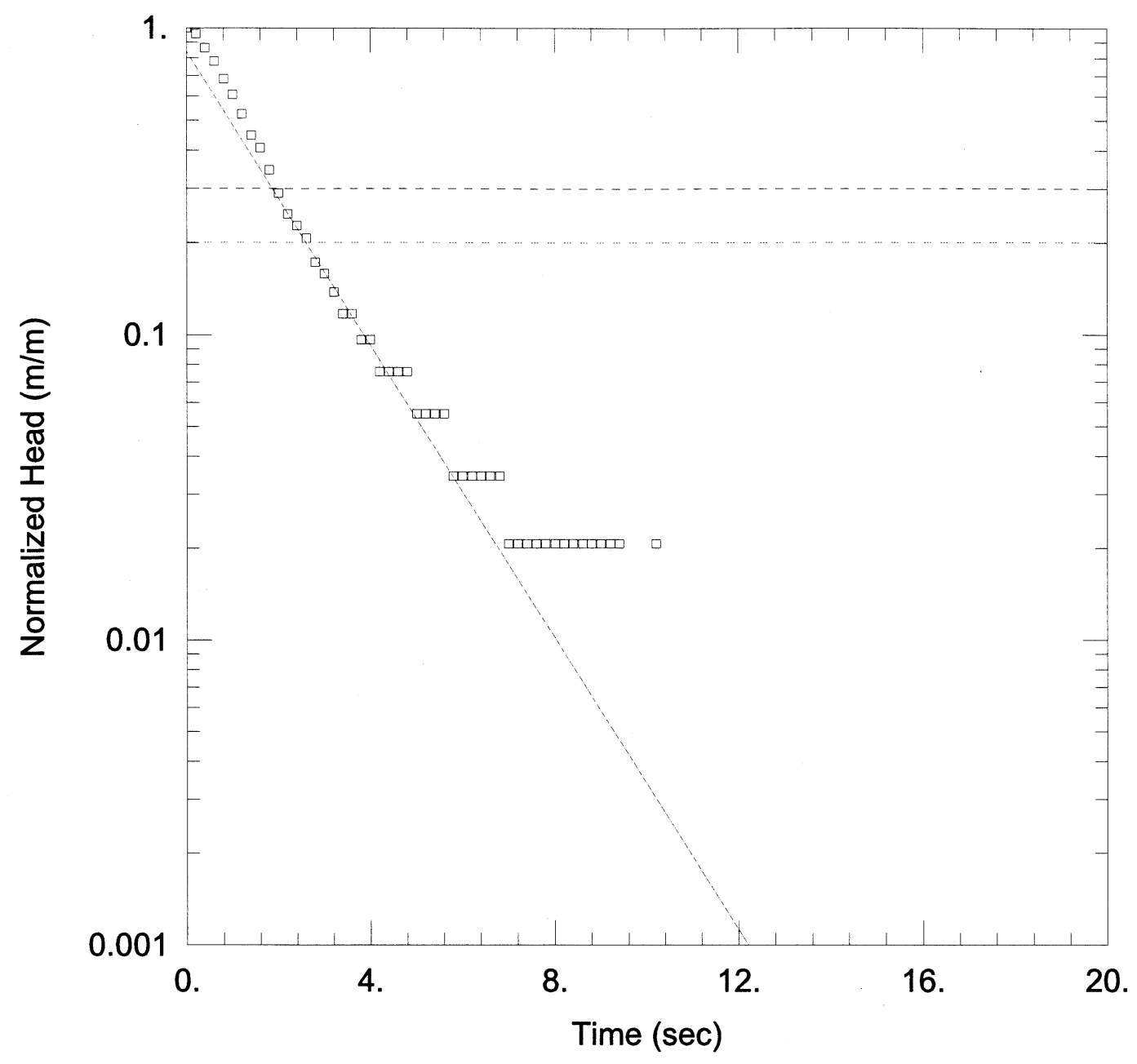

\section{WELL TEST ANALYSIS}

Data Set: E:I...IMW13_3.aqt

Date: 09/14/08

Time: 15:39:02

\section{PROJECT INFORMATION}

Company: University of Nebraska

Location: Injection Pilot Study

Test Well: MW-13

\section{AQUIFER DATA}

Saturated Thickness: $15.24 \mathrm{~m}$

Anisotropy Ratio $(\mathrm{Kz} / \mathrm{Kr}): 1$.

\section{WELL DATA (MW-13)}

Initial Displacement: $1 . \mathrm{m}$

Total Well Penetration Depth: $7.616 \mathrm{~m}$

Casing Radius: $0.0254 \mathrm{~m}$
Static Water Column Height: $6.096 \mathrm{~m}$

Screen Length: $6.096 \mathrm{~m}$

Well Radius: $0.0254 \mathrm{~m}$
Aquifer Model: Unconfined

$\mathrm{K}=10.02 \mathrm{~m} / \mathrm{day}$
Solution Method: Bouwer-Rice

y0 $=0.8368 \mathrm{~m}$ 


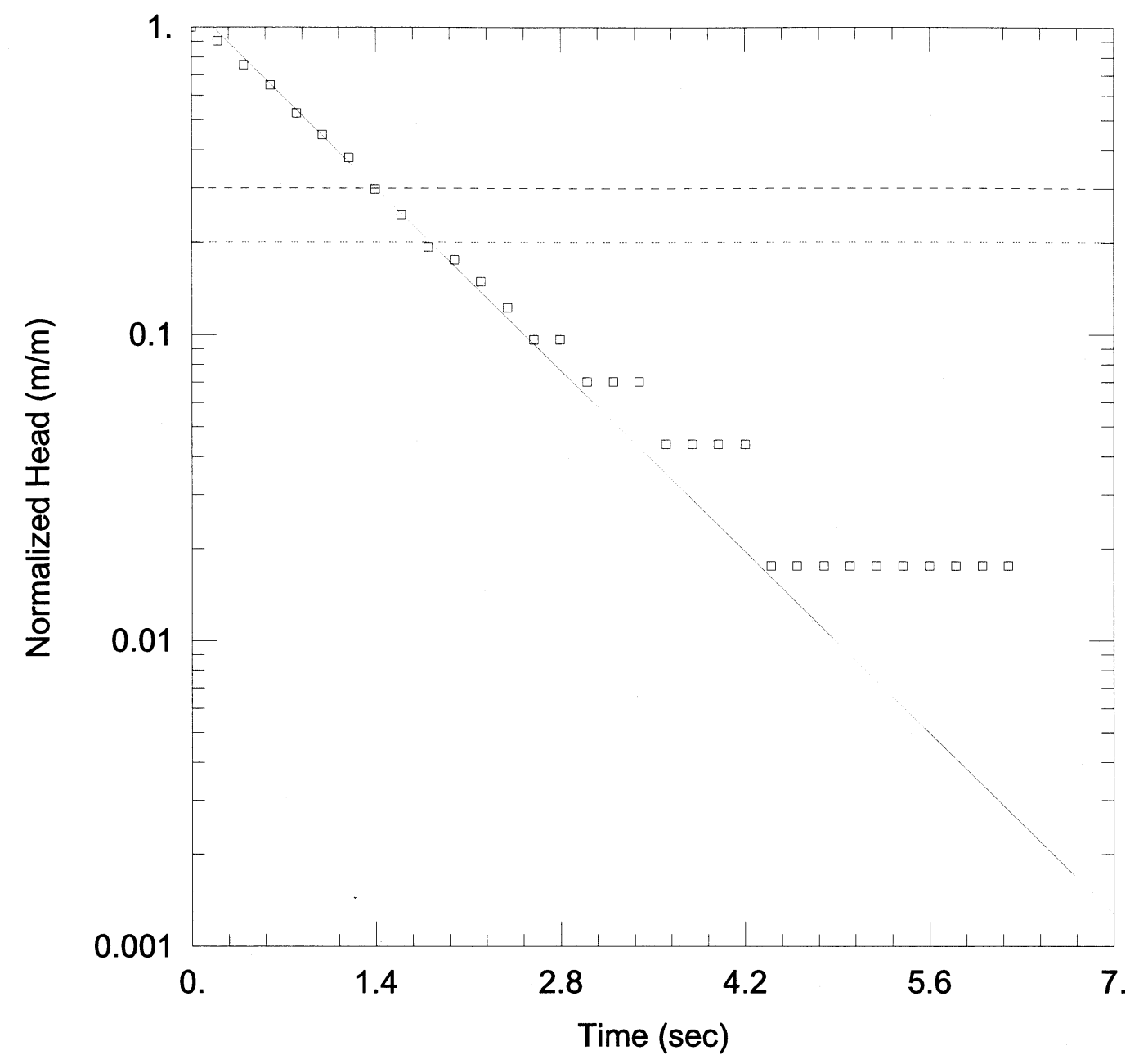

WELL TEST ANALYSIS

Data Set: E:I...IMW14_1.aqt

Date: $09 / 14 / 08$

Time: $15: 40: 24$

\section{PROJECT INFORMATION}

Company: University of Nebraska

Location: Injection Pilot Study

Test Well: MW-14

\section{AQUIFER DATA}

Saturated Thickness: $15.24 \mathrm{~m}$

Anisotropy Ratio (Kz/Kr): 1.

\section{WELL DATA (MW-14)}

Initial Displacement: 1. m

Total Well Penetration Depth: $7.616 \mathrm{~m}$

Casing Radius: $0.0254 \mathrm{~m}$
Static Water Column Height: $6.096 \mathrm{~m}$ Screen Length: $6.096 \mathrm{~m}$

Well Radius: $\underline{0.0254 \mathrm{~m}}$

\section{SOLUTION}

Aquifer Model: Unconfined

Solution Method: Bouwer-Rice

$\mathrm{K}=17.74 \mathrm{~m} / \mathrm{day}$

yo $=1.177 \mathrm{~m}$ 


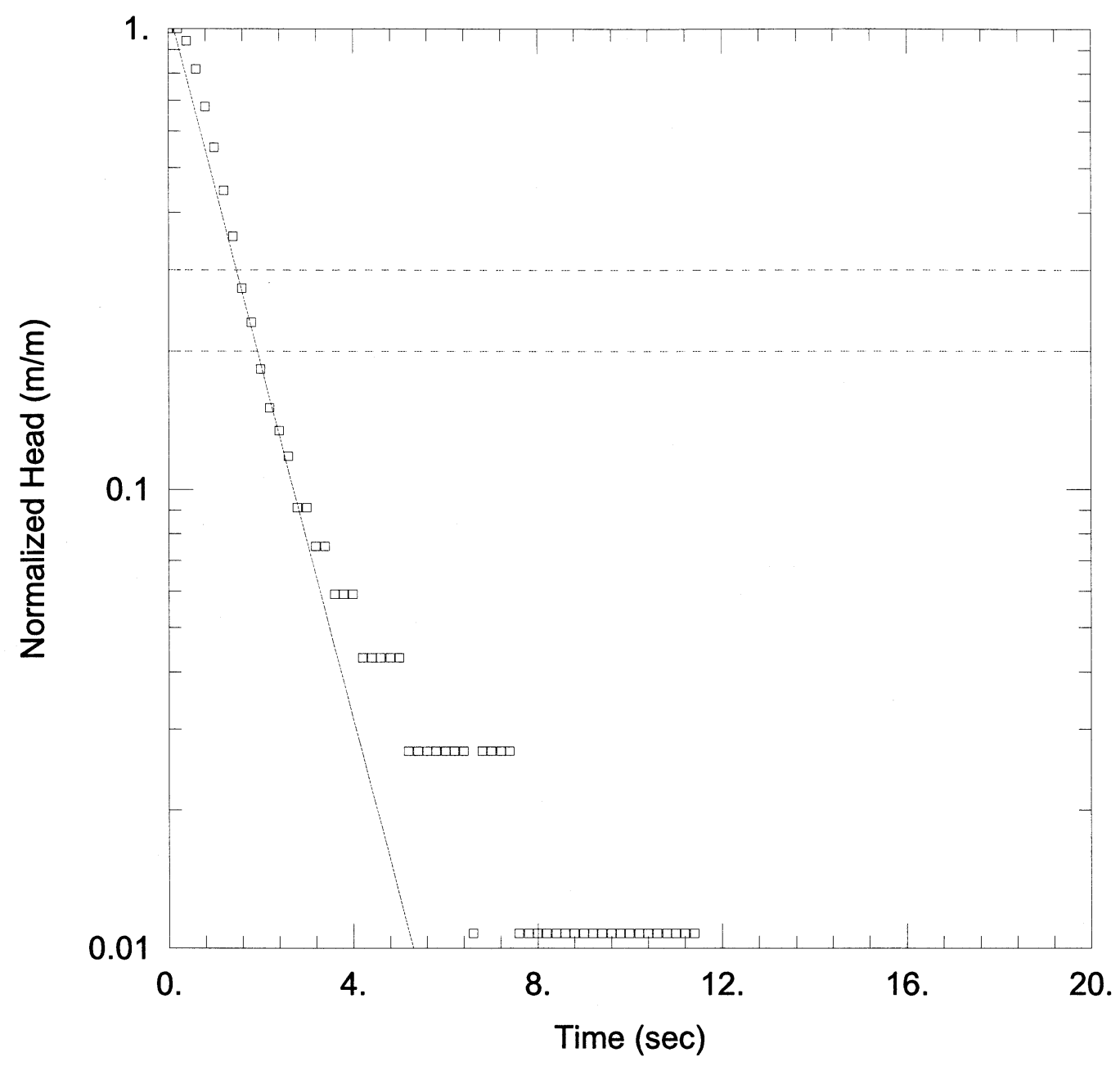

\section{WELL TEST ANALYSIS}

Data Set: E:I...IMW14_2.aqt

Date: $09 / 14 / 08$

Time: 15:41:02

\section{PROJECT INFORMATION}

Company: University of Nebraska

Location: Injection Pilot Study

Test Well: MW-14

\section{AQUIFER DATA}

Saturated Thickness: $15.24 \mathrm{~m}$

Anisotropy Ratio (Kz/Kr): 1.

WELL DATA (MW-14)

Initial Displacement: $1 . \mathrm{m}$

Total Well Penetration Depth: $7.616 \mathrm{~m}$

Casing Radius: $0.0254 \mathrm{~m}$
Static Water Column Height: 6.096 m Screen Length: $6.096 \mathrm{~m}$

Well Radius: $0.0254 \mathrm{~m}$

\section{SOLUTION}

Aquifer Model: Unconfined

Solution Method: Bouwer-Rice

$\mathrm{K}=16.15 \mathrm{~m} /$ day

y0 $=\underline{1.11 ~ m ~}$ 


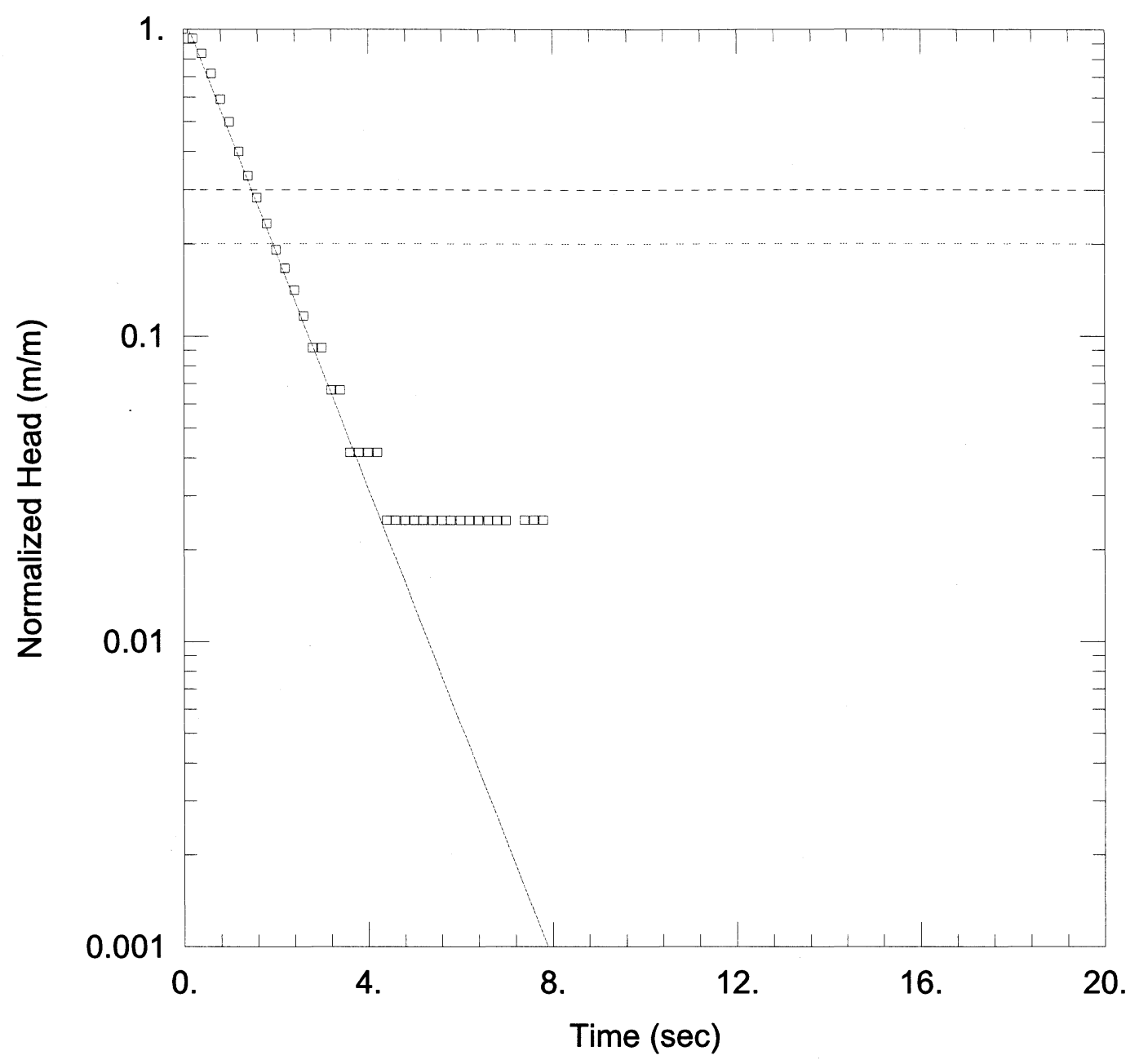

\section{WELL TEST ANALYSIS}

Data Set: E:I...IMW14_3.aqt

Date: $09 / 14 / 08$

Time: 15:41:38

\section{PROJECT INFORMATION}

Company: University of Nebraska

Location: Injection Pilot Study

Test Well: MW-14

\section{AQUIFER DATA}

Saturated Thickness: $15.24 \mathrm{~m}$

Anisotropy Ratio (Kz/Kr): 1.

WELL DATA (MW-14)

Initial Displacement: $1 . \mathrm{m}$

Total Well Penetration Depth: $7.616 \mathrm{~m}$

Casing Radius: $0.0254 \mathrm{~m}$
Static Water Column Height: $6.096 \mathrm{~m}$ Screen Length: $6.096 \mathrm{~m}$

Well Radius: $0.0254 \mathrm{~m}$

\section{SOLUTION}

Aquifer Model: Unconfined

Solution Method: Bouwer-Rice

$\mathrm{K}=16.15 \mathrm{~m} /$ day y0 $=1.11 \mathrm{~m}$ 


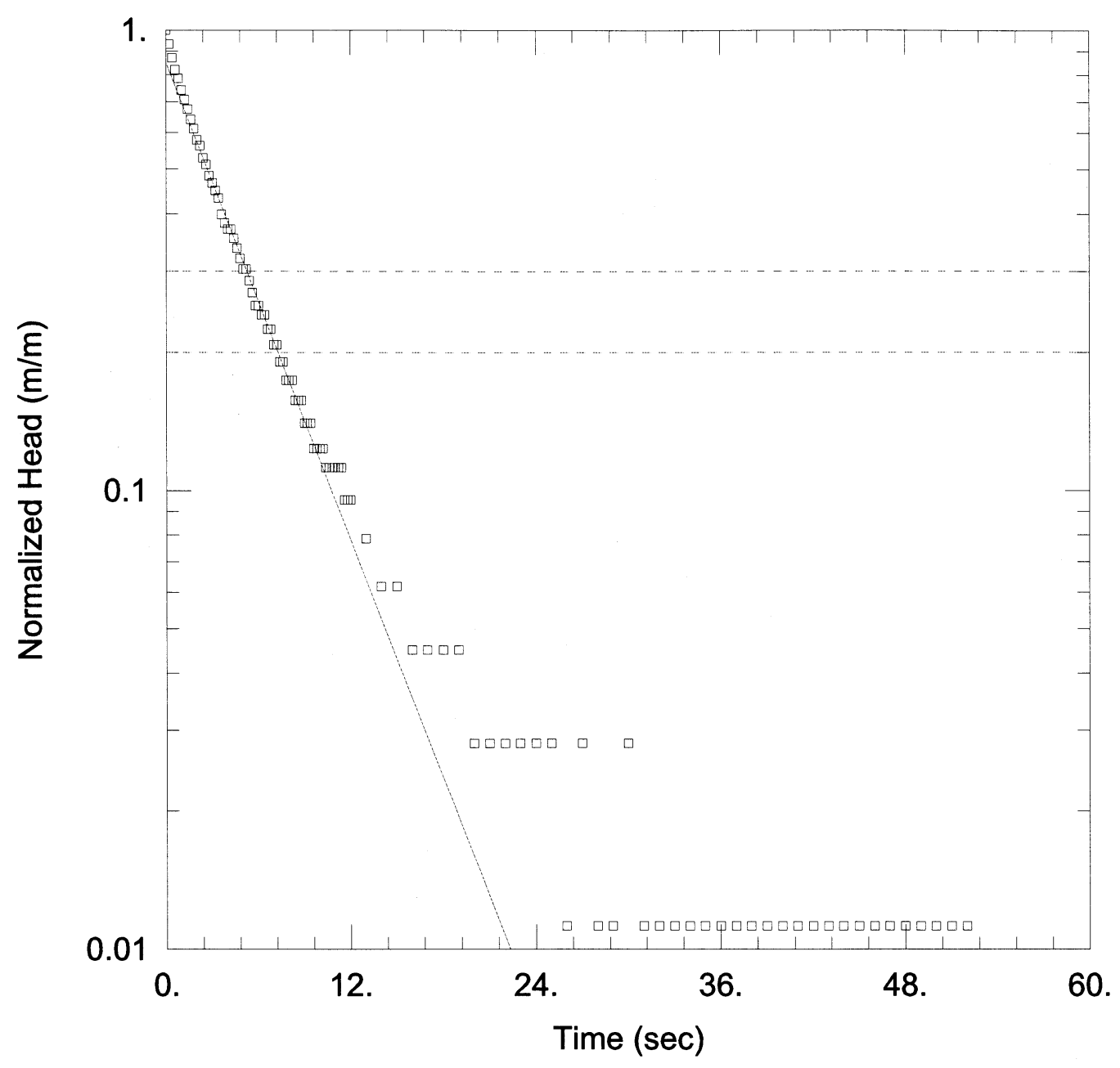

WELL TEST ANALYSIS

Data Set: E:I...IMW15_1.aqt

Date: $09 / 14 / 08$

Time: $15: 42: 43$

\section{PROJECT INFORMATION}

Company: University of Nebraska

Location: Injection Pilot Study

Test Well: MW-15

\section{AQUIFER DATA}

Saturated Thickness: $15.24 \mathrm{~m}$

Anisotropy Ratio (Kz/Kr): 1.

\section{WELL DATA (MW-15)}

Initial Displacement: 1. m

Total Well Penetration Depth: $7.616 \mathrm{~m}$

Casing Radius: $0.0508 \mathrm{~m}$
Static Water Column Height: $6.096 \mathrm{~m}$ Screen Length: $6.096 \mathrm{~m}$

Well Radius: $0.0508 \mathrm{~m}$

\section{SOLUTION}

Aquifer Model: Unconfined

Solution Method: Bouwer-Rice

$\mathrm{K}=\underline{12.38 \mathrm{~m} / \text { day }}$

y0 $=0.8506 \mathrm{~m}$ 


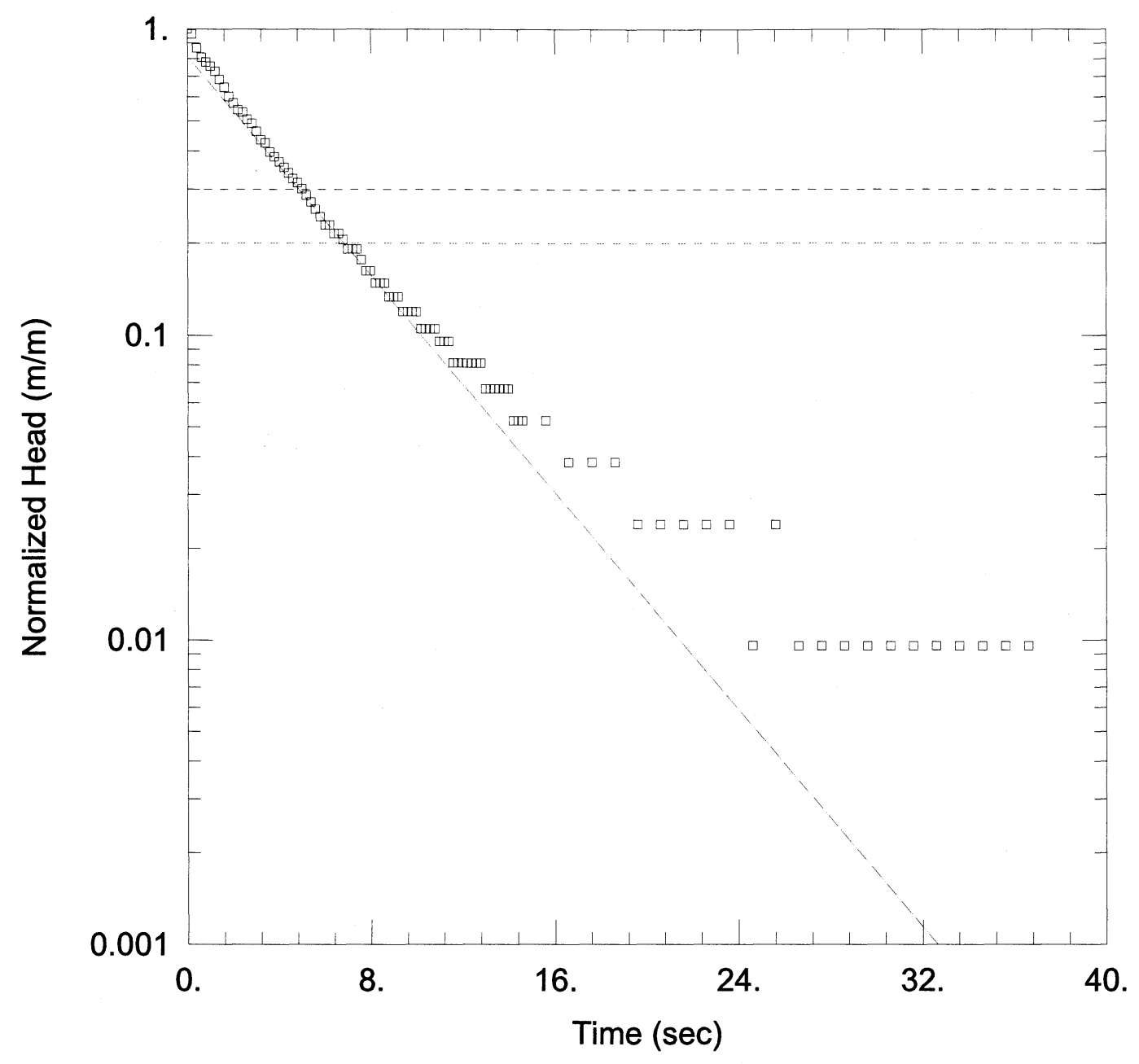

\begin{tabular}{|c|c|}
\hline \multicolumn{2}{|c|}{ WELL TEST ANALYSIS } \\
\hline $\begin{array}{l}\text { Data Set: E:I...IMW15_2.aqt } \\
\text { Date: } 09 / 14 / 08\end{array}$ & Time: $15: 43: 20$ \\
\hline \multicolumn{2}{|c|}{ PROJECT INFORMATION } \\
\hline \multicolumn{2}{|l|}{$\begin{array}{l}\text { Company: University of Nebraska } \\
\text { Location: Injection Pilot Study } \\
\text { Test Well: } \\
\text { MW-15 }\end{array}$} \\
\hline \multicolumn{2}{|c|}{ AQUIFER DATA } \\
\hline Saturated Thickness: $\underline{15.24} \mathrm{~m}$ & Anisotropy Ratio (Kz/Kr): 1. \\
\hline \multicolumn{2}{|c|}{ WELL DATA (MW-15) } \\
\hline $\begin{array}{l}\text { Initial Displacement: } 1 . \mathrm{m} \\
\text { Total Well Penetration Depth: } \underline{7.616 \mathrm{~m}} \\
\text { Casing Radius: } \underline{0.0508 \mathrm{~m}}\end{array}$ & $\begin{array}{l}\text { Static Water Column Height: } \underline{6.096 \mathrm{~m}} \\
\text { Screen Length: } 6.096 \mathrm{~m} \\
\text { Well Radius: } 0.0508 \mathrm{~m}\end{array}$ \\
\hline \multicolumn{2}{|c|}{ SOLUTION } \\
\hline Aquifer Model: Unconfined & Solution Method: Bouwer-Rice \\
\hline $\mathrm{K}=12.77 \mathrm{~m} / \mathrm{day}$ & $\mathrm{y} 0=0.8117 \mathrm{~m}$ \\
\hline
\end{tabular}




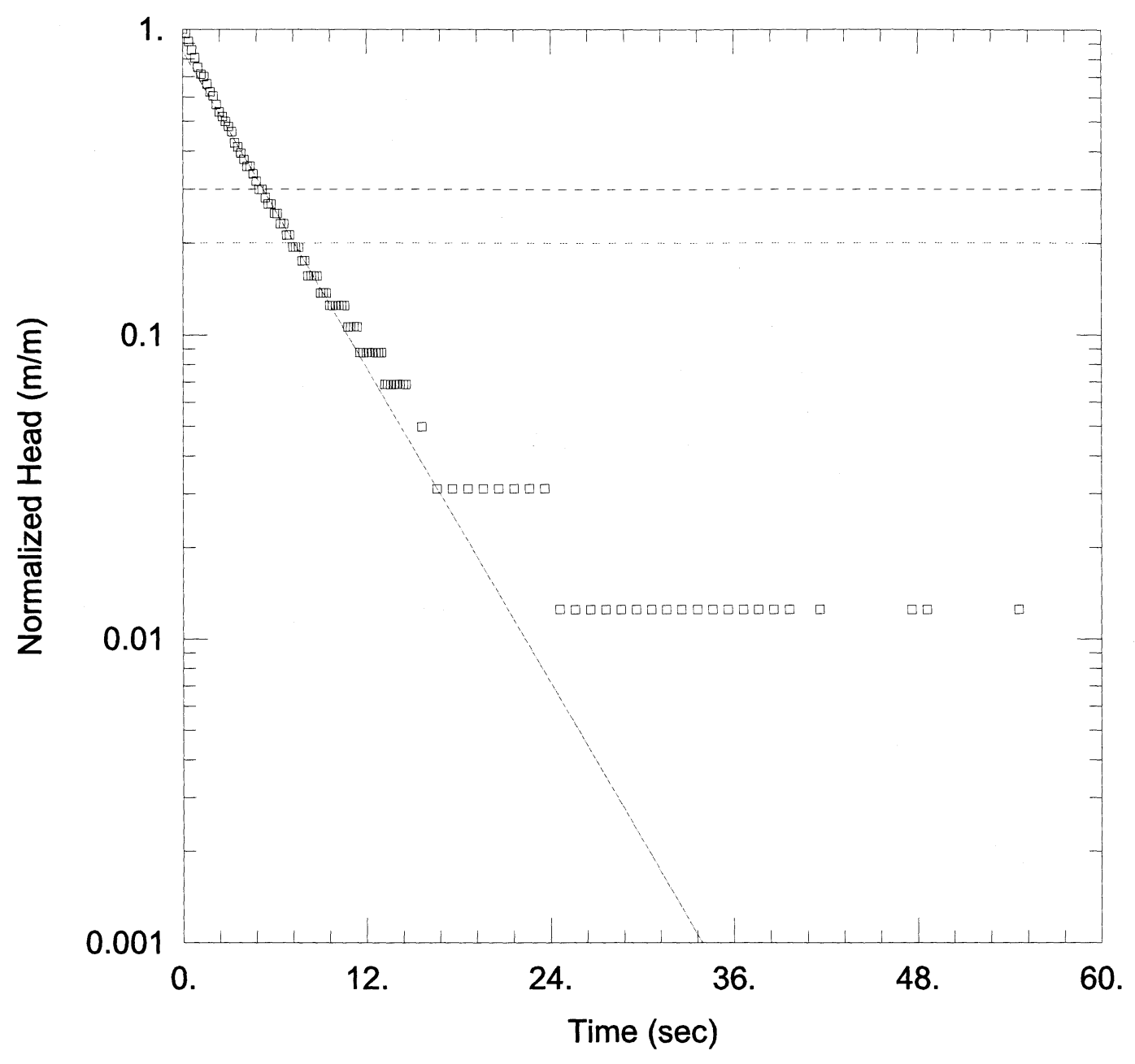

\section{WELL TEST ANALYSIS}

Data Set: E:I...IMW15_3.aqt

Date: $09 / 14 / 08$

Time: $15: 44: 06$

\section{PROJECT INFORMATION}

Company: University of Nebraska

Location: Injection Pilot Study

Test Well: MW-15

\section{AQUIFER DATA}

Saturated Thickness: $15.24 \mathrm{~m}$

Anisotropy Ratio (Kz/Kr): 1.

WELL DATA (MW-15)

Initial Displacement: $1 . \mathrm{m}$

Total Well Penetration Depth: $7.616 \mathrm{~m}$

Casing Radius: $0.0508 \mathrm{~m}$
Static Water Column Height: 6.096 m Screen Length: $6.096 \mathrm{~m}$ Well Radius: $0.0508 \mathrm{~m}$

\section{SOLUTION}

Aquifer Model: Unconfined

Solution Method: Bouwer-Rice

$\mathrm{K}=12.38 \mathrm{~m} /$ day y0 $=0.8506 \mathrm{~m}$ 


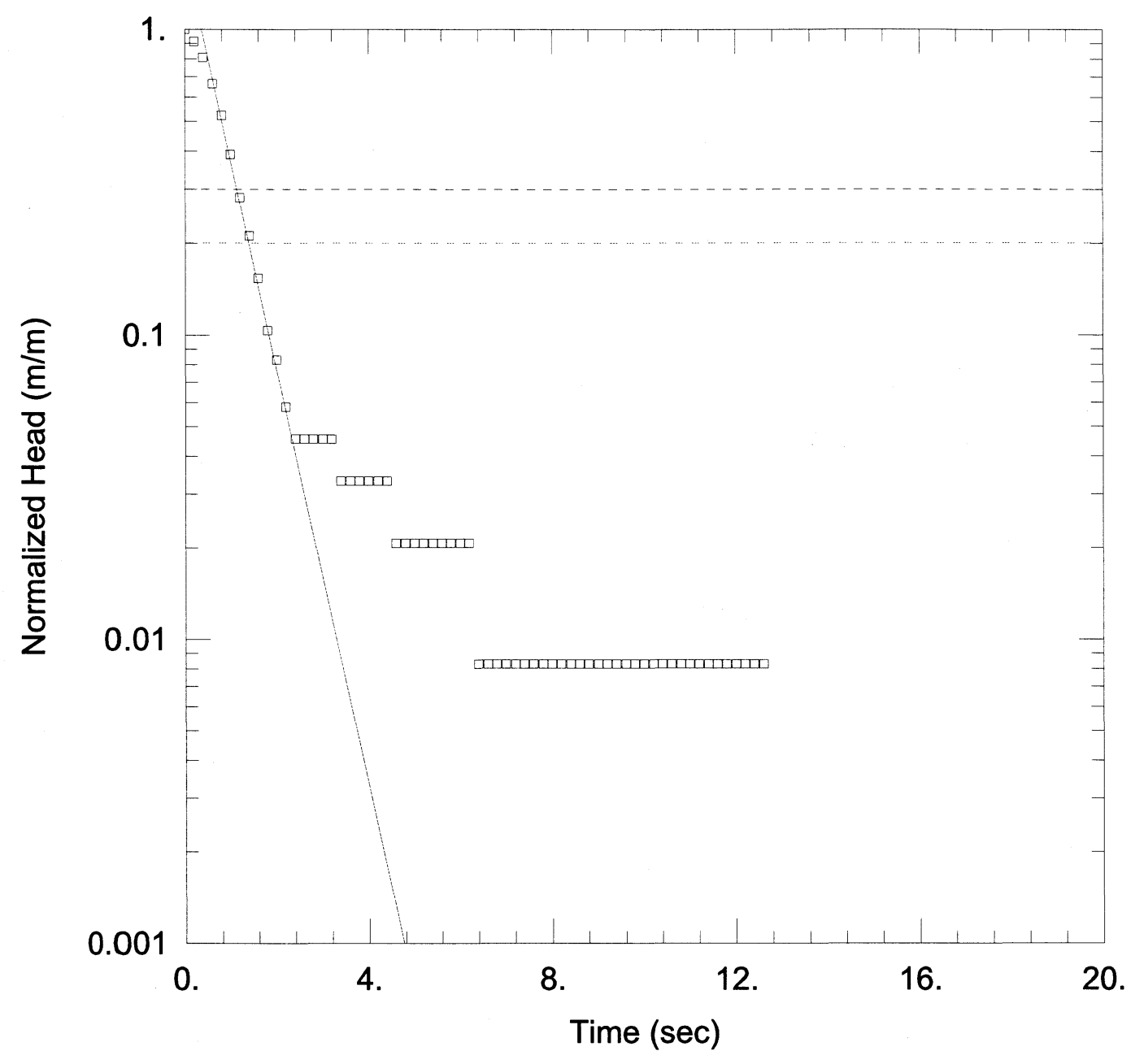

\section{WELL TEST ANALYSIS}

Data Set: E:L...IMW16_1.aqt

Date: $09 / 14 / 08$

Time: $15: 45: 18$

\section{PROJECT INFORMATION}

Company: University of Nebraska

Location: Injection Pilot Study

Test Well: MW-16

\section{AQUIFER DATA}

Saturated Thickness: $15.24 \mathrm{~m}$

Anisotropy Ratio (Kz/Kr): 1.

\section{WELL DATA (MW-16)}

Initial Displacement: 1. m

Total Well Penetration Depth: $7.616 \mathrm{~m}$

Casing Radius: $0.0254 \mathrm{~m}$
Static Water Column Height: 6.096 m

Screen Length: $6.096 \mathrm{~m}$

Well Radius: $0.0254 \mathrm{~m}$

\section{SOLUTION}

Aquifer Model: Unconfined

Solution Method: Bouwer-Rice

$\mathrm{K}=28.55 \mathrm{~m} / \mathrm{day}$

y0 $=1.758 \mathrm{~m}$ 


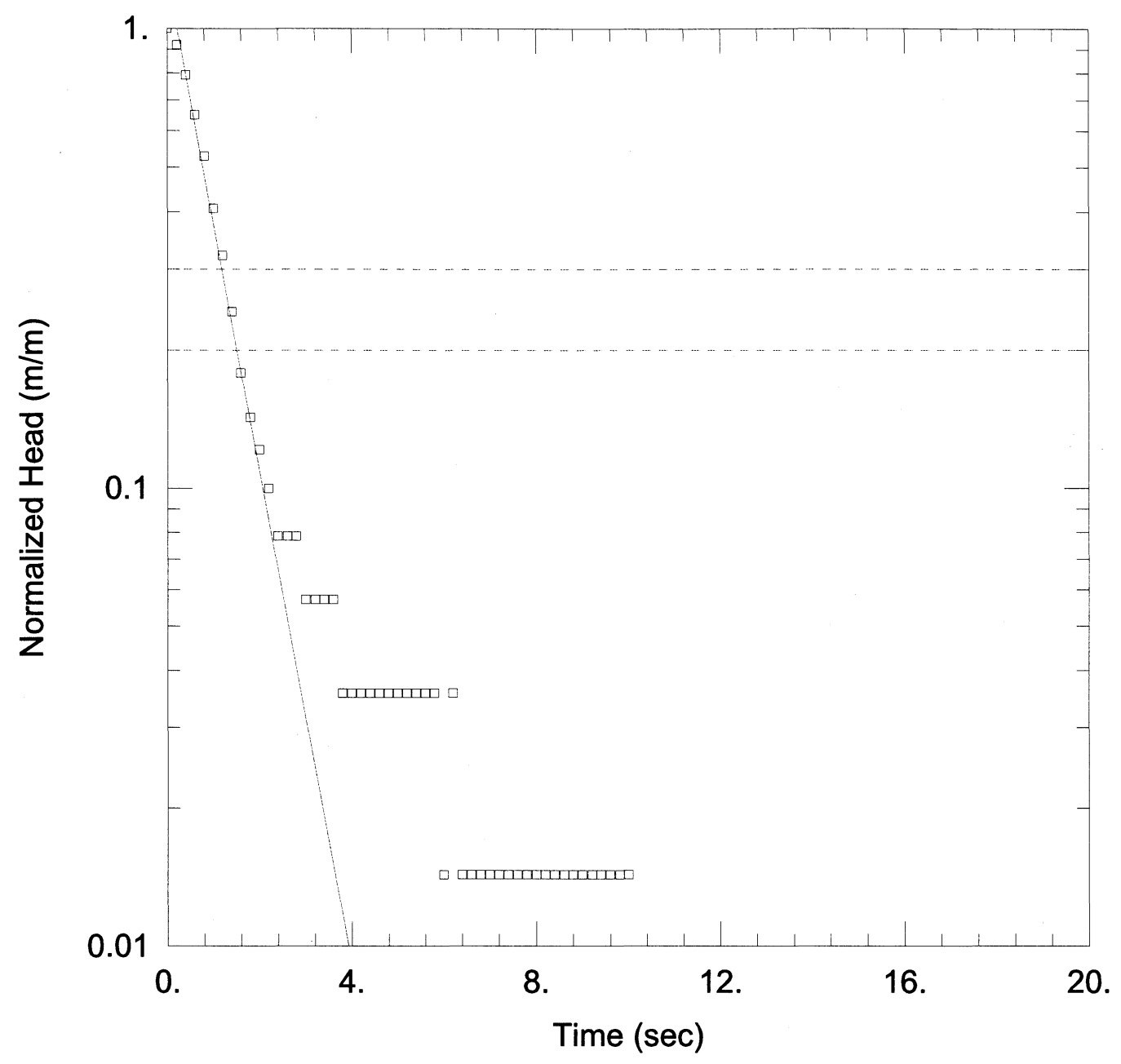

\section{WELL TEST ANALYSIS}

Data Set: E:I...IMW16_2.aqt

Date: $09 / 14 / 08$

Time: $15: 45: 49$

\section{PROJECT INFORMATION}

Company: University of Nebraska

Location: Injection Pilot Study

Test Well: MW-16

\section{AQUIFER DATA}

Saturated Thickness: $15.24 \mathrm{~m}$

Anisotropy Ratio (Kz/Kr): 1.

WELL DATA (MW-16)

Initial Displacement: $1 . \mathrm{m}$

Total Well Penetration Depth: $7.616 \mathrm{~m}$

Casing Radius: $0.0254 \mathrm{~m}$
Static Water Column Height: $6.096 \mathrm{~m}$ Screen Length: $6.096 \mathrm{~m}$

Well Radius: $0.0254 \mathrm{~m}$

\section{SOLUTION}

Aquifer Model: Unconfined

Solution Method: Bouwer-Rice

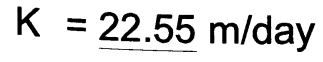
$\mathrm{y} 0=1.313 \mathrm{~m}$ 


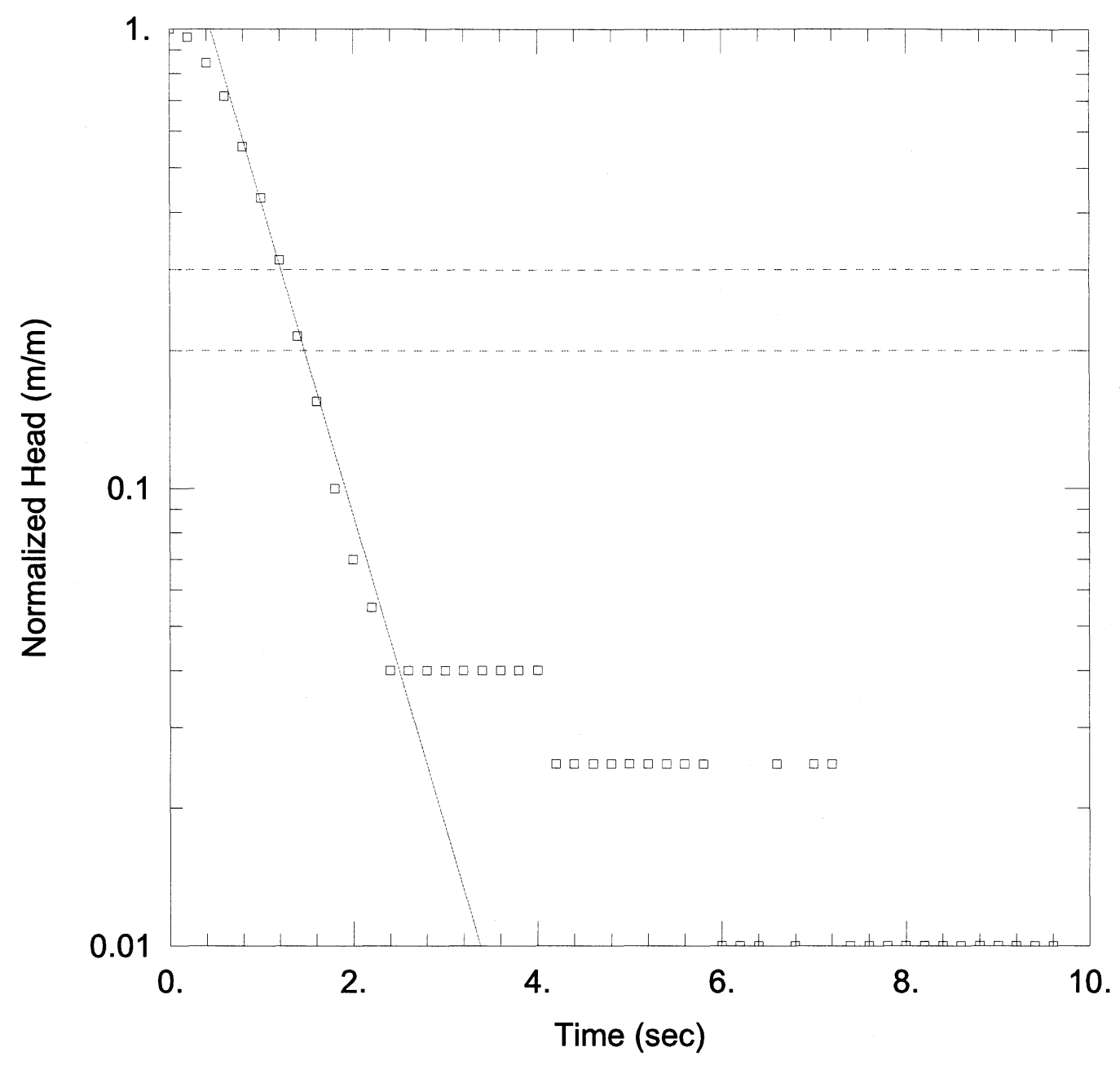

\section{WELL TEST ANALYSIS}

Data Set: E:I...MW16_3.aqt

Date: $09 / 14 / 08$

Time: $15: 46: 30$

\section{PROJECT INFORMATION}

Company: University of Nebraska

Location: Injection Pilot Study

Test Well: MW-16

\section{AQUIFER DATA}

Saturated Thickness: $15.24 \mathrm{~m}$

Anisotropy Ratio $(\mathrm{Kz} / \mathrm{Kr})$ : 1.

\section{WELL DATA (MW-16)}

Initial Displacement: $1 . \mathrm{m}$

Total Well Penetration Depth: $7.616 \mathrm{~m}$

Casing Radius: $0.0254 \mathrm{~m}$
Static Water Column Height: 6.096 m Screen Length: $6.096 \mathrm{~m}$

Well Radius: $0.0254 \mathrm{~m}$

\section{SOLUTION}

Aquifer Model: Unconfined

Solution Method: Bouwer-Rice

$\mathrm{K}=28.55 \mathrm{~m} / \mathrm{day}$

yo $=2.019 \mathrm{~m}$ 


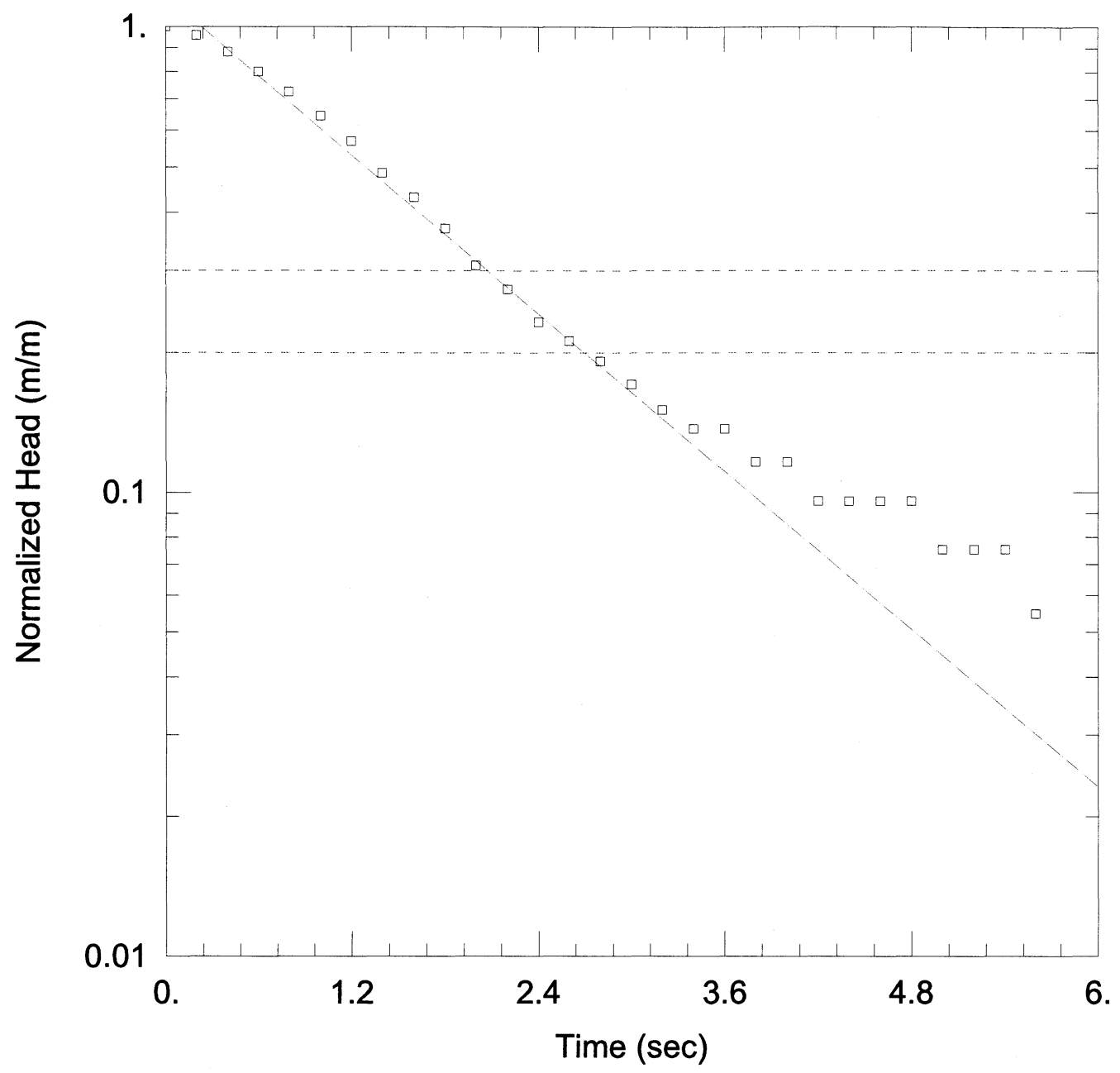

\section{WELL TEST ANALYSIS}

Data Set: E:I...IMW17_1.aqt

Date: $09 / 14 / 08$
Time: $15: 47: 24$

\section{PROJECT INFORMATION}

Company: University of Nebraska

Location: Injection Pilot Study

Test Well: MW-17

\section{AQUIFER DATA}

Saturated Thickness: $15.24 \mathrm{~m}$

Anisotropy Ratio (Kz/Kr): 1.

\section{WELL DATA (MW-17)}

Initial Displacement: $1 . \mathrm{m}$

Total Well Penetration Depth: $7.616 \mathrm{~m}$

Casing Radius: $0.0254 \mathrm{~m}$
Static Water Column Height: $6.096 \mathrm{~m}$

Screen Length: $6.096 \mathrm{~m}$

Well Radius: $0.0254 \mathrm{~m}$

\section{SOLUTION}

Aquifer Model: Unconfined

Solution Method: Bouwer-Rice

$\mathrm{K}=11.86 \mathrm{~m} / \mathrm{day}$ 


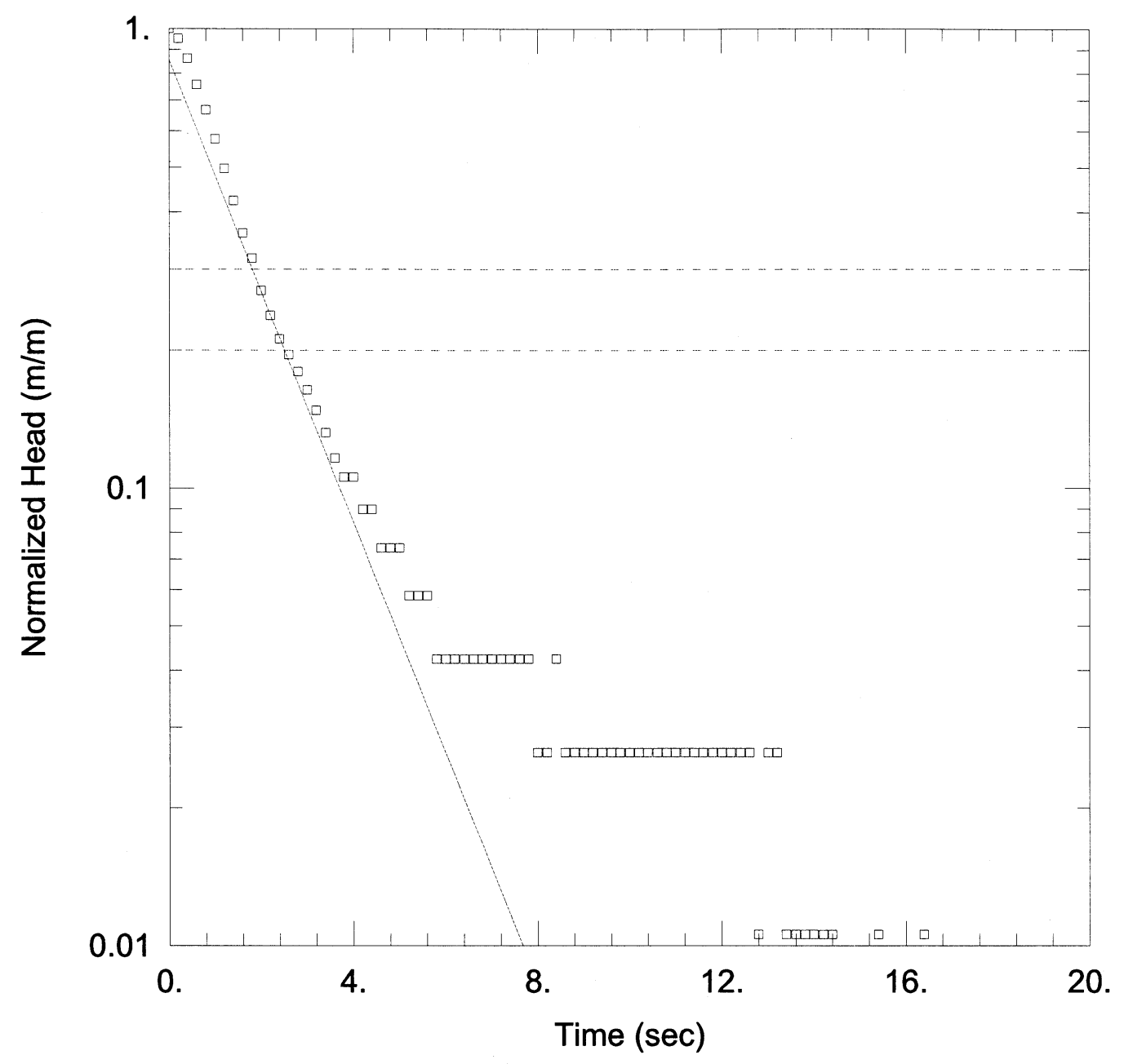

\section{WELL TEST ANALYSIS}

Data Set: E:I...IMW17_2.aqt

Date: $09 / 14 / 08$

Time: 15:48:04

\section{PROJECT INFORMATION}

Company: University of Nebraska

Location: Injection Pilot Study

Test Well: MW-17

\section{AQUIFER DATA}

Saturated Thickness: $15.24 \mathrm{~m}$

Anisotropy Ratio $(\mathrm{Kz} / \mathrm{Kr}): 1$.

WELL DATA (MW-17)

Initial Displacement: 1. m

Total Well Penetration Depth: $7.616 \mathrm{~m}$

Casing Radius: $0.0254 \mathrm{~m}$
Static Water Column Height: $6.096 \mathrm{~m}$ Screen Length: $6.096 \mathrm{~m}$

Well Radius: $0.0254 \mathrm{~m}$

\section{SOLUTION}

Aquifer Model: Unconfined

Solution Method: Bouwer-Rice

$\mathrm{K}=10.54 \mathrm{~m} / \mathrm{day}$ y0 $=0.8551 \mathrm{~m}$ 


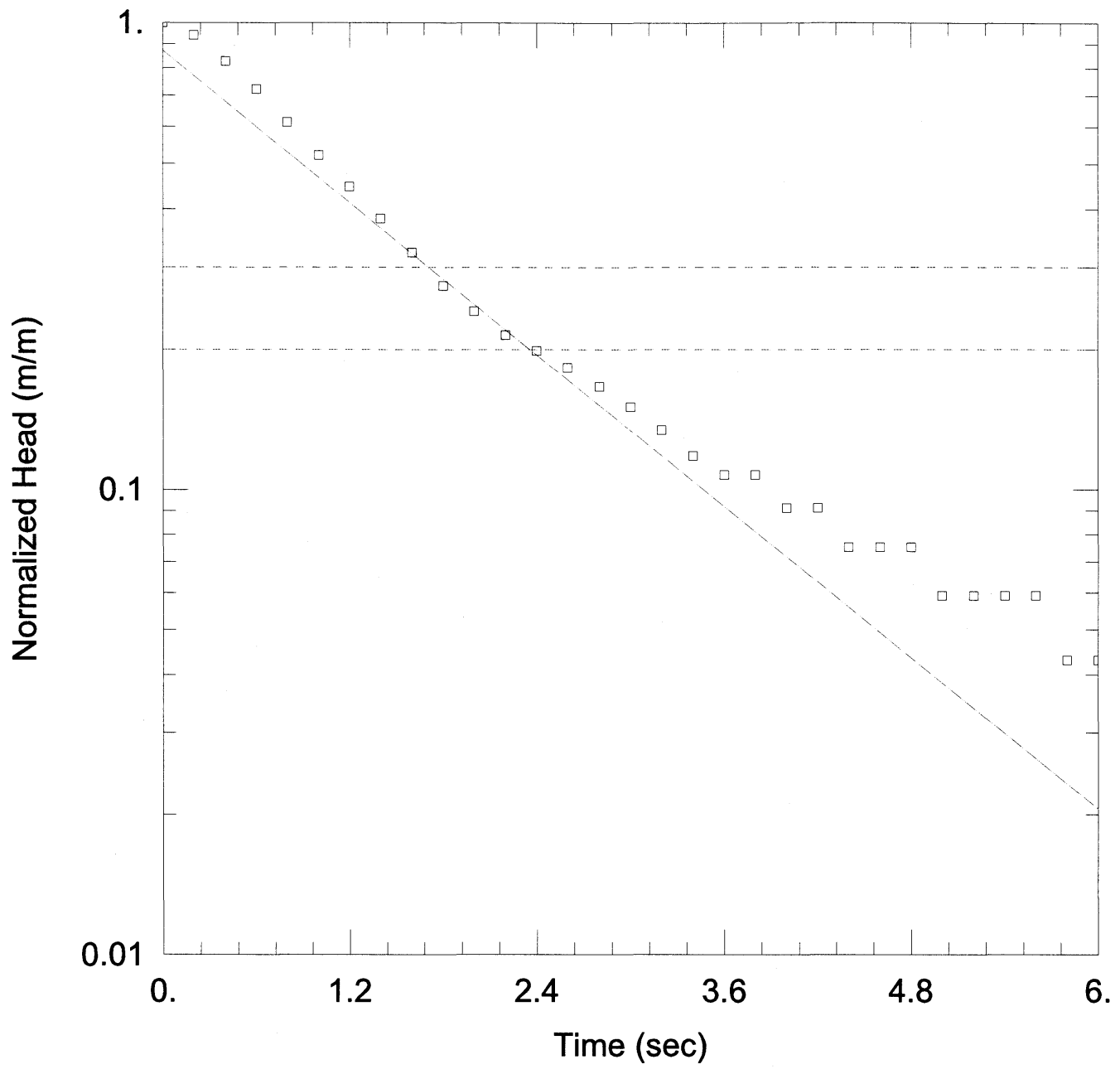

\section{WELL TEST ANALYSIS}

Data Set: E:I...IMW17_3.aqt

Date: $09 / 14 / 08$
Time: $15: 48: 38$

\section{PROJECT INFORMATION}

Company: University of Nebraska

Location: Injection Pilot Study

Test Well: MW-17

\section{AQUIFER DATA}

Saturated Thickness: $15.24 \mathrm{~m}$

Anisotropy Ratio (Kz/Kr): 1.

\section{WELL DATA (MW-17)}

Initial Displacement: 1. m

Total Well Penetration Depth: $7.616 \mathrm{~m}$

Casing Radius: $0.0254 \mathrm{~m}$
Static Water Column Height: $6.096 \mathrm{~m}$

Screen Length: $6.096 \mathrm{~m}$

Well Radius: $0.0254 \mathrm{~m}$

\section{SOLUTION}

Aquifer Model: Unconfined

Solution Method: Bouwer-Rice

$\mathrm{K}=11.35 \mathrm{~m} / \mathrm{day}$

$\mathrm{y} 0=0.871 \mathrm{~m}$ 


\section{APPENDIX D}

Full Screen Pneumatic Slug Test Results

Post Sodium Permanganate Injection 


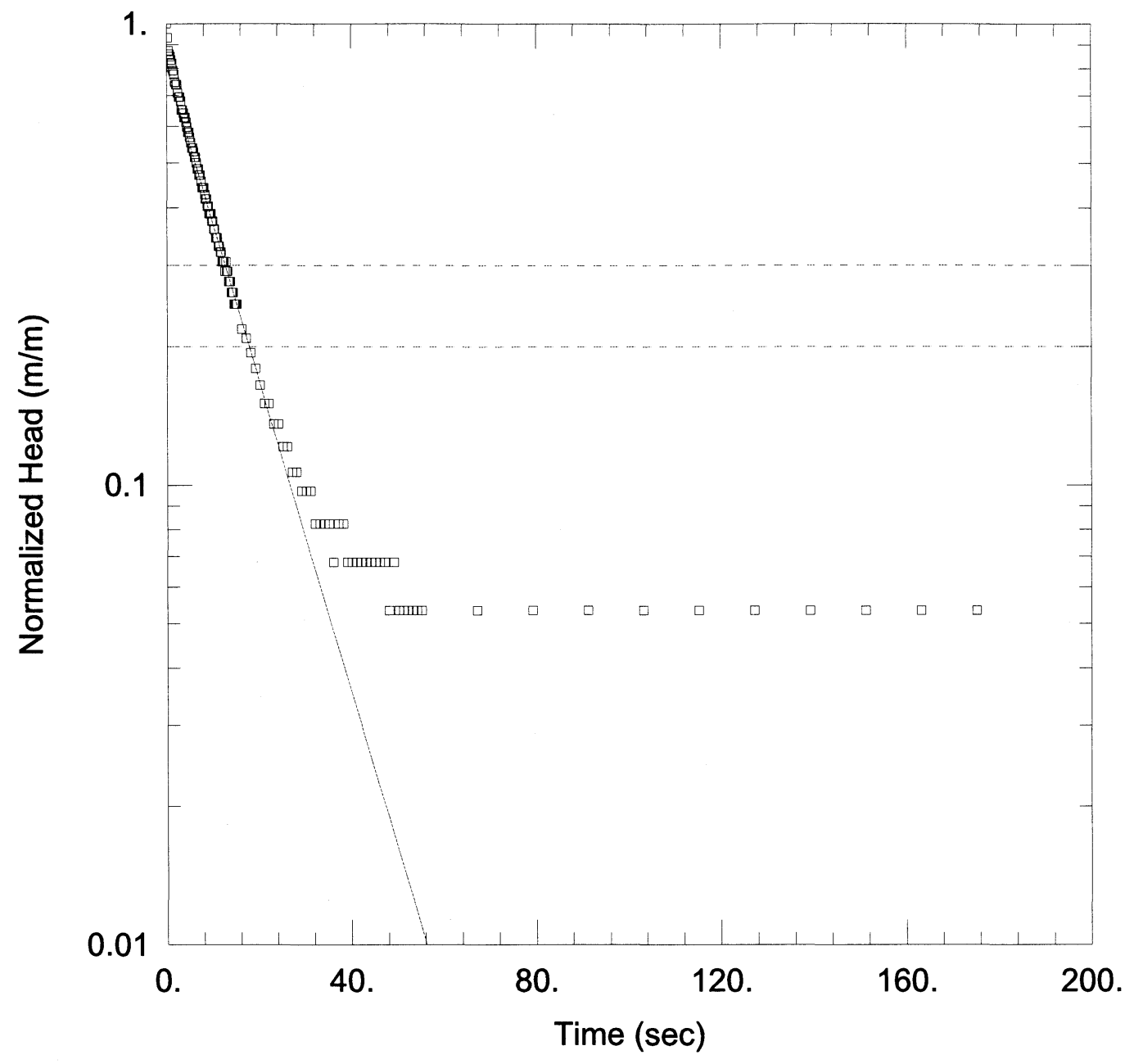

\section{WELL TEST ANALYSIS}

Data Set: E:I...IVW-1_1.aqt

Date: $09 / 20 / 08$

Time: 11:17:48

\section{PROJECT INFORMATION}

Company: University of Nebraska

Location: Injection Pilot Study

Test Well: IW-1

\section{AQUIFER DATA}

Saturated Thickness: $15.24 \mathrm{~m}$

Anisotropy Ratio (Kz/Kr): 1 .

WELL DATA (IW-1)

Initial Displacement: $1 . \mathrm{m}$

Total Well Penetration Depth: $7.616 \mathrm{~m}$

Casing Radius: $0.0508 \mathrm{~m}$
Static Water Column Height: 6.096 m Screen Length: $6.096 \mathrm{~m}$

Well Radius: $0.0508 \mathrm{~m}$

\section{SOLUTION}

Aquifer Model: Unconfined

Solution Method: Bouwer-Rice

$\mathrm{K}=4.859 \mathrm{~m} / \mathrm{day}$

$\mathrm{y} 0=0.8041 \mathrm{~m}$ 


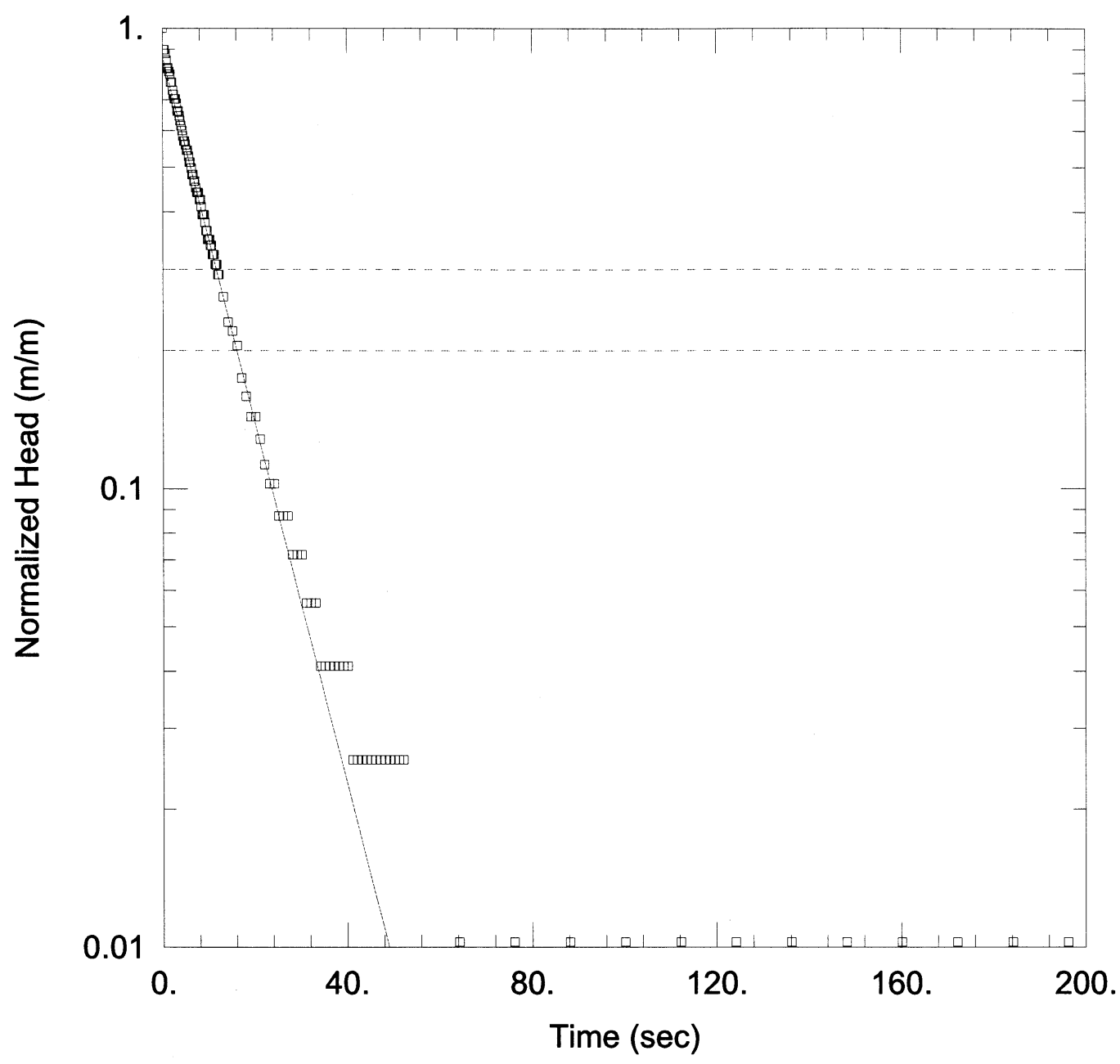

WELL TEST ANALYSIS

Data Set: E:I...IIW-1_2.aqt

Date: 09/20/08

Time: 11:18:03

\section{PROJECT INFORMATION}

Company: University of Nebraska

Location: Injection Pilot Study

Test Well: IW-1

\section{AQUIFER DATA}

Saturated Thickness: $15.24 \mathrm{~m}$

Anisotropy Ratio (Kz/Kr): 1.

WELL DATA (IW-1)

Initial Displacement: $1 . \mathrm{m}$

Total Well Penetration Depth: $7.616 \mathrm{~m}$

Casing Radius: $0.0508 \mathrm{~m}$
Static Water Column Height: $6.096 \mathrm{~m}$ Screen Length: $6.096 \mathrm{~m}$

Well Radius: $0.0508 \mathrm{~m}$

\section{SOLUTION}

Aquifer Model: Unconfined

Solution Method: Bouwer-Rice

$\mathrm{K}=5.664 \mathrm{~m} / \mathrm{day}$

$\mathrm{y} 0=\underline{0.8643} \mathrm{~m}$ 


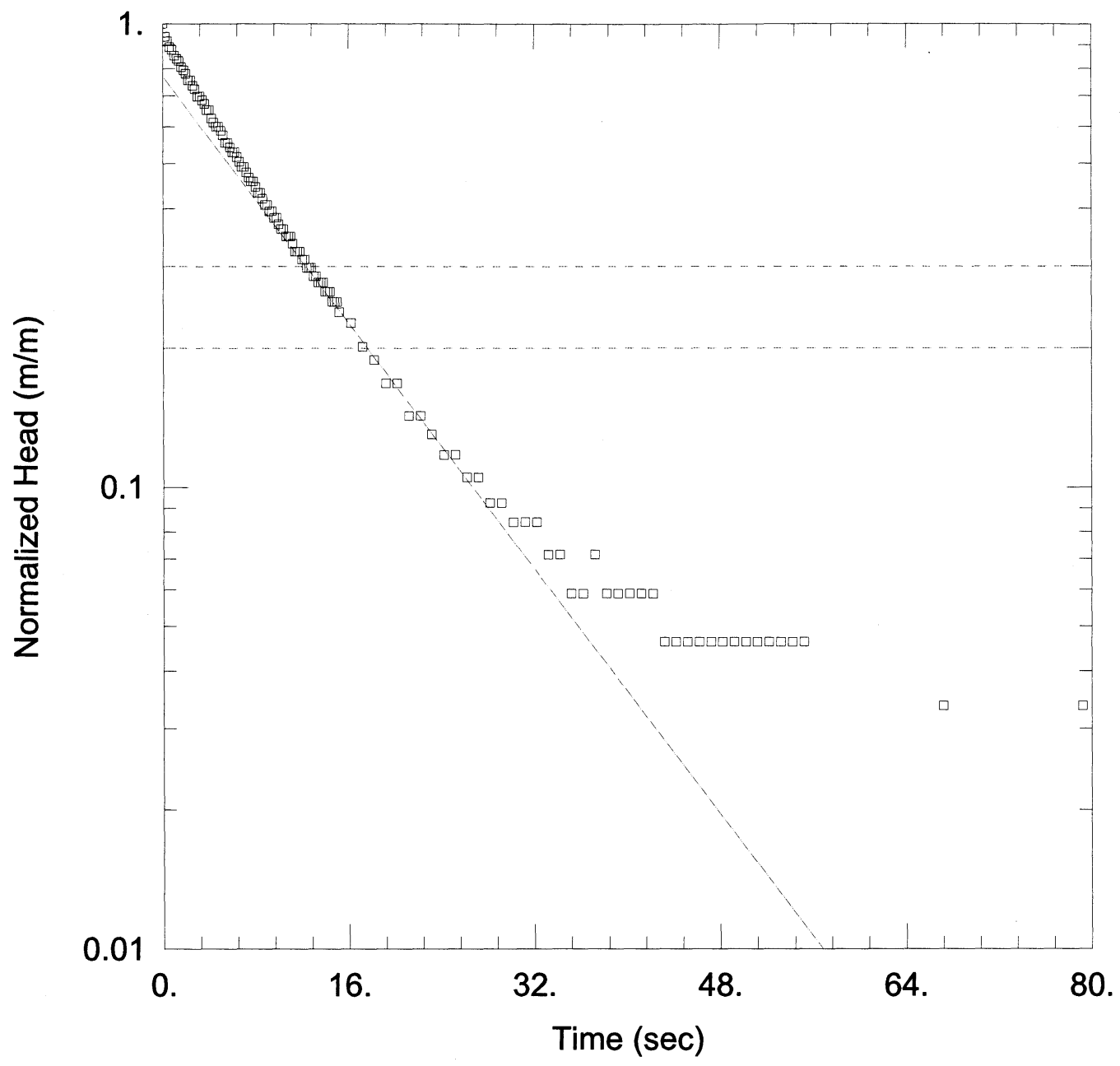

WELL TEST ANALYSIS

Data Set: E:I...IVW-1_3.aqt

Date: $09 / 20 / 08$

Time: 11:18:18

PROJECT INFORMATION

Company: University of Nebraska

Location: Injection Pilot Study

Test Well: IW-1

\section{AQUIFER DATA}

Saturated Thickness: $15.24 \mathrm{~m}$

Anisotropy Ratio $(\mathrm{Kz} / \mathrm{Kr})$ : 1.

WELL DATA (IW-1)

Initial Displacement: 1. m

Total Well Penetration Depth: $7.616 \mathrm{~m}$

Casing Radius: $0.0508 \mathrm{~m}$
Static Water Column Height: $6.096 \mathrm{~m}$ Screen Length: $6.096 \mathrm{~m}$ Well Radius: $0.0508 \mathrm{~m}$

\section{SOLUTION}

Aquifer Model: Unconfined

Solution Method: Bouwer-Rice

$\mathrm{K}=4.761 \mathrm{~m} / \mathrm{day}$

$\mathrm{y} 0=\underline{0.7693 \mathrm{~m}}$ 


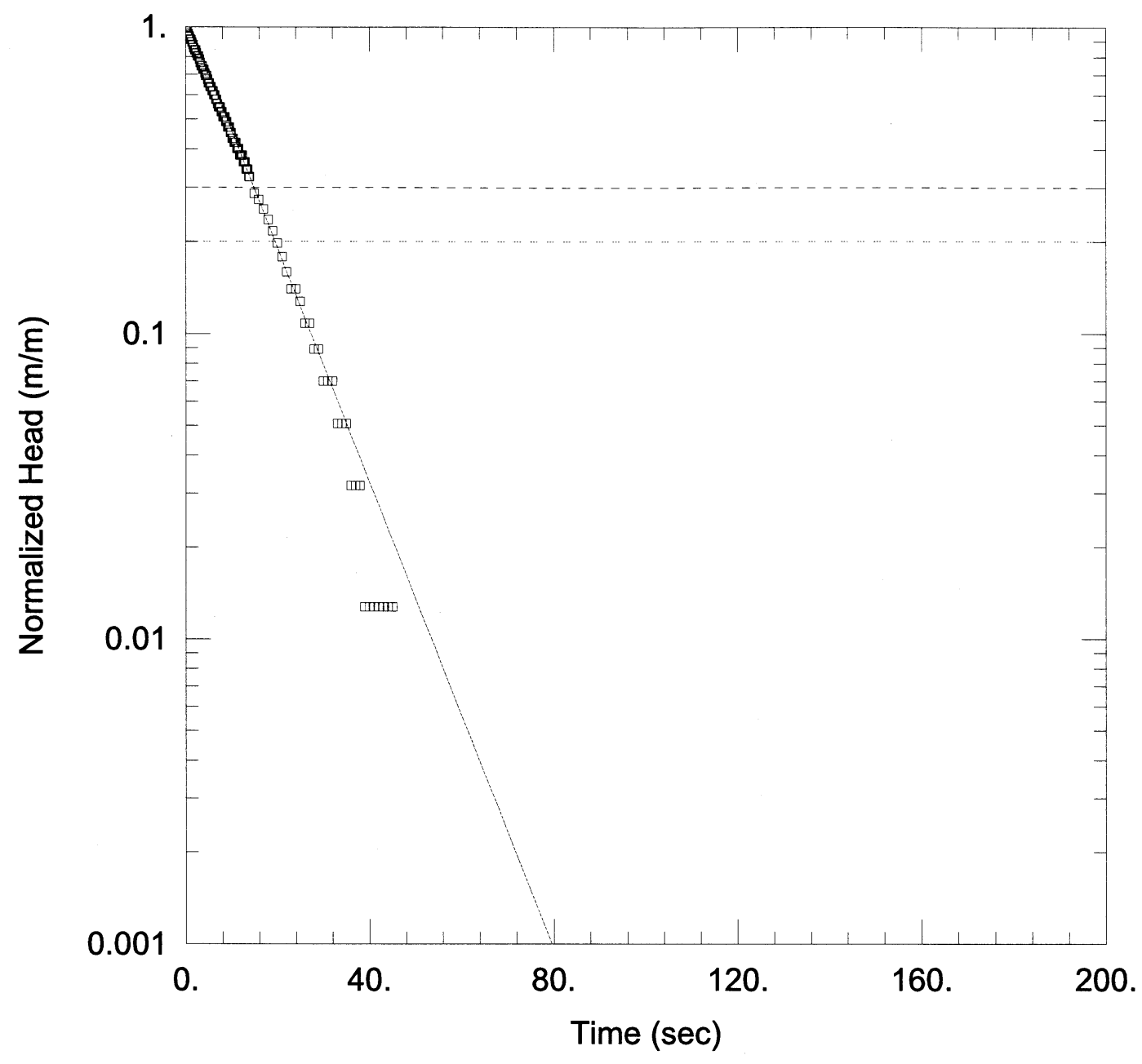

WELL TEST ANALYSIS

Data Set: E:I...IIW-2_1.aqt

Date: 09/20/08

Time: 11:18:40

PROJECT INFORMATION

Company: University of Nebraska

Location: Injection Pilot Study

Test Well: IW-2

\section{AQUIFER DATA}

Saturated Thickness: $15.24 \mathrm{~m}$

Anisotropy Ratio (Kz/Kr): 1.

WELL DATA (IW-2)

Initial Displacement: $1 . \mathrm{m}$

Total Well Penetration Depth: $\underline{7.616 \mathrm{~m}}$

Casing Radius: $0.0508 \mathrm{~m}$

Static Water Column Height: $6.096 \mathrm{~m}$

Screen Length: $6.096 \mathrm{~m}$

Well Radius: $\underline{0.0508 \mathrm{~m}}$

\section{SOLUTION}

Aquifer Model: Unconfined

Solution Method: Bouwer-Rice

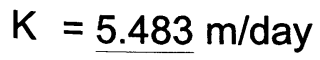

$\mathrm{y} 0=1.109 \mathrm{~m}$ 


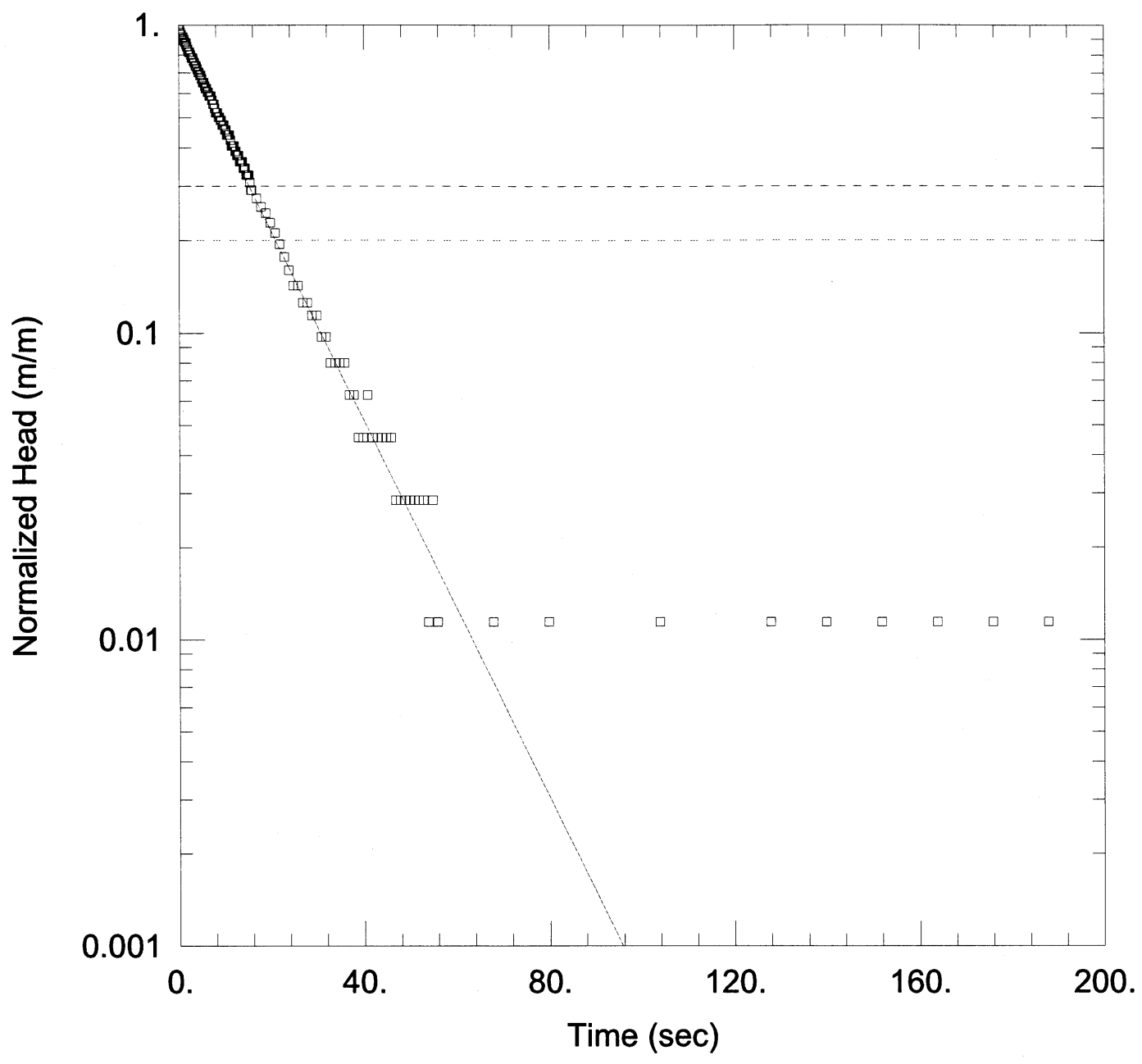

WELL TEST ANALYSIS

Data Set: E:I...IIW-2_2.aqt

Date: $09 / 20 / 08$

Time: 11:18:54

\section{PROJECT INFORMATION}

Company: University of Nebraska

Location: Injection Pilot Study

Test Well: IW-2

\section{AQUIFER DATA}

Saturated Thickness: $15.24 \mathrm{~m}$

Anisotropy Ratio (Kz/Kr): 1.

WELL DATA (IW-2)

Initial Displacement: 1. m

Total Well Penetration Depth: $7.616 \mathrm{~m}$

Casing Radius: $0.0508 \mathrm{~m}$
Static Water Column Height: $6.096 \mathrm{~m}$ Screen Length: $6.096 \mathrm{~m}$ Well Radius: $0.0508 \mathrm{~m}$

\section{SOLUTION}

Aquifer Model: Unconfined

Solution Method: Bouwer-Rice

$\mathrm{K}=4.408 \mathrm{~m} / \mathrm{day}$

y0 $=0.878 \mathrm{~m}$ 


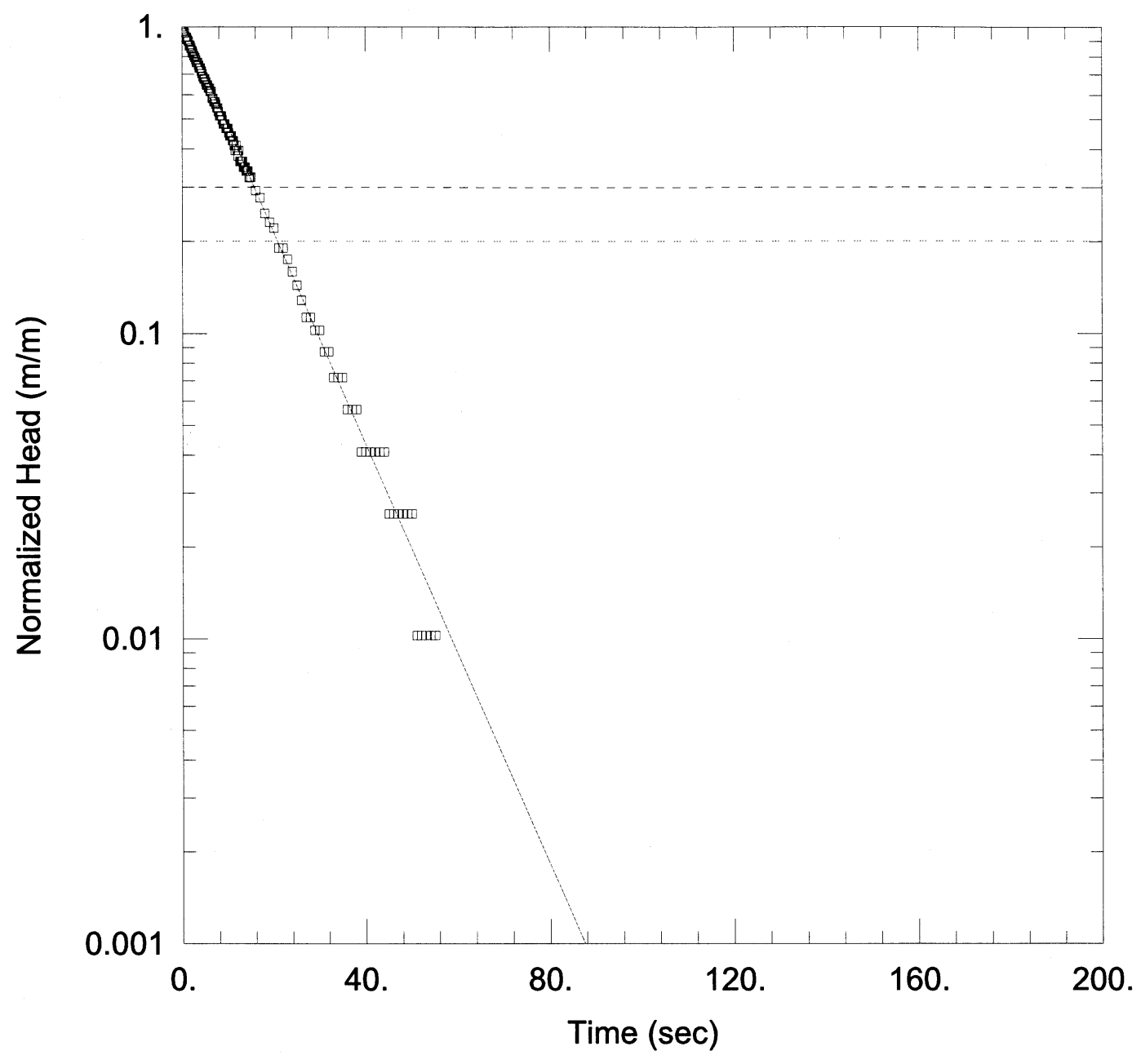

WELL TEST ANALYSIS

Data Set: E:I...IV-2_3.aqt

Date: 09/20/08

Time: 11:19:33

\section{PROJECT INFORMATION}

Company: University of Nebraska

Location: Injection Pilot Study

Test Well: IW-2

\section{AQUIFER DATA}

Saturated Thickness: $15.24 \mathrm{~m}$

Anisotropy Ratio (Kz/Kr): 1.

WELL DATA (IW-2)

Initial Displacement: 1. m

Total Well Penetration Depth: $7.616 \mathrm{~m}$

Static Water Column Height: $6.096 \mathrm{~m}$

Casing Radius: $0.0508 \mathrm{~m}$ Screen Length: $6.096 \mathrm{~m}$

Well Radius: $0.0508 \mathrm{~m}$

\section{SOLUTION}

Aquifer Model: Unconfined

Solution Method: Bouwer-Rice

$\mathrm{K}=\underline{4.947} \mathrm{~m} / \mathrm{day}$

y0 $=\underline{1.048} \mathrm{~m}$ 


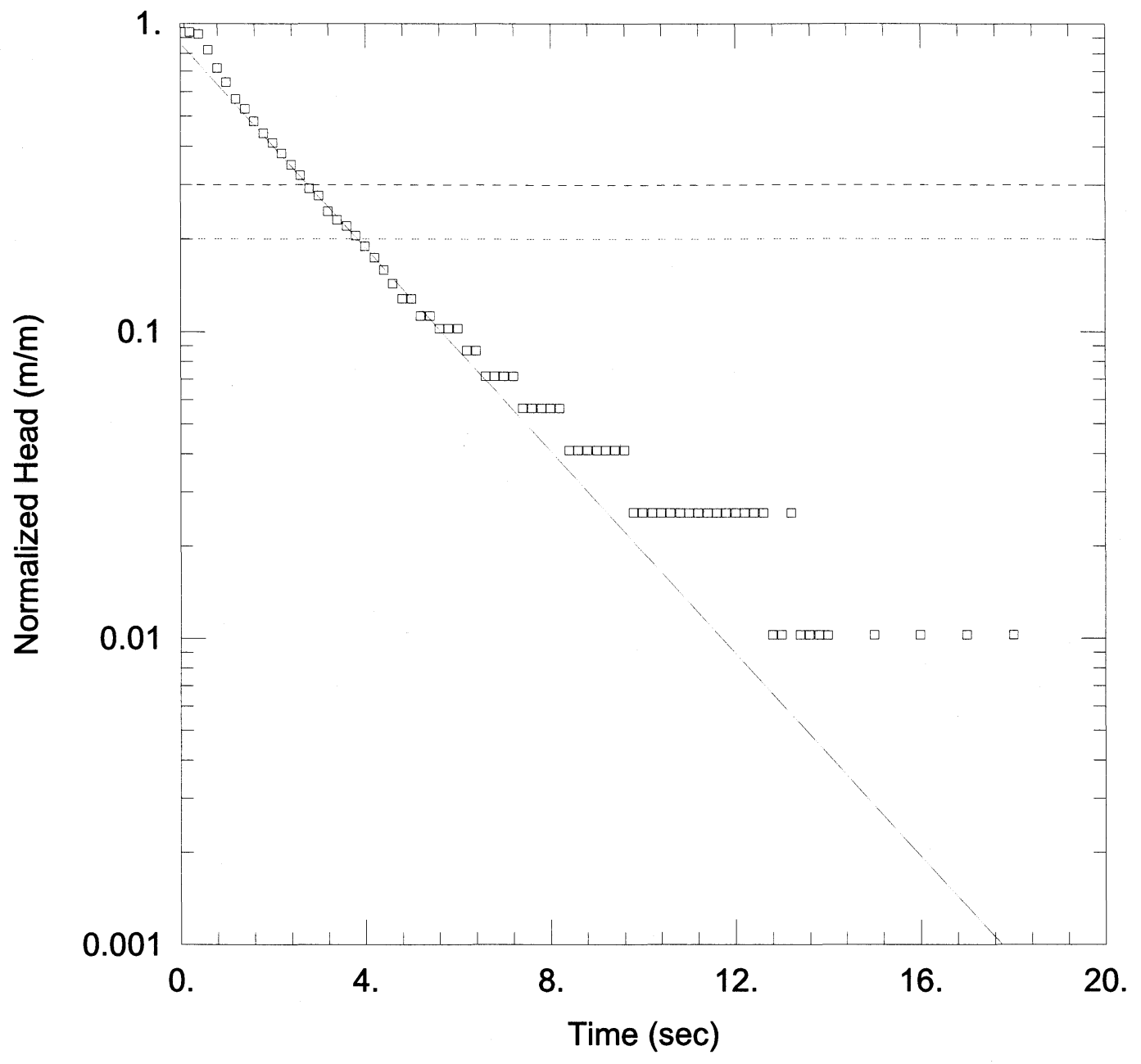

WELL TEST ANALYSIS

Data Set: E:I...IMW2_1.aqt

Date: $09 / 20 / 08$

Time: 11:20:03

\section{PROJECT INFORMATION}

Company: University of Nebraska

Location: Injection Pilot Study

Test Well: MW-2

\section{AQUIFER DATA}

Saturated Thickness: $15.24 \mathrm{~m}$

Anisotropy Ratio (Kz/Kr): 1.

\section{WELL DATA (MW-2)}

Initial Displacement: 1. m

Total Well Penetration Depth: $7.616 \mathrm{~m}$

Casing Radius: $0.0254 \mathrm{~m}$
Static Water Column Height: $6.096 \mathrm{~m}$ Screen Length: $6.096 \mathrm{~m}$ Well Radius: $0.0254 \mathrm{~m}$

\section{SOLUTION}

Aquifer Model: Unconfined

Solution Method: Bouwer-Rice

$\mathrm{K}=\underline{6.923 \mathrm{~m} / \text { day }}$

y0 $=0.8599 \mathrm{~m}$ 


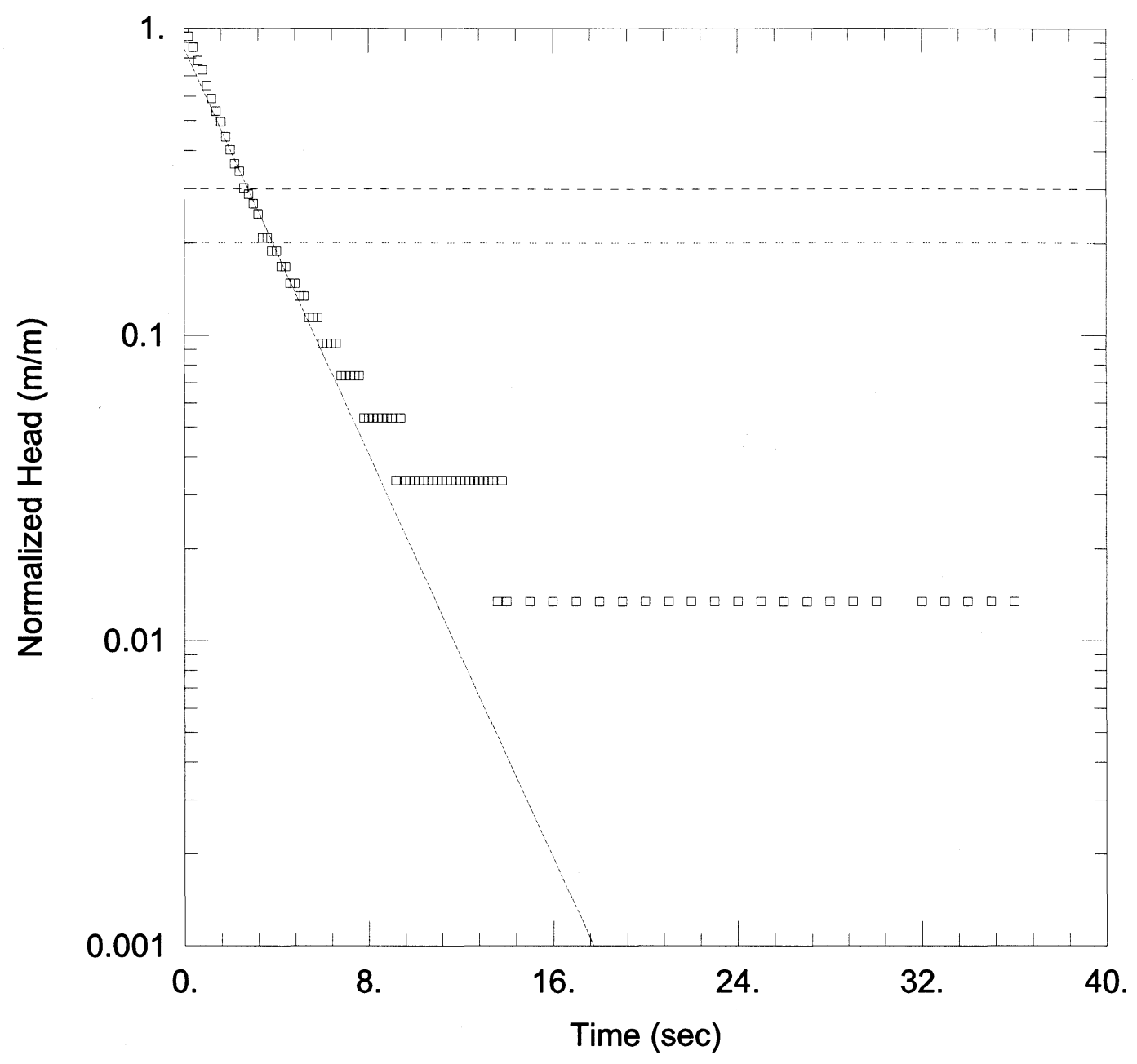

\section{WELL TEST ANALYSIS}

Data Set: E:I...MWW2_2.aqt

Date: $09 / 20 / 08$

Time: 11:20:20

\section{PROJECT INFORMATION}

Company: University of Nebraska

Location: Injection Pilot Study

Test Well: MW-2

\section{AQUIFER DATA}

Saturated Thickness: $15.24 \mathrm{~m}$

Anisotropy Ratio (Kz/Kr): 1.

WELL DATA (MW-2)

Initial Displacement: 1. m

Total Well Penetration Depth: $7.616 \mathrm{~m}$

Casing Radius: $0.0254 \mathrm{~m}$
Static Water Column Height: $6.096 \mathrm{~m}$

Screen Length: $6.096 \mathrm{~m}$

Well Radius: $0.0254 \mathrm{~m}$
Aquifer Model: Unconfined

$\mathrm{K}=6.923 \mathrm{~m} /$ day
Solution Method: Bouwer-Rice

y0 $=0.8599 \mathrm{~m}$ 


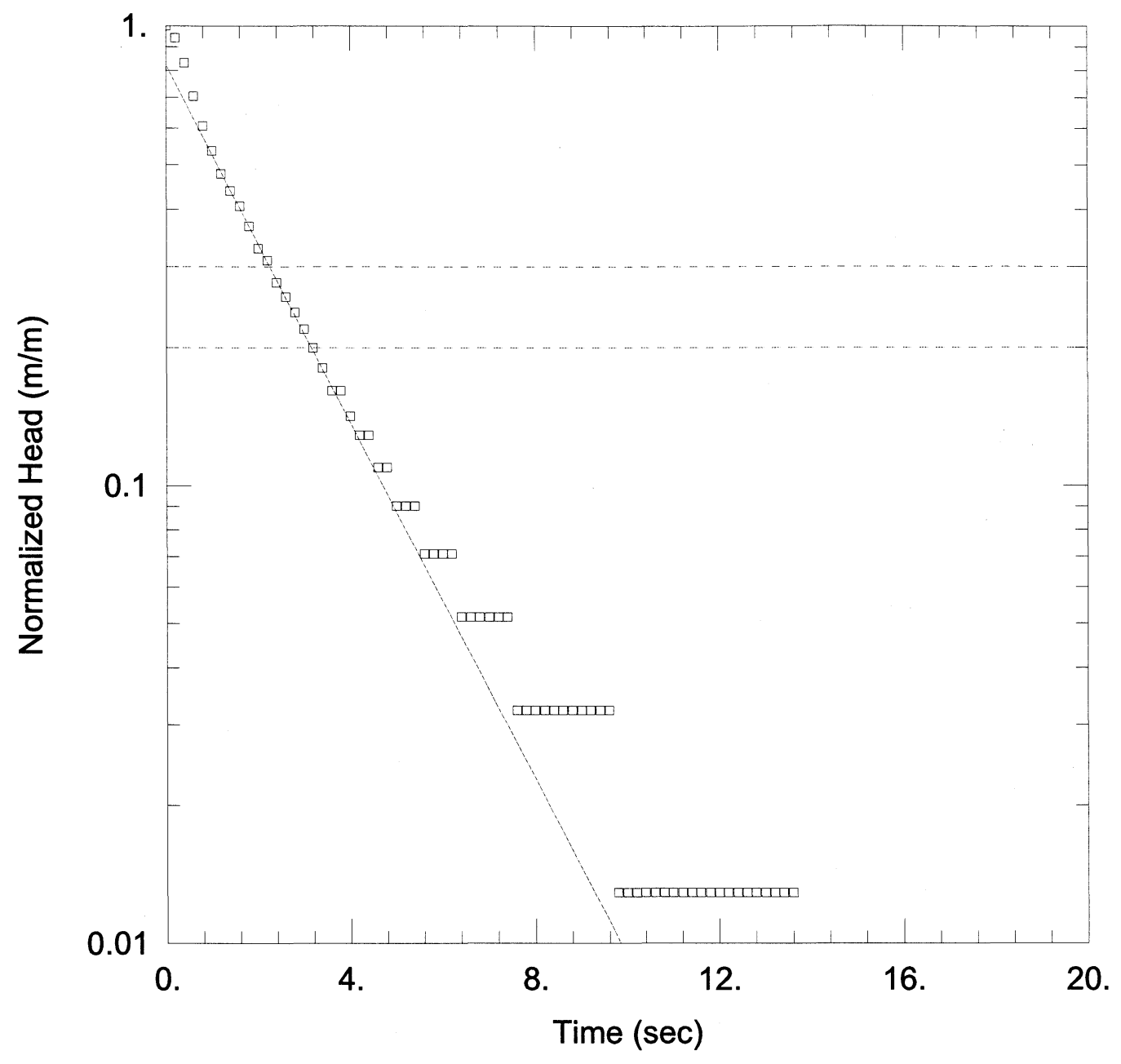

\section{WELL TEST ANALYSIS}

Data Set: E:I...MWW3_1.aqt

Date: $09 / 20 / 08$

Time: 11:20:33

\section{PROJECT INFORMATION}

Company: University of Nebraska

Location: Injection Pilot Study

Test Well: MW-3

\section{AQUIFER DATA}

Saturated Thickness: $15.24 \mathrm{~m}$

Anisotropy Ratio (Kz/Kr): 1.

\section{WELL DATA (MW-3)}

Initial Displacement: $1 . \mathrm{m}$

Total Well Penetration Depth: $7.616 \mathrm{~m}$

Casing Radius: $0.0254 \mathrm{~m}$
Static Water Column Height: $6.096 \mathrm{~m}$ Screen Length: $6.096 \mathrm{~m}$

Well Radius: $0.0254 \mathrm{~m}$

\section{SOLUTION}

Aquifer Model: Unconfined

$\mathrm{K}=8.143 \mathrm{~m} / \mathrm{day}$
Solution Method: Bouwer-Rice

y0 $=0.8223 \mathrm{~m}$ 


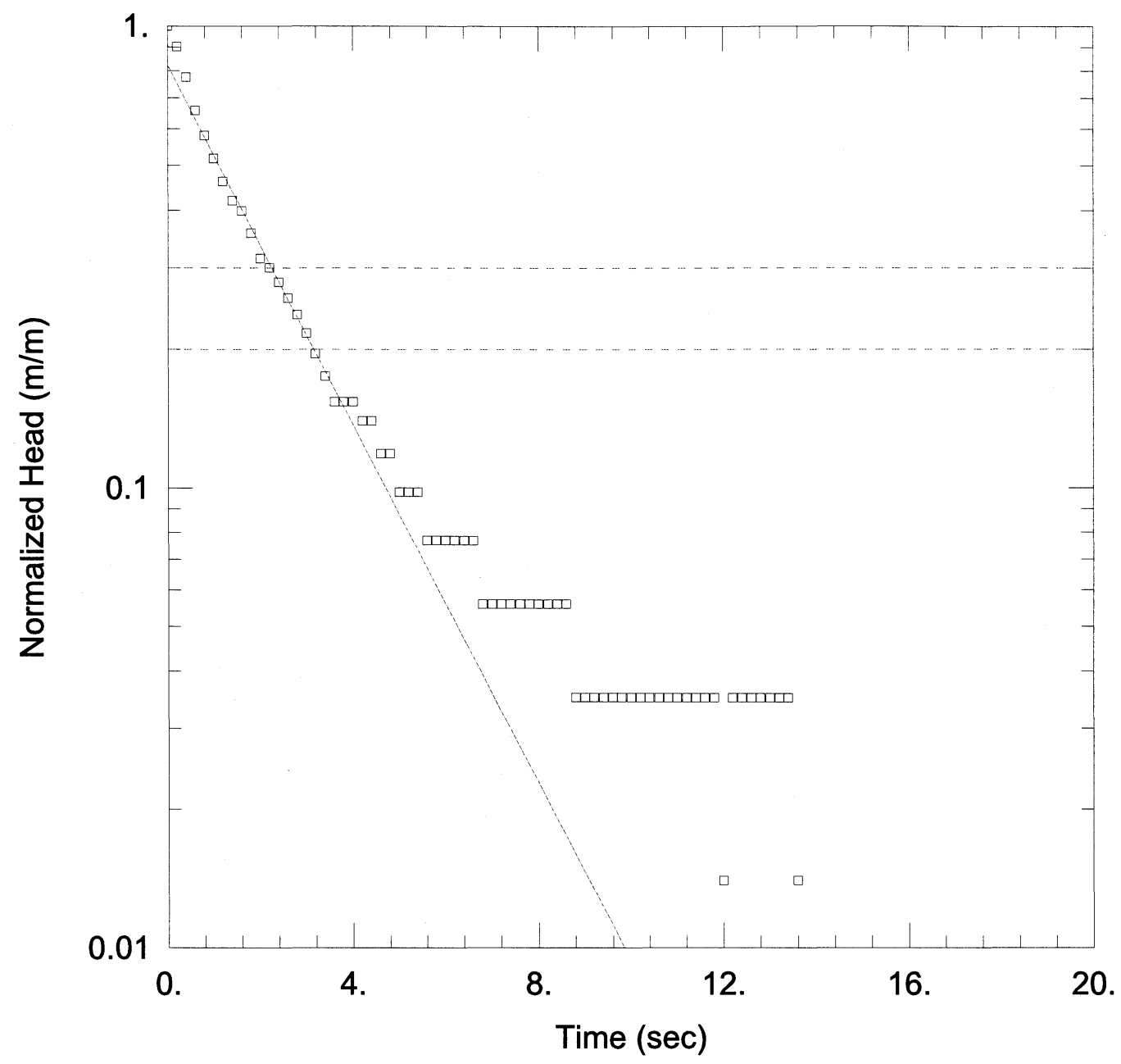

\section{WELL TEST ANALYSIS}

Data Set: E:I...IMW3_2.aqt

Date: 09/20/08
Time: 11:20:54

\section{PROJECT INFORMATION}

Company: University of Nebraska

Location: Injection Pilot Study

Test Well: MW-3

\section{AQUIFER DATA}

Saturated Thickness: $15.24 \mathrm{~m}$

Anisotropy Ratio (Kz/Kr): 1.

WELL DATA (MW-3)

Initial Displacement: 1. m

Total Well Penetration Depth: $7.616 \mathrm{~m}$

Casing Radius: $0.0254 \mathrm{~m}$
Static Water Column Height: $6.096 \mathrm{~m}$

Screen Length: $6.096 \mathrm{~m}$

Well Radius: $0.0254 \mathrm{~m}$

\section{SOLUTION}

Aquifer Model: Unconfined

Solution Method: Bouwer-Rice

$\mathrm{K}=8.143 \mathrm{~m} /$ day

$\mathrm{y} 0=0.8223 \mathrm{~m}$ 


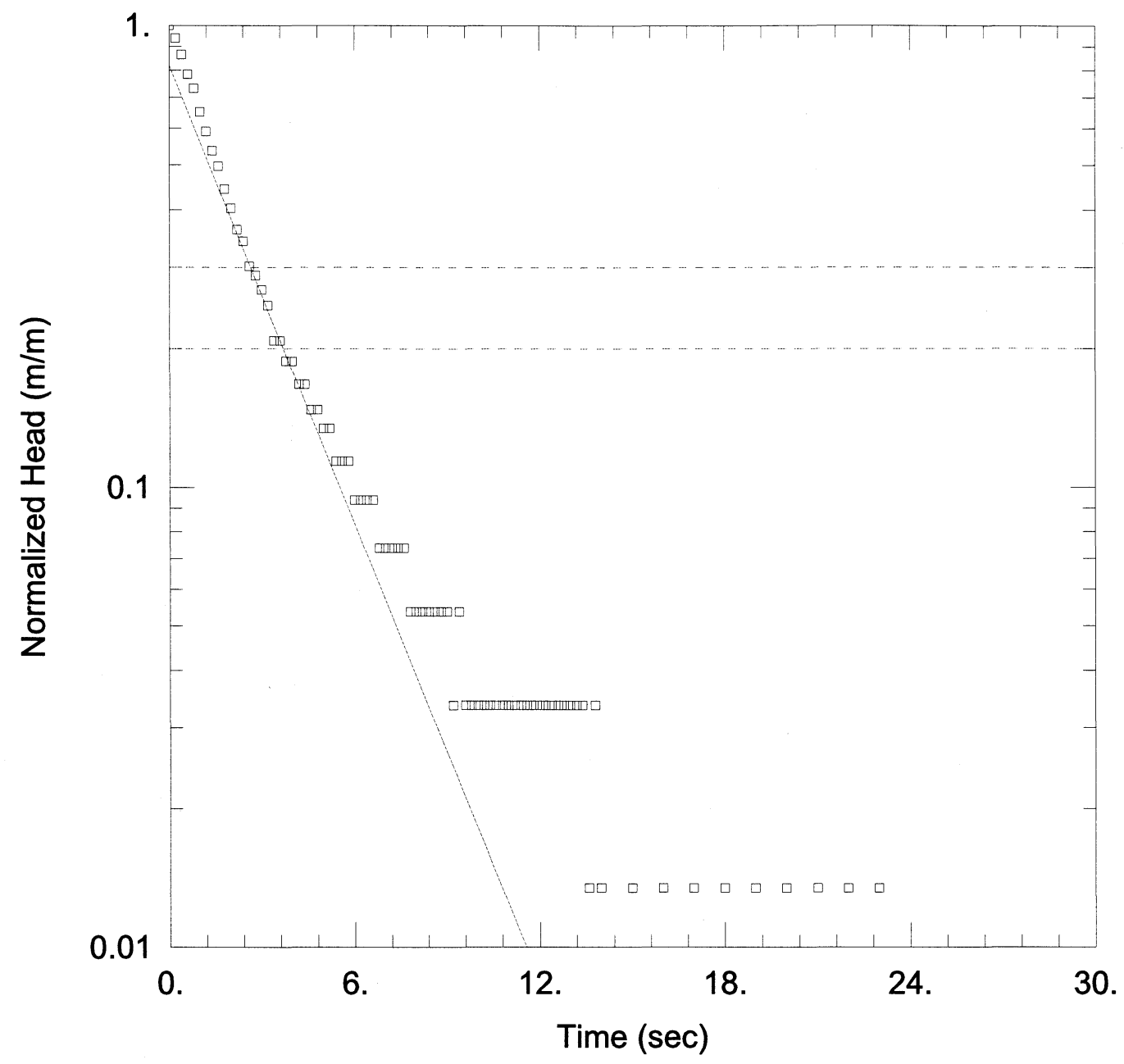

\section{WELL TEST ANALYSIS}

Data Set: E:I...IMW3_3.aqt

Date: $09 / 20 / 08$

Time: 11:21:17

\section{PROJECT INFORMATION}

Company: University of Nebraska

Location: Injection Pilot Study

Test Well: MW-3

\section{AQUIFER DATA}

Saturated Thickness: $15.24 \mathrm{~m}$

Anisotropy Ratio $(\mathrm{Kz} / \mathrm{Kr})$ : 1.

\section{WELL DATA (MW-3)}

Initial Displacement: $1 . \mathrm{m}$

Total Well Penetration Depth: $7.616 \mathrm{~m}$

Casing Radius: $0.0254 \mathrm{~m}$
Static Water Column Height: $6.096 \mathrm{~m}$ Screen Length: $6.096 \mathrm{~m}$

Well Radius: $0.0254 \mathrm{~m}$ 


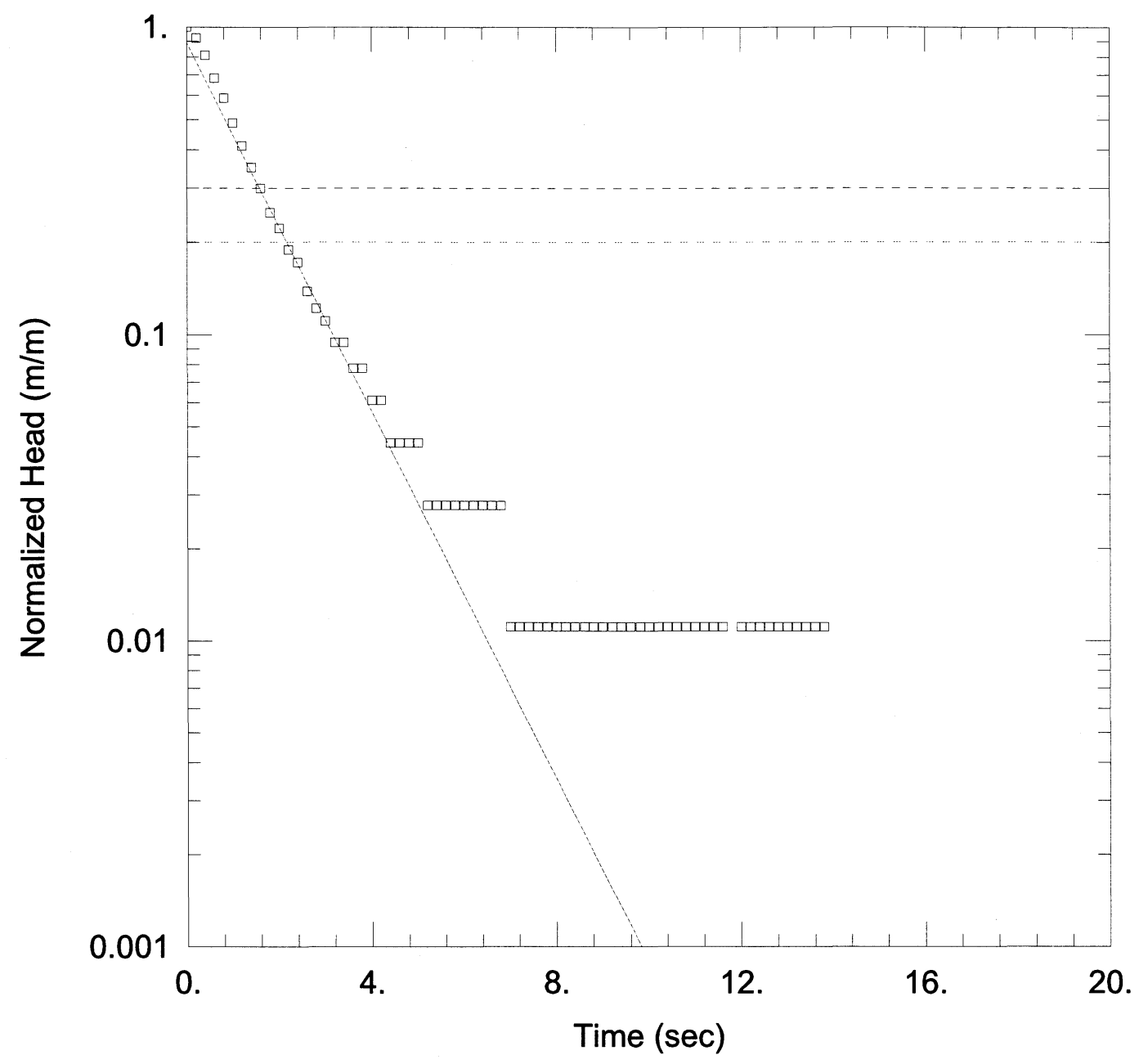

\section{WELL TEST ANALYSIS}

Data Set: E:I...MW4_1.aqt

Date: $09 / 20 / 08$

Time: 11:21:31

\section{PROJECT INFORMATION}

Company: University of Nebraska

Location: Injection Pilot Study

Test Well: MW-4

\section{AQUIFER DATA}

Saturated Thickness: $15.24 \mathrm{~m}$

Anisotropy Ratio (Kz/Kr): 1.

\section{WELL DATA (MW-4)}

Initial Displacement: 1. m

Total Well Penetration Depth: $7.616 \mathrm{~m}$

Casing Radius: $0.0254 \mathrm{~m}$
Static Water Column Height: $6.096 \mathrm{~m}$

Screen Length: $6.096 \mathrm{~m}$

Well Radius: $0.0254 \mathrm{~m}$ 


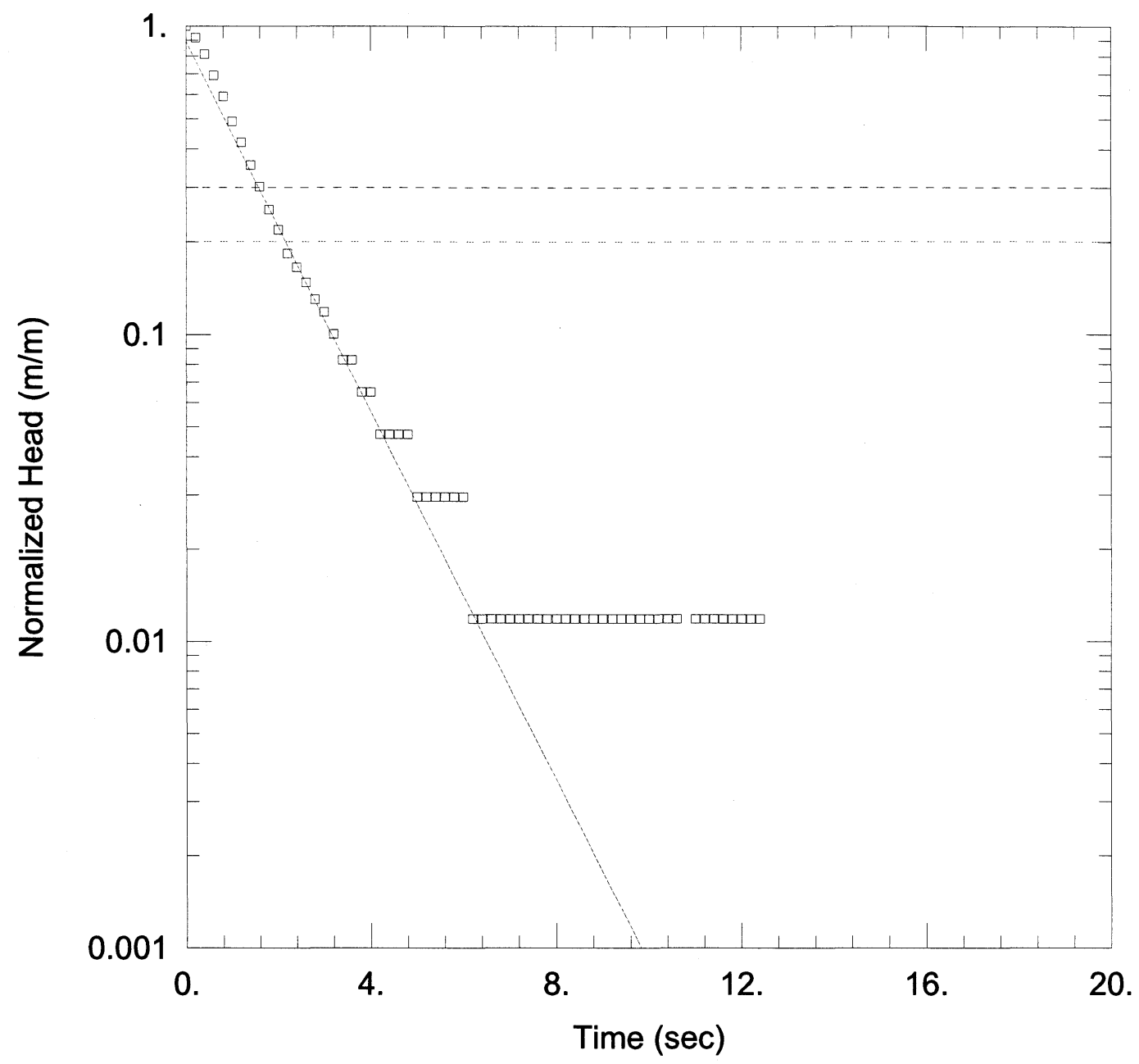

\section{WELL TEST ANALYSIS}

Data Set: E:I...MW4_2.aqt

Date: $09 / 20 / 08$

Time: 11:21:47

\section{PROJECT INFORMATION}

Company: University of Nebraska

Location: Injection Pilot Study

Test Well: MW-4

\section{AQUIFER DATA}

Saturated Thickness: $15.24 \mathrm{~m}$

Anisotropy Ratio (Kz/Kr): 1.

WELL DATA (MW-4)

Initial Displacement: $1 . \mathrm{m}$

Total Well Penetration Depth: $7.616 \mathrm{~m}$

Casing Radius: $0.0254 \mathrm{~m}$
Static Water Column Height: $6.096 \mathrm{~m}$

Screen Length: $6.096 \mathrm{~m}$

Well Radius: $0.0254 \mathrm{~m}$

\section{SOLUTION}

Aquifer Model: Unconfined

Solution Method: Bouwer-Rice

$\mathrm{K}=\underline{12.56 \mathrm{~m} / \mathrm{day}}$

$\mathrm{y} 0=0.8913 \mathrm{~m}$ 


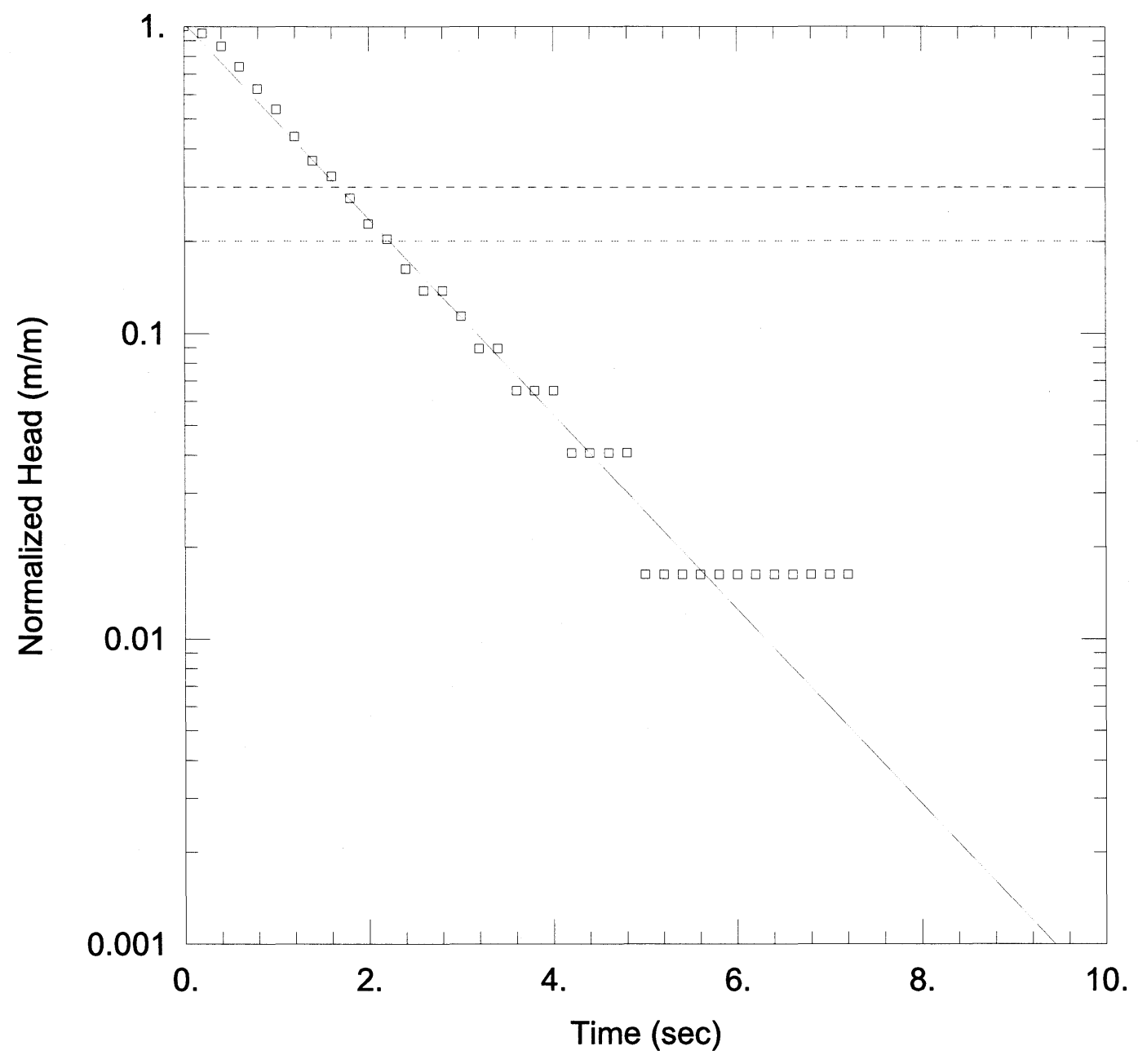

\section{WELL TEST ANALYSIS}

Data Set: E:I...IMW4_3.aqt

Date: 09/20/08

Time: 11:22:08

\section{PROJECT INFORMATION}

Company: University of Nebraska

Location: Injection Pilot Study

Test Well: MW-4

\section{AQUIFER DATA}

Saturated Thickness: $15.24 \mathrm{~m}$

Anisotropy Ratio (Kz/Kr): 1.

WELL DATA (MW-4)

Initial Displacement: $1 . \mathrm{m}$

Total Well Penetration Depth: $7.616 \mathrm{~m}$

Static Water Column Height: $6.096 \mathrm{~m}$ Screen Length: $6.096 \mathrm{~m}$

Casing Radius: $\underline{0.0254} \mathrm{~m}$ Well Radius: $0.0254 \mathrm{~m}$

\section{SOLUTION}

Aquifer Model: Unconfined

Solution Method: Bouwer-Rice

$\mathrm{K}=13.35 \mathrm{~m} /$ day

$\mathrm{y} 0=1.025 \mathrm{~m}$ 


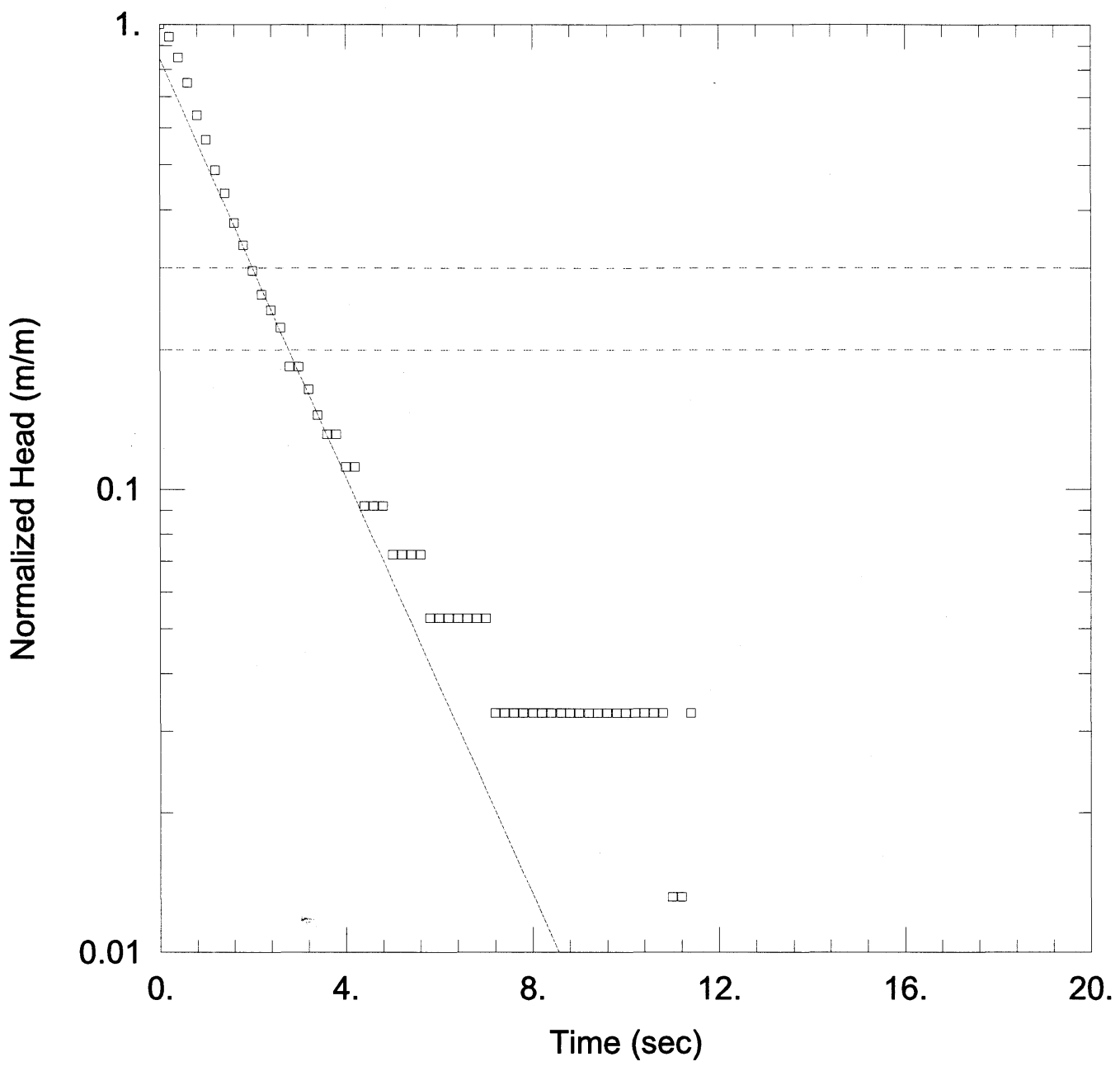

Data Set: E:I...IMW12_1.aqt

Date: $09 / 20 / 08$

WELL TEST ANALYSIS

Time: 11:22:18

\section{PROJECT INFORMATION}

Company: University of Nebraska

Location: Injection Pilot Study

Test Well: MW-12

\section{AQUIFER DATA}

Saturated Thickness: $15.24 \mathrm{~m}$

Anisotropy Ratio (Kz/Kr): 1.

\section{WELL DATA (MW-12)}

Initial Displacement: 1. m

Static Water Column Height: $6.096 \mathrm{~m}$

Total Well Penetration Depth: $7.616 \mathrm{~m}$

Screen Length: $6.096 \mathrm{~m}$

Casing Radius: $0.0254 \mathrm{~m}$

Well Radius: $0.0254 \mathrm{~m}$

\section{SOLUTION}

Aquifer Model: Unconfined

Solution Method: Bouwer-Rice

$\mathrm{K}=\underline{9.422} \mathrm{~m} / \mathrm{day}$

y0 $=0.8454 \mathrm{~m}$ 


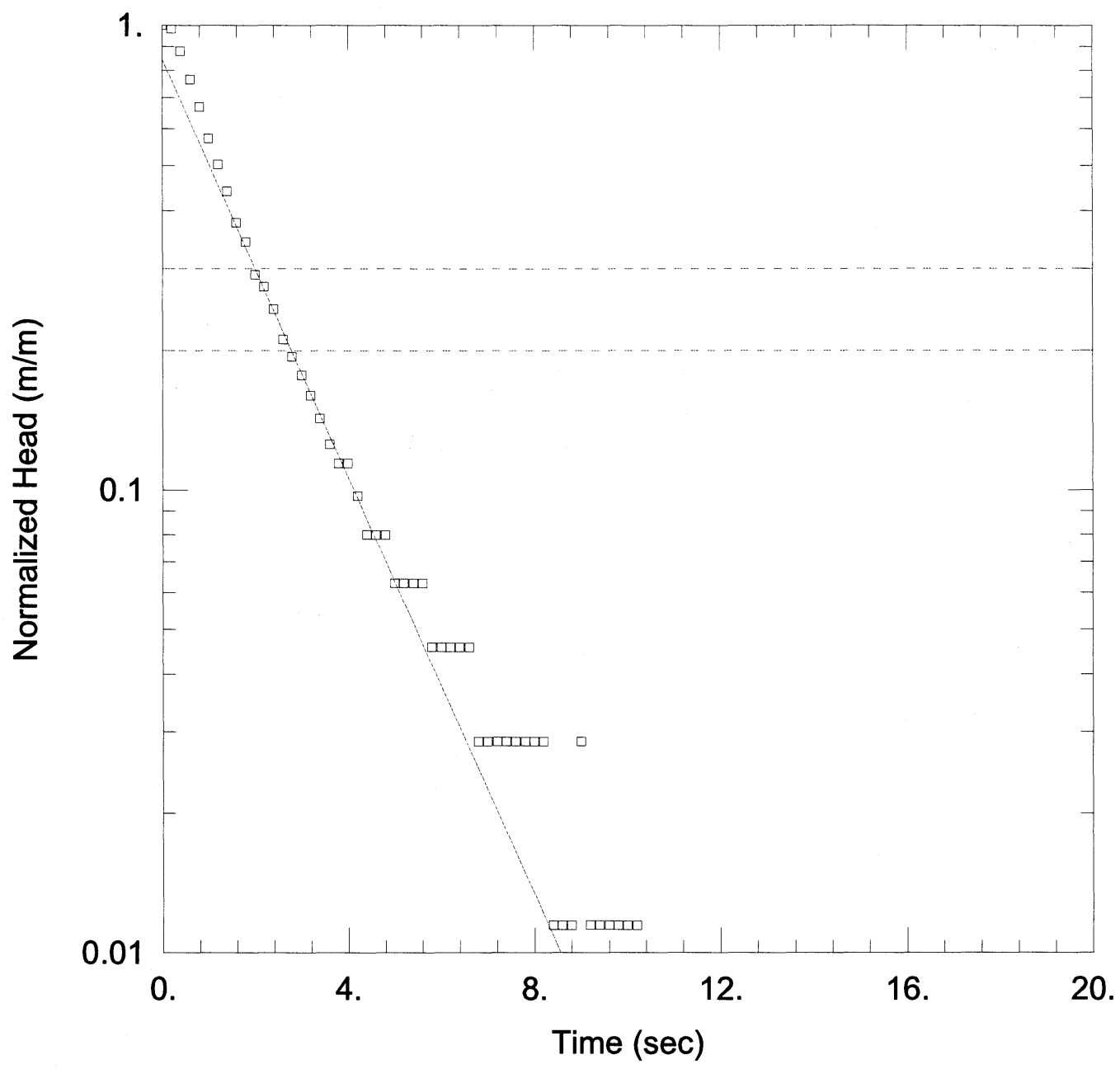

\section{WELL TEST ANALYSIS}

Data Set: E:I...IMW12_2.aqt

Date: $09 / 20 / 08$

Time: 11:22:36

PROJECT INFORMATION

Company: University of Nebraska

Location: Injection Pilot Study

Test Well: MW-12

\section{AQUIFER DATA}

Saturated Thickness: $15.24 \mathrm{~m}$

Anisotropy Ratio (Kz/Kr): 1.

WELL DATA (MW-12)

Initial Displacement: 1. m

Total Well Penetration Depth: $7.616 \mathrm{~m}$

Casing Radius: $0.0254 \mathrm{~m}$
Static Water Column Height: $6.096 \mathrm{~m}$

Screen Length: $6.096 \mathrm{~m}$

Well Radius: $0.0254 \mathrm{~m}$

\section{SOLUTION}

Aquifer Model: Unconfined

Solution Method: Bouwer-Rice

$\mathrm{K}=9.422 \mathrm{~m} /$ day

yo $=0.8454 m$ 


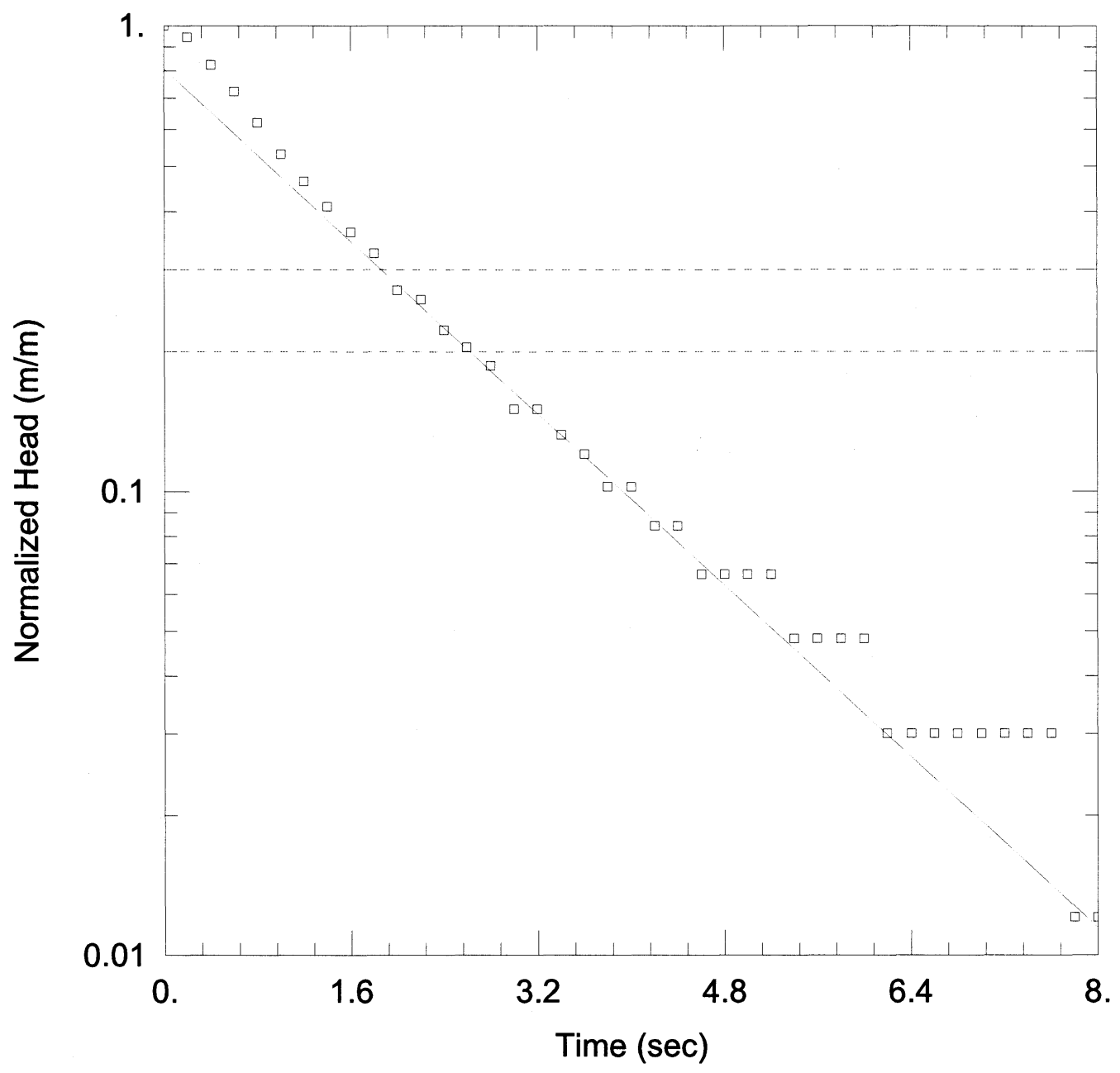

WELL TEST ANALYSIS

Data Set: E:I...IMW12_3.aqt

Date: $09 / 20 / 08$

Time: 11:23:01

PROJECT INFORMATION

Company: University of Nebraska

Location: Injection Pilot Study

Test Well: MW-12

\section{AQUIFER DATA}

Saturated Thickness: $15.24 \mathrm{~m}$

Anisotropy Ratio (Kz/Kr): 1.

WELL DATA (MW-12)

Initial Displacement: $1 . \mathrm{m}$

Total Well Penetration Depth: $7.616 \mathrm{~m}$

Static Water Column Height: $6.096 \mathrm{~m}$

Casing Radius: $0.0254 \mathrm{~m}$ Screen Length: $6.096 \mathrm{~m}$

Well Radius: $0.0254 \mathrm{~m}$

\section{SOLUTION}

Aquifer Model: Unconfined

Solution Method: Bouwer-Rice

$K=9.674 \mathrm{~m} /$ day

y0 $=\underline{0.808} \mathrm{~m}$ 


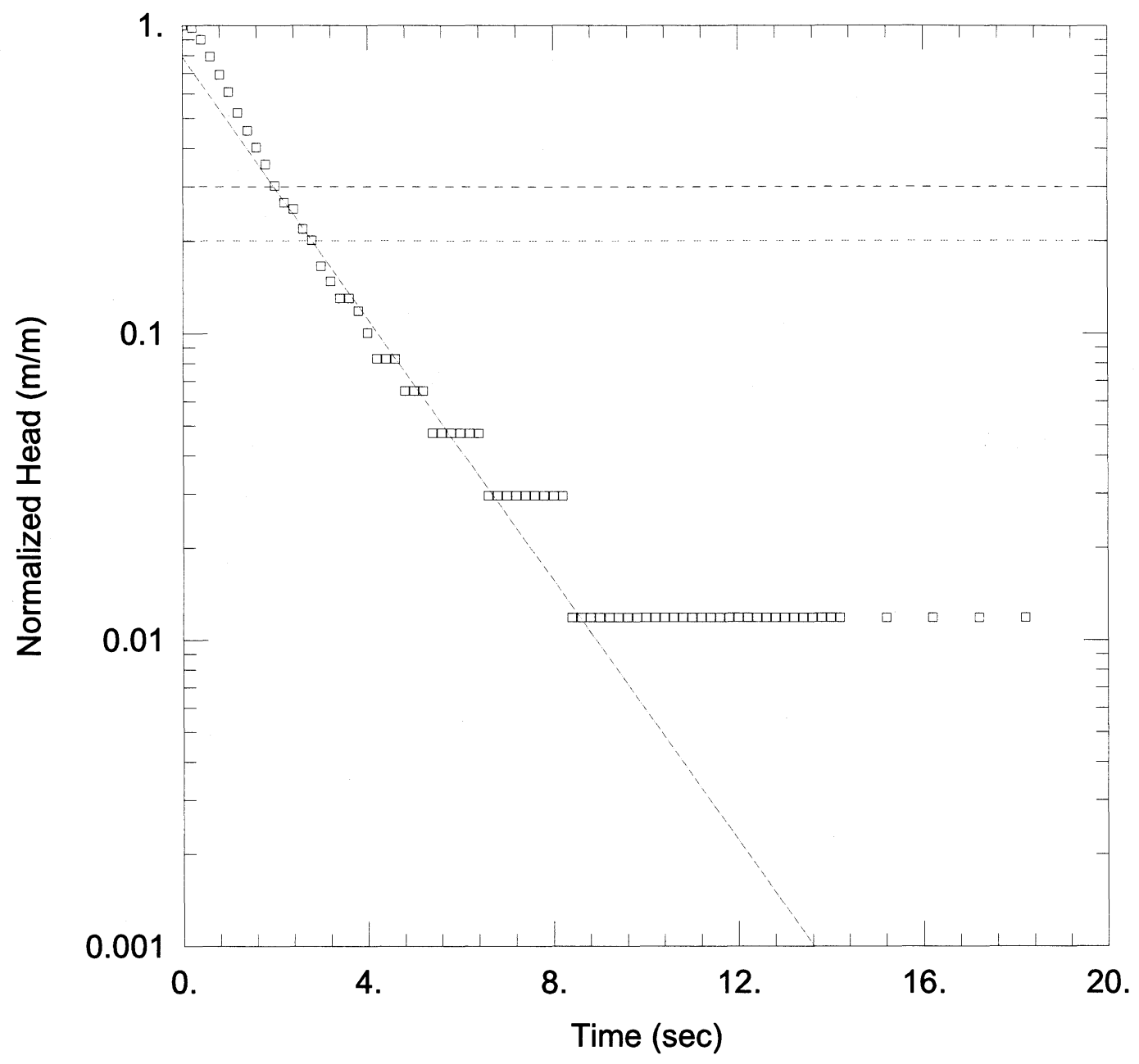

WELL TEST ANALYSIS

Data Set: E:I...IMW13_1.aqt

Date: $09 / 20 / 08$

Time: 11:23:15

PROJECT INFORMATION

Company: University of Nebraska

Location: Injection Pilot Study

Test Well: MW-13

\section{AQUIFER DATA}

Saturated Thickness: $15.24 \mathrm{~m}$

Anisotropy Ratio (Kz/Kr): 1.

WELL DATA (MW-13)

Initial Displacement: $1 . \mathrm{m}$

Total Well Penetration Depth: $7.616 \mathrm{~m}$

Static Water Column Height: $6.096 \mathrm{~m}$

Screen Length: $6.096 \mathrm{~m}$

Casing Radius: $0.0254 \mathrm{~m}$

Well Radius: $0.0254 \mathrm{~m}$

\section{SOLUTION}

Aquifer Model: Unconfined

Solution Method: Bouwer-Rice

$\mathrm{K}=8.899 \mathrm{~m} / \mathrm{day}$

y0 $=0.7877 \mathrm{~m}$ 


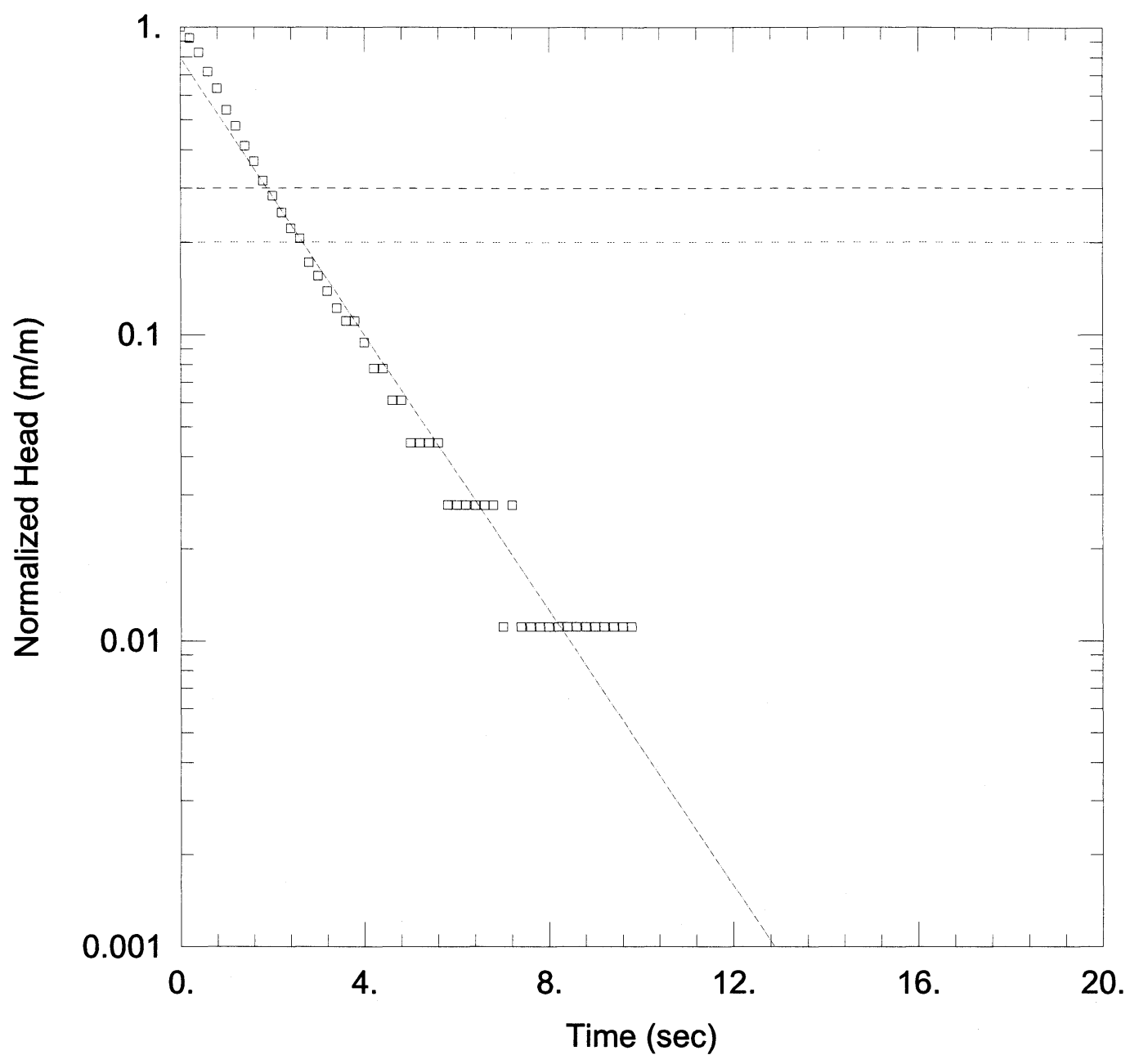

\section{WELL TEST ANALYSIS}

Data Set: E:I...IMW13_2.aqt

Date: $\underline{09 / 20 / 08}$

Time: 11:23:44

\section{PROJECT INFORMATION}

Company: University of Nebraska

Location: Injection Pilot Study

Test Well: MW-13

\section{AQUIFER DATA}

Saturated Thickness: $15.24 \mathrm{~m}$ Anisotropy Ratio (Kz/Kr): 1.

WELL DATA (MW-13)

Initial Displacement: 1. m

Total Well Penetration Depth: $7.616 \mathrm{~m}$

Casing Radius: $0.0254 \mathrm{~m}$
Static Water Column Height: $6.096 \mathrm{~m}$ Screen Length: $6.096 \mathrm{~m}$

Well Radius: $0.0254 \mathrm{~m}$

\section{SOLUTION}

Aquifer Model: Unconfined

Solution Method: Bouwer-Rice

$\mathrm{K}=9.422 \mathrm{~m} / \mathrm{day}$

y0 $=0.7943 \mathrm{~m}$ 


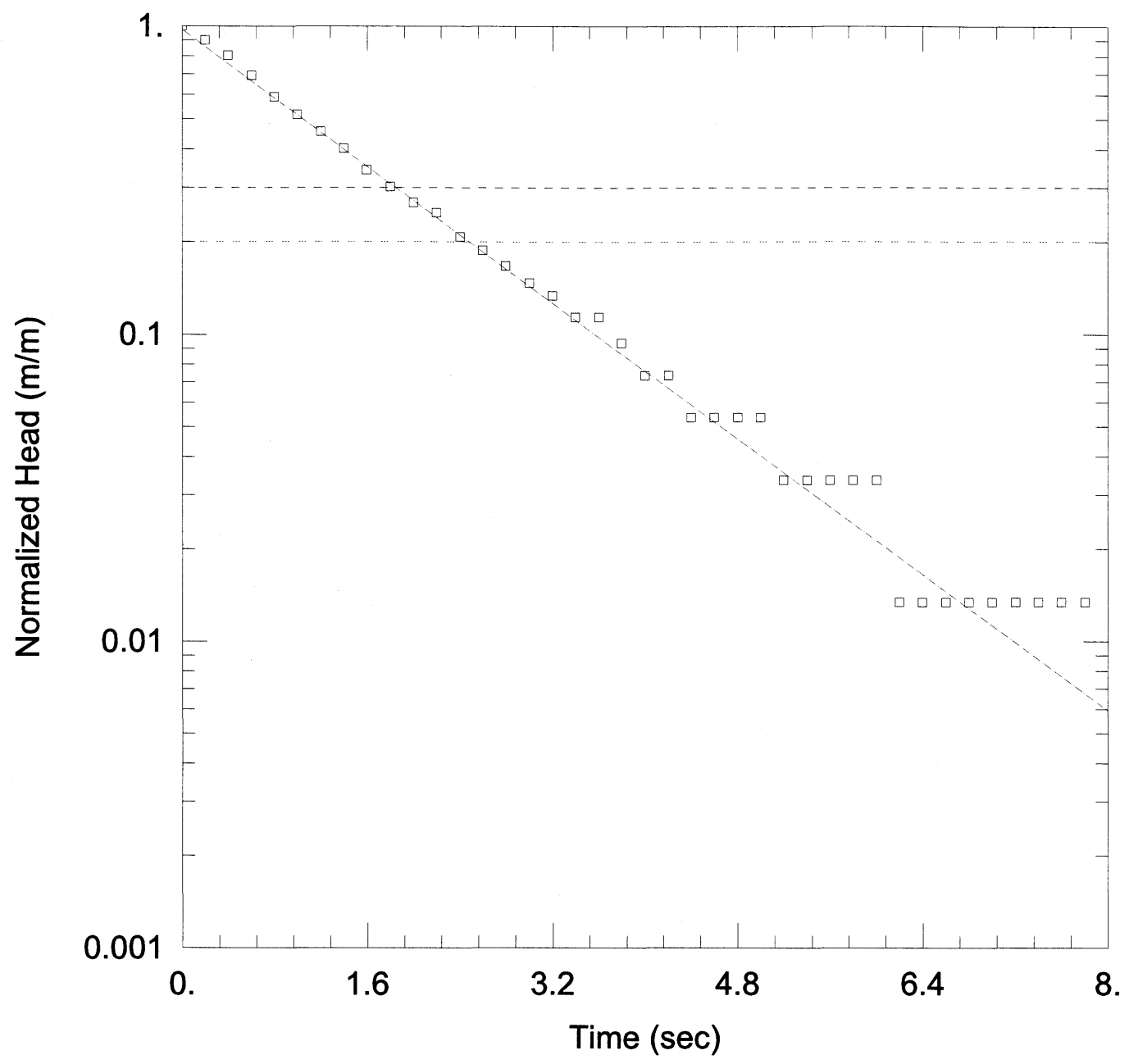

\section{WELL TEST ANALYSIS}

Data Set: E:I...IMW13_3.aqt

Date: 09/20/08
Time: 11:24:01

\section{PROJECT INFORMATION}

Company: University of Nebraska

Location: Injection Pilot Study

Test Well: MW-13

\section{AQUIFER DATA}

Saturated Thickness: $15.24 \mathrm{~m}$

Anisotropy Ratio (Kz/Kr): 1.

\section{WELL DATA (MW-13)}

Initial Displacement: 1. m

Total Well Penetration Depth: $7.616 \mathrm{~m}$

Casing Radius: $0.0254 \mathrm{~m}$
Static Water Column Height: $6.096 \mathrm{~m}$

Screen Length: $6.096 \mathrm{~m}$

Well Radius: $0.0254 \mathrm{~m}$

\section{SOLUTION}

Aquifer Model: Unconfined

Solution Method: Bouwer-Rice

$\mathrm{K}=11.58 \mathrm{~m} /$ day

y0 $=0.9728 m$ 


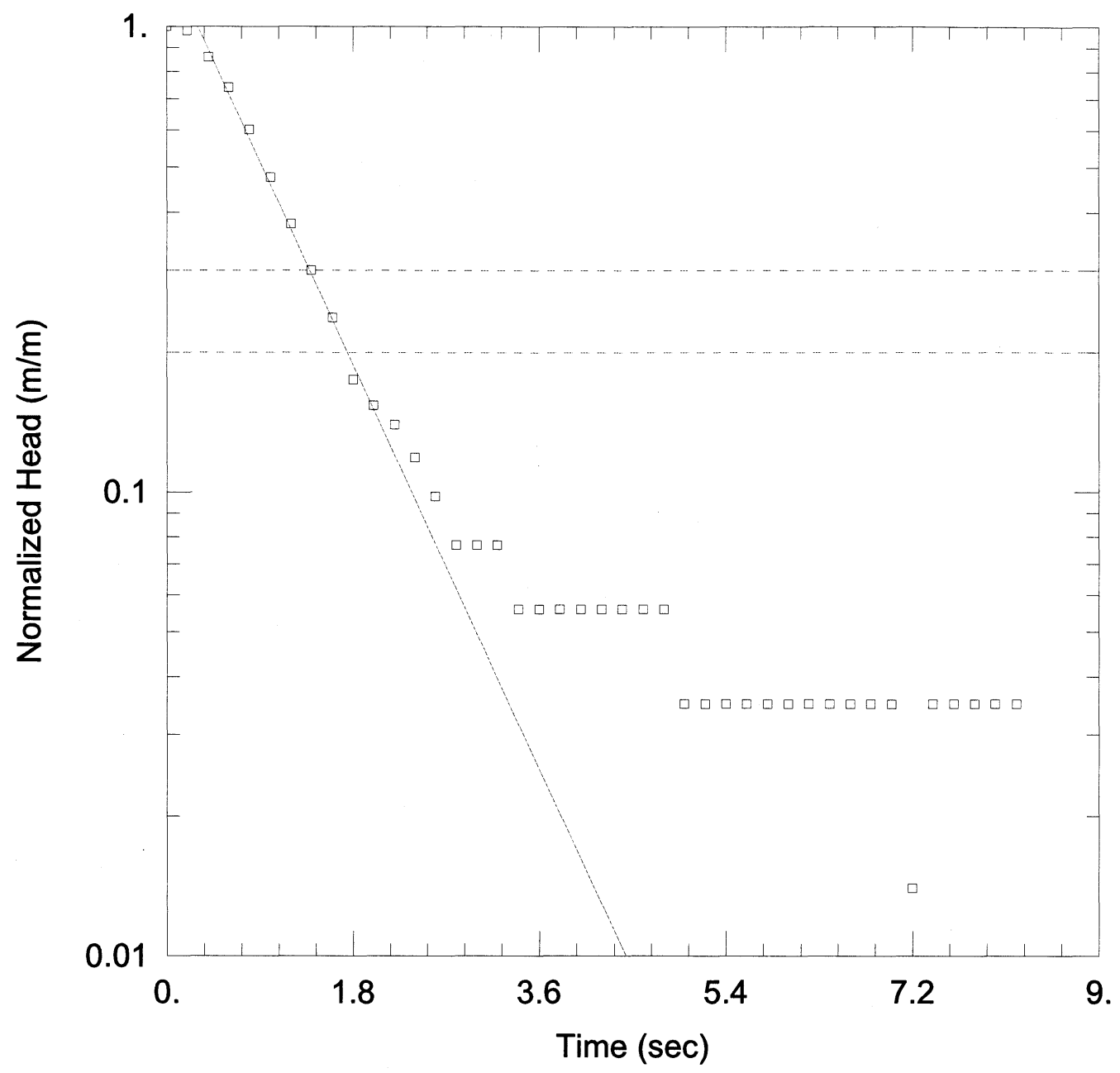

WELL TEST ANALYSIS

Data Set: E:I...IMW14_1.aqt

Date: 09/20/08

Time: 11:24:21

PROJECT INFORMATION

Company: University of Nebraska

Location: Injection Pilot Study

Test Well: MW-14

\section{AQUIFER DATA}

Saturated Thickness: $15.24 \mathrm{~m}$

Anisotropy Ratio $(\mathrm{Kz} / \mathrm{Kr}): 1$.

WELL DATA (MW-14)

Initial Displacement: 1. m

Total Well Penetration Depth: $7.616 \mathrm{~m}$

Casing Radius: $0.0254 \mathrm{~m}$
Static Water Column Height: $6.096 \mathrm{~m}$ Screen Length: $6.096 \mathrm{~m}$

Well Radius: $0.0254 \mathrm{~m}$

\section{SOLUTION}

Aquifer Model: Unconfined

Solution Method: Bouwer-Rice

$\mathrm{K}=\underline{20.25 \mathrm{~m} / \text { day }}$

$\mathrm{y} 0=1.396 \mathrm{~m}$ 


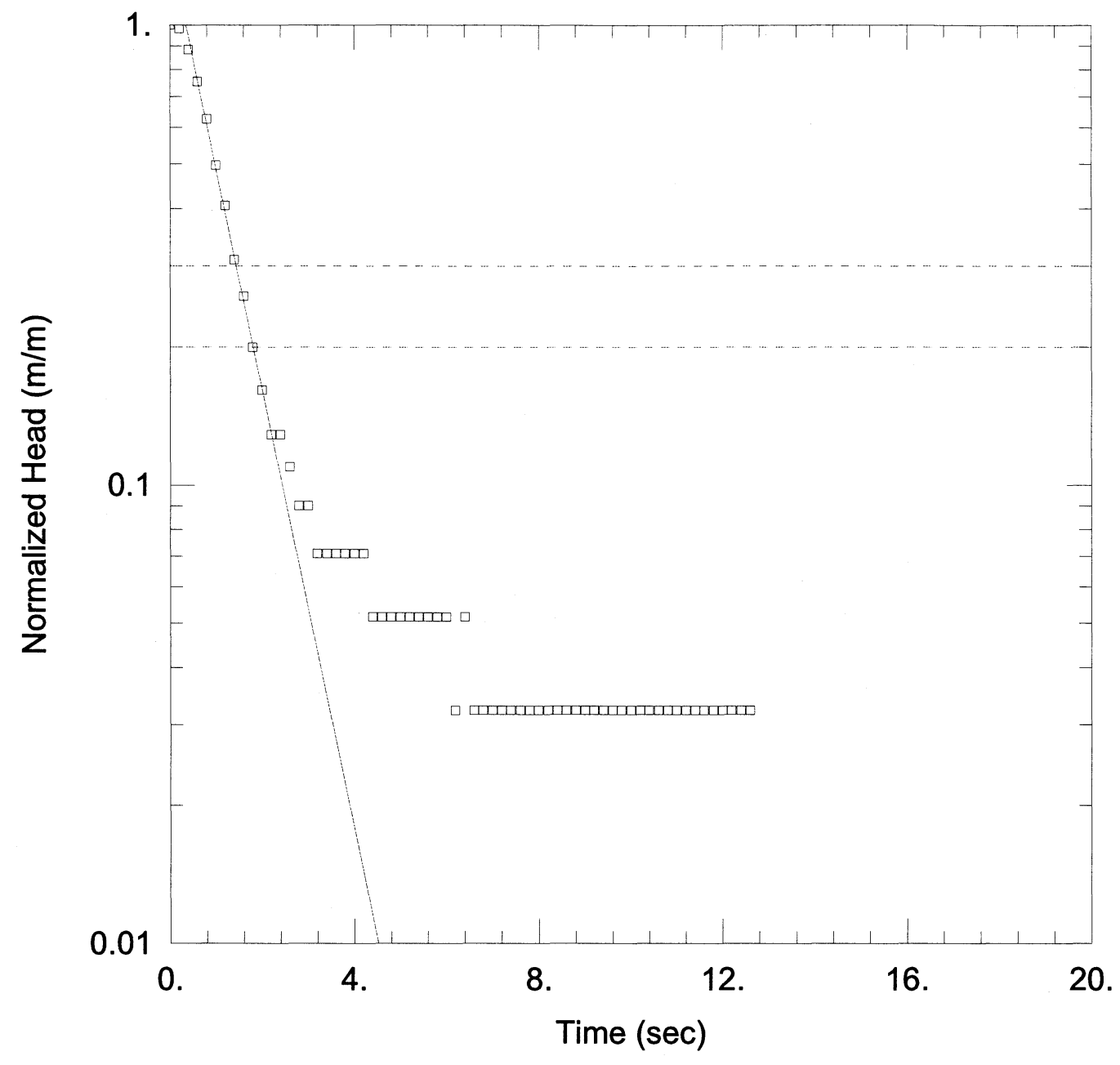

\section{WELL TEST ANALYSIS}

Data Set: E:I...IMW14_2.aqt

Date: 09/20/08

Time: 11:24:49

\section{PROJECT INFORMATION}

Company: University of Nebraska

Location: Injection Pilot Study

Test Well: MW-14

\section{AQUIFER DATA}

Saturated Thickness: $15.24 \mathrm{~m}$

Anisotropy Ratio (Kz/Kr): 1.

\section{WELL DATA (MW-14)}

Initial Displacement: $1 . \mathrm{m}$

Total Well Penetration Depth: $7.616 \mathrm{~m}$

Static Water Column Height: $6.096 \mathrm{~m}$

Casing Radius: $0.0254 \mathrm{~m}$ Screen Length: $6.096 \mathrm{~m}$

Well Radius: $0.0254 \mathrm{~m}$

\section{SOLUTION}

Aquifer Model: Unconfined

Solution Method: Bouwer-Rice

$\mathrm{K}=20.04 \mathrm{~m} /$ day

$\mathrm{y} 0=1.467 \mathrm{~m}$ 


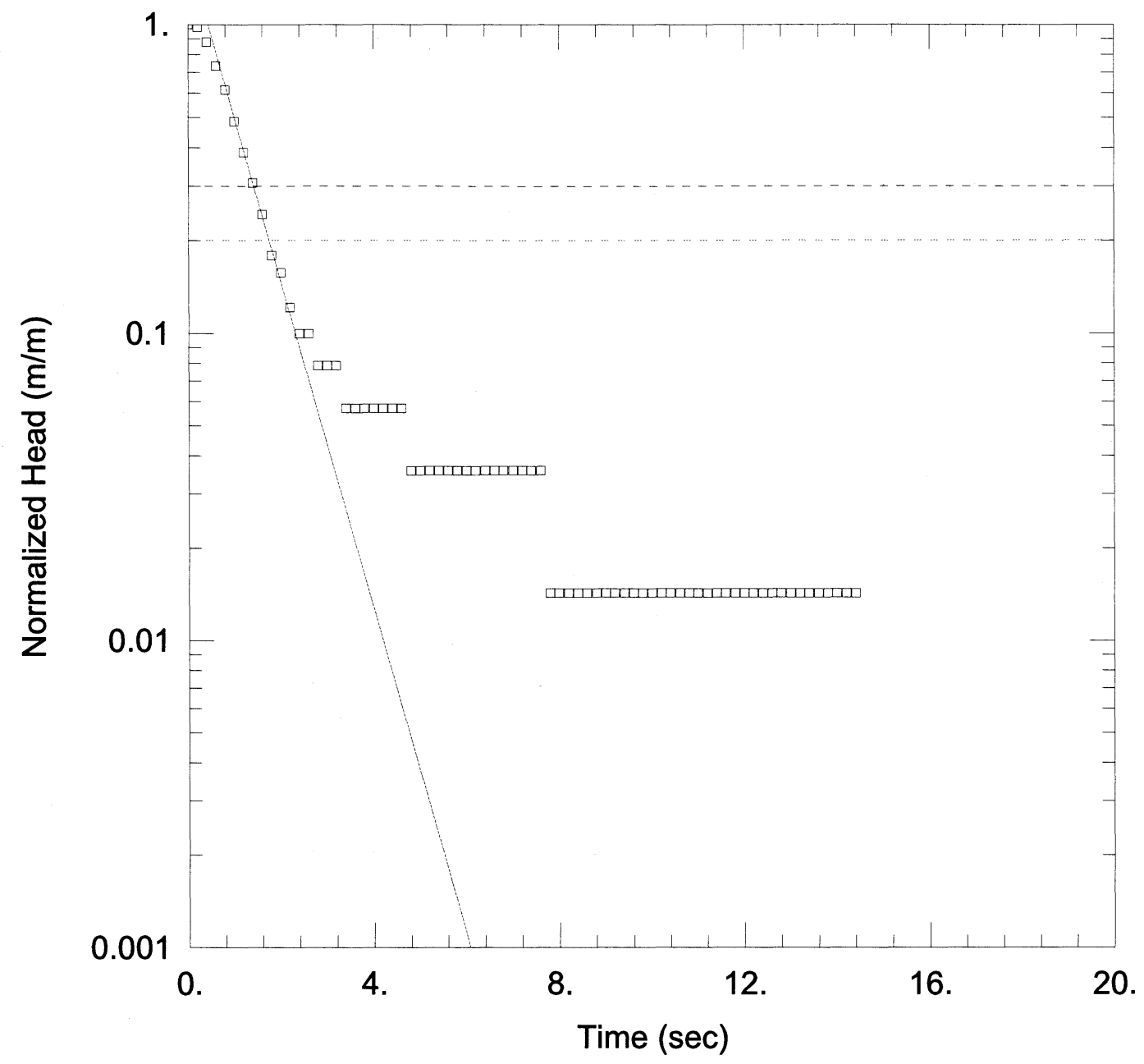

WELL TEST ANALYSIS

Data Set: E:I...IMW14_3.aqt

Date: $09 / 20 / 08$

Time: 11:25:03

\section{PROJECT INFORMATION}

Company: University of Nebraska

Location: Injection Pilot Study

Test Well: MW-14

\section{AQUIFER DATA}

Saturated Thickness: $15.24 \mathrm{~m}$

Anisotropy Ratio (Kz/Kr): 1.

\section{WELL DATA (MW-14)}

Initial Displacement: 1. m

Total Well Penetration Depth: $7.616 \mathrm{~m}$

Static Water Column Height: $6.096 \mathrm{~m}$

Casing Radius: $0.0254 \mathrm{~m}$ Screen Length: $6.096 \mathrm{~m}$

Well Radius: $0.0254 \mathrm{~m}$

Aquifer Model: Unconfined

Solution Method: Bouwer-Rice

$\mathrm{K}=22.27 \mathrm{~m} / \mathrm{day}$

$\mathrm{y} 0=1.699 \mathrm{~m}$ 


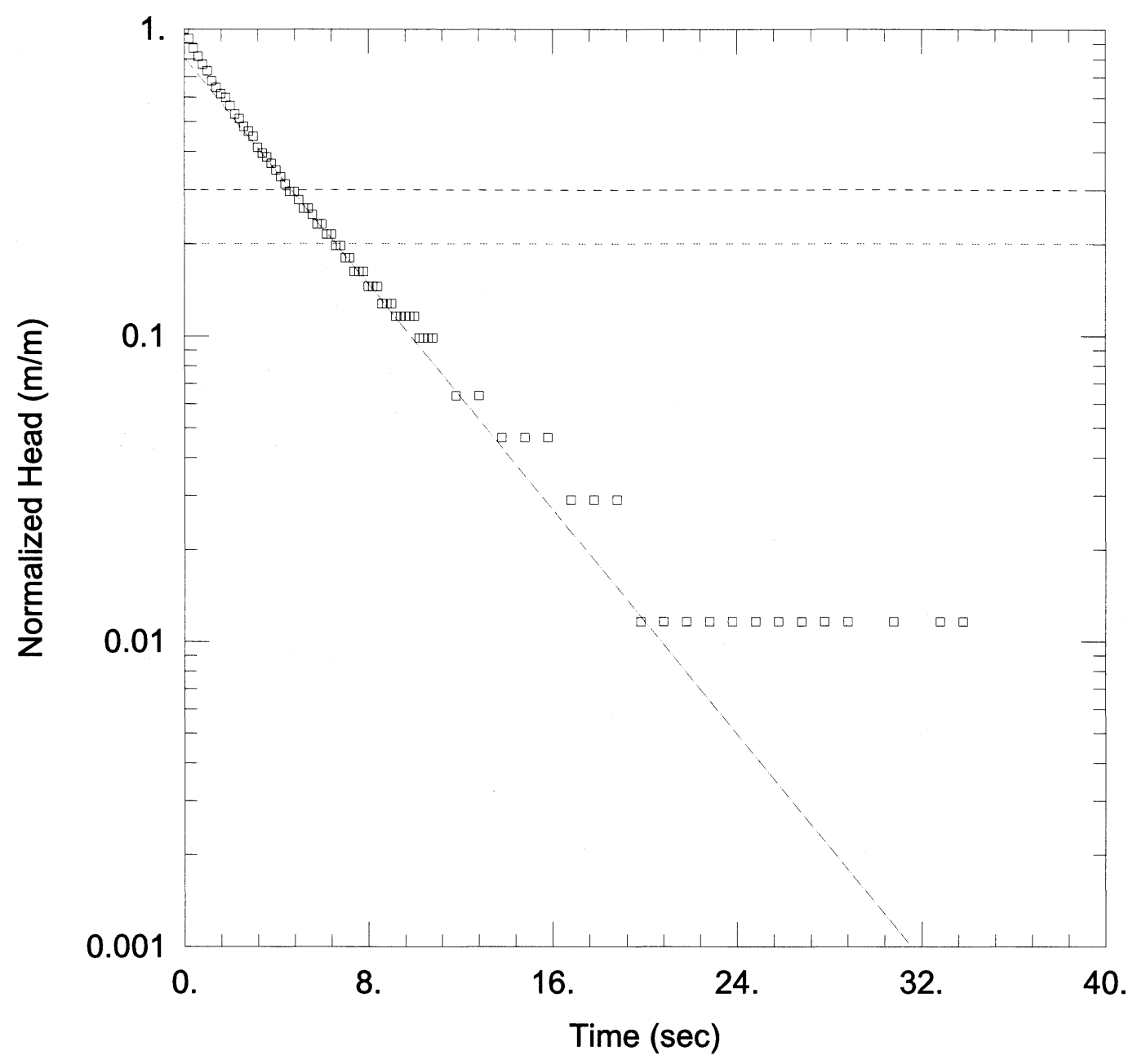

WELL TEST ANALYSIS

Data Set: E:I...IMW15_1.aqt

Date: $09 / 20 / 08$

Time: 11:25:24

PROJECT INFORMATION

Company: University of Nebraska

Location: Injection Pilot Study

Test Well: MW-15

\section{AQUIFER DATA}

Saturated Thickness: $15.24 \mathrm{~m}$

Anisotropy Ratio $(\mathrm{Kz} / \mathrm{Kr}): 1$.

WELL DATA (MW-15)

Initial Displacement: 1. m

Static Water Column Height: $6.096 \mathrm{~m}$

Total Well Penetration Depth: $7.616 \mathrm{~m}$

Screen Length: $6.096 \mathrm{~m}$

Casing Radius: $0.0508 \mathrm{~m}$

Well Radius: $0.0508 \mathrm{~m}$

\section{SOLUTION}

Aquifer Model: Unconfined

Solution Method: Bouwer-Rice

$\mathrm{K}=13.21 \mathrm{~m} / \mathrm{day}$

y0 $=0.8081 \mathrm{~m}$ 


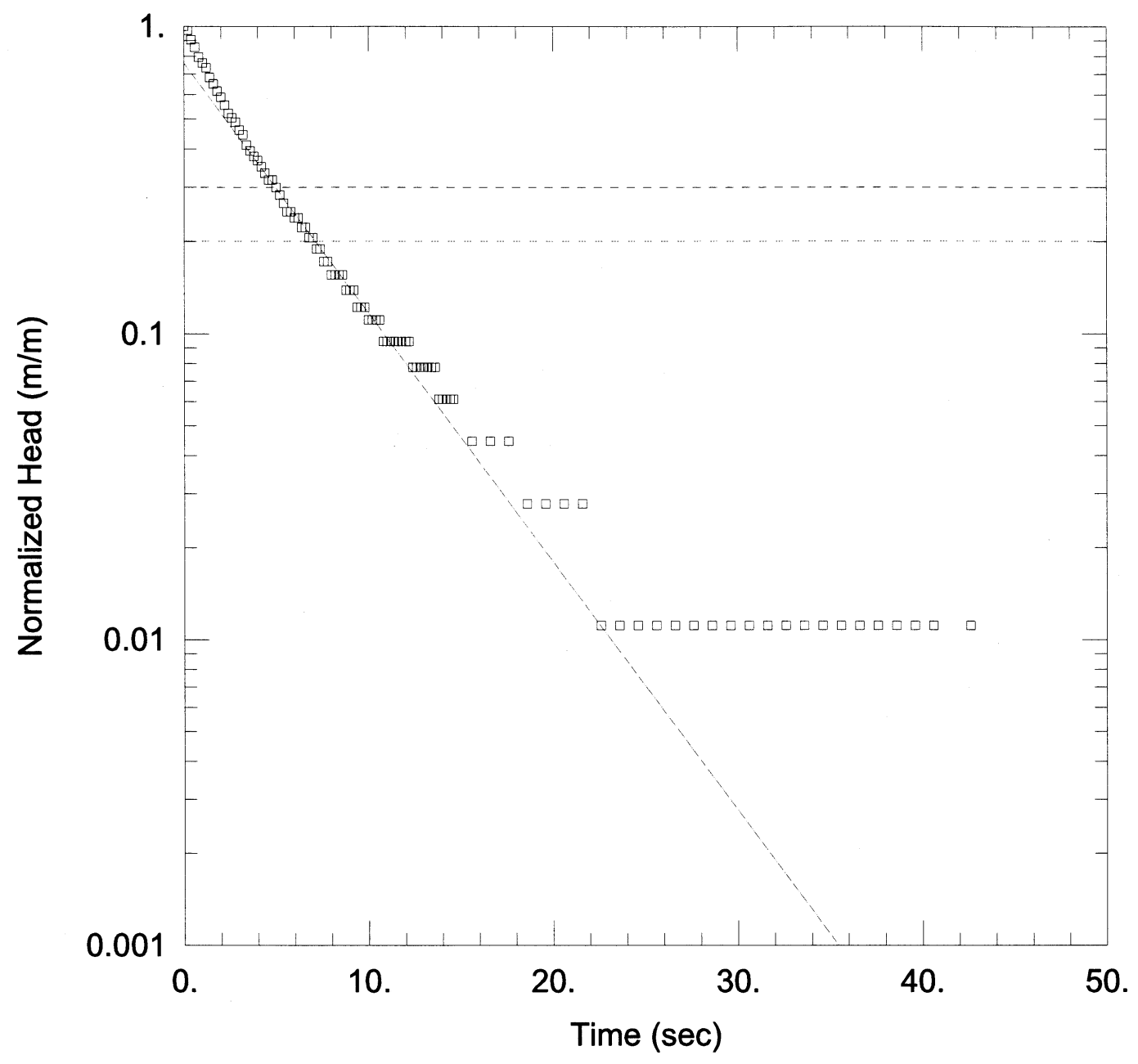

WELL TEST ANALYSIS

Data Set: E:I...IMW15_2.aqt

Date: $09 / 20 / 08$

Time: 11:25:39

PROJECT INFORMATION

Company: University of Nebraska

Location: Injection Pilot Study

Test Well: MW-15

\section{AQUIFER DATA}

Saturated Thickness: $15.24 \mathrm{~m}$

Anisotropy Ratio (Kz/Kr): 1.

\section{WELL DATA (MW-15)}

Initial Displacement: 1. m

Total Well Penetration Depth: $7.616 \mathrm{~m}$

Casing Radius: $0.0508 \mathrm{~m}$

Static Water Column Height: $6.096 \mathrm{~m}$

Screen Length: $6.096 \mathrm{~m}$

Well Radius: $0.0508 \mathrm{~m}$

\section{SOLUTION}

Aquifer Model: Unconfined

Solution Method: Bouwer-Rice

$\mathrm{K}=\underline{11.65 \mathrm{~m} / \text { day }}$

y0 $=0.7589 \mathrm{~m}$ 


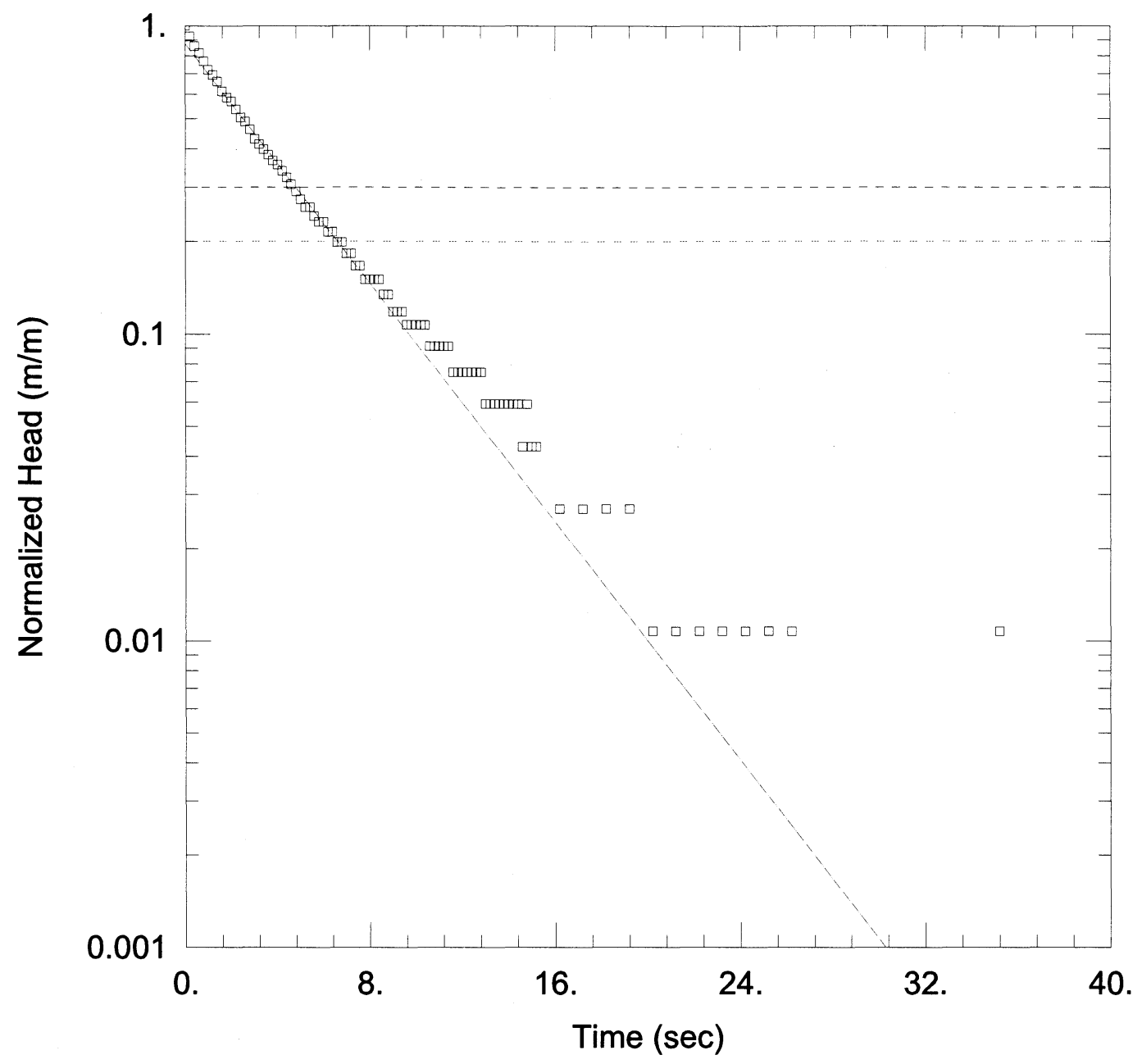

\section{WELL TEST ANALYSIS}

Data Set: E:I...IMW15_3.aqt

Date: $09 / 20 / 08$

Time: 11:25:53

\section{PROJECT INFORMATION}

Company: University of Nebraska

Location: Injection Pilot Study

Test Well: MW-15

\section{AQUIFER DATA}

Saturated Thickness: $15.24 \mathrm{~m}$

Anisotropy Ratio $(\mathrm{Kz} / \mathrm{Kr})$ : 1.

WELL DATA (MW-15)

Initial Displacement: 1. m

Total Well Penetration Depth: $7.616 \mathrm{~m}$

Casing Radius: $0.0508 \mathrm{~m}$
Static Water Column Height: $6.096 \mathrm{~m}$

Screen Length: $6.096 \mathrm{~m}$

Well Radius: $0.0508 \mathrm{~m}$

Aquifer Model: Unconfined

Solution Method: Bouwer-Rice

$\mathrm{K}=13.93 \mathrm{~m} / \mathrm{day}$

$\mathrm{y} 0=0.875 \mathrm{~m}$ 


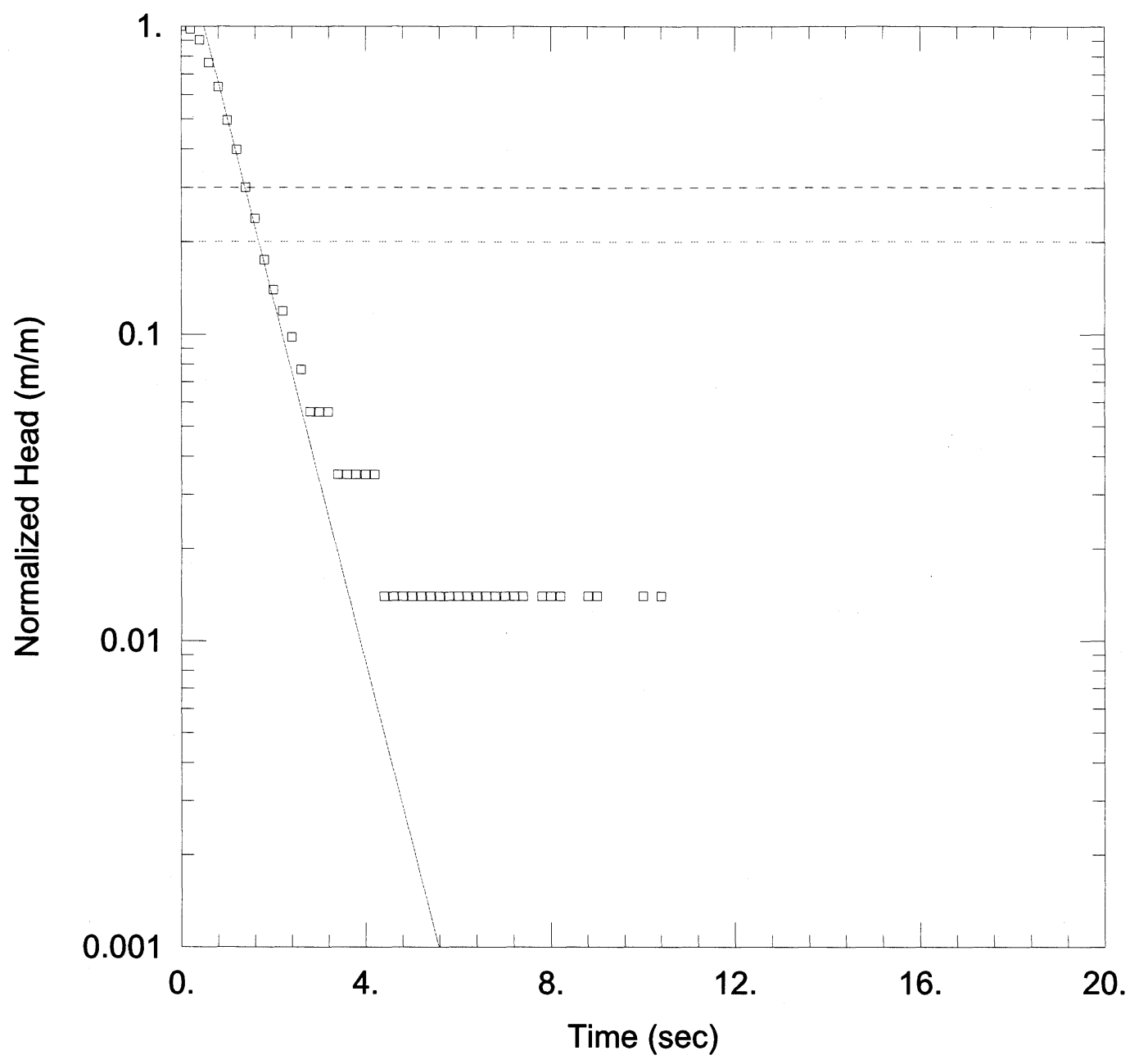

WELL TEST ANALYSIS

Data Set: E:I...IMW16_1.aqt

Date: $09 / 20 / 08$

Time: 11:26:07

\section{PROJECT INFORMATION}

Company: University of Nebraska

Location: Injection Pilot Study

Test Well: MW-16

\section{AQUIFER DATA}

Saturated Thickness: $15.24 \mathrm{~m}$

Anisotropy Ratio (Kz/Kr): 1.

\section{WELL DATA (MW-16)}

Initial Displacement: $1 . \mathrm{m}$

Total Well Penetration Depth: $7.616 \mathrm{~m}$

Casing Radius: $0.0254 \mathrm{~m}$
Static Water Column Height: $6.096 \mathrm{~m}$ Screen Length: $6.096 \mathrm{~m}$

Well Radius: $0.0254 \mathrm{~m}$

\section{SOLUTION}

Aquifer Model: Unconfined

Solution Method: Bouwer-Rice

$\mathrm{K}=24.71 \mathrm{~m} /$ day

y0 $=1.971 \mathrm{~m}$ 


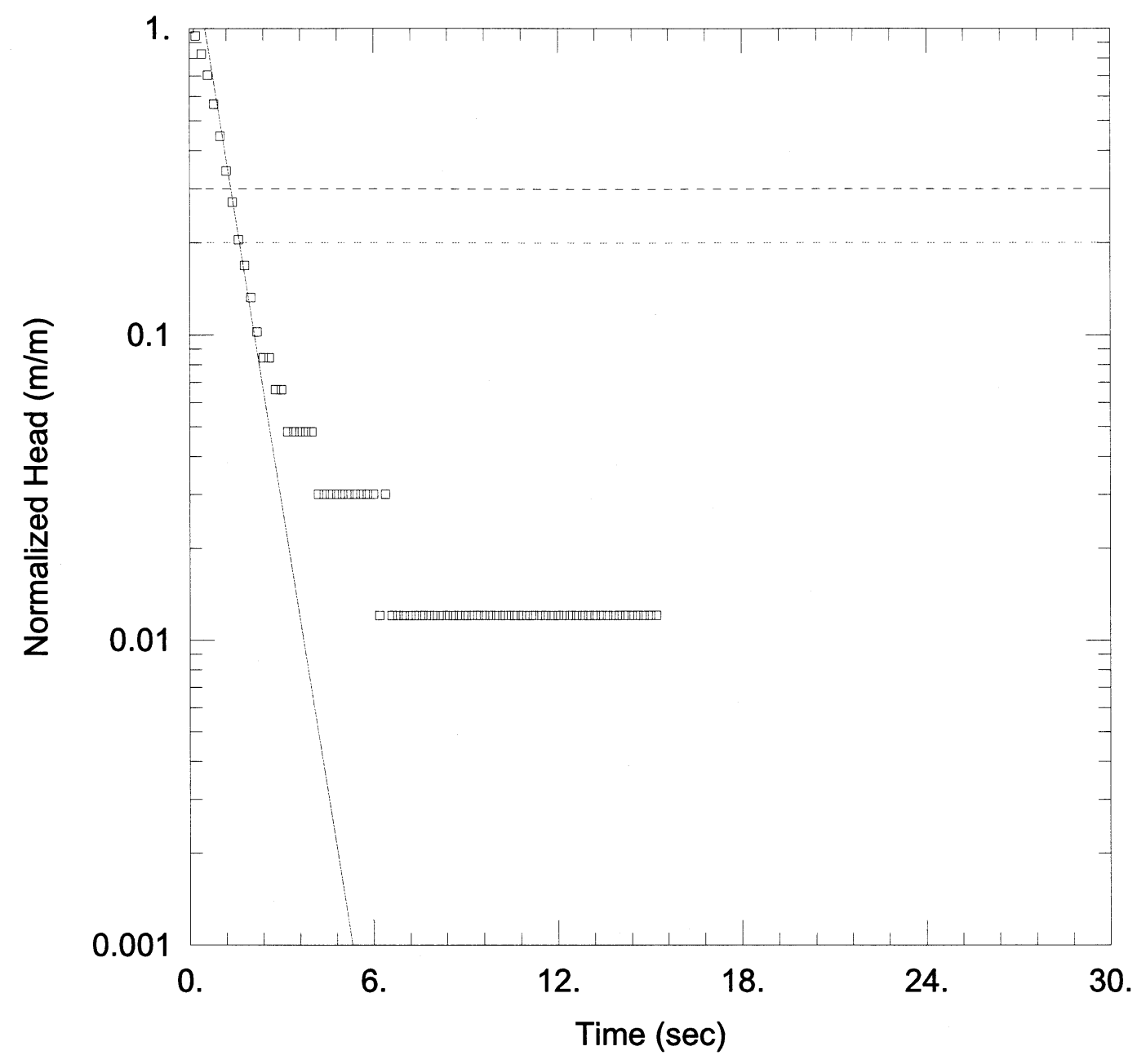

\section{WELL TEST ANALYSIS}

Data Set: E:I...IMW16_2.aqt

Date: $\underline{09 / 20 / 08}$

Time: 11:26:24

\section{PROJECT INFORMATION}

Company: University of Nebraska

Location: Injection Pilot Study

Test Well: MW-16

\section{AQUIFER DATA}

Saturated Thickness: $15.24 \mathrm{~m}$

Anisotropy Ratio (Kz/Kr): 1.

\section{WELL DATA (MW-16)}

Initial Displacement: 1. m

Total Well Penetration Depth: $7.616 \mathrm{~m}$

Casing Radius: $0.0254 \mathrm{~m}$
Static Water Column Height: $6.096 \mathrm{~m}$ Screen Length: $6.096 \mathrm{~m}$

Well Radius: $0.0254 \mathrm{~m}$

\section{SOLUTION}

Aquifer Model: Unconfined

Solution Method: Bouwer-Rice

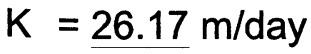

y0 $=2.083 \mathrm{~m}$ 


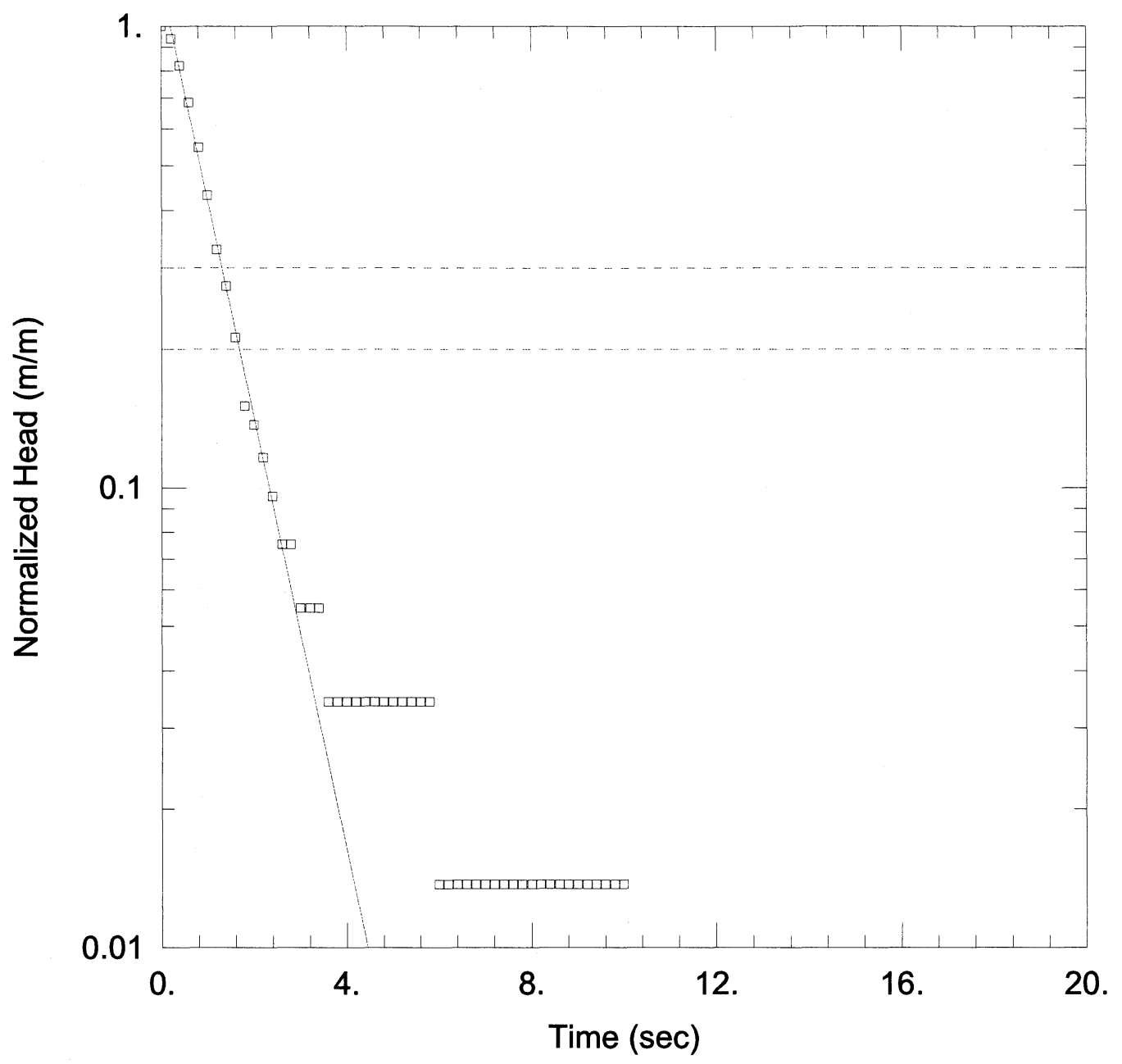

WELL TEST ANALYSIS

Data Set: E:I...IMW16_3.aqt

Date: $09 / 20 / 08$

Time: 11:26:45

PROJECT INFORMATION

Company: University of Nebraska

Location: Injection Pilot Study

Test Well: MW-16

\section{AQUIFER DATA}

Saturated Thickness: $15.24 \mathrm{~m}$

Anisotropy Ratio (Kz/Kr): 1.

WELL DATA (MW-16)

Initial Displacement: $1 . \mathrm{m}$

Total Well Penetration Depth: $7.616 \mathrm{~m}$

Casing Radius: $0.0254 \mathrm{~m}$
Static Water Column Height: $6.096 \mathrm{~m}$ Screen Length: $6.096 \mathrm{~m}$

Well Radius: $0.0254 \mathrm{~m}$

\section{SOLUTION}

Aquifer Model: Unconfined

Solution Method: Bouwer-Rice

$\mathrm{K}=19.71 \mathrm{~m} / \mathrm{day}$

y0 $=1.244 \mathrm{~m}$ 


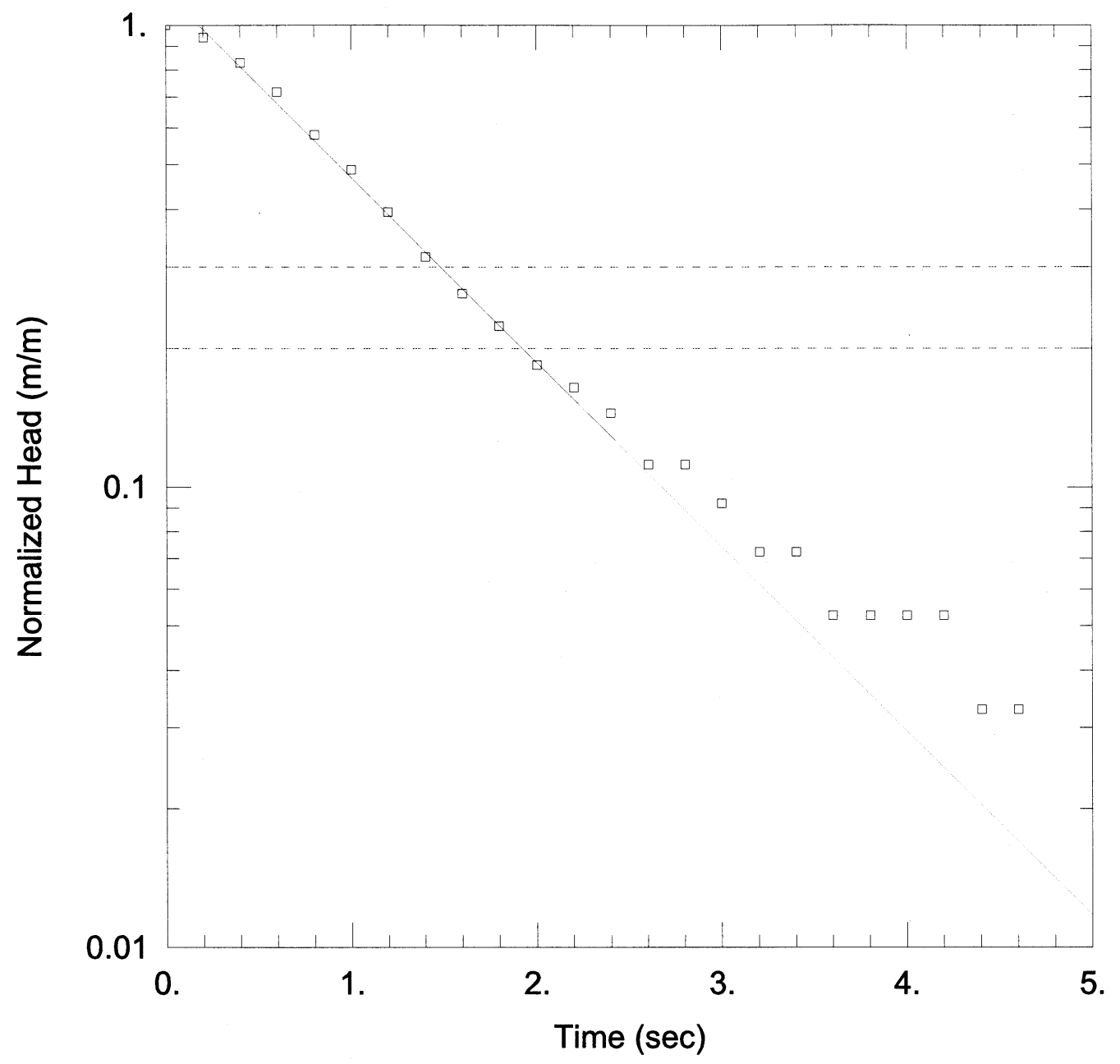

WELL TEST ANALYSIS

Data Set: E:I...IMW17_1.aqt

Date: $09 / 20 / 08$

Time: 11:26:58

PROJECT INFORMATION

Company: University of Nebraska Location: Injection Pilot Study

Test Well: MW-17

\section{AQUIFER DATA}

Saturated Thickness: $15.24 \mathrm{~m}$

Anisotropy Ratio (Kz/Kr): 1.

WELL DATA (MW-17)

Initial Displacement: 1. m

Total Well Penetration Depth: $7.616 \mathrm{~m}$

Casing Radius: $0.0254 \mathrm{~m}$
Static Water Column Height: $6.096 \mathrm{~m}$

Screen Length: $6.096 \mathrm{~m}$

Well Radius: $0.0254 \mathrm{~m}$

\section{SOLUTION}

Aquifer Model: Unconfined

Solution Method: Bouwer-Rice

$\mathrm{K}=16.75 \mathrm{~m} /$ day

$\mathrm{y} 0=1.177 \mathrm{~m}$ 


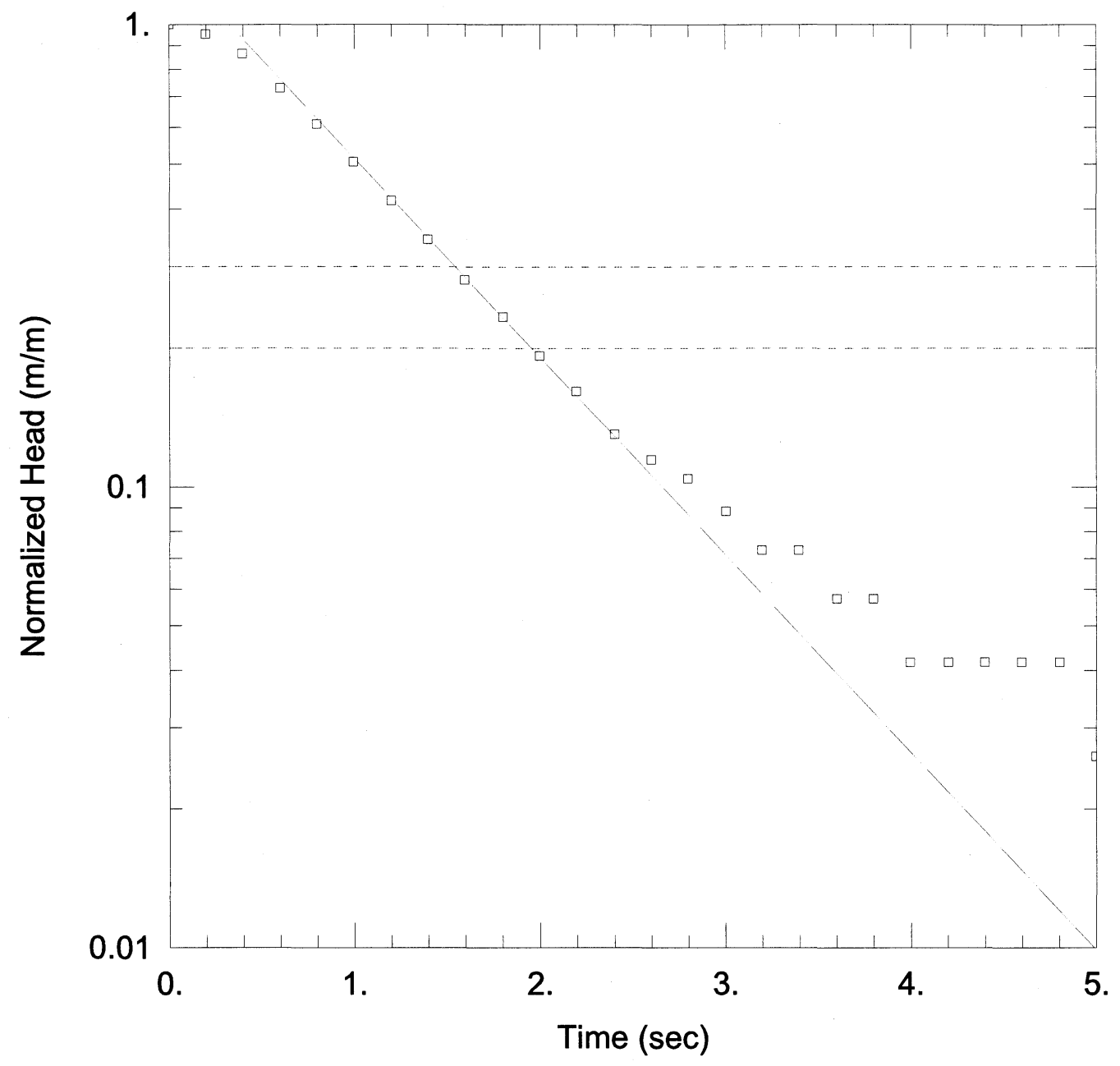

\section{WELL TEST ANALYSIS}

Data Set: E:I...MW17_2.aqt

Date: $09 / 20 / 08$
Time: $11: 27: 11$

\section{PROJECT INFORMATION}

Company: University of Nebraska

Location: Injection Pilot Study

Test Well: MW-17

\section{AQUIFER DATA}

Saturated Thickness: $15.24 \mathrm{~m}$

$$
\text { Anisotropy Ratio (Kz/Kr): } 1 .
$$

\section{WELL DATA (MW-17)}

Initial Displacement: 1. m

Total Well Penetration Depth: $7.616 \mathrm{~m}$

Casing Radius: $0.0254 \mathrm{~m}$
Static Water Column Height: $6.096 \mathrm{~m}$

Screen Length: $6.096 \mathrm{~m}$

Well Radius: $0.0254 \mathrm{~m}$

\section{SOLUTION}

Aquifer Model: Unconfined

Solution Method: Bouwer-Rice

$\mathrm{K}=17.96 \mathrm{~m} / \mathrm{day}$

$\mathrm{y} 0=1.381 \mathrm{~m}$ 


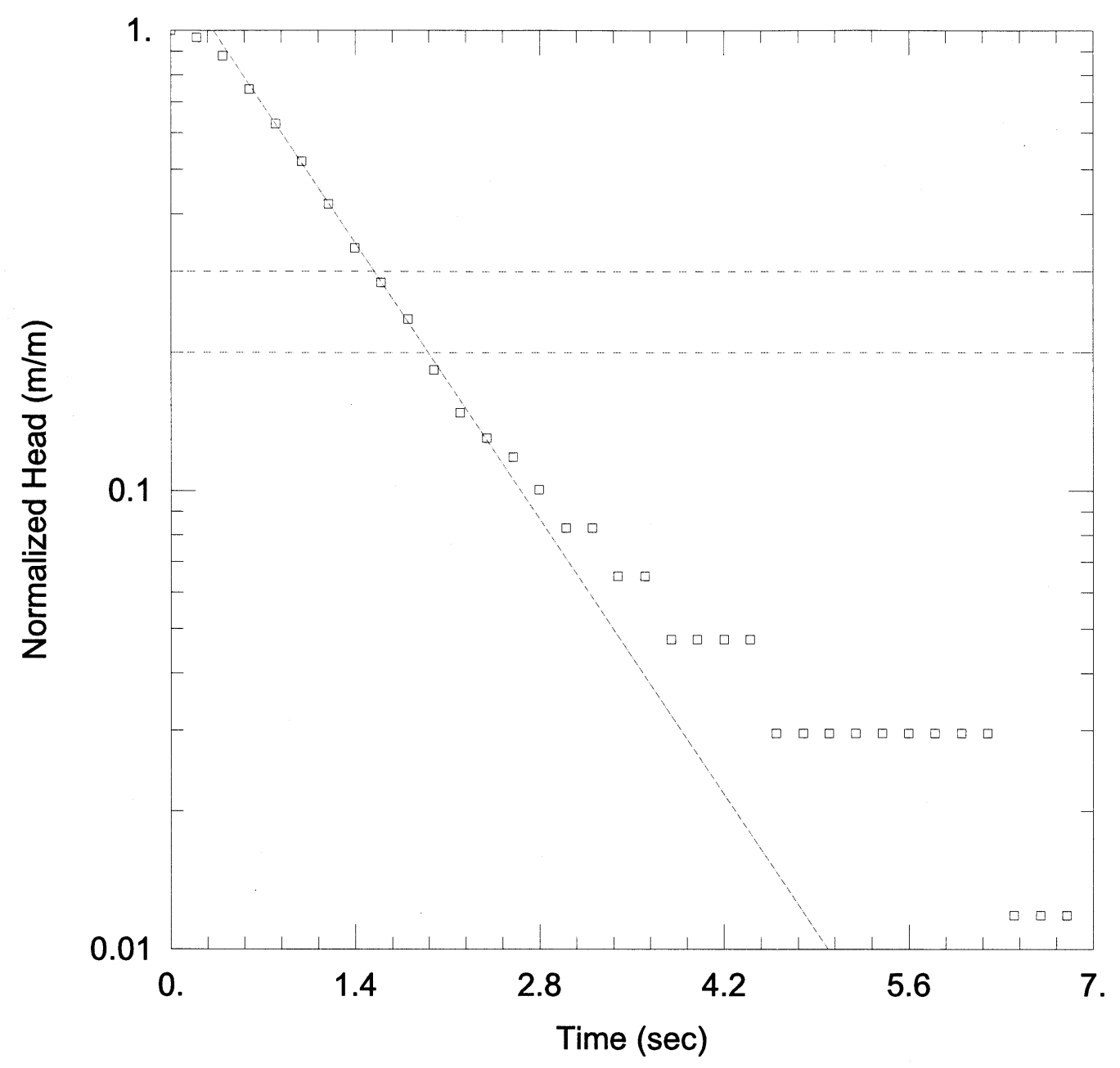

\section{WELL TEST ANALYSIS}

Data Set: E:I...IMW17_3.aqt

Date: $09 / 20 / 08$

Time: 11:27:26

\section{PROJECT INFORMATION}

Company: University of Nebraska

Location: Injection Pilot Study

Test Well: MW-17

\section{AQUIFER DATA}

Saturated Thickness: $15.24 \mathrm{~m}$

Anisotropy Ratio (Kz/Kr): 1 .

\section{WELL DATA (MW-17)}

Initial Displacement: 1. m

Total Well Penetration Depth: $7.616 \mathrm{~m}$

Static Water Column Height: $6.096 \mathrm{~m}$

Casing Radius: $0.0254 \mathrm{~m}$ Screen Length: $6.096 \mathrm{~m}$

Well Radius: $0.0254 \mathrm{~m}$

\section{SOLUTION}

Aquifer Model: Unconfined

Solution Method: Bouwer-Rice

$\mathrm{K}=\underline{17.96 \mathrm{~m} / \text { day }}$ $\mathrm{y} 0=1.381 \mathrm{~m}$ 


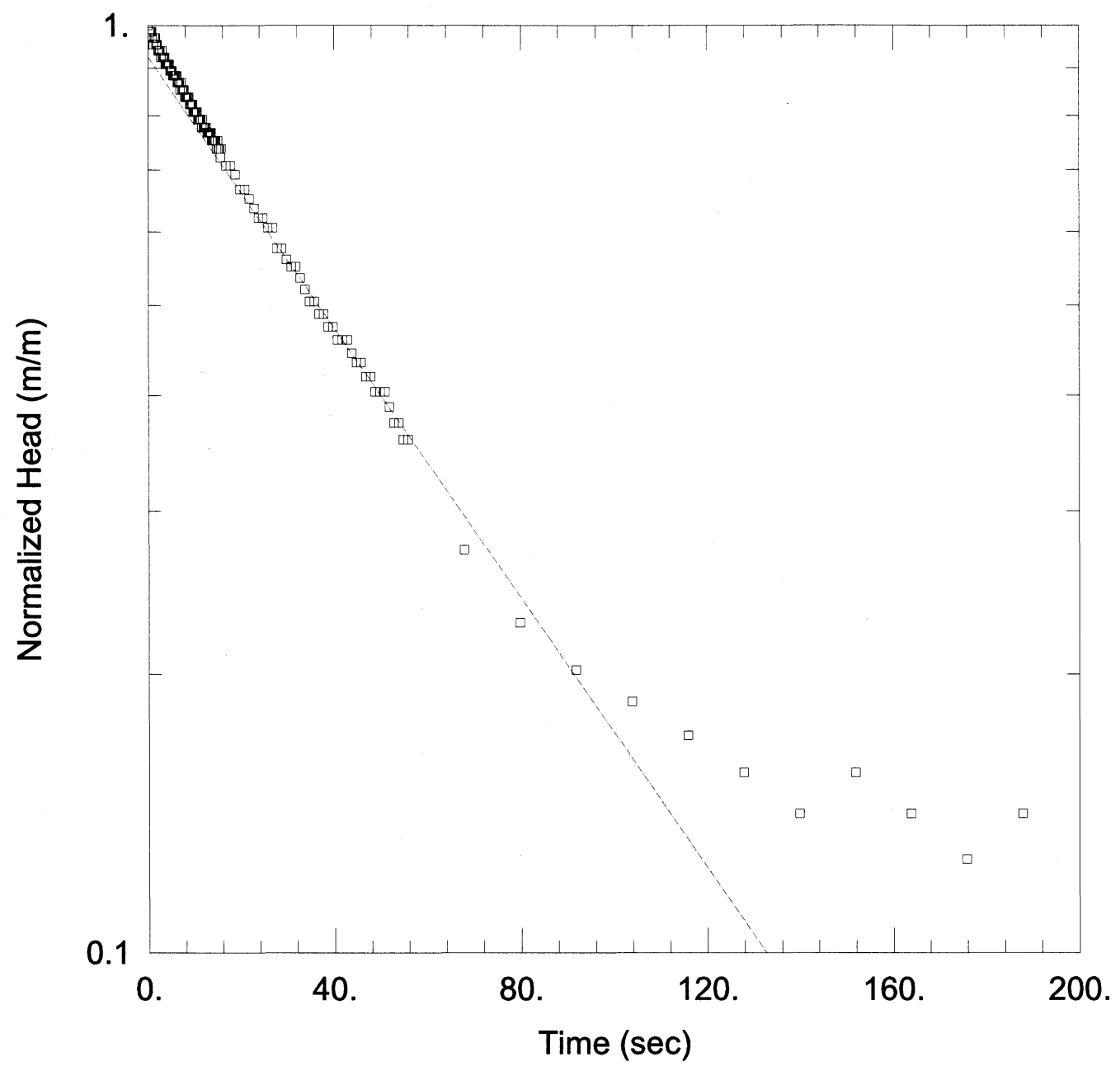

\section{WELL TEST ANALYSIS}

Data Set: E:I...IEW1_1.aqt

Date: $09 / 20 / 08$

Time: 11:16:41

PROJECT INFORMATION

Company: University of Nebraska

Location: Injection Pilot Study

Test Well: EW-1

AQUIFER DATA

Saturated Thickness: $15.24 \mathrm{~m}$

Anisotropy Ratio $(\mathrm{Kz} / \mathrm{Kr}): 1$.

WELL DATA (EW-1)

Initial Displacement: 1. m

Total Well Penetration Depth: $7.616 \mathrm{~m}$

Casing Radius: $0.0762 \mathrm{~m}$
Static Water Column Height: $6.096 \mathrm{~m}$

Screen Length: $6.096 \mathrm{~m}$

Well Radius: $0.0762 \mathrm{~m}$

Aquifer Model: Unconfined

Solution Method: Bouwer-Rice

$\mathrm{K}=2.129 \mathrm{~m} / \mathrm{day}$

y0 $=0.925 \mathrm{~m}$ 


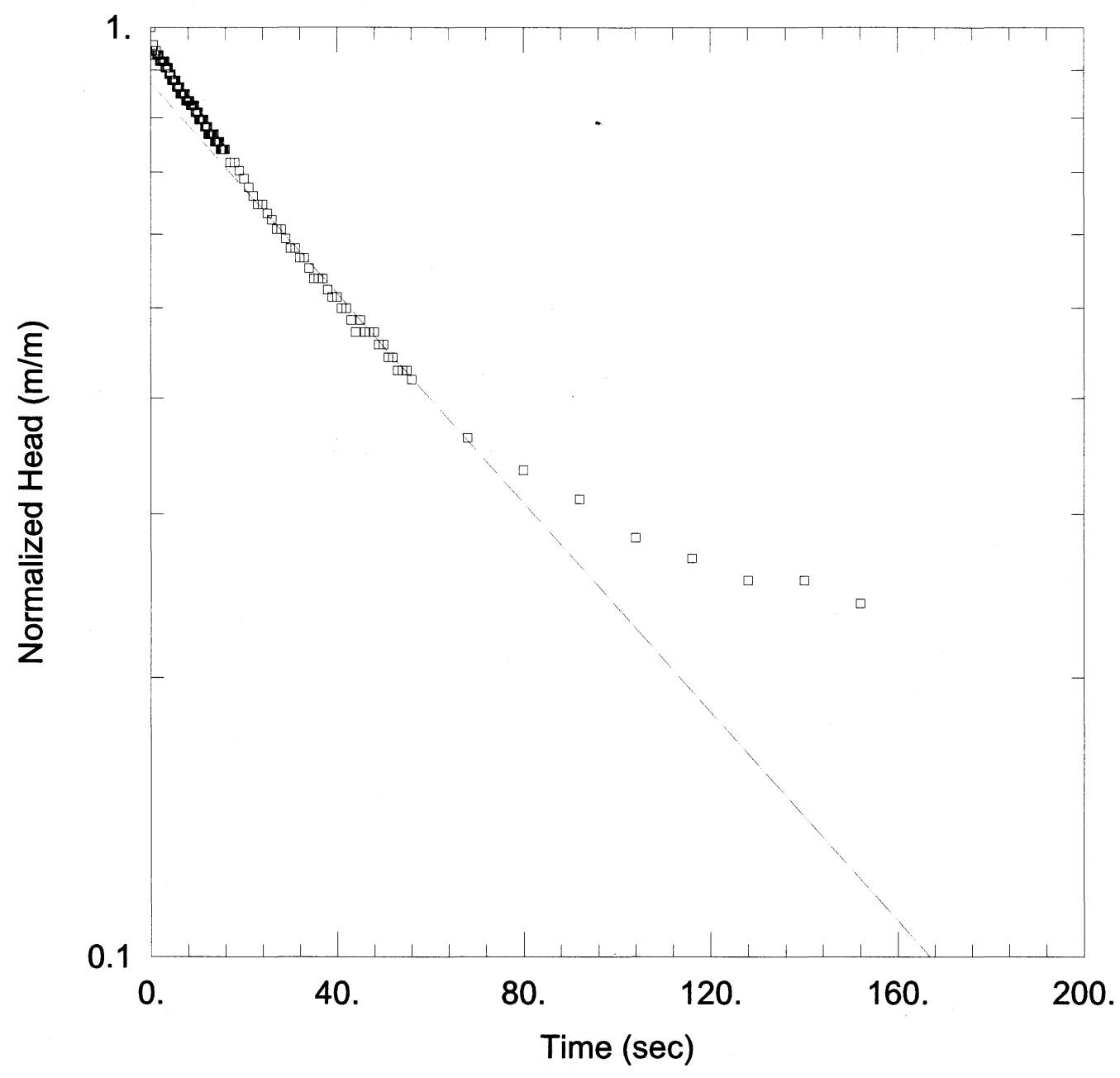

\section{WELL TEST ANALYSIS}

Data Set: E:I...IEW1_2.aqt

Date: $09 / 20 / 08$

Time: 11:17:15

\section{PROJECT INFORMATION}

Company: University of Nebraska

Location: Injection Pilot Study

Test Well: EW-1

\section{AQUIFER DATA}

Saturated Thickness: $15.24 \mathrm{~m}$

Anisotropy Ratio $(\mathrm{Kz} / \mathrm{Kr})$ : 1 .

\section{WELL DATA (EW-1)}

Initial Displacement: 1. $\mathrm{m}$

Total Well Penetration Depth: $7.616 \mathrm{~m}$

Casing Radius: $0.0762 \mathrm{~m}$
Static Water Column Height: $6.096 \mathrm{~m}$

Screen Length: $6.096 \mathrm{~m}$

Well Radius: $0.0762 \mathrm{~m}$

\section{SOLUTION}

Aquifer Model: Unconfined

Solution Method: Bouwer-Rice

$\mathrm{K}=1.647 \mathrm{~m} /$ day

$\mathrm{y} 0=0.8718 \mathrm{~m}$ 


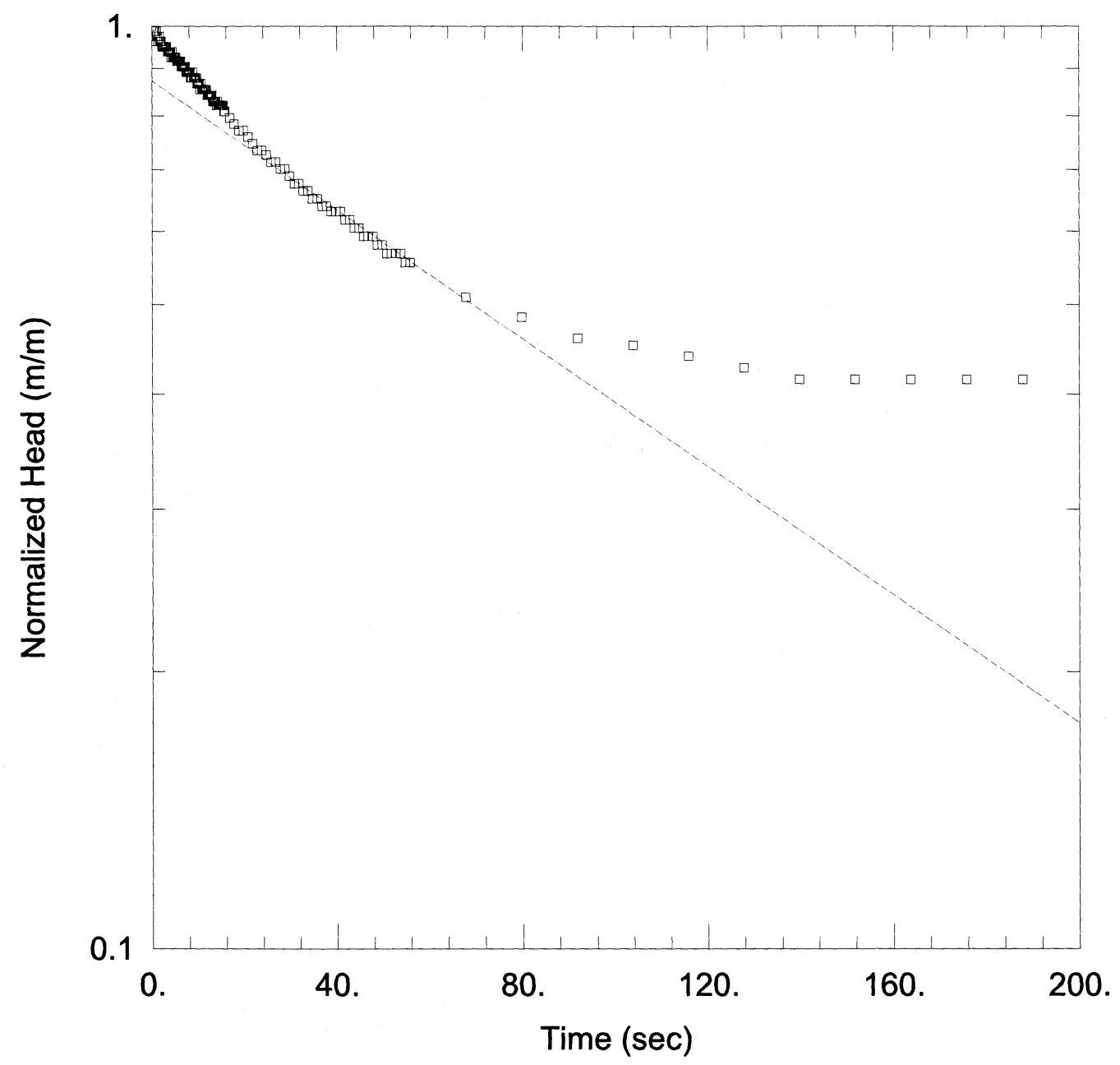

\section{WELL TEST ANALYSIS}

Data Set: E:I...IEW1_3.aqt

Date: $09 / 20 / 08$

Time: 11:17:33

\section{PROJECT INFORMATION}

Company: University of Nebraska

Location: Injection Pilot Study

Test Well: EW-1

\section{AQUIFER DATA}

Saturated Thickness: $15.24 \mathrm{~m}$

Anisotropy Ratio (Kz/Kr): 1.

\section{WELL DATA (EW-1)}

Initial Displacement: 1. m

Total Well Penetration Depth: $7.616 \mathrm{~m}$

Casing Radius: $0.0762 \mathrm{~m}$
Static Water Column Height: $6.096 \mathrm{~m}$

Screen Length: $6.096 \mathrm{~m}$

Well Radius: $0.0762 \mathrm{~m}$
Aquifer Model: Unconfined

$\mathrm{K}=1.016 \mathrm{~m} / \mathrm{day}$
Solution Method: Bouwer-Rice

$\mathrm{y} 0=0.8725 \mathrm{~m}$ 


\title{
APPENDIX E
}

\author{
Miscellaneous Graphs Showing Data Collected During the \\ Injection/Extraction of Sodium Permanganate injection
}
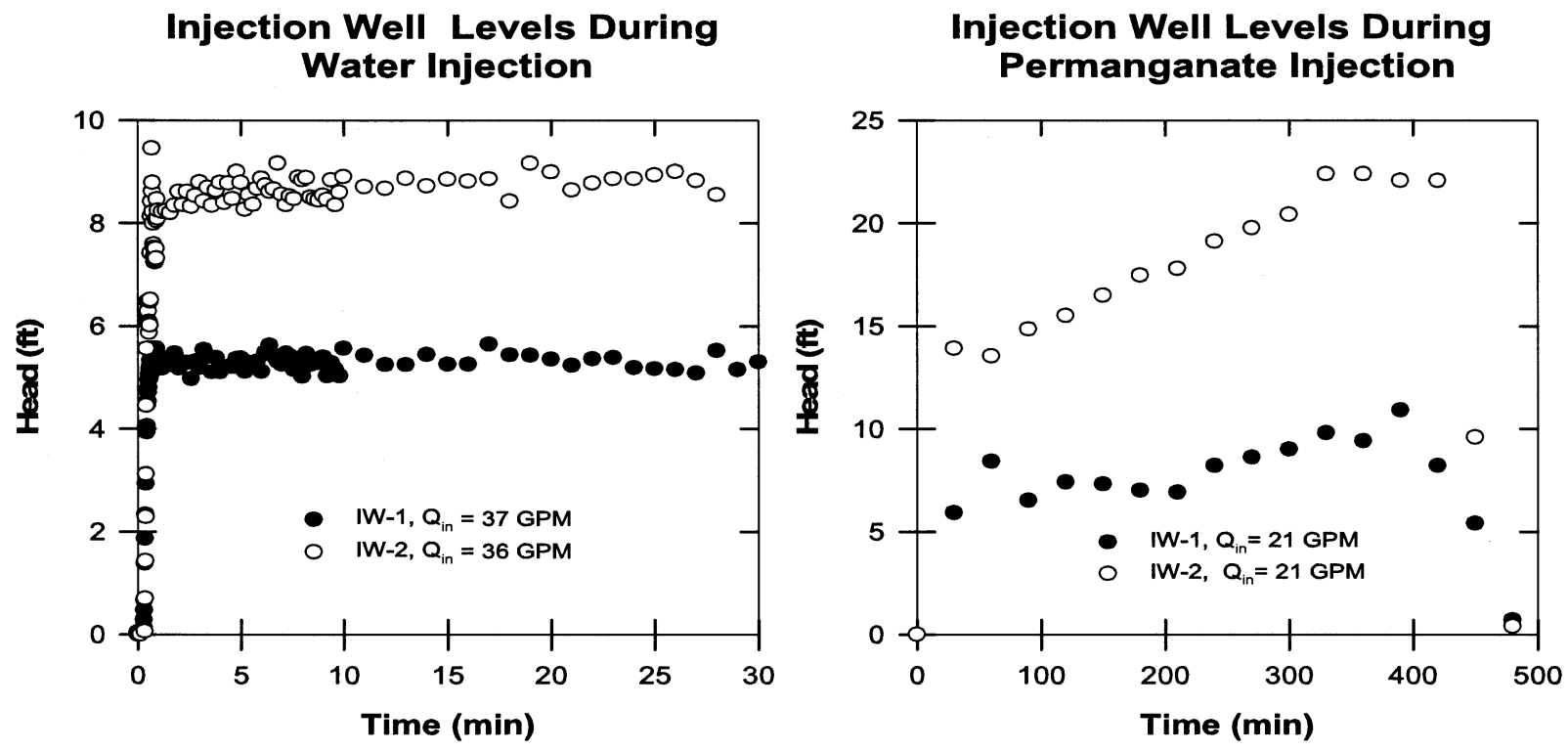

Figure 1. Water level measurements in injections wells IW-1 and IW-2 during sodium permanganate injection. 


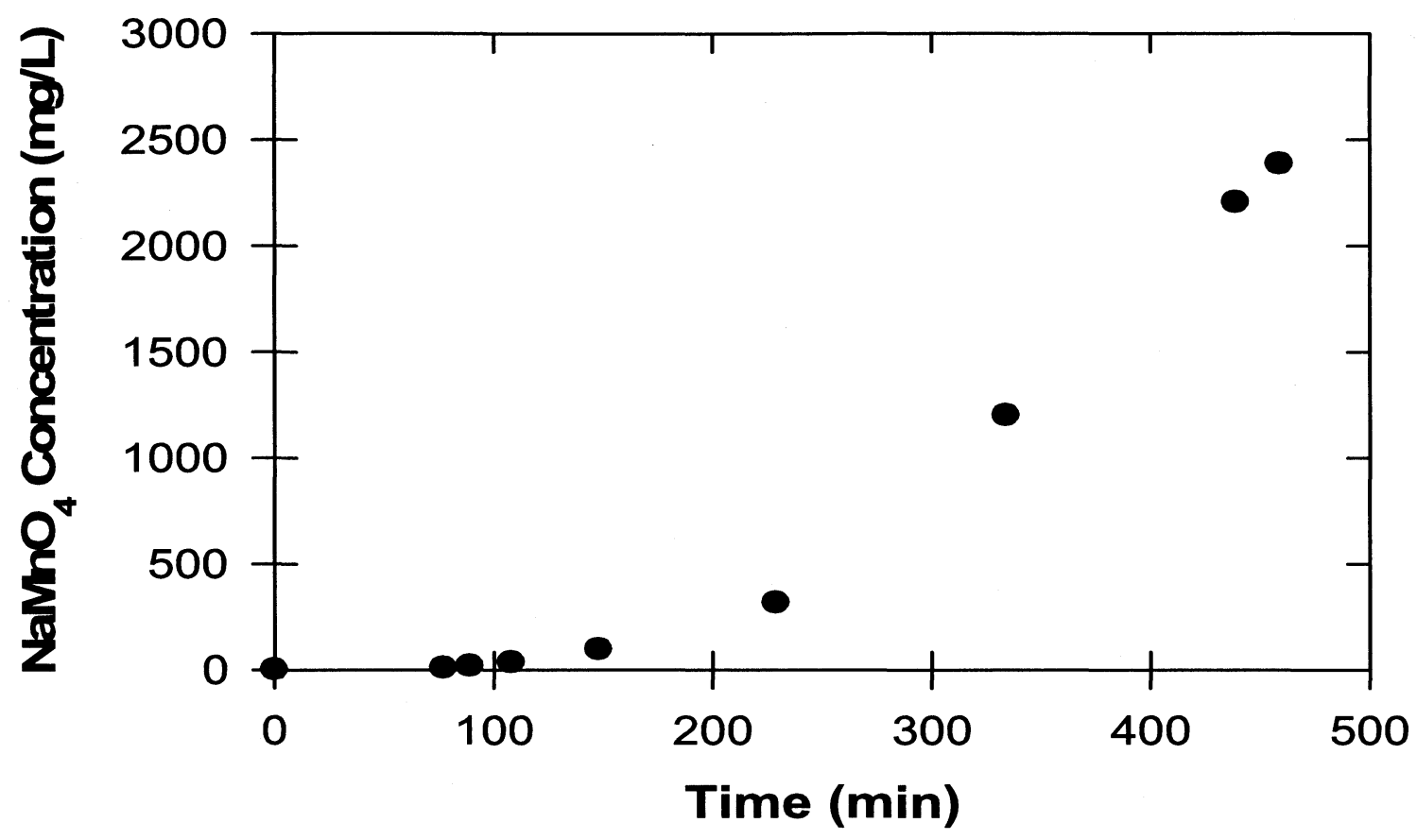

Figure 2. Extraction well EW-1 sodium permanganate breakthrough curve observed during injection/extraction process. 


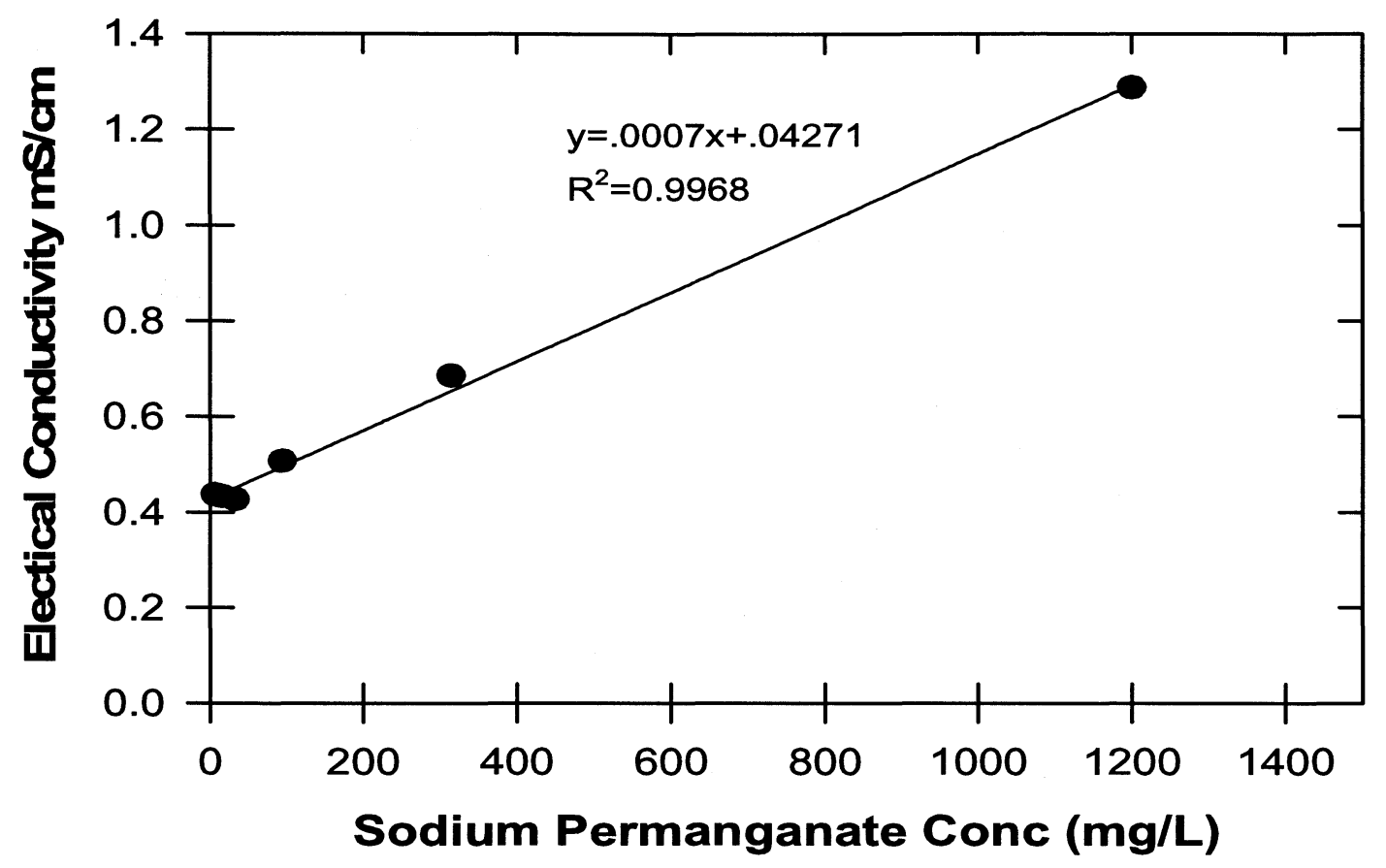

Figure 3. Sodium permanganate vs electrical conductivity curve used to calculate well sodium permanganate concentration profiles. 